\title{
Seleção bayesiana de variáveis em modelos multiníveis da teoria de resposta ao item com aplicações em genômica
}

\author{
Tiago de Miranda Fragoso
}

TESE APRESENTADA

$\mathrm{AO}$

Instituto De Matemática e Estatística

DA

Universidade DE SÃo PaUlo

PARA

OBTENÇÃO DO TÍTULO

$\mathrm{DE}$

DOUTOR EM CIÊNCIAS

Programa: Estatística

Orientador: Prof ${ }^{\mathrm{a}}$. Dr ${ }^{\mathrm{a}}$. Júlia Maria Pavan Soler

Durante o desenvolvimento deste trabalho o autor recebeu auxílio financeiro da CAPES e do $\mathrm{CNPq}$

São Paulo, setembro de 2014 


\title{
Seleção bayesiana de variáveis em modelos multiníveis da teoria de resposta ao item com aplicações em genômica
}

\author{
Esta versão da tese contém as correções e alterações sugeridas \\ pela Comissão Julgadora durante a defesa da versão original do trabalho, \\ realizada em 12/09/2014. Uma cópia da versão original está disponível no \\ Instituto de Matemática e Estatística da Universidade de São Paulo.
}

Comissão Julgadora:

- Prof ${ }^{a}$. Dra ${ }^{a}$. Júlia Maria Pavan Soler (orientadora) - IME-USP

- Prof. Dr. Guilherme Jordão de Magalhães Rosa - UW-Madison

- Prof. Dr. Heleno Bolfarine - IME-USP

- Prof ${ }^{a}$. Drª . Mariana Cúri - ICMC-USP

- Prof. Dr. Caio Lucidius Naberezny Azevedo - UNICAMP 


\section{Agradecimentos}

A conclusão da presente tese representa o fim de um período de aprendizado intenso e diverso, grandemente estimulado pelas pessoas notáveis com quem tive a felicidade de conviver, colaborar e aprender.

Dessa forma, agradeço à minha orientadora, Prof ${ }^{a}$. Júlia M. Pavan Soler pela orientação ao longo do meu doutorado, pela experiência, competência, paciência e inúmeros exemplos que me guiaram nesses primeiros anos trabalhando com a pesquisa em Estatística e suas aplicações.

Agradeço aos meus professores no IME, especialmente à Prof ${ }^{\text {a }}$ Silvia L. P. Ferrari e ao Prof. Anatoly Yambartsev pelos excelentes cursos, capitais para a minha formação e pela seriedade e competência com a qual me mostraram na prática como proceder no exercício da docência. Agradeço aos meus colegas no IME, Gilberto Sassi, Ariadne Nogueira, Alice Lemos, Giovana Fumes e Lina Thomas pela grande convivência durante meus anos em São Paulo.

Ao Dr. Alexandre da Costa Pereira, Andréa Horimoto, Núbia E. Duarte, Silvano C. Costa, Hadassa Santos e Deisy Gysi pela intensa, frutífera e educativa convivência no Instituto do Coração, no qual pude aprender de perto sobre Genética, Genômica e toda a estatística envolvida. Agradeço também a Doutora Mariza de Andrade da Mayo Clinic pela colaboração e sempre presentes objetividade e senso critico.

Aos membros da banca do meu exame de qualificação, Profs. Drs. Dalton F. Andrade e Luis A. Milan pelas constribuições, fundamentais para o direcionamento da presente tese. Agradeço também aos docentes do Departamento de Estatística da Universidade Federal de São Carlos pela calorosa recepção e extraordinária convivência durante a minha breve estada nos seus quadros, especialmente aos Profs. Adriano Polpo de Campos e Luis A. Milan.

Ao Prof. Guilherme J. M. Rosa por me receber na University of Wisconsin - Madison, pelas excelentes discussões, pela oportunidade de conhecer ainda mais de perto as aplicações da Estatística em Genética e por me mostrar diversas direções previamente ignoradas. Agradeço aos meus colegas no Department of Animal Science da UW-Madison, Vivian Felipe, Bruno Valente, Francisco Peñagaricano, Yaodong Hu, Adriana Somavilla, Saleh Shahinfar e Tom Murphy pela convivência, colaboração e apoio durante meu tempo em Madison.

Agradeço ainda a Rafael Stern e Lucas Peres pelas conversas, opiniões e conselhos sobre computação e estatística. Por último, mas não menos importante, agradeço a Imyra M. M. de Souza pela paciência, apoio e suporte e inestimável companhia ao longo de todos esses anos. 


\section{Resumo}

FRAGOSO, T. M. Seleção bayesiana de variáveis em modelos multiníveis da teoria de resposta ao item com aplicações em genômica. 2014. 61 f. Tese (Doutorado) - Instituto de Matemática e Estatística, Universidade de São Paulo, São Paulo, 2014.

As investigações sobre as bases genéticas de doenças complexas em Genômica utilizam diversos tipos de informação. Diversos sintomas são avaliados de maneira a diagnosticar a doença, os indivíduos apresentam padrões de agrupamento baseados, por exemplo no seu parentesco ou ambiente comum e uma quantidade imensa de características dos indivíduos são medidas por meio de marcadores genéticos. No presente trabalho, um modelo multiníveis da Teoria de Resposta ao Item (TRI) é proposto de forma a integrar todas essas fontes de informação e caracterizar doenças complexas através de uma variável latente. Além disso, a quantidade de marcadores moleculares induz um problema de seleção de variáveis, para o qual uma seleção baseada nos métodos da Busca Estocástica e do LASSO Bayesiano são propostos. Os parâmetros do modelo e a seleção de variáveis são realizados sob um paradigma Bayesiano, no qual um algoritmo Monte Carlo via Cadeias de Markov é construído e implementado para a obtenção de amostras da distribuição a posteriori dos parâmetros. O mesmo é validado através de estudos de simulação, nos quais a capacidade de recuperação dos parâmetros, de escolha de variáveis e características das estimativas pontuais dos parâmetros são avaliadas em cenários similares aos dados reais. O processo de estimação apresenta uma recuperação satisfatória nos parâmetros estruturais do modelo e capacidade de selecionar covariáveis em espaços de dimensão elevada apesar de um viés considerável nas estimativas das variáveis latentes associadas ao traço latente e ao efeito aleatório. Os métodos desenvolvidos são então aplicados aos dados colhidos no estudo de associação familiar 'Corações de Baependi', nos quais o modelo multiníveis se mostra capaz de caracterizar a Síndrome Metabólica, uma série de sintomas associados com o risco cardiovascular. O modelo multiníveis e a seleção de variáveis se mostram capazes de recuperar características conhecidas da doença e selecionar um marcador associado.

Palavras-chave: Teoria da Resposta ao Item, Busca Estocástica, LASSO Bayesiano. 


\section{Abstract}

FRAGOSO, T.M Bayesian variable selection for multilevel item response theory models with applications in genomics. 2014. 61 f. Tese (Doutorado) - Instituto de Matemática e Estatística, Universidade de São Paulo, São Paulo, 2014.

Recent investigations about the genetic architecture of complex diseases use different sources of information. Different symptoms are measured to obtain a diagnosis, individuals may not be independent due to kinship or common environment and their genetic makeup may be measured through a large quantity of genetic markers. In the present work, a multilevel Item Response Theory (IRT) model is proposed that unifies all these different sources of information through a latent variable. Furthermore, the large ammount of molecular markers induce a variable selection problem, for which procedures based on Stochastic Search Variable Selection and the Bayesian LASSO are considered. Parameter estimation and variable selection is conducted under a Bayesian framework in which a Markov Chain Monte Carlo algorithm is derived and implemented to obtain posterior distribution samples. The estimation procedure is validated through a series of simulation studies in which parameter recovery, variable selection and estimation error are evaluated in scenarios similar to the real dataset. The estimation procedure showed adequate recovery of the structural parameters and the capability to correctly find a large number of the covariates even in high dimensional settings albeit it also produced biased estimates for the incidental latent variables. The proposed methods were then applied to the real dataset collected on the 'Corações de Baependi' familiar association study and was able to apropriately model the Metabolic Syndrome, a series of symptoms associated with elevated heart failure and diabetes risk. The multilevel model produced a latent trait that could be identified with the syndrome and an associated molecular marker was found.

Keywords: Item Response Theory, Stochastic Search Variable Selection, Bayesian LASSO. 


\section{Sumário}

$\begin{array}{ll}\text { Lista de Abreviaturas } & \text { ix }\end{array}$

Lista de Símbolos $\quad$ xi

Lista de Figuras $\quad$ xiii

$\begin{array}{lc}\text { Lista de Tabelas } & \text { xvii }\end{array}$

1 Introdução $\quad 1$

1.1 Modelagem com Variáveis Latentes . . . . . . . . . . . . . . . . . . . 1

1.2 Síndrome Metabólica e o estudo 'Corações de Baependi' . . . . . . . . . . . . . . . 2

1.3 Teoria da Resposta ao Item e seleção de variáveis . . . . . . . . . . . . . . . . . . 3

2 Modelos multiníveis da teoria de resposta ao item 5

2.1 Modelos da teoria de resposta ao item . . . . . . . . . . . . . . . 5

2.2 Inferência Bayesiana e métodos Monte Carlo via Cadeias de Markov . . . . . . . . . 9

2.3 Estudos de Simulação . . . . . . . . . . . . . . . . . . . . . 15

2.3.1 Recuperação dos parâmetros . . . . . . . . . . . . . 15

2.3 .2 Erro quadrático médio . . . . . . . . . . . . . . . . . . . 17

2.4 Projeto 'Corações de Baependi' . . . . . . . . . . . . . . . . . . . . 21

3 Seleção de covariáveis em modelos multiníveis $\quad 47$

3.1 Introdução . . . . . . . . . . . . . . . . . . . . . . . . . . 47

3.2 Seleção Bayesiana de variáveis em modelos multiníveis . . . . . . . . . . . . . . . 50

3.2.1 LASSO Bayesiano para o modelo multiníveis . . . . . . . . . . . . . . . 52

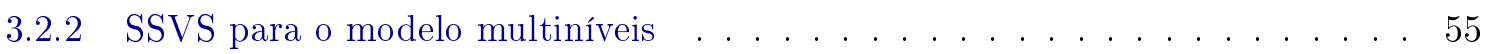

3.3 Estudo de simulação . . . . . . . . . . . . . . . . . . . . . . . 58

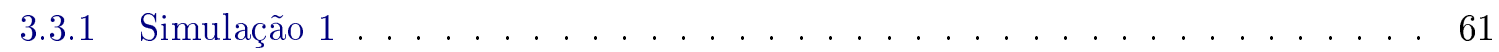

3.3 .2 Simulação $2 \ldots \ldots \ldots \ldots \ldots \ldots$. . . . . . . . . . . . . . . . . . . . .

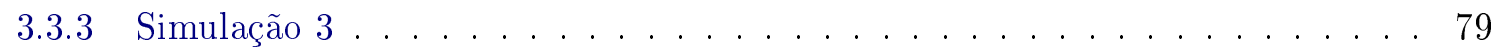

3.4 Seleção de marcadores no projeto 'Corações de Baependi' . . . . . . . . . . . . . 86

4 Conclusões e Estudos Futuros $\quad 93$

$\begin{array}{ll}\text { A Condicionais completas para o nível funcional } & 101\end{array}$

A.1 Preliminares . . . . . . . . . . . . . . . . . . . . . 101

A.2 Condicionais completas . . . . . . . . . . . . . . . 103 
viii SUMÁRIO

Referências Bibliográficas

105 


\section{Lista de Abreviaturas}

TRI Teoria da Resposta ao Item

SM Síndrome Metabólica

SNP Polimorfismo de uma base (Single Nucleotide Polymorphism)

GWAS Estudo de associação genética ampla (Genome Wide Association Studies)

LASSO Least Absolute Shinkage Selection Operator

SSVS Seleção de variáveis por busca estocástica (Stochastic Search Variable Selection)

DNA Ácido desoxirribonucleico(Deoxyribonucleic acid)

AT Par Adenina-Timina

CG Par Citosina-Guanina

EQM Erro quadrático médio

MCMC Monte Carlo via Cadeias de Markov (Markov Chain Monte Carlo )

MH Metropolis - Hastings 


\title{
Lista de Símbolos
}

\author{
$N \quad$ Número de indivíduos \\ I Número de itens/fenótipos/sintomas \\ $\boldsymbol{Y}$ Matriz de respostas dos indivíduos aos itens \\ $\theta$ Traço latente \\ $b$ Parâmetro de escala do item \\ $g \quad$ Efeito poligênico \\ $p \quad$ Número de covariáveis \\ $\boldsymbol{X}$ Matriz de covariáveis \\ $\boldsymbol{\beta}$ Vetor de efeitos fixos \\ $\sigma_{g}^{2}$ Componente da variância do efeito poligênico \\ $\sigma_{e}^{2} \quad$ Componente da variância residual \\ $h^{2}$ Coeficiente de correlação intraclasses (herdabilidade) \\ $\boldsymbol{U}$ Variável aumentada \\ $\boldsymbol{\tau}$ Encolhimentos para cada variável no LASSO Bayesiano \\ $\lambda$ Hiperparâmetro de encolhimento no LASSO Bayesiano \\ c Hiperparâmetro da $g$-prior \\ $\gamma \quad$ Vetor de indicadores na Busca Estocástica \\ $m$ Tamanho do modelo de regressão na Busca Estocástica \\ $s \quad$ Número de substituições na Busca Estocástica
}




\section{Lista de Figuras}

2.1 Heredograma da estrutura familiar utilizada na simulação. . . . . . . . . . . . . . . 15

2.2 EQM para os parâmetros dos $I=5$ itens com a estrutura familiar homogênea. . . . . 18

2.3 EQM para os parâmetros dos $I=7$ itens com a estrutura familiar homogênea . . . . 19

2.4 EQMs para os parâmetros dos $I=5$ itens com as famílias de Baependi . . . . . . . . 20

2.5 EQMs para os parâmetros dos $I=7$ itens com as famílias de Baependi . . . . . . . . 20

2.6 EQM das componentes da variância e herdabilidades para as simulações com pedigrees homogêneos, pontos cheios indicam a configuração com 5 itens, enquanto pontos vazios indicam a configuração com 7 itens. . . . . . . . . . . . . . . . . 22

2.7 EQM de $g$ e $\theta$ para os pedigrees homogêneos e $K=20$ famílias. . . . . . . . . . . . 23

2.8 EQM de $g$ e $\theta$ para os pedigrees homogêneos e $K=200$ famílias. . . . . . . . . . . . 24

2.9 EQM de $g$ e $\theta$ para os pedigrees homogêneos e $K=2000$ famílias. . . . . . . . . . . 25

2.10 EQM de $g$ e $\theta$ para as famílias de Baependi com 5 e 7 itens. . . . . . . . . . . 26

2.11 Variância dos estimadores $\hat{g}$ e $\hat{\theta}$ para $K=20$ famílias e pedigrees homogêneos. . . . . 27

2.12 Variância dos estimadores $\hat{g}$ e $\hat{\theta}$ para $K=200$ famílias e pedigrees homogêneos. . . . 28

2.13 Variância dos estimadores $\hat{g}$ e $\hat{\theta}$ para $K=2000$ famílias e pedigrees homogêneos. . 29

2.14 Variância dos estimadores $\hat{g}$ e $\hat{\theta}$ para os pedigrees de Baependi. . . . . . . . . . . . 30

2.15 Viés dos estimadores $\hat{g}$ e $\hat{\theta}$ para $K=20$ famílias e pedigrees homogêneos . . . . . . 31

2.16 Viés dos estimadores $\hat{g}$ e $\hat{\theta}$ para $K=200$ famílias e pedigrees homogêneos . . . . . . 32

2.17 Viés dos estimadores $\hat{g}$ e $\hat{\theta}$ para $K=2000$ famílias e pedigrees homogêneos . . . . . . 33

2.18 Viés dos estimadores $\hat{g}$ e $\hat{\theta}$ para os pedigrees de Baependi . . . . . . . . . . . . 34

2.19 Histograma dos sintomas da SM e da idade para a amostra de Baependi. . . . . . . . 41

2.20 Histórico, densidade e função de autocorrelação para o parâmetro $\beta_{1} \ldots$. . . . . . . . 42

2.21 Funções de Informação do teste para o modelo 1 (linha sólida) e modelo 2(linha

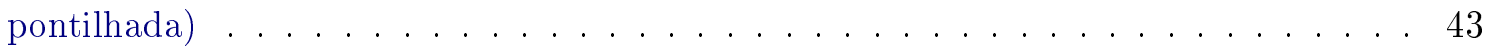

2.22 CPP utilizando a frequência de escores para o modelo $1 \ldots \ldots$. . . . . . . . . . 44

2.23 Box-plots para o traço latente e efeito poligênico em cada classe de padrão de resposta para o modelo 1. . . . . . . . . . . . . . . . . . . . . . 44 4

2.24 Box-plots para o traço latente e efeito poligênico em cada classe de padrão de resposta para o modelo $2 \ldots \ldots \ldots \ldots \ldots \ldots \ldots \ldots$. . . . . . . . . . . . . . . . . . . . . . .

3.1 Amostrador de Gibbs proposto para os parâmetros do modelo multiníveis e seleção de covariáveis através do LASSO Bayesiano . . . . . . . . . . . . . . . 55

3.2 Amostrador de Gibbs proposto para os parâmetros do modelo multiníveis e seleção de covariáveis . . . . . . . . . . . . . . . . . . . 58 
3.3 Simulação dos dados para a seleção de variáveis. Retângulos representam dados utilizados como entrada no método de estimação, retângulos arredondados indicam variáveis aleatórias simuladas. . . . . . . . . . . . . . . 60

3.4 Probabilidades de inclusão do SSVS para $p=1.000$ marcadores e $g$-prior, a linha pontilhada marca o ponto de corte de 0,5 .

3.5 Probabilidades de inclusão do SSVS para $p=1.000$ marcadores e priori $I_{p}$, a linha pontilhada marca o ponto de corte de 0,5 .

3.6 Estimativas dos efeitos para $p=1.000$ marcadores sob a $g$-priori para o SSVS versus o LASSO Bayesiano. Pontos representam os valores reais, e a reta com quadrados passa pelas estimativas . . . . . . . . . . . . . . . . .

3.7 Estimativas dos efeitos para $p=1.000$ marcadores sob a priori $I_{p}$ para o SSVS versus o LASSO Bayesiano. Pontos representam os valores reais, e a reta com quadrados passa pelas estimativas . . . . . . . . . . . . . . . .

3.8 Probabilidades de inclusão do SSVS para $p=10^{4}$ marcadores e $g$-prior, e a linha pontilhada marca o ponto de corte de $0,5 \ldots \ldots \ldots$. . . . . . . . . . 66

3.9 Probabilidades de inclusão do SSVS para $p=10^{4}$ marcadores e priori $I_{p}$, a linha pontilhada marca o ponto de corte de 0,5 .

3.10 Estimativas dos efeitos para $p=10^{4}$ marcadores sob a $g$-prior para o SSVS. Pontos representam os valores reais, a reta com quadrados passa pelas estimativas . . . . . . 68

3.11 Estimativas dos efeitos para $p=10^{4}$ marcadores sob a priori $I_{p}$ para o SSVS. Pontos representam os valores reais, a reta com quadrados passa pelas estimativas . . . . . .

3.12 Probabilidades de inclusão do SSVS para $p=1.000$ marcadores e $g$-prior na Simulação 2 , a linha pontilhada marca o ponto de corte de $0,5 \ldots \ldots \ldots$. . . . . 71

3.13 Probabilidades de inclusão do SSVS para $p=1.000$ marcadores e priori $I_{p}$ na Simulação 2 , a linha pontilhada marca o ponto de corte de $0,5 \ldots \ldots \ldots$. . . . . . .

3.14 Estimativas dos efeitos para $p=1.000$ marcadores sob a $g$-prior para o SSVS versus o LASSO Bayesiano na Simulação 2, pontos representam os valores reais, a reta com quadrados passa pelas estimativas . . . . . . . . . . . . . .

3.15 Estimativas dos efeitos para $p=1.000$ marcadores sob a priori $I_{p}$ para o SSVS versus o LASSO Bayesiano na Simulação 2, pontos representam os valores reais, a reta com quadrados passa pelas estimativas . . . . . . . . . . . . . . . .

3.16 Probabilidades de inclusão do SSVS para $p=10.000$ marcadores e $g$-prior na Simulação 2 , a linha pontilhada marca o ponto de corte de $0,5 \ldots \ldots$. . . . . . . . . 75

3.17 Probabilidades de inclusão do SSVS para $p=10.000$ marcadores e priori $I_{p}$ na Simulação 2, a linha pontilhada marca o ponto de corte de 0,5 . . . . . . . . . 76

3.18 Estimativas dos efeitos para $p=10.000$ marcadores sob a $g$-prior para o SSVS. Pontos representam os valores reais, a reta com quadrados passa pelas estimativas. . 77

3.19 Estimativas dos efeitos para $p=10.000$ marcadores sob a priori $I_{p}$ para o SSVS. Pontos representam os valores reais, a reta com quadrados passa pelas estimativas.

3.20 Probabilidades de inclusão do SSVS para $p=1.000$ marcadores e $g$-prior para a Simulação 3 , a linha pontilhada marca o ponto de corte de $0,5 \ldots$. . . . . . . . 80

3.21 Probabilidades de inclusão do SSVS para $p=1.000$ marcadores e priori independente para a Simulação 3, a linha pontilhada marca o ponto de corte de 0,5 . . . . . . . . 
3.22 Estimativas dos efeitos para $p=1.000$ marcadores sob a $g$-priori para o SSVS versus o LASSO Bayesiano para a Simulação 3, pontos representam os valores reais, e a reta passa pelas estimativas. . . . . . . . . . . . . . . . 82

3.23 Estimativas dos efeitos para $p=1.000$ marcadores sob priori independente para $o$ SSVS versus o LASSO Bayesiano para a Simulação 3, pontos representam os valores reais, e a reta passa pelas estimativas. . . . . . . . . . . . . . 83

3.24 Probabilidades de inclusão do SSVS para $p=10.000$ marcadores e $g$-prior para a Simulação 3 , a linha pontilhada marca o ponto de corte de $0,5 \ldots$. . . . . . . 84

3.25 Probabilidades de inclusão do SSVS para $p=10.000$ marcadores e priori independente para a Simulação 3, a linha pontilhada marca o ponto de corte de $0,5 \ldots$. . . 85

3.26 Estimativas dos efeitos para $p=10.000$ marcadores sob a $g$-priori para o SSVS versus o LASSO Bayesiano para a Simulação 3. Pontos representam os valores reais, quadrados as estimativas. . . . . . . . . . . . . . . . . . 87

3.27 Estimativas dos efeitos para $p=10.000$ marcadores sob priori independente para o SSVS versus o LASSO Bayesiano para a Simulação 3, pontos representam os valores reais, quadrados as estimativas. . . . . . . . . . . . . . . . . 88

3.28 Probabilidades de inclusão para as covariáveis no estudo 'Corações de Baependi', a linha horizontal representa o ponto de corte de $0,5 \ldots \ldots$. . . . . . . . 90

3.29 Mapa estilizado das regiões do Cromossomo 1 associadas na literatura com sintomas da SM relativas ao marcador encontrado na SSVS. . . . . . . . . . . . . . . . 92

4.1 Um grafo orientado acíclico para um modelo de regressão linear . . . . . . . . . . . 95

4.2 Um grafo orientado acíclico para o modelo multiníveis da TRI . . . . . . . . . . . 96

4.3 Grafo orientado acíclico para SNPs agindo diretamente sobre os itens . . . . . . . . . 97

4.4 Grafo orientado acíclico para um modelo bi-fatorial englobando a SM . . . . . . . . . 97

4.5 Grafo orientado acíclico para o efeito de fenótipos sobre outros fenótipos . . . . . . 98

$4.6 \mathrm{Um}$ grafo orientado acíclico para SNPs como itens . . . . . . . . . . . . . 98 


\section{Lista de Tabelas}

2.1 Recuperação dos parâmetros para $h^{2}=0,25 \ldots \ldots \ldots \ldots \ldots$

2.2 Recuperação dos parâmetros $h^{2}=0,5 \ldots \ldots \ldots \ldots \ldots \ldots$

2.3 Recuperação dos parâmetros para $h^{2}=0,75 \ldots \ldots \ldots \ldots \ldots \ldots$

2.4 Estatísticas descritivas para os dados de Baependi e prevalência (Prev) do diagnóstico de alteração segundo o critério ATP-III. Circunf. = Circunferência truncal, Trig = Triglicérides, Glic $=$ Glicose, HDL $=$ baixo colesterol de alta densidade, $\mathrm{PAS}=$ pressão arterial sistólica, $\mathrm{PAD}=$ pressao arterial diastólica $\ldots \ldots \ldots \ldots$

2.5 Estimativas pontuais e intervalares para o modelo $1 \ldots \ldots \ldots$. . . . . . 37

2.6 Estimativas pontuais e intervalares para o modelo $2 \ldots \ldots \ldots$. . . . . . . 37

3.1 Efeitos e frequências alélicas para a Simulação $3 \ldots \ldots$. . . . . . . . . . . 59

3.2 Estimativas dos efeitos para o cenário $p=1.000$ na Simulação 2. $I_{m}$ representa a priori independente, $g$ a $g$-prior e LASSO o LASSO Bayesiano . . . . . . . . 70

3.3 Estimativas dos efeitos para o cenário $p=1.000$. $I_{m}$ representa a priori independente, $g$ a $g$-prior e LASSO o LASSO Bayesiano. . . . . . . . . . . . . . 79

3.4 Estimativas dos parâmetros do modelo multiníveis com seleção de variáveis para o conjunto de dados de Baependi . . . . . . . . . . . . . . . . . . . 89 


\section{Capítulo 1}

\section{Introdução}

Inicia-se este trabalho apresentando-se as motivações que nortearam o desenvolvimento dos métodos discutidos na presente tese e a contribuição dos mesmos na busca pela fundamentação genética de doenças complexas.

Na Seção 1.1 faz-se uma breve discussão sobre o papel de variáveis latentes na modelagem estatística dando ênfase ao problema alvo de estudo do presente trabalho. Na Seção 1.2, descrevemse, no contexto do problema alvo, os desafios impostos à modelagem pelas múltiplas fontes de informação, desenho experimental e abundância de preditores. Conclui-se o Capítulo com uma breve discussão na Seção 1.3 de como modelos multinível da Teoria de Resposta ao Item podem prover uma modelagem adequada para o problema.

\subsection{Modelagem com Variáveis Latentes}

Uma variável latente é frequentemente definida na literatura (como em Fox (2010) por exemplo) como uma variável aleatória cuja realização não pode ser medida, apenas inferida em termos de outros indicadores.

Variáveis latentes são usadas extensivamente em modelos de regressão para descrever agrupamentos devido a diversos fatores como o delineamento ou a medição repetida de unidades experimentais. Neste sentido, modelos com variáveis latentes têm sido utilizados em Genética para descrever a heterogeneidade e o padrão de dependência entre indivíduos (ou mesmo entre animais e plantas) devido ao parentesco e outros agrupamentos. Uma revisão dessa modelagem em estudos com humanos pode ser encontrada em Almasy e Blangero (1998).

As variáveis latentes também provêm uma formulação matemática para construtos não-observáveis como os de interesse em Psicometria (p. ex. depressão, ansiedade), Educação ( p. ex. proficiência), Ciências Políticas (p. ex. democracia) entre outras áreas. Nesses casos, o construto é operacionalizado (Shmueli, 2010) em um modelo com o objetivo de explicar a ação do mesmo sobre as variáveis observadas,ou ainda explicar sua decorrência a partir delas.

Além disso, variáveis latentes podem também descrever um processo não observado gerando uma variável observada. Por exemplo, em Vazquez et al. (2012), uma variável relativa ao risco de câncer de pele em humanos é construída levando em conta uma série de efeitos fixos relativos a características dos pacientes permitindo a comparação de indivíduos de maneira mais informativa do que o diagnóstico de câncer e evidenciando o papel de cada covariável sobre o risco.

No presente trabalho, utilizam-se variáveis latentes para a construção de um modelo operacional que conjuntamente liga variáveis observáveis, latentes e preditoras e discute-se abordagens alternativas que respondem aos propósitos de modelagem descritos acima. Através de modelos hierárquicos utilizando variáveis latentes, o desenho experimental e as diversas fontes de informação são integradas no modelo. Além disso, variáveis latentes são utilizadas para auxiliar um processo de seleção de variáveis, potencializando o poder explanatório do modelo.

As possibilidades da modelagem com variáveis latentes descritas nessa seção não são exaustivas. O leitor interessado é direcionado para uma revisão em Skrondal e Rabe-Hesketh (2004). 


\subsection{Síndrome Metabólica e o estudo 'Corações de Baependi'}

Insuficiência cardíaca e diabetes são doenças complexas prevalentes e com sérias consequências para a qualidade de vida dos pacientes. A ocorrência dessas doenças é influenciada pela existência de fatores de risco como hipertensão, obesidade, colesterol e outros associados com o consumo e administração dos recursos energéticos do corpo além de fatores ambientais como sedentarismo e tabagismo.

É sabido que as doenças e fatores de risco têm alguma base genética, e que a mesma não é restrita a variações em apenas uma região do genoma. Frequentemente, múltiplos genes e diversos fatores ambientais podem contribuir para a ocorrência da doença, demandando estudos que levem tais variações no ambiente e no modo que a doença é passada de uma geração para a seguinte em consideração.

Com esse propósito, um estudo de associação familiar (com dados de famílias) foi realizado na população da cidade de Baependi, no estado de Minas Gerais, denominado estudo 'Corações de Baependi'. O estudo selecionou aleatoriamente indivíduos da população de Baependi, seguindo um processo de amostragem em três fases (setor censitário, unidade domiciliar dentro de setor censitário, indivíduo) e, após a inclusão do indivíduo no estudo, todos os seus familiares foram convidados a participarem do estudo. Cada um dos indivíduos foi então avaliado para uma série de variáveis incluindo a presença de fatores de risco cardiovasculares (como circunferência truncal e pressão arterial) e submetidos a questionários para avaliar a presença de fatores ambientais como tabagismo ou medicamentos.

Com base na estrutura familiar e potenciais confundidores, modelos poligênicos foram ajustados para cada um dos fatores de risco com o objetivo de investigar a contribuição de fatores genéticos e ambientais. Resultados dessa investigação e detalhes sobre o planejamento do estudo podem ser obtidos em Oliveira et al. (2008).

Apesar de cada fator de risco apresentar seu particular modo de regulação, é esperado que uma série de fatores apresente características em comum motivando um estudo do denominador comum dos fatores de risco. A Síndrome Metabólica (SM) é uma doença definida como uma desordem no armazenamento e utilização de energia pelo corpo, diagnosticada através de sintomas como obesidade, níveis elevados de triglicérides e colesterol e, portanto, associada ao aumento do risco de doenças cardiovasculares.

Estudos da SM enfrentam a complicação de que a SM não é um sintoma que possa ser diretamente observado e medido, e sim uma doença caracterizada pela observação de uma série de sintomas. Dessa forma, autoridades na área de Saúde estabelecem critérios diagnósticos para os sintomas e considera-se que um sintoma (ou fenótipo em Genética) é diagnosticado se uma observação extrema com respeito ao critério é observada.

Cada critério reduz a medida a uma variável aleatória dicotômica, que pode ser definida como

$$
Y=\left\{\begin{array}{l}
1, \text { se observa-se um sintoma } \\
0, \text { caso contrário, }
\end{array}\right.
$$

e diagnósticos da severidade da SM podem ser feitos baseados no número total de sintomas de cada indivíduo. Sob esse critério, diversos indivíduos bem diferentes podem ser considerados idênticos para o diagnóstico de SM.

De fato, um indivíduo obeso e hipertenso é considerado idêntico a um indivíduo com altos níveis de colesterol 'ruim' e baixos níveis de colesterol 'bom' com respeito ao numero de sintomas, mas ambos representam casos bem diferentes da doença. Nesse particular exemplo, a presença de obesidade é considerada um sintoma mais relevante de SM do que colesterol (Grundy et al., 2005).

Um estudo do construto deve considerar os potenciais confundidores na coleta dos sintomas. $\mathrm{O}$ agrupamento em famílias com o objetivo de investigar as componentes genéticas cria uma estrutura de covariância nos dados que deve ser levada em consideração. A idade do indivíduo também é responsável por uma série de mudanças fisiológicas e está associada com a SM (Ford et al., 2002; Pollex e Hegele, 2006). Portanto, é desejável investigar a influência da idade (efeito linear ou qua- 
drático) em qualquer medida de SM além de outras variáveis como o gênero do indivíduo.

Além das medidas fenotípicas avaliadas nos indivíduos e da informação de parentesco, o estudo 'Corações de Baependi' também obteve informações genéticas dos indivíduos através de marcadores moleculares. O posições do genoma dos indivíduos foram medidos com respeito às suas bases constituintes ${ }^{1}$. Supõe-se que variações em algumas dessas bases servem como marcadores (ou em raros casos, causadores) de alterações no genoma ${ }^{2}$ entre indivíduos, podendo ser responsáveis pela suscetibilidade a doenças.

Um problema central no uso da informação genética dos indivíduos por meio de marcadores encontra-se na enorme quantidade de informação coletada de cada indivíduo. As plataformas atuais de coleta de dados de marcadores moleculares são da ordem de milhares de medidas relativas às bases constituintes do código genético de um indivíduo, o qual é responsável por uma série de características não relacionadas com a doença sendo modelada. Portanto, é de interesse determinar, em meio à quantidade considerável de informação genética do indivíduo quais variáveis medidas são relevantes ou não.

\subsection{Teoria da Resposta ao Item e seleção de variáveis}

Os modelos da Teoria da Resposta ao Item (TRI) formam uma série de modelos para a análise de dados de questionários em Educação, Psicometria e outras áreas. Usualmente deseja-se investigar um construto que não é diretamente observável (como proficiência ou depressão) em termos de um instrumento de avaliação (como uma prova ou inventário) com questões (denominadas itens) relativas ao construto em questão.

O objeto central modelado na TRI é a probabilidade de uma resposta de determinado tipo em um certo tipo de item. Retornando a aplicação de interesse, podemos considerar a SM como o construto sobre o qual queremos realizar inferências e cada um dos sintomas como itens em um modelo da TRI, e considerando $Y_{i j}$ uma variável aleatória definida como em (1.1) para cada indivíduo $j, j=1, \cdots, N$ e cada sintoma $i$ (que usaremos de forma intercambiável como item e fenótipo ao longo do texto) $i=1, \cdots, I$.

A literatura em TRI apresenta uma série de alternativas para modelar a probabilidade $P\left(Y_{i j}=\right.$ $\left.1 \mid \theta_{j}, \zeta_{i}\right)$, em que $\theta_{j}$ representa o traço latente do indivíduo $j$ e $\zeta_{i}$ representa um vetor de parâmetros do item $i$.

A forma da probabilidade em função do traço latente pode ser estimada, gerando uma medida não paramétrica do traço latente (Rossi et al., 2002), mas as formulações mais usuais da TRI são paramétricas derivadas dos trabalhos de Lord (1952) e Rasch (1960), nas quais uma função de ligação logistica ou normal é proposta para um preditor linear envolvendo o traço latente e os parâmetros dos itens.

Dentro dessa classe paramétrica de modelos da TRI, o construto latente pode ter mais de uma dimensão, motivando modelos multidimensionais (Reckase, 1985), e cada item pode ter uma série de características próprias, os ditos modelos de um, dois ou três parâmetros descritos, por exemplo, em Baker e Kim (2004).

O agrupamento de indivíduos não é um problema novo em Educação. Apesar de respondentes serem usualmente assumidos independentes, indivíduos podem frequentar a mesma instituição de ensino ou serem privilegiados por algum programa de fomento, induzindo uma estrutura de covariância entre os indivíduos. Além disso, espera-se que a idade do aluno e fatores econômicos tenham efeito sobre o seu o grau de proficiência.

Essas características motivaram o desenvolvimento de modelos multiníveis na TRI (Fox e Glas , 2001), capazes de modelar a estrutura dos dados e múltiplas fontes de informação. Em genética quantitativa, alguns modelos multiníveis foram aplicados para estudos de gêmeos respondendo a

\footnotetext{
${ }^{1}$ o DNA é constituído de quatro bases agrupadas em dois pares Adenina-Timina (A/T) e Citosina-Guanina (C/G), por exemplo

${ }^{2}$ o genoma é definido como a totalidade do material genético de um indivíduo, tanto o DNA contendo o material genético quanto o RNA responsável pela ação do DNA sobre a célula
} 
questionários construídos para avaliar a chegada da puberdade (Eaves et al., 2004), alterações de humor (Eaves et al., 2005), problemas de atenção (van der Berg et al., 2007) e sintomas de enxaqueca (Chen et al., 2009).

Com respeito à modelagem, o presente trabalho inova em algumas direções. Ao invés de questionários formulados com o objetivo de investigar o construto, utilizam-se sintomas dos quais a doença é o denominador comum como itens, cujas respostas são modeladas pela TRI. Essa escolha permite que todos os sintomas sejam agregados em um único indicador, mas demanda mais cuidado na caracterização do traço latente. Além disso, a literatura se concentra em estudos de gêmeos, enquanto o presente trabalho apresenta um modelo aplicável em famílias de tamanho e configurações quaisquer para modelar a estrutura de dependência.

A literatura envolvendo a SM mostra que a modelagem dessa variável em termos de um modelo multiníveis da TRI é factível, permitindo a agregação dos diversos sintomas em termos de um traço latente, o qual pode ser inserido em um modelo de efeitos mistos utilizado em genética quantitativa (como a classe de modelos exposta em Almasy e Blangero (1998) por exemplo) no qual o agrupamento familiar, efeitos ambientais e confundidores podem ser modelados. Tal abordagem se mostra frutífera, sendo capaz de descrever adequadamente a SM e recuperar características conhecidas da doença. Uma descrição detalhada é feita no Capítulo 2 e em Fragoso et al. (2014).

Esse modelo para os sintomas da doença também permite que os marcadores moleculares, relativos a bases constituintes do genoma do indivíduo sejam inseridos diretamente no traço latente. Com o traço latente identificado como a SM, a associação entre marcadores e o traço latente fornece algum indicativo da arquitetura genética da SM, fornecendo uma investigação mais profunda das suas bases genéticas do que o estudo dos sintomas em separado.

Nesse contexto, a busca por marcadores genéticos da SM se reduz a um problema de seleção de covariáveis em um modelo de regressão, o qual tem sido bastante explorado na literatura estatística tanto pelo problema de decisão envolvido quanto pelas dificuldades derivadas de situações em que o número de preditores é muito maior do que o tamanho amostral.

Diversos métodos de seleção têm sido propostos na literatura estatística, tanto sob abordagens clássicas como a seleção por passos ${ }^{3}$, critérios de informação e métodos penalizados como o LASSO 4 (Tibshirani, 1996) e eventuais extensões, quanto sob abordagens Bayesianas como a busca estocástica (George e McCulloch, 1993, 1997), o reversible jump MCMC (Green, 1995) e encolhimentos de maneira análoga ao LASSO (Hayes et al., 2001; Park e Casella, 2008).

A aplicação de um método de seleção de variáveis em um modelo multiníveis é possível dentro do paradigma de estimação de parâmetros exposto no Capítulo 3, resultando em um processo capaz de agregar os sintomas, caracterizar a SM e realizar explorações sobre os marcadores genéticos associados à síndrome. Dessa forma, o presente trabalho apresenta um método de estimação capaz de estimar os parâmetros do modelo multiníveis e realizar simultaneamente uma seleção de variáveis, provendo indicadores interpretáveis de associação entre os marcadores e a doença.

Os modelos multiníveis da TRI são essencialmente um modelo hierárquico, no qual o modelo da TRI para as respostas compõe o que na literatura de modelos de equações estruturais é denominado o modelo de medição enquanto os outros níveis compreendem os modelos estruturais. A imersão dos modelos da TRI dentro dos modelos de equações estruturais é um assunto pouco explorado (Lu et al., 2005), mas essa imersão é capaz de elucidar as premissas causais relativamente restringentes da modelagem proposta e propor diversas direções na qual o trabalho pode ser estendido de maneira a acomodar diversas premissas com respeito às variáveis modeladas.

Concluímos o presente trabalho no Capítulo 4 com uma discussão da abrangência da modelagem e direções nas quais o trabalho pode ser estendido. Para tal, emprestamos a linguagem de grafos direcionados acíclicos utilizada em Pearl (2000) para descrever o modelo multiníveis e outros possíveis modelos, investigando as premissas causais e a estrutura de dependência condicional do presente modelo e possíveis extensões.

\footnotetext{
${ }^{3}$ como o método stepwise e modificações

${ }^{4}$ operador de seleção e menor encolhimento absoluto, do inglês Least Absolute Shrinkage and Selection Operator
} 


\section{Capítulo 2}

\section{Modelos multiníveis da teoria de resposta ao item}

No presente capítulo é feita uma breve exposição da Teoria de Resposta ao Item (TRI) e de seus modelos multiníveis aplicados em Genética devidamente adaptados para a estrutura familiar.

Procedimentos de inferência Bayesiana e métodos de Monte Carlo via Cadeias de Markov (MCMC) são considerados. Sob esse paradigma, o processo de estimação desenvolvido é apresentado, no qual o trabalho de Fu et al. (2009) é estendido para modelos multiníveis e uma verificação de ajuste do modelo através de checagens preditivas da posteriori é considerada.

São executados estudos de simulação para avaliar a recuperação dos parâmetros em conjuntos de dados simulados bem como para verificar a confiabilidade do algoritmo implementado em termos do erro quadrático médio, viés e variância dos estimadores.

Conclui-se o capítulo aplicando-se a modelagem ao conjunto de dados estudado em Oliveira et al. (2008), modelando a síndrome metabólica e sua herdabilidade (coeficiente de correlação intraclasses) resultante da estrutura de dados familiares. Parte dos resultados expostos nesse capítulo foram também publicadas na forma de artigo científico em Fragoso et al. (2014).

\subsection{Modelos da teoria de resposta ao item}

Modelos da Teoria de Resposta ao Item (TRI) foram originalmente propostos em Educação e Psicometria para avaliar respostas de indivíduos a questionários de múltipla escolha como avaliações educacionais ou inventários relacionados com distúrbios psicológicos. A TRI propõe um modelo para a probabilidade de cada resposta em termos de parâmetros relativos aos itens em conjunto com parâmetros latentes inerentes aos indivíduos, possibilitando a separação entre respondente e instrumento de avaliação.

Devido a essa separação, a modelagem com a TRI permite a criação de escalas que independem do instrumento de avaliação, medindo a coerência do indivíduo com relação ao construto cujo instrumento de avaliação almeja medir.

Além disso, podemos derivar características do instrumento que enriquecem a interpretação do parâmetro do indivíduo, denominado traço latente nas modelagens com a TRI.

Usualmente nas aplicações da TRI temos um conjunto de respondentes independentes, representando o conjunto de alunos ou pacientes avaliados. Entretanto, é possível que os respondentes sejam agrupados de alguma forma. Por exemplo, em Educação fatores como a instituição de ensino ou a presença de algum programa de fomento podem influenciar o desempenho dos alunos, tendo um efeito em seus traços latentes.

Nesse sentido, Fox e Glas (2001) propuseram um modelo multinível no qual a resposta do indivíduo ao item é modelada como o primeiro nível em um modelo hierárquico, no qual a resposta depende de parâmetros do item e do traço latente como modelado pela TRI. O traço latente afetando a resposta é então inserido no segundo nível do modelo como a variável dependente em um modelo linear misto, no qual efeitos que representem o agrupamento dos indivíduos podem ser inseridos. 
Níveis adicionais podem ser inseridos de maneira a utilizar alguns dos efeitos do segundo nível como variáveis dependentes em outros modelos de regressão, representando características da instituição de ensino ou do programa de fomento por exemplo. A aplicação que motivou a presente modelagem consiste de dois níveis. O primeiro, denominado nível funcional, consiste das respostas dos indivíduos aos itens enquanto o segundo, denominado nível estrutural, diz respeito aos efeitos fixos devidos a confundidores como idade e variantes genéticas e efeitos aleatórios representando o agrupamento dos indivíduos em famílias.

Modelos multiníveis foram aplicados em Genética para modelar vários construtos relacionados com mudanças devido à puberdade (Eaves et al., 2004), depressão (Eaves et al., 2005), deficit de atenção (van der Berg et al., 2007) e enxaqueca (Chen et al., 2009), em estudos de gêmeos. Considera-se que o construto sofre influências genéticas e ambientais de maneira que efeitos aleatórios são inseridos nos traços latentes para modelar o entre os indivíduos. Contudo, as modelagens presentes na literatura se preocupam primariamente com estudos envolvendo gêmeos, motivando uma extensão para dados agrupados em famílias estendidas.

Em Educação e Psicometria, os itens a serem medidos são construídos e colocados em um inventário ou prova de múltipla escolha. Na presente modelagem, estamos interessados em modelar a probabilidade da observação de um fenótipo (uma variável de interesse) alterado, representando um sintoma de uma doença complexa que não pode ser diretamente diagnosticada. Ao longo do texto, os termos item e fenótipo serão utilizados de maneira intercambiável.

A variável observada estudada na TRI é a resposta do indivíduo ao item. Diversos tipos de resposta foram modelados na literatura mas, inspirados pela aplicação descrita no Capítulo anterior, modelamos respostas dicotômicas representando a presença ou ausência de um comportamento coerente com o construto medido.

Os indivíduos estão agrupados em $K$ famílias, indexadas por $k=1, \cdots, K$, compostas de $j$, $j=1,2, \cdots, n_{k}$ indivíduos medidos em $i, i=1,2, \cdots, I$ fenótipos. Seja $Y_{i j k}$ a variável aleatória definida como

$$
Y_{i j k}=\left\{\begin{array}{l}
1, \text { observa-se alteração no fenótipo } i \text { do indivíduo } j \text { na família } k \\
0, \text { caso contrário }
\end{array}\right.
$$

para cada indivíduo, família e fenótipo $\operatorname{com} \boldsymbol{Y}_{(N \times I)}=\left(\boldsymbol{Y}_{\left(n_{1} \times I\right)}, \cdots, \boldsymbol{Y}_{\left(n_{K} \times I\right)}\right)^{\prime}$ composta das matrizes $\boldsymbol{Y}_{n_{k} \times I}=\left\{Y_{i j k}\right\}, j=1 \cdots, n_{k}, i=1, \cdots, I$ das respostas aos itens dos indivíduos de cada uma das $K$ famílias com $N=\sum_{k=1}^{K} n_{k}$ definidas acima.

Supomos que cada variável observada $Y_{i j k}$ é uma variável aleatória com distribuição de Bernoulli e probabilidade de sucesso dada pelo modelo de Rasch (Rasch, 1960)

$$
P_{i j k}=P\left(Y_{i j k}=1 \mid b_{i}, \theta_{j k}\right)=\frac{1}{1+\exp \left(-\left(\theta_{j k}-b_{i}\right)\right)},
$$

em que $\theta_{j k}$ é o traço latente do indivíduo $j$ da família $k$ e $b_{i}$ é um parâmetro de locação do fenótipo $i$ na escala dos traços latentes. Um valor elevado de $b_{i}$ indica que um alto valor do traço latente é necessário para uma alta probabilidade de alteração, enquanto um valor menos elevado indica que o sintoma é prevalente mesmo em indivíduos com baixos valores do traço latente.

Denote por $\boldsymbol{b}_{(I \times 1)}$ o vetor de todos os parâmetros de locação, $\boldsymbol{\theta}_{(N \times 1)}$ o vetor de todos os traços latentes, $\boldsymbol{\theta}_{k}$ o vetor de tamanho $n_{k} \times 1$ de traços latentes da família $k$ e $\boldsymbol{\theta}_{-j k}$ o vetor de tamanho $\left(n_{k}-1\right) \times 1$ de traços latentes da família $k$ com o elemento correspondente ao indivíduo $j$ removido. No presente trabalho, o modelo de Rasch é assumido para a resposta dos indivíduos aos itens.

A modelagem com a TRI é bem flexível, admitindo uma ampla gama de formas para a probabilidade de alteração. A função logística (2.2) é apenas uma das funções densidade de probabilidade que poderiamos utilizar. Freqüentemente adota-se a função distribuição acumulada da normal, resultando no modelo de ogiva

$$
P_{i j k}=P\left(Y_{i j k}=1 \mid b_{i}, \theta_{j k}\right)=\Phi\left(\theta_{j k}-b_{i}\right),
$$


em que $\Phi(\cdot)$ é a função distribuição acumulada da normal. Apesar da facilidade analítica de (2.3) comparada a (2.2), as caudas mais pesadas da logística provêm alguma robustez com respeito a comportamentos aberrantes dos respondentes (Lord, 1980), justificando sua aplicação quando possível. Outras formas podem ser adotadas, como distribuições assimétricas (Bazan et al., 2006) e extensões (Azevedo et al., 2012).

Parâmetros também podem ser inseridos regulando a influência de variações no traço latente sobre a probabilidade (modelos de dois parâmetros) ou formulando a probabilidade em termos de uma mistura da probabilidade de acerto na forma (2.2) e uma probabilidade de sucesso devido a fatores não correlacionados com o construto (modelos de três parâmetros). Uma exposição mais detalhada dessas extensões pode ser encontrada em Baker e Kim (2004).

Considerando o agrupamento dos indivíduos em famílias, modelamos o vetor de traços latentes $\boldsymbol{\theta}_{k}$ no nível estrutural como a variável resposta no modelo linear misto

$$
\boldsymbol{\theta}_{k}=\boldsymbol{X}_{k} \boldsymbol{\beta}+\boldsymbol{g}_{k}+\boldsymbol{e}_{k},
$$

em que $\boldsymbol{X}_{k}$ é a matriz $n_{k} \times p$ de $p$ covariáveis para cada indivíduo, $\boldsymbol{\beta}$ é o vetor de $p$ efeitos fixos, $\boldsymbol{g}_{k}$ é o efeito aleatório da família $k$ sobre o vetor de traços latentes e $\boldsymbol{e}_{k}$ é o vetor de erros aleatórios da família $k$.

Supõe-se que os erros aleatórios são independentes para cada indivíduo e seguem uma distribuição normal multivariada

$$
\boldsymbol{e}_{k} \sim N_{n_{k}}\left(0, \sigma_{e}^{2} I_{n_{k}}\right)
$$

de maneira que $\sigma_{e}^{2}$ é a variância do erro e $I_{n_{k}}$ é a matriz identidade de ordem $n_{k}$.

Para o efeito das famílias, supomos que a estrutura de covariâncias é modelada pela matriz de parentesco esperada da família, $\Phi_{k}=\left(2 \phi_{l m}\right)_{l, m=1, \cdots, n_{k}}, \phi_{l m}$ é o coeficiente de parentesco entre dois indivíduos. Os coeficientes são conhecidos e representam a proporção esperada do genótipo em comum entre dois indivíduos. Por exemplo, espera-se que irmãos completos (com os mesmos pais) compartilhem metade dos seus genes.

Supõe-se que o efeito da família (ou efeito poligênico) é centrado na origem e possui distribuição normal multivariada

$$
\boldsymbol{g}_{k} \sim N_{n_{k}}\left(0, \sigma_{g}^{2} \Phi_{k}\right),
$$

analogamente, $\sigma_{g}^{2}$ é denominada variância genética ou poligênica. Assume-se ainda que os efeitos poligênicos e o erro são não correlacionados.

Assim, temos

$$
\operatorname{Cov}\left(\theta_{j k}, \theta_{j^{\prime} k^{\prime}}\right)=\left\{\begin{array}{l}
\sigma_{g}^{2}+\sigma_{e}^{2}, \text { se } j=j^{\prime} \text { e } k=k^{\prime} \\
2 \phi_{k k^{\prime}} \sigma_{g}^{2}, \text { se } j \neq j^{\prime} \text { e } k=k^{\prime} \\
0, \text { se } j \neq j^{\prime} \text { e } k \neq k^{\prime}
\end{array}\right.
$$

Cabe notar que essa formulação do modelo linear misto difere sutilmente do que observa-se usualmente na literatura. Por exemplo, em se tratando da construção de uma matriz de parentesco baseada em marcadores (Yang et al., 2011) usam

$$
\boldsymbol{\theta}_{k}=\boldsymbol{X}_{k} \boldsymbol{\beta}+\boldsymbol{Z}_{k} \boldsymbol{u}_{k}+\boldsymbol{e}_{k}
$$

$\boldsymbol{Z}_{k}$ representa uma matriz de incidência para os efeitos aleatórios da família $k$ atendendo $2 \Phi_{k}=$ $\boldsymbol{Z}_{k}^{\prime} \boldsymbol{Z}_{k}$ e $\boldsymbol{u}_{k} \sim N\left(0, \sigma_{g}^{2} I_{n_{k}}\right)$. Os dois modelos são equivalentes fazendo-se $\boldsymbol{g}_{k}=\boldsymbol{Z}_{k} \boldsymbol{u}_{k}$, pois $\operatorname{Var}\left(\boldsymbol{g}_{k}\right)=$ $\sigma_{g}^{2} \boldsymbol{Z}_{k}^{\prime} I_{n_{k}} \boldsymbol{Z}_{k}=2 \boldsymbol{\Phi}_{k}$ com a mesma estrutura de covariâncias.

A proporção da variância devida à componente genética é de particular interesse, pois representa a correlação entre o traço modelado e a herança genética do indivíduo. A correlação intraclasses ou herdabilidade, denominação usada em Genética, é dada por 


$$
h^{2}=\frac{\sigma_{g}^{2}}{\sigma_{e}^{2}+\sigma_{g}^{2}} .
$$

O modelo (2.8) representa a partição usada em genética quantitativa sob a premissa de que a característica observada (ou, no caso, inferida como o traço latente da TRI) é influenciada por fatores genéticos $(g)$ e ambientais (e). Essa partição pode ser ainda mais refinada nessas duas direções (Almasy e Blangero, 1998) de maneira a levar outras fontes de covariância genética ou ambiental em consideração.

De fato, diversos estudos na mesma população envolvendo tabagismo (Horimoto et al., 2012), atividade física (Horimoto et al., 2011) e fatores de risco em doenças cardiovasculares (Giolo et al., 2010) permitem que a covariância entre dois indivíduos que compartilham um mesmo ambiente seja maior do que a esperada apenas pelas suas relações de parentesco. Tal efeito de ambiente comum pode ser inserido no modelo (2.4) através de um vetor aleatório $\boldsymbol{c}_{(1 \times S)}, S$ o número de ambientes compartilhados na amostra (casas, no caso do estudo em Oliveira et al. (2008)), com

$$
\boldsymbol{c} \sim N\left(\mathbf{0}, \sigma_{h}^{2} \boldsymbol{H}\right)
$$

e modifica-se o modelo (2.4) com a adição de um termo no modelo de regressão

$$
\boldsymbol{\theta}=\boldsymbol{X} \boldsymbol{\beta}+\boldsymbol{g}+\boldsymbol{c}+\boldsymbol{e},
$$

a matriz $\boldsymbol{H}_{(N \times N)}$ representa uma matriz de indicadores com elemento típico

$$
h_{l m}=\left\{\begin{array}{l}
1, \text { se os indivíduos } l \text { e } m \text { compartilham o ambiente } \\
0, \text { caso contrário }
\end{array}\right.
$$

e $\sigma_{h}^{2}$ representa a componente da variância devido ao ambiente compartilhado. Tal componente faz parte da variância ambiental e é inserida no denominador da equação (2.9) para o cálculo da herdabilidade.

Claramente, a covariância entre dois indivíduos $j$ e $j^{\prime}$, que compartilham a mesma condição ambiental, é modificada para

$$
\operatorname{Cov}\left(\theta_{j}, \theta_{j^{\prime}}\right)=2 \phi_{j j^{\prime}} \sigma_{g}^{2}+h_{j j^{\prime}} \sigma_{h}^{2}+I\left(j=j^{\prime}\right) \sigma_{e}^{2} .
$$

$I(\cdot)$ indica a função indicadora.

$\mathrm{Na}$ construção da escala do traço latente é importante avaliar que região dos traços latentes é medida pelo instrumento de avaliação (no caso o conjunto de sintomas). Para isso, usa-se tradicionalmente (Baker e Kim, 2004) a função de informação do item dada por

$$
I_{i}(\theta)=P_{i}\left(1-P_{i}\right)
$$

em que $P_{i}$ é a probabilidade dada em (2.2) e interpretada como uma função do traço latente. A função de informação do item nos diz que intervalo da escala dos traços latentes os ites medem com maior precisão.

Adicionando as funções de informação de cada item, temos a função de informação conjunta dos $I$ fenótipos

$$
I(\theta)=\sum_{i=1}^{I} I_{i}(\theta) .
$$

Da mesma maneira, utilizando-se os parâmetros de locação de cada fenótipo e interpretando a informação como uma função do traço latente, temos uma idéia da precisão da série de fenótipos como um todo em avaliar uma região da escala. A forma da função de informação do item é obtida calculando-se a segunda derivada com respeito a $\theta$ da probabilidade (2.2), de forma que a informação do conjunto de itens (2.15) é obtida somando-se a informação de cada item sob a 
premissa de independência local.

Dizemos que dois itens $i$ e $i^{\prime}$ são localmente independentes se, dado um valor do traço latente,

$$
P\left(Y_{i}=1 ; Y_{i^{\prime}}=1 \mid \theta\right)=P\left(Y_{i}=1 \mid \theta\right) P\left(Y_{i^{\prime}}=1 \mid \theta\right),
$$

isto é, dois itens são independentes dado o conhecimento do traço latente. Tal premissa é central para a construção da função de verossimilhança dos dados, e é uma premissa relativamente direta nas aplicações da TRI em Educação e Psiquiatria, tendo em vista a construção dos instrumentos de avaliação. O mesmo não acontece em Genética, pois não é tão direto que dois sintomas dicotômicos são condicionalmente independentes, o que requer mais cuidado na interpretação. Uma discussão desse aspecto no contexto da aplicação é feita na Seção 2.4 .

Tal formulação é reminiscente do paradigma de estimação conjunta dos parâmetros pelo método da máxima verossimilhança (Baker e Kim, 2004). Nesse contexto, a informação é relacionada com a precisão do estimador do parâmetro para cada valor de $\theta$. No presente trabalho, adotamos um paradigma de estimação Bayesiano, que não utiliza largamente a informação de Fisher exceto em casos particulares como a aproximação de Laplace para a posteriori (Marin e Robert, 2007). Ainda assim, utilizamos a informação como uma medida gráfica da região da escala melhor avaliada pelo instrumento de avaliação.

Essa região diz algo sobre a capacidade de avaliação do instrumento. Tomando um exemplo em Educação, suponha que trocamos provas (devidamente construídas com itens fáceis, médios e difíceis) destinadas a alunos do Ensino Fundamental com a avaliação que deveria ser aplicada a alunos do Ensino Médio. Os alunos do Ensino Médio terão facilidade em acertar todos os itens e dessa forma os parâmetros de locação serão todos extremamente baixos, resultando em uma função de informação concentrada em valores negativos de $\theta$.

Por outro lado, os alunos do Ensino Fundamental terão extrema dificuldade com os itens da sua prova, resultando em parâmetros de locação elevados, resultando em uma função de informação centrada em valores positivos de $\theta$. Nos dois casos, a ausência de indivíduos distribuídos ao longo do espectro do traço latente prejudicou a caracterização da escala.

O mesmo se aplica ao traço latente proposto no presente trabalho, representando uma doença complexa. Para que o traço latente faça sentido, gostaríamos que uma ampla variedade de indivíduos faça parte da amostra, apresentando indivíduos com risco alto, médio e baixo para a doença. Com essa certeza, gostaríamos então de observar uma função de informação concentrada em valores elevados de $\theta$, indicando que o instrumento de avaliação está focado em indivíduos de alto risco.

Como uma medida geral de ajuste do modelo aos dados no nível funcional (expressão (2.2)), adota-se neste trabalho uma checagem preditiva da posteriori (Gelman et al., 2004) utilizando a estatística com a frequência dos escores observados proposta em Beguin e Glas (2001).

A checagem preditiva tem como objetivo observar se o modelo é capaz de gerar dados similares aos dados reais em algum aspecto de interesse como padrões de resposta para os indivíduos consistentes com a frequência observada dos escores. Essa técnica deriva do paradigma Bayesiano adotado para a obtenção das estimativas dos parâmetros do modelo. Os métodos empregados serão brevemente descritos na seção seguinte.

\subsection{Inferência Bayesiana e métodos Monte Carlo via Cadeias de Markov}

Os parâmetros dos modelos da TRI (dificuldades, traços latentes, componentes da variância, efeitos fixos) expostos anteriormente serão estimados utilizando-se uma abordagem Bayesiana via algoritmos do tipo Monte Carlo via Cadeias de Markov (MCMC) em uma extensão do método apresentado em Fu et al. (2009).

A estimação de parâmetros em modelos da TRI não é uma tarefa trivial. Do ponto de vista clássico, além da falta de identificabilidade que prejudica a maximização da função de verossimilhança, os modelos da TRI apresentam pelo menos um parâmetro para cada indivíduo e parâmetros para 
os itens, o que implica que o número de parâmetros aumenta com o tamanho da amostra. Considerando os itens como parâmetros estruturais (no contexto de (Neyman e Scott, 1948), não do nosso nível estrutural) e os traços latentes como parâmetros incidentais, temos o problema descrito em Neyman e Scott (1948), de maneira que os estimadores de máxima verossimilhança não apresentam propriedades ótimas assintóticas como eficiência ou ausência de viés (Baker e Kim, 2004).

A falta de identificabilidade é um problema endêmico de modelos da TRI causando diversos problemas numéricos como infinitas soluções para as equações de verossimilhança e problemas de convergência das cadeias nos métodos MCMC.

Os modelos da TRI são geralmente invariantes por transformações lineares do traço latente. Isto é, se fazemos $\theta^{*}=\theta+c$ para o traço latente dos individuos e $b^{*}=b-c$ para os parâmetros de locação dos fenótipos no modelo (2.2), temos a mesma probabilidade de acerto e consequentemente a mesma verossimilhança para infinitos valores de $c$. Além disso, essa invariância complica a interpretação do valor de $\theta$, sendo necessário um centro para a escala.

Uma solução usual na literatura de TRI usando o modelo de Rasch é supor que os traços latentes são centrados na população em um valor conhecido, usualmente $E(\theta)=0$. Classicamente, mitiga-se o problema dos parâmetros incidentais supondo-se uma distribuição normal centrada na origem para os traços latentes. No presente trabalho, assume-se que o modelo de regressão (2.4) tem intercepto nulo, de forma que translações rígidas do centro da escala não levam na mesma verossimilhança.

Apesar de esforços com funções de verossimilhança modificadas (Bock e Aitkin, 1981; Bock et al. , 1988), avanços significativos foram feitos utilizando-se inferência Bayesiana e algoritmos MCMC tanto para o modelo de ogiva (Albert, 1992; Beguin e Glas, 2001; Sahu, 2002) como para o modelo logístico (Fu et al., 2009; Patz e Junker, 1999).

A inferência Bayesiana modela os parâmetros do modelo, considerados fixos e desconhecidos na inferência clássica a serem inferidos da função de verossimilhança (ou modificações), como variáveis aleatórias não observadas de maneira a quantificar a incerteza sobre os seus valores através de premissas na forma de densidades a priori.

Supõe-se que cada parâmetro do modelo, genericamente denotado por $\zeta$, tem uma função densidade de probabilidade a priori $\pi(\zeta)$ representando algum conhecimento prévio ou desejado do parâmetro. Os dados observados são então modelados pela função de verossimilhança $L(\boldsymbol{Y} \mid \zeta)$ e combinados com a priori através do teorema de Bayes

$$
\pi(\zeta \mid \boldsymbol{Y})=\frac{L(\boldsymbol{Y} \mid \zeta) \pi(\zeta)}{\int L(\boldsymbol{Y} \mid \zeta) \pi(\zeta) d \zeta}
$$

resultando na densidade a posteriori do parâmetro condicionados aos dados observados. A integral no denominador é definida sobre o conjunto suporte do parâmetro.

As inferências sobre os parâmetros do modelo são então derivadas de propriedades da posteriori como a esperança, a mediana, a variância e os quantis. A decisão sobre qual característica (ou medida resumo) da posteriori será utilizada como estimativa pontual ou intervalar pode ser fundamentada na minimização de uma função de perda.

Por exemplo, a esperança da posteriori é o estimador que minimiza o risco associado com o erro quadrático médio, enquanto outras funções de perda podem ser consideradas de maneira que a moda e os quantis são os estimadores ótimos. Detalhes sobre a optimalidade dos estimadores sob o paradigma de Teoria da Decisão podem ser encontrados em DeGroot (2005).

A adequação do modelo aos dados observados não é trivial em modelos complexos como a TRI e não existe consenso na literatura com respeito às medidas mais adequadas (Sinharay et al., 2006). Entretanto, o paradigma de estimação Bayesiano fornece uma maneira intuitiva de verificar o ajuste. Utilizando-se a posteriori, gera-se um novo conjunto de dados $\boldsymbol{Y}^{*}$ utilizando-se a distribuição preditiva

$$
\pi\left(\boldsymbol{Y}^{*} \mid \boldsymbol{Y}\right)=\int L\left(\boldsymbol{Y}^{*} \mid \zeta\right) \pi(\zeta \mid \boldsymbol{Y}) d \zeta
$$

e então avalia-se se os dados gerados do modelo são extremos com respeito aos dados observados. 
Usualmente, fixa-se uma estatística de teste $T(\boldsymbol{Y})$ que dependa dos dados e eventualmente de parâmetros do modelo e avalia-se o comportamento da sua distribuição preditiva. Detalhes sobre a interpretação e implementação das checagens preditivas podem ser encontrados em Gelman et al. (2004).

No presente trabalho, utilizamos a frequência de cada um dos $t, t=0, \cdots, I$ escores dos indivíduos (Beguin e Glas, 2001) como medida de ajuste do modelo. Diagnosticamos a bondade do ajuste em termos de intervalos de credibilidade de cada uma das categorias do escore e consideramos o modelo bem ajustado se os intervalos de credibilidade da distribuição preditiva contém as frequências observadas. Pode-se utilizar tanto gráficos quanto alguma estimativa numérica da probabilidade de que o valor observado seja extremo. Seguindo a literatura, utilizamos métodos gráficos quando possível.

Ao longo do presente trabalho, utilizaremos a esperança a posteriori de cada parâmetro $\hat{\zeta}=$ $E[\zeta \mid \boldsymbol{Y}]$ como estimador pontual dos parâmetros do modelo e os quantis da posteriori como estimadores intervalares. Entretanto, a posteriori frequentemente não é analiticamente travável, o que inviabiliza a obtenção analítica dos estimadores.

Métodos Monte Carlo via Cadeias de Markov (MCMC) são amplamente utilizados para esse fim. Constrói-se uma cadeia de Markov sobre o suporte dos parâmetros do modelo cuja distribuição estacionária corresponde à posteriori. Simulam-se amostras da função de distribuição do estado atual da cadeia $\zeta^{(r)}$ para $r=1,2, \cdots, R$ passos do processo. Sob premissas bem gerais, a distribuição dos estados converge para a distribuição estacionária, resultando em amostras da posteriori (Robert e Casella, 1999). Essas amostras são utilizadas para obter estimativas das características desejadas da posteriori através de integração pelo método de Monte Carlo.

Uma vantagem adicional dos métodos MCMC é que o cálculo de propriedades da distribuição preditiva (2.18) é direto. Assim como podemos gerar amostras dos parâmetros, podemos replicar os dados em cada iteração e gerar amostras da estatística de teste, facilitando grandemente a checagem preditiva de caracteristicas de interesse do modelo, como sua capacidade de prever os escores observados.

O paradigma Bayesiano também oferece algumas ferramentas para a seleção de modelos. $\mathrm{O}$ critério de informação do desvio (DIC, do inglês Deviance Information Criteria, como exposto em Gelman et al. (2004)) utiliza o desvio

$$
D(\zeta)=-2 \log (\pi(\boldsymbol{Y} \mid \zeta))+C(\boldsymbol{Y}),
$$

com $C(\cdot)$ uma função apenas dos dados, como um critério de seleção, utilizando a esperança $\bar{D}=$ $E_{\zeta}(D(\zeta))$ e uma estimativa pontual dos parâmetros $\zeta$, denotada por $\bar{\zeta}$ para formar uma penalidade $p_{D}=\bar{D}-D(\bar{\zeta})$ sob a log verossimilhança no critério

$$
D I C=\bar{D}+p_{D}
$$

e o modelo com menor DIC é o escolhido.

Um outro critério de comparação de modelos é através do fator de Bayes (Kass e Raftery, 1995). Denotando por $m(\boldsymbol{Y} \mid M)$ a probabilidade marginal dos dados condicionais a um modelo $M$ dado pela constante normalizadora em $(2.17)$

$$
m(\boldsymbol{Y} \mid M)=\int L(\boldsymbol{Y} \mid \zeta, M) \pi(\zeta \mid M) d \zeta
$$

o fator de Bayes em favor de um modelo $M_{1}$ com respeito a um modelo $M_{2}$ é dado pela razao

$$
B F=\frac{m\left(\boldsymbol{Y} \mid M_{1}\right)}{m\left(\boldsymbol{Y} \mid M_{2}\right)}
$$

para a qual valores acima de 1 indicam maior evidência em favor de $M_{1}$, enquanto valores abaixo de 1 indicam evidências em favor de $M_{2}$, onde valores acima de 10 são interpretados como forte evidência de $M_{1}$. Usualmente utiliza-se o logarítmo em base 10, de maneira que valores positivos 
indicam maior evidência em prol de $M_{1}$ e valores maiores que 1 são indicativos fortes de $M_{1}$.

O cálulo da constante (2.21) não é uma tarefa trivial (Marin e Robert, 2007), e diversos métodos foram propostos na literatura. No presente trabalho utiliza-se o estimador da média harmônica ao longo dos $R$ passos da cadeia

$$
m\left(\hat{\boldsymbol{Y} \mid} M_{1}\right)=\frac{1}{R}\left(\sum_{r=1}^{R} \frac{1}{L\left(\boldsymbol{Y} \mid \zeta^{(r))}\right.}\right)^{-1}
$$

$\zeta^{(r)}$ é a amostra do parâmetro no passo $r=1,2, \cdots, R$. O estimador converge em probabilidade para a constante normalizadora, mas é numericamente instável (Gianola e Sorensen, 2002) além de ter variância infinita para diversos modelos. O leitor interessado nessa e outras técnicas para a estimação da constante normalizadora pode encontrar uma revisão compreensiva em (Marin e Robert, 2009).

Os métodos MCMC apresentam duas limitações em sua formulação. A convergência para a distribuição estacionária é garantida para qualquer valor inicial, mas sabemos pouco sobre a taxa de convergência em geral. Na prática, usualmente descartam-se algumas amostras no início da cadeia em um período denominado burn-in, no qual espera-se descartar amostras que não pertençam à distribuição estacionária. Apesar de ser alvo de críticas (Geyer, 2011), o burn-in é uma prática inofensiva e amplamente adotada. Na presente aplicação, o burn-in parece diminuir a influência do valor inicial nas estimativas e será adotado.

Uma outra preocupação é que as amostras são correlacionadas, o que implica que a lei forte dos grandes números não garante a convergência quase certa das médias amostrais utilizadas na integração por Monte Carlo. Entretanto, o teorema ergódico garante a convergência das médias amostrais para as quantidades de interesse mesmo para amostras correlacionadas. Uma discussão detalhada da teoria envolvida pode ser encontrada em Robert e Casella (1999).

Os métodos MCMC então diferem na maneira de construir a cadeia de Markov e, consequentemente, gerar as amostras da posteriori. Para simplificar a notação, suponha que o modelo tem 2 parâmetros, denominados $\zeta$ e $\eta$. O algorítmo de Metropolis-Hastings (MH) é baseado na proposta de um novo valor para a cadeia $\left(\zeta^{(*)}, \eta^{(*)}\right)$ amostrado de uma densidade de probabilidade $q\left(\zeta^{(*)}, \eta^{(*)} \mid \zeta^{(r)}, \eta^{(r)}\right)$ denominada densidade de proposta.

O valor proposto é aceito como o próximo passo da cadeia com probabilidade

$$
\alpha\left(\zeta^{(*)}, \eta^{(*)} ; \zeta^{(r)}, \eta^{(r)}\right)=\min \left\{1, \frac{q\left(\zeta^{(r)}, \eta^{(r)} \mid \zeta^{(*)}, \eta^{(*)}\right) \pi\left(\zeta^{(*)}, \eta^{(*)}\right)}{q\left(\zeta^{(*)}, \eta^{(*)} \mid \zeta^{(r)}, \eta^{(r)}\right) \pi\left(\zeta^{(r)}, \eta^{(r)}\right)}\right\}
$$

denominada probabilidade de aceitação. Um caso particular de interesse é o amostrador de Gibbs (Geman e Geman, 1984) para o qual o novo valor da cadeia é proposto utilizando-se

$$
\begin{aligned}
\zeta^{(*)} & \sim \pi\left(\zeta \mid \eta^{(r)}, \boldsymbol{Y}\right) \\
\eta^{(*)} & \sim \pi\left(\eta \mid \zeta^{(*)}, \boldsymbol{Y}\right)
\end{aligned}
$$

em que $\pi(\zeta \mid \eta, \boldsymbol{Y})$ é a distribuição condicional a posteriori de um dos parâmetros condicional aos restantes e aos dados, usualmente denominada condicional completa. Pode-se demonstrar que o amostrador de Gibbs é equivalente a um algorítmo MH com probabilidade de aceitação igual a um.

No presente capítulo, adaptamos o amostrador de Gibbs proposto para os parâmetros dos itens e traços latentes em Fu et al. (2009) para modelos multinível, consistindo de um nivel com o modelo de medição (nível funcional) e um nível estrutural. Assim como (Fu et al., 2009), a verossimilhança intratável do modelo de Rasch é estendida utilizando-se variáveis auxiliares em um método de dados aumentados (Tanner e Wong, 1987) exposto a seguir.

O algoritmo de Fu et al. (2009) supõe como variável não observada realizações da distribuição uniforme. Para cada item $i, i=1, \cdots, I$, família $k, k=1, \cdots, N$ e indivíduo $j, j=1, \cdots, n_{k}$, seja $U_{i j k} \sim U(0,1)$ tal que 


$$
Y_{i j k}=I\left(U_{i j k} \leq P_{i j k}\right),
$$

$Y_{i j k}$ são as respostas aos itens, $P_{i j k}$ é a probabilidade de sucesso $(2.2)$ e $I(\cdot)$ é a função indicadora.

Pode-se observar que a esperança com respeito à variável não observada é $P_{i j k}$. Então temos que a contribuição do item $i$ respondido pelo indivíduo $j$ da família $k$ é dada por

$$
L_{i j k}=I\left(Y_{i j k}=1\right) P_{i j k}+I\left(Y_{i j k}=0\right)\left(1-P_{i j k}\right)
$$

que é igual à esperança da componente da verossimilhança dos dados completos com respeito aos dados aumentados dada por

$$
L_{i j k}^{c}=I\left(Y_{i j k}=1\right) I\left(U_{i j k} \leq P_{i j k}\right)+I\left(Y_{i j k}=0\right) I\left(U_{i j k}>P_{i j k}\right) .
$$

Com isso, derivamos a distribuição a posteriori condicional aos dados completos

$$
\begin{array}{r}
\pi\left(\boldsymbol{\theta}, \boldsymbol{b}, \boldsymbol{\beta}, \sigma_{e}^{2}, \sigma_{g}^{2} \mid \boldsymbol{X}, \boldsymbol{Y}, \boldsymbol{U}\right)=\prod_{i=1}^{I} \prod_{k=1}^{K} \prod_{j=1}^{n_{k}} L_{i j k}^{c} \pi\left(b_{i}\right) \pi\left(\boldsymbol{\theta}_{. k} \mid \boldsymbol{g}_{k}, \boldsymbol{\beta}, \sigma_{e}^{2}\right), \pi\left(\boldsymbol{g}_{k} \mid \sigma_{g}^{2}\right) \\
\pi(\boldsymbol{\beta}) \pi\left(\sigma_{g}^{2}\right) \pi\left(\sigma_{e}^{2}\right) .
\end{array}
$$

Utilizamos as seguintes distribuições a priori

1. Para cada item $i=1,2, \cdots, I, b_{i} \sim N(0,1)$ como em Fu et al. (2009)

2. Para cada família $k=1,2, \cdots, K$, temos $\boldsymbol{\theta}_{k} \mid \boldsymbol{\beta}, \boldsymbol{g}_{k}, \sigma_{e}^{2} \sim N_{n_{k}}\left(\boldsymbol{X}_{k} \boldsymbol{\beta}+\boldsymbol{g}_{k}, \sigma_{e}^{2} I_{n_{k}}\right)$

3. $\boldsymbol{g}_{k} \mid \sigma_{g}^{2} \sim N_{n_{k}}\left(0, \sigma_{e g}^{2} \Phi_{k}\right)$, onde $\Phi_{k}$ é a matriz de parentesco da família $k$.

4. Para as componentes da variância, assumimos $\pi\left(\sigma_{.}^{2}\right) \sim \operatorname{Gama}(1,1)$ para evitar amostras degeneradas das componentes da variância (Gelman, 2006; Wang et al., 1994).

5. Assumimos a g-prior de Zellner (1986) para os efeitos fixos $\boldsymbol{\beta} \sim N_{p}\left(0, c\left(\boldsymbol{X}^{\prime} \boldsymbol{X}\right)^{-1}\right), c$ é um hiperparâmetro representando a influência da matriz de planejamento sobre os efeitos fixos. $\mathrm{Na}$ presente aplicação, utilizamos $c=1.000$, representando pouca informação prévia da amostra sobre os efeitos fixos (Marin e Robert, 2007).

Uma vantagem da implementação de Fu et al. (2009) é que os dados se relacionam com as distribuições a priori apenas por intermédio de limites de truncamento induzidos pelo modelo (2.2) e pelos dados aumentados. Dessa maneira, as condicionais completas do nível funcional são dadas por distribuições truncadas da família das distribuições a priori assumidas, com os limites de truncamento mudando a cada passo do algoritmo. Tal qualidade flexibiliza a modelagem, aumentando as possíveis escolhas de distribuição a priori para além de prioris conjugadas como é comum em implementações da TRI com o modelo de ogiva (Albert (1992), Sahu (2002)).

Denotamos por $\cdot$ o conjunto dos parâmetros mais os dados, ou seja, quando nos referimos à condicional de $b_{1} \mid \cdot$, isso significa a condicional de $b_{1} \mid \boldsymbol{Y}, \boldsymbol{X}, \boldsymbol{U}, \boldsymbol{b}_{-1}, \boldsymbol{\theta}, \boldsymbol{g}, \boldsymbol{\beta}, \sigma_{g}^{2}, \sigma_{e}^{2}$.

Então, o algoritmo para amostrar a posteriori por MCMC, para $r=1,2, \cdots, R$ iterações, é dado por

1. Fixam-se valores iniciais para os parâmetros.

2. Amostra-se $u_{i j k}^{r+1} \mid \cdot$ condicionalmente por

- Se $Y_{i j k}=0$, tome $U_{i j k} \mid \cdot \sim U\left(P_{i j k}, 1\right)$

- Se $Y_{i j k}=1$, tome $U_{i j k} \mid \cdot \sim U\left(0, P_{i j k}\right)$ 
3. Amostra-se, para $i=1,2, \cdots, I, b_{i}^{r+1} \mid \cdot \sim N(0,1) I\left(b_{i}^{L}<b_{i}<b_{i}^{R}\right)$, onde o indicador denota a função de distribuição truncada entre os dois extremos

4. Para $k=1,2, \cdots, K$ famílias e $j=1,2, \cdots, n_{k}$ indivíduos, amostra-se $\theta_{j k}^{r+1} \mid \cdot \sim N\left(\mu_{j k}, \sigma_{e}^{2}\right) I\left(\theta_{j k}^{L}<\theta_{j k}<\theta\right.$ onde $\mu_{j k}=\boldsymbol{X}_{j k} \beta+g_{j k}$.

5. Amostre para cada $k, \boldsymbol{g}_{k} \mid \cdot \sim N_{n_{k}}\left(\Sigma_{k}^{-1} \boldsymbol{\theta}_{k} \Sigma_{k}^{-1}\right)$, para $\Sigma_{k}=\sigma_{e}^{-2} I_{n_{k}}+\sigma_{g}^{-2} \Phi_{k}^{-1}$

6. $\sigma_{g}^{2} \mid \cdot \sim I G\left(\frac{N}{2}, \sum_{k=1}^{K} \boldsymbol{g}_{k}^{\prime} \Phi_{k}^{-1} \boldsymbol{g}_{k}\right)$, onde $I G()$ é a distribuição gama inversa e $N=\sum_{k=1}^{K} n_{k}$

7. $\sigma_{e}^{2} \mid \cdot \sim I G\left(\frac{N}{2}, \sum_{k=1}^{K}\left(\boldsymbol{\theta}_{k}^{\prime}-\boldsymbol{g}_{k}^{\prime}\right)\left(\boldsymbol{\theta}_{k}-\boldsymbol{g}_{k}\right)\right)$

8. $\boldsymbol{\beta} \mid \cdot \sim N_{p}\left(\mu_{\beta}, V_{\beta}^{-1}\right), \operatorname{com} V_{\beta}=\left(\frac{1}{c}+\frac{1}{\sigma_{e}^{2}}\right) \sum_{k=1}^{K} \boldsymbol{X}_{k}^{\prime} \boldsymbol{X}_{k}$ e $\mu_{\beta}=V_{\beta}^{-1} \frac{1}{\sigma_{e}^{2}} \sum_{k=1}^{K} \boldsymbol{X}_{k}^{\prime}\left(\boldsymbol{\theta}_{k}-\boldsymbol{g}_{k}\right)$

Os limites de truncamento são dados por

$$
b_{i}^{L}=\max _{j \in C_{i}}\left\{\theta_{j k}-\log \left(\frac{u_{i j k}}{1-u_{i j k}}\right)\right\},
$$

$\operatorname{com} C_{i}=\left\{j, k: u_{i j k}>P_{i j k}\right\}$

$$
b_{i}^{R}=\min _{j \in D_{i}}\left\{\theta_{j k}-\log \left(\frac{u_{i j k}}{1-u_{i j k}}\right)\right\},
$$

$\operatorname{com} D_{i}=\left\{j, k: u_{i j k} \leq P_{i j k}\right\}$,

$$
\theta_{j k}^{L}=\max _{i \in D_{j k}}\left\{b_{i}+\log \left(\frac{u_{i j k}}{1-u_{i j k}}\right)\right\},
$$

com $D_{j k}=\left\{i: u_{i j k} \leq P_{i j k}\right\} \mathrm{e}$

$$
\theta_{j k}^{R}=\min _{i \in C_{j k}}\left\{b_{i}+\log \left(\frac{u_{i j k}}{1-u_{i j k}}\right)\right\},
$$

com $C_{j k}=\left\{i: u_{i j k}>P_{i j k}\right\}$. A derivação das condicionais completas para os parâmetros do nível funcional e dos limites de truncamento são não triviais e estão apresentadas no Apêndice A.

A convergência da cadeia para a posteriori é verificada graficamente através dos gráficos dos valores de cada parâmetro pelo número da iteração e gráficos de autocorrelação.

Uniformemente, a literatura tem considerado as aplicações da TRI para dados obtidos de estudos com gêmeos. Tais dados têm a vantagem de apresentar uma matriz de parentesco de ordem fixa $\left(n_{k}=2\right)$, o que favorece a implementação em softwares como o BUGS (Thomas et al., 2006). Em nosso trabalho, a flexibilização para tamanhos arbitrários de famílias dificulta tal abordagem. Tal limitação, somadas com a instabilidade do programa com respeito à utilização da memória e o elevado custo computacional em tempo e memória demandam um maior controle sobre a implementação do processo de estimação.

Uma outra abordagem é utilizar algum pacote que estime os parâmetros do modelo da TRI supondo independência entre indivíduos, como o pacote $1 \mathrm{tm}$ do R (Rizopoulos, 2006) e utilizar um outro software para estimar a herdabilidade, como feito em Chen et al. (2009). Apesar da facilidade, tal procedimento tende a subestimar a herdabilidade. Um estudo detalhado desse efeito pode ser visto em van der Berg et al. (2007).

Optamos então por implementar o processo descrito anteriormente no software computacional $\mathrm{R}$ (Team, 2005). O número elevado de condicionais completas $(N(I+1)+K+I+3$ distribuições, $K+1$ delas multivariadas) resulta em um número extremamente elevado de operações computacionalmente custosas, motivando a implementação do algorítmo na linguagem C. Para tal, utilizamos a integração do $\mathrm{R}$ com programas em $\mathrm{C}++$ implementada no pacote $\mathrm{RCpp}$ (Eddelbuettel e François, 2011) e a adaptação da biblioteca de álgebra linear Armadillo para o R (Eddelbuettel e Sanderson 
, 2013). O ganho em performance se mostrou significativo, obtendo tempos de execução cerca de 70 vezes menores do que o mesmo algoritmo implementado apenas em $\mathrm{R}$ quando submetidos à avaliação pelo pacote rbenchmark (Kusnierczyk, 2012) em um laptop Dell Inspiron 1525 com dois processadores Intel Pentium Core 2 Duo e 2 gigabytes de memória RAM.

\subsection{Estudos de Simulação}

Dois estudos de simulação foram realizados. Um estudo preliminar foi feito com o objetivo de observar a recuperação dos parâmetros estruturais do modelo (parâmetros de locação e componentes da variância) em conjuntos de dados simulados na presença de herdabilidades pequenas, moderadas e altas. Além da recuperação, a qualidade das estimativas foram avaliadas utilizando o erro quadrático médio (EQM) para todos os parâmetros estruturais e incidentais. Nesse caso, uma herdabilidade moderada foi fixada $\left(h^{2}=\frac{1}{2}\right)$ e diversos numeros de itens, tamanhos amostrais e configurações das famílias foram avaliadas com respeito ao seu efeito no EQM, na variância e no viés das estimativas.

\subsubsection{Recuperação dos parâmetros}

O amostrador de Gibbs descrito anteriormente foi aplicado em $R=100.000$ iterações, descartando as 10.000 primeiras iterações para mitigar a influência de valores iniciais.

A estacionariedade das cadeias foi verificada para cada parâmetro dos fenótipos, variâncias e efeitos fixos graficamente através do gráfico dos valores pela iteração e do gráfico de autocorrelações, verificando-se mixing e estacionariedade da cadeia.

Simulamos $K=250$ famílias compostas de $n_{k}=6$ indivíduos com o objetivo de obter uma amostra de tamanho $(N=1.500)$ comparável com o tamanho do conjunto de dados do projeto 'Corações de Baependi' (Oliveira et al., 2008). Além disso, as simulações foram realizadas considerando $\boldsymbol{X}_{k}=\mathbf{1}_{n_{k}}$ e $\beta=0$, sem efeitos fixos.

A estrutura familiar foi imposta igual para todas as famílias, com o heredograma exposto na Figura 2.1.

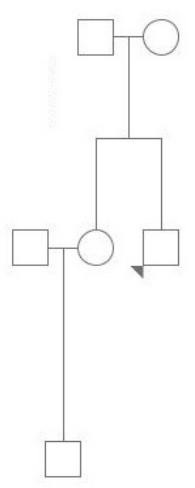

Figura 2.1: Heredograma da estrutura familiar utilizada na simulação.

Utilizando a estrutura comum para a matriz de parentesco esperada

$$
\Phi_{6 \times 6}=\left(\begin{array}{llllll}
1 & 0 & 0 & 0,5 & 0,5 & 0,25 \\
0 & 1 & 0 & 0,5 & 0,5 & 0,25 \\
0 & 0 & 1 & 0 & 0,5 & 0,5 \\
0,5 & 0,5 & 0 & 1 & 0,5 & 0,5 \\
0,5 & 0,5 & 0 & 0,5 & 1 & 0,25 \\
0,25 & 0,25 & 0,5 & 0,5 & 0,25 & 1
\end{array}\right),
$$

valores dos efeitos poligênicos foram simulados por valores da normal multivariada (2.6) e valores do erro aleatório foram simulados de (2.5) para cada família. Foram simulados $I=5$ itens com 
valores do parâmetro de locação distribuídos em torno de 0 na escala dos traços latentes, isto é, $b_{1}=-2, b_{2}=-1, b_{3}=0, b_{4}=1$ e $b_{5}=2$. Com respeito às componentes da variância, três cenários foram simulados compreendendo herdabilidades pequenas, moderadas e altas. Simulamos respostas sob as seguintes configurações: $\sigma_{e}^{2}=3$ e $\sigma_{g}^{2}=1, \sigma_{e}^{2}=1$ e $\sigma_{g}^{2}=1$ e $\sigma_{e}^{2}=1$ e $\sigma_{g}^{2}=3$, resultando em herdabilidades $h^{2}=0,25, h^{2}=0,5$ e $h^{2}=0,75$, respectivamente.

Utilizando esses valores, a matriz $N=1.500 \times I=5$ de respostas dos indivíduos aos itens foi simulada utilizando-se realizações de uma variável Bernoulli com probabilidade de sucesso dada pelo modelo de Rasch (2.2).

As amostras foram então utilizadas para obter estimativas pontuais dos parâmetros e do erro de estimação, além de estimativas intervalares do intervalo de credibilidade de $95 \%$ para os parâmetros dos fenótipos, variâncias e herdabilidade. As estatísticas resumo foram calculadas utilizando o pacote coda do R.

Os resultados para as configurações simuladas foram tabulados e podem ser vistos nas Tabelas $2.1,2.2$ e 2.3 .

Tabela 2.1: Recuperação dos parâmetros para $h^{2}=0,25$.

\begin{tabular}{rrrrrr}
\hline Parametro & Real & Média(dp) & Quantil $2,5 \%$ & Mediana & Quantil $97,5 \%$ \\
\hline$b_{1}$ & -2 & $-1,90(0,09)$ & $-2,08$ & $-1,90$ & $-1,70$ \\
$b_{2}$ & -1 & $-0,89(0,08)$ & $-1,06$ & $-0,89$ & $-0,72$ \\
$b_{3}$ & 0 & $-0,05(0,08)$ & $-0,24$ & $-0,05$ & 0,10 \\
$b_{4}$ & 1 & $1,01(0,07)$ & 0,86 & 1,01 & 1,16 \\
$b_{5}$ & 2 & $2,05(0,09)$ & 1,87 & 2,05 & 2,23 \\
$\sigma_{g}^{2}$ & 1 & $0,86(0,25)$ & 0,40 & 0,85 & 1,39 \\
$\sigma_{e}^{2}$ & 3 & $2,88(0,31)$ & 2,28 & 2,87 & 3,52 \\
$h^{2}$ & 0,25 & $0,23(0,06)$ & 0,11 & 0,22 & 0,36 \\
\hline
\end{tabular}

Tabela 2.2: Recuperação dos parâmetros $h^{2}=0,5$.

\begin{tabular}{rrrrrr}
\hline Parâmetro & Real & Média $(\mathrm{dp})$ & Quantil $2,5 \%$ & Mediana & Quantil $97,5 \%$ \\
\hline$b_{1}$ & -2 & $-2,02(0,09)$ & $-2,20$ & $-2,01$ & $-1,85$ \\
$b_{2}$ & -1 & $-1,03(0,08)$ & $-1,18$ & $-1,03$ & $-0,87$ \\
$b_{3}$ & 0 & $-0,06(0,06)$ & $-0,19$ & $-0,07$ & 0,07 \\
$b_{4}$ & 1 & $0,88(0,07)$ & 0,74 & 0,88 & 1,03 \\
$b_{5}$ & 2 & $1,95(0,08)$ & 1,78 & 1,95 & 2,12 \\
$\sigma_{g}^{2}$ & 1 & $0,85(0,17)$ & 0,52 & 0,85 & 1,22 \\
$\sigma_{e}^{2}$ & 1 & $1,19(0,18)$ & 0,83 & 1,19 & 1,58 \\
$h^{2}$ & 0,5 & $0,41(0,07)$ & 0,26 & 0,41 & 0,57 \\
\hline
\end{tabular}

Podemos observar que o modelo parece estimar adequadamente os parâmetros estruturais. Todos os valores das esperanças e medianas a posteriori são próximos dos valores reais, os quais encontramse dentro dos intervalos de credibilidade.

Apesar de animador, o resultado valida apenas uma das partes do modelo. Os parâmetros de locação nos permitem avaliar os fenótipos utilizados no diagnóstico da doença complexa associada com o traço latente, enquanto as variâncias informam sobre a influência da herança genética ao longo das gerações. O traço latente em si (e o efeito aleatório) são de particular interesse na modelagem, o primeiro como uma medida quantitativa da doença em si que permite comparar diferentes indivíduos, o segundo como uma medida do genótipo em si.

Tais perguntas motivam uma investigação mais elaborada das estimativas, sendo o tema da 
Tabela 2.3: Recuperação dos parâmetros para $h^{2}=0,75$.

\begin{tabular}{rrrrrr}
\hline Parâmetro & Real & Média $(\mathrm{dp})$ & Quantil $2,5 \%$ & Mediana & Quantil $97,5 \%$ \\
\hline$b_{1}$ & -2 & $-2,06(0,09)$ & $-2,26$ & $-2,06$ & $-1,87$ \\
$b_{2}$ & -1 & $-0,90(0,08)$ & $-1,07$ & $-0,90$ & $-0,72$ \\
$b_{3}$ & 0 & $-0,03(0,09)$ & $-0,20$ & $-0,04$ & 0,15 \\
$b_{4}$ & 1 & $0,86(0,09)$ & 0,66 & 0,86 & 1,05 \\
$b_{5}$ & 2 & $1,82(0,09)$ & 1,63 & 1,83 & 2,01 \\
$\sigma_{g}^{2}$ & 3 & $2,82(0,32)$ & 2,21 & 2,81 & 3,49 \\
$\sigma_{e}^{2}$ & 1 & $0,93(0,22)$ & 0,52 & 0,93 & 1,39 \\
$h^{2}$ & 0,75 & $0,75(0,05)$ & 0,63 & 0,75 & 0,85 \\
\hline
\end{tabular}

seção seguinte.

\subsubsection{Erro quadrático médio}

Avaliamos a qualidade das estimativas de todos os parâmetros do modelo sem efeitos fixos utilizando o erro quadrático médio

$$
\operatorname{EQM}(\hat{\zeta})=E\left[(\hat{\zeta}-\zeta)^{2}\right]
$$

para cada parâmetro $\zeta$ do modelo. Foram gerados $R e p=100$ conjuntos de dados sob cada configuração do experimento e a esperança a posteriori de cada parâmetro do modelo foi estimada utilizando-se 90.000 iterações do algorítmo MCMC. Foi utilizado um burn in de 10.000 das iterações ao longo do experimento.

Variamos o número de itens em $I=5$ e 7 , representando um número de itens próximos aos observados na aplicação considerada nesse trabalho, tendo valores distribuídos igualmente no intervalo de -2 a 2 no caso de 5 itens e igualmente espaçados no intervalo de -3 a 3 no caso de 7 itens. Utilizamos duas estruturas familiares para a amostra, primeiramente simulamos um número $K=20,200,2000$ de famílias todas com a mesma estrutura familiar representada pelo heredograma da Figura 2.1 (homogênea) resultando em tamanhos amostrais de $N=120,1200$ e 12000 respectivamente e configurações utilizando estrutura dos dados reais no projeto 'Corações de Baependi' (denominada Baependi) composta de $N=1.696$ indivíduos com famílias de tamanhos e estruturas variáveis. Outros formatos são possíveis para o estudo de simulação, por exemplo, envolvendo-se mais itens no mesmo intervalo do cenário com 5 , mas nos atemos aos presentes casos neste trabalho.

Os efeitos poligênicos foram simulados utilizando-se uma normal multivariada com matriz de covariâncias apropriadas, enquanto os erros aleatórios foram simulados de uma normal padrão para cada indivíduo. Os traços foram simulados somando-se as duas componentes. As componentes da variância foram fixadas em 1 resultando em uma herdabilidade de 50\%. Finalmente, as respostas dos indivíduos aos itens foram simu-ladas como a realização de uma Bernoulli com probabilidade dada pelo modelo de Rasch (2.2).

Cada uma das 8 configurações planejadas para o EQM foram realizadas no servidor 'brucutu' mantido pela Seção de Informática do IME-USP composto de 23 processadores Intel Xeon E5645 de $2.40 \mathrm{GHz}$ com $130 \mathrm{~GB}$ de RAM. As simulações rodaram paralelamente quando possível, apesar das 100 replicações de cada configuração ocorrerem sequencialmente. Cada uma das configurações tomou entre 8 e 10 dias de tempo computacional.

Os gráficos para o EQM dos parâmetros dos itens sob todas as configurações encontram-se nas Figuras 2.2, 2.3, 2.4 e 2.5. Podemos observar que o erro é muito baixo para todas as configurações.

Temos uma situação parecida para as variâncias. Podemos observar na Figura 2.6 que os EQM são extremamente pequenos, indicando que as componentes da variância são recuperadas com precisão. O mesmo é observado para o conjunto de dados de Baependi, os EQM são 0, 02, 0, 03 e 0, 006 

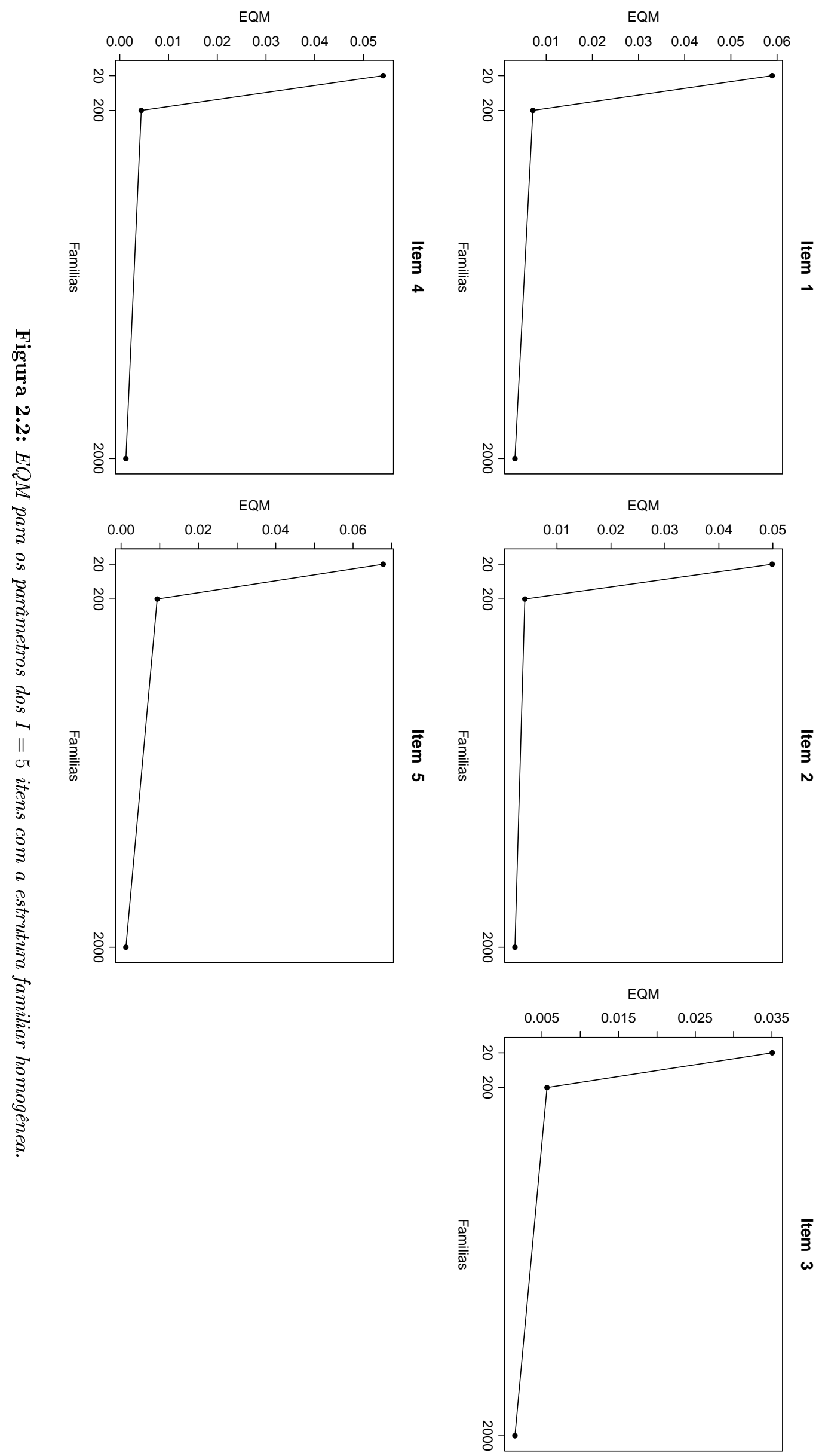

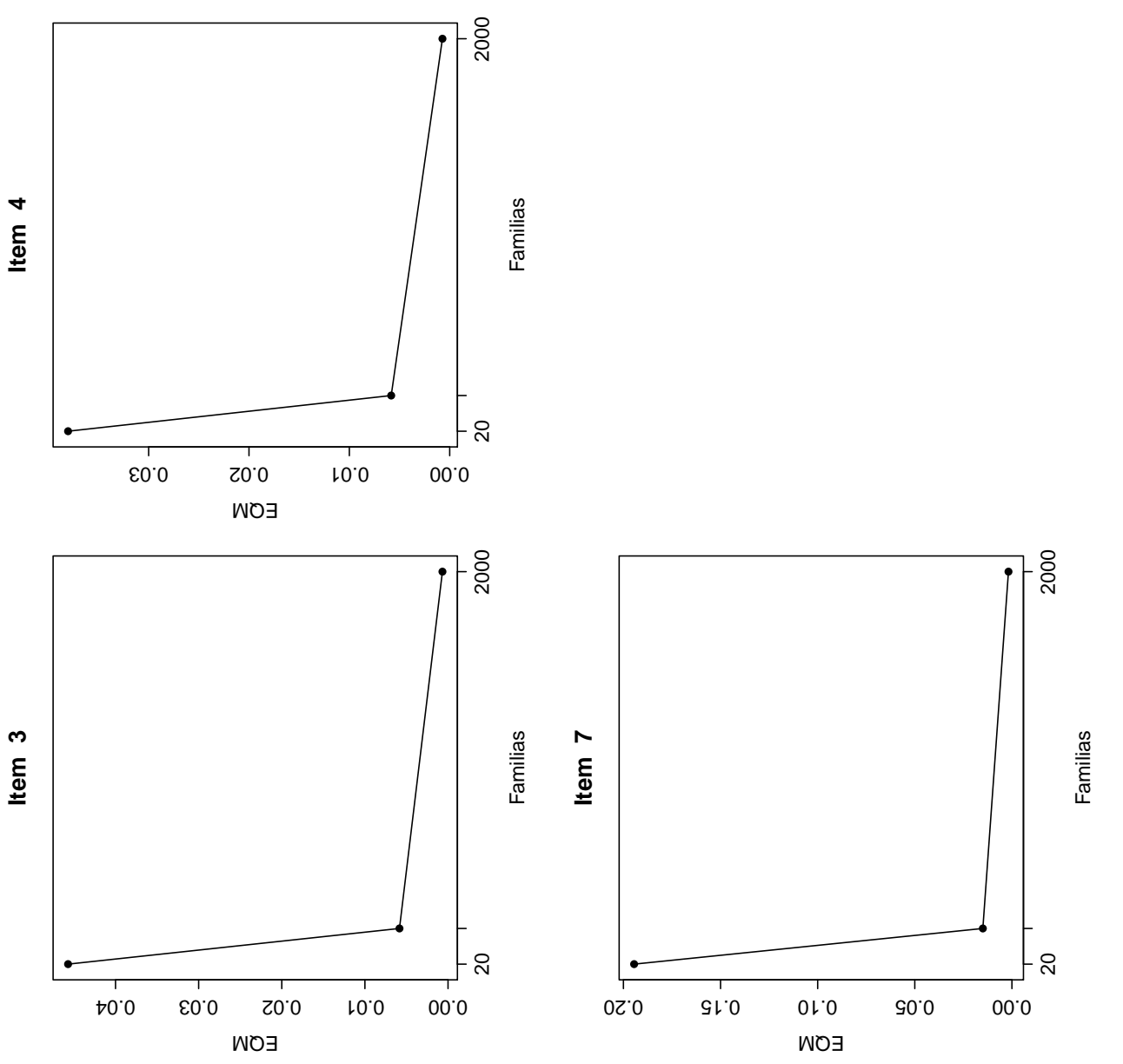

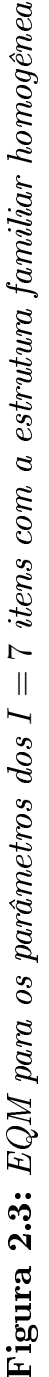
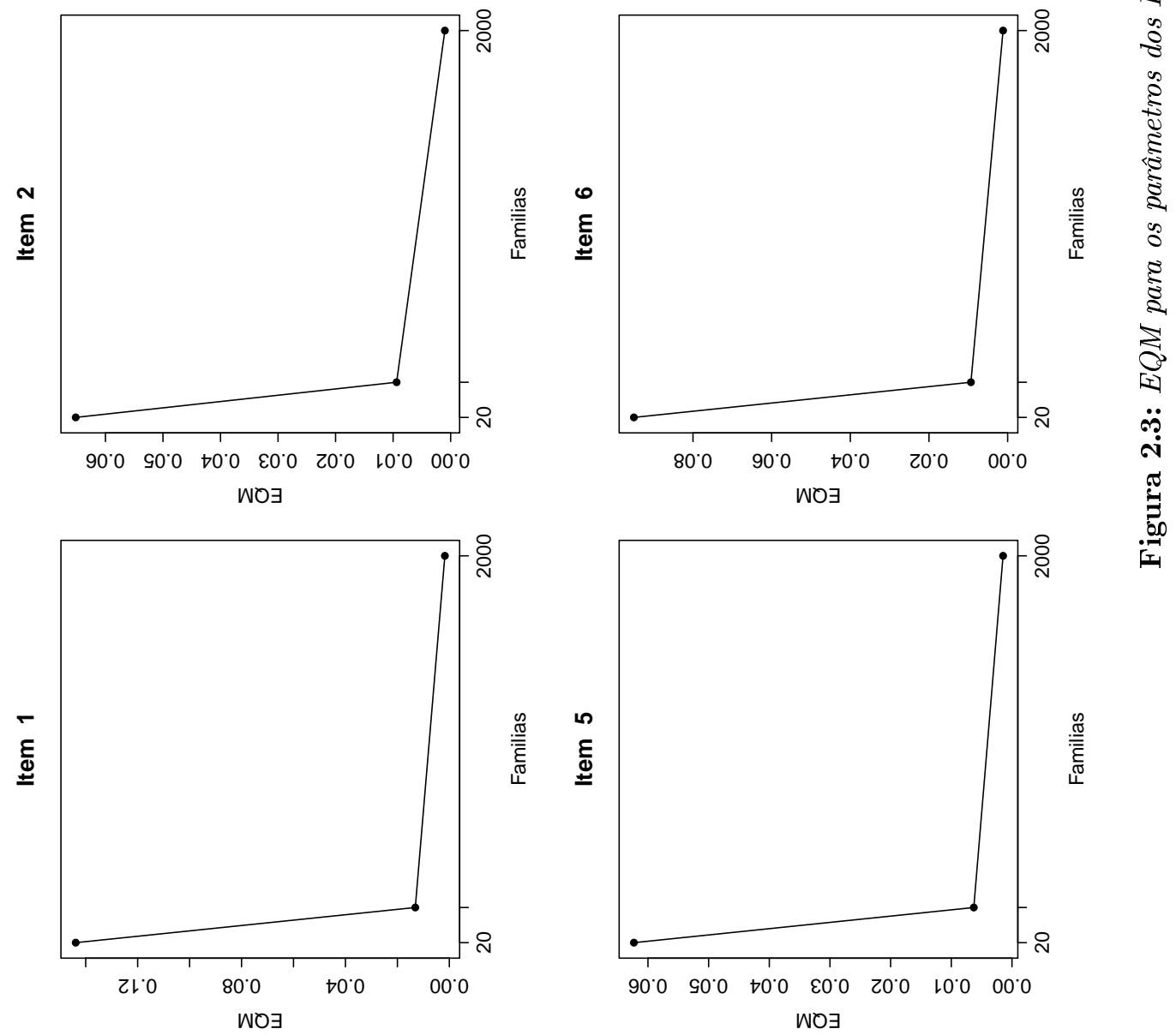


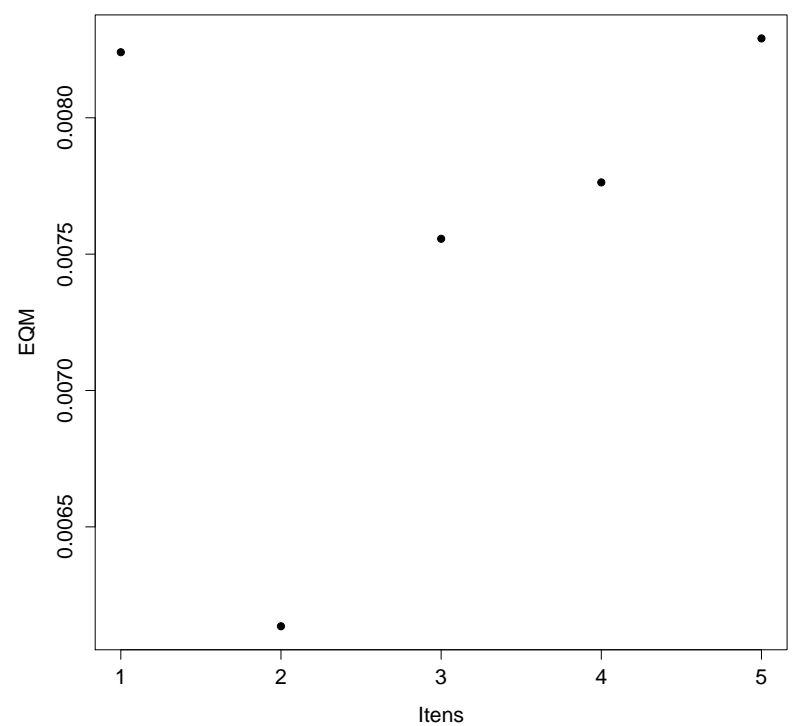

Figura 2.4: EQMs para os parâmetros dos $I=5$ itens com as familias de Baependi

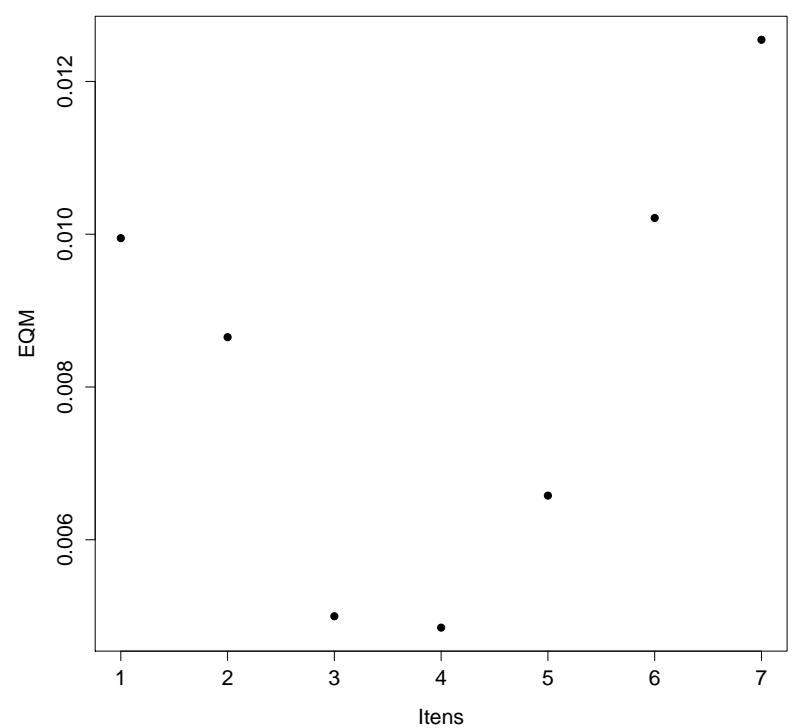

Figura 2.5: EQMs para os parâmetros dos $I=7$ itens com as familias de Baependi 
para os parâmetros $\sigma_{g}^{2}, \sigma_{e}^{2}$ e $h^{2}$ respectivamente para o caso de $I=5$ itens e $0,11,0,07$ e 0,02 para os parâmetros $\sigma_{g}^{2}, \sigma_{e}^{2}$ e $h^{2}$ respectivamente para o caso de $I=7$ itens.

Os problemas aparecem quando tentamos estimar os traços latentes $(\theta)$ e efeitos poligênicos $(g)$. Apesar da ampla literatura na recuperação dos parâmetros dos itens nos mais diversos modelos da TRI (Baker e Kim, 2004), pouco é estudado com respeito à recuperação dos traços latentes e do número de itens necessários para uma boa recuperação. Uma simulação utilizando-se 15,30 e 60 itens sob os modelos de 2 e 3 parâmetros utilizando-se máxima verossimilhança (Hulin e Drasgow, 1982) mostra um erro quadrático médio elevado nas configurações com menos itens. Esse resultado é corroborado por Borgatto et al. (2013) em um estudo de simulação um pouco diferente no qual observam-se grandes erros mesmo para um número elevado de itens.

Esse fenômeno é observado pelo presente método. Podemos observar nas Figuras 2.7, 2.8 e 2.9 que o EQM é extremamente elevado nos valores mais extremos de $\theta$ e $g$, e um pouco menor próximo ao centro, porém chegando a valores extremos como 25 tanto para 5 quanto para 7 itens nas configurações com o pedigree homogeneo. Entretanto, cabe notar que o EQM das replicações utilizando os pedigrees de Baependi (Figura 2.10) parecem bem menores que as outras configurações.

Decompomos então o EQM na soma do viés e da variância do estimador para investigar a contribuição de cada componente ao valor elevado do EQM. Figuras para a variância do estimador podem ser observadas nas Figuras 2.11, 2.12 e 2.13. Observamos que as variâncias de ambos os estimadores são pequenas para todos os valores do efeito poligênico e do traço latente tanto para 5 itens quanto para 7 itens (primeira e segunda colunas) e que não parece haver um padrão entre as duas configurações (terceira coluna dos valores ordenados plotados contra a reta normal). O mesmo é observado nas simulações com os pedigrees de Baependi, porém com variâncias um pouco menores (Figura 2.14).

As figuras para o viés mostram um padrão diferente. Nas Figuras 2.15, 2.16 e 2.17, observamos que o viés é bem alto para todos os valores do traço latente. Os valores mais próximos de -3 parecem ter um forte viés positivo, enquanto os valores próximos de 3 parecem ter um forte viés negativo. A linha horizontal nas duas primeiras colunas representa a linha em que o viés é igual a 0. Seguindo a tendência do EQM e da variância, observamos que o viés ainda é elevado para a simulação com os pedigrees de Baependi, mas é menor do que na situação homogênea.

Essa tendência mostra um encolhimento das estimativas na direção da esperança da priori. Tal efeito é conhecido na estimação dos traços latentes em modelos da TRI (de Ayala, 2009) e o mesmo padrão é observado na presença de mais parâmetros relativos ao indivíduo.

\subsection{Projeto 'Corações de Baependi'}

A síndrome metabólica (SM) é uma doença multifatorial que consiste de uma série de sintomas, que, em conjunto aumentam o risco de doenças cardiovasculares e diabetes. A SM é uma doença complexa, cujo diagnóstico não pode ser obtido diretamente pois depende de diversos sintomas, cada um dos quais é considerado alterado e, portanto, indicativo de SM se ultrapassa um certo limite préestabelecido. Por exemplo, um indivíduo é considerado hipertenso de acordo com o critério ATP-III (Expert Panel on Detection and Evaluation and and Treatment of High Blood Cholesterol in Adults , 2001) da associação norte-americana do coração se apresenta pressão arterial sistólica superior a $140 \mathrm{mmHg}$ e/ou pressão arterial diastólica superior a $90 \mathrm{mmHg}$. Usualmente, o diagnóstico utilizando-se o ATP-III e feito utilizando-se sete sintomas associados com a SM.

Os estudos epidemiológicos sobre a SM são realizados baseados na observação de diversos fenótipos como obesidade truncal, colesterol e hipertensão, os quais são dicotomizados de acordo com alguma autoridade médica e avaliados em conjunto para avaliar a prevalência da condição na população. Estudos de sua herdabilidade são usualmente feitos (como por exemplo, em Oliveira et al. (2008)) em termos da herdabilidade de cada fenótipo individualmente relacionado com a SM ou da herdabilidade do diagnóstico de fenótipo alterado (em termos da dicotomização) utilizando-se um modelo de regressão análogo a (2.4), ou ainda em função dos componentes principais (Ott e Rabinowitz, 1999; Oualkacha et al., 2012) das variáveis da SM. 


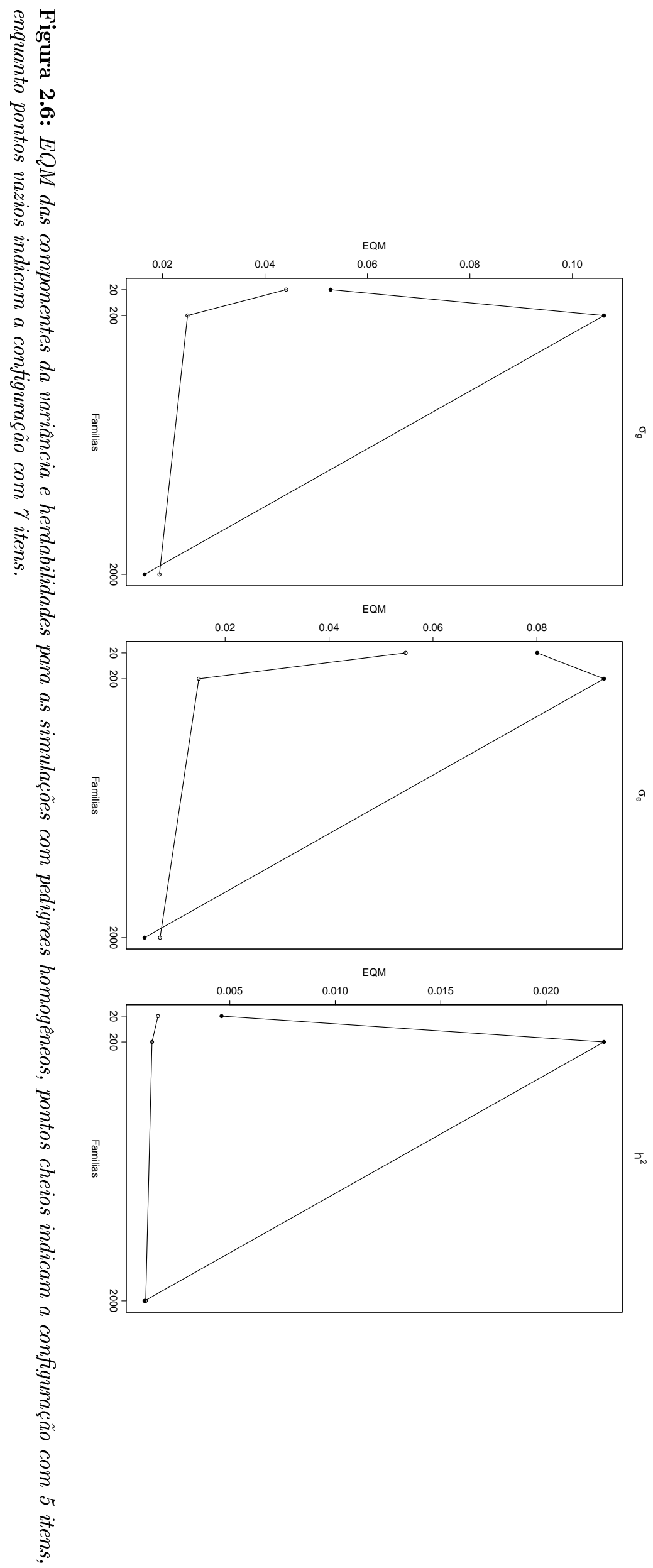



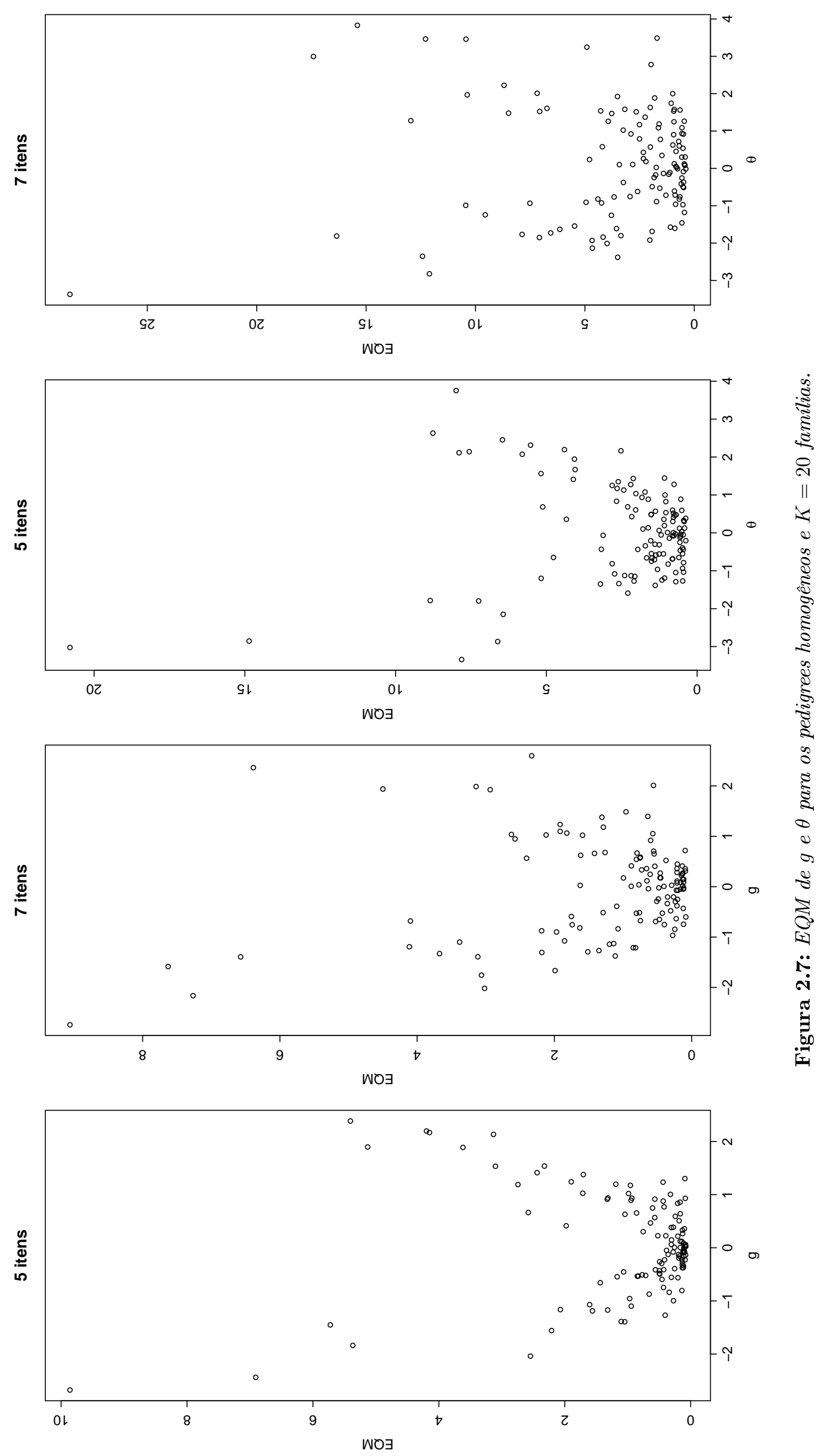

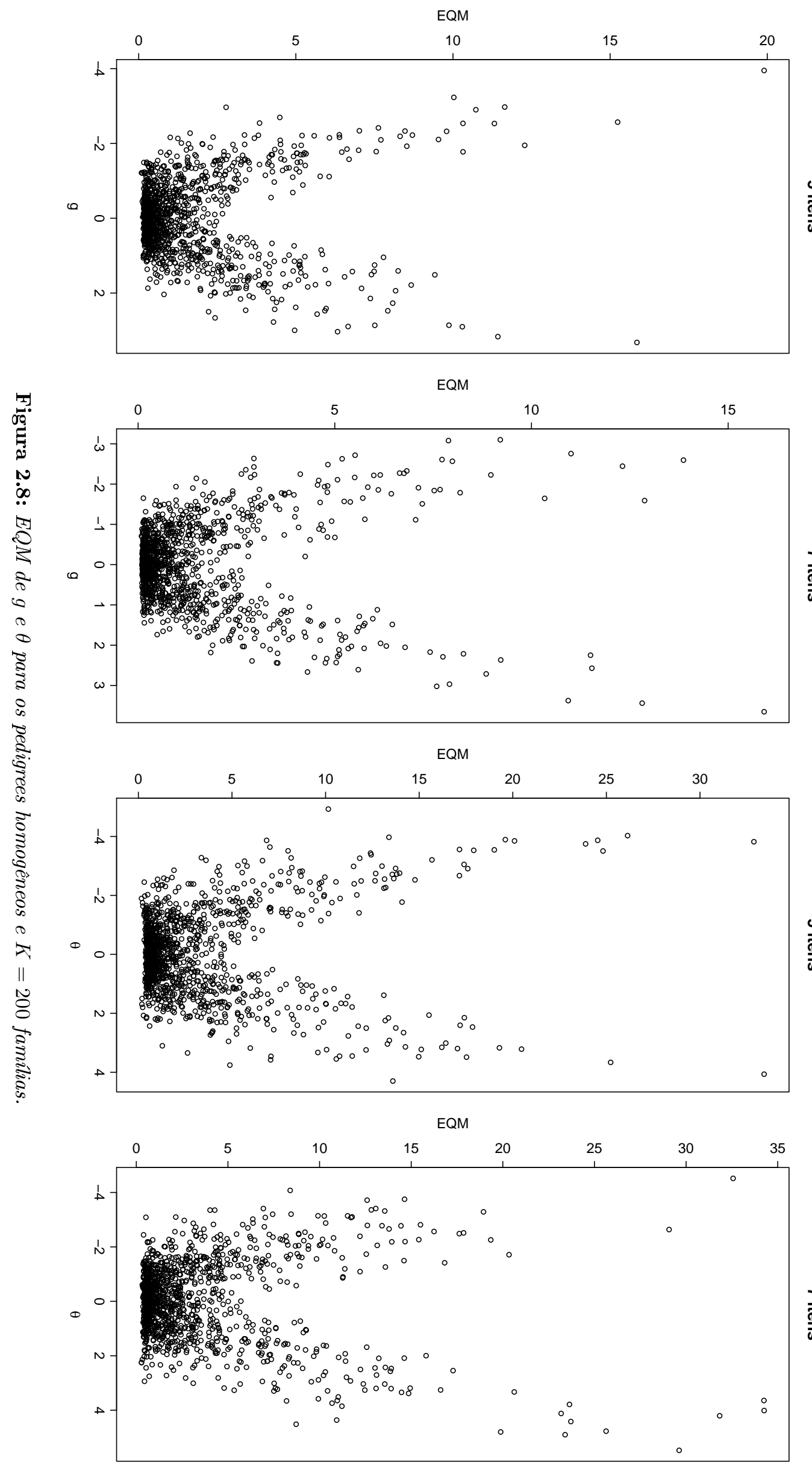

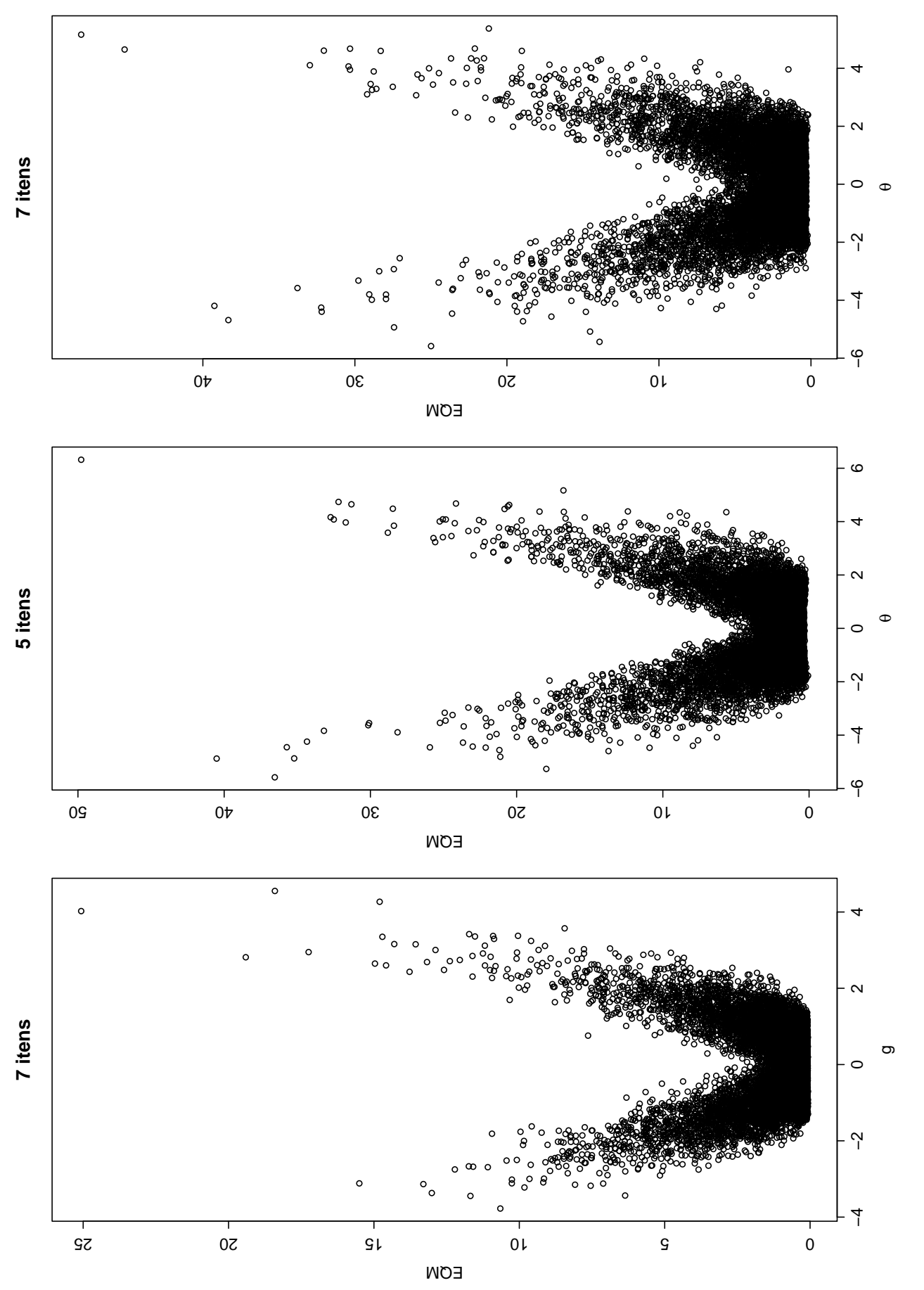

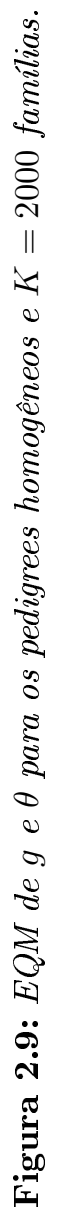

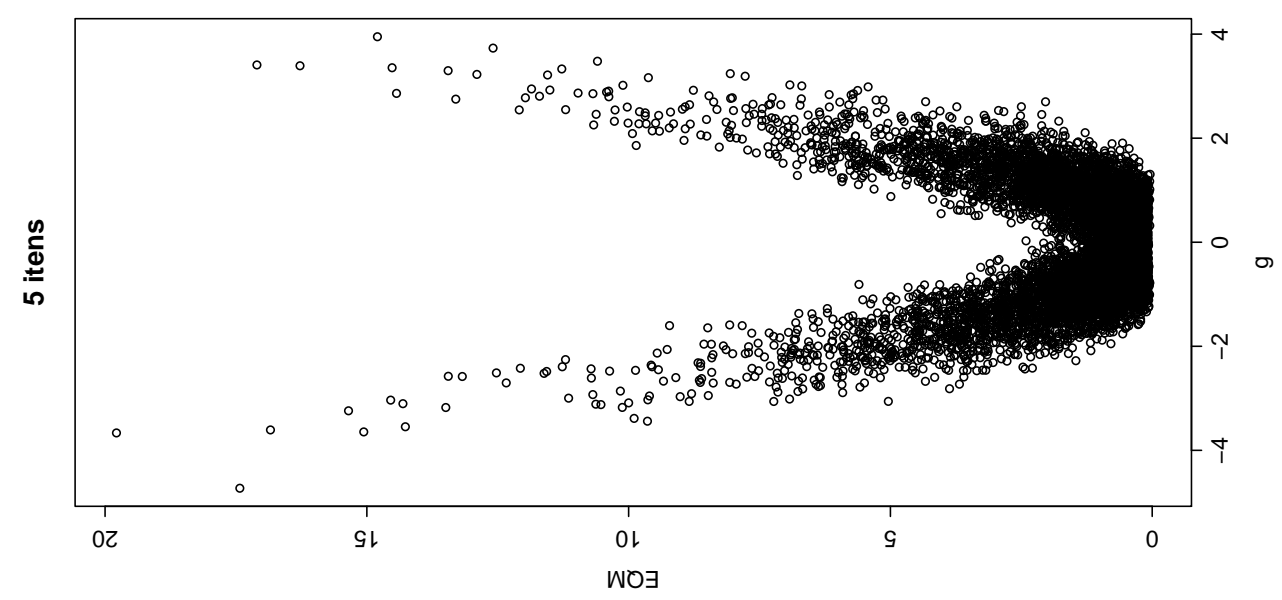



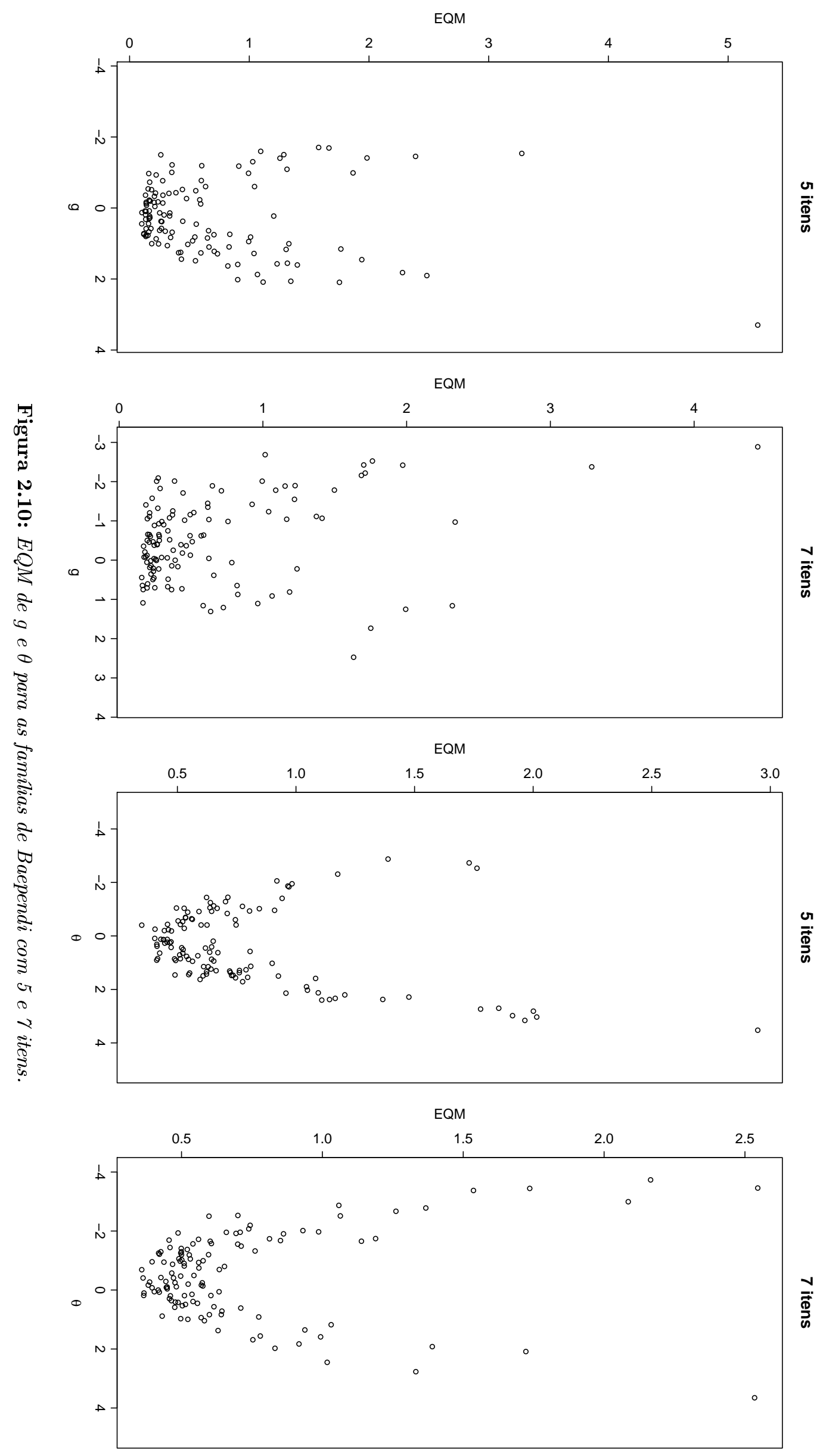

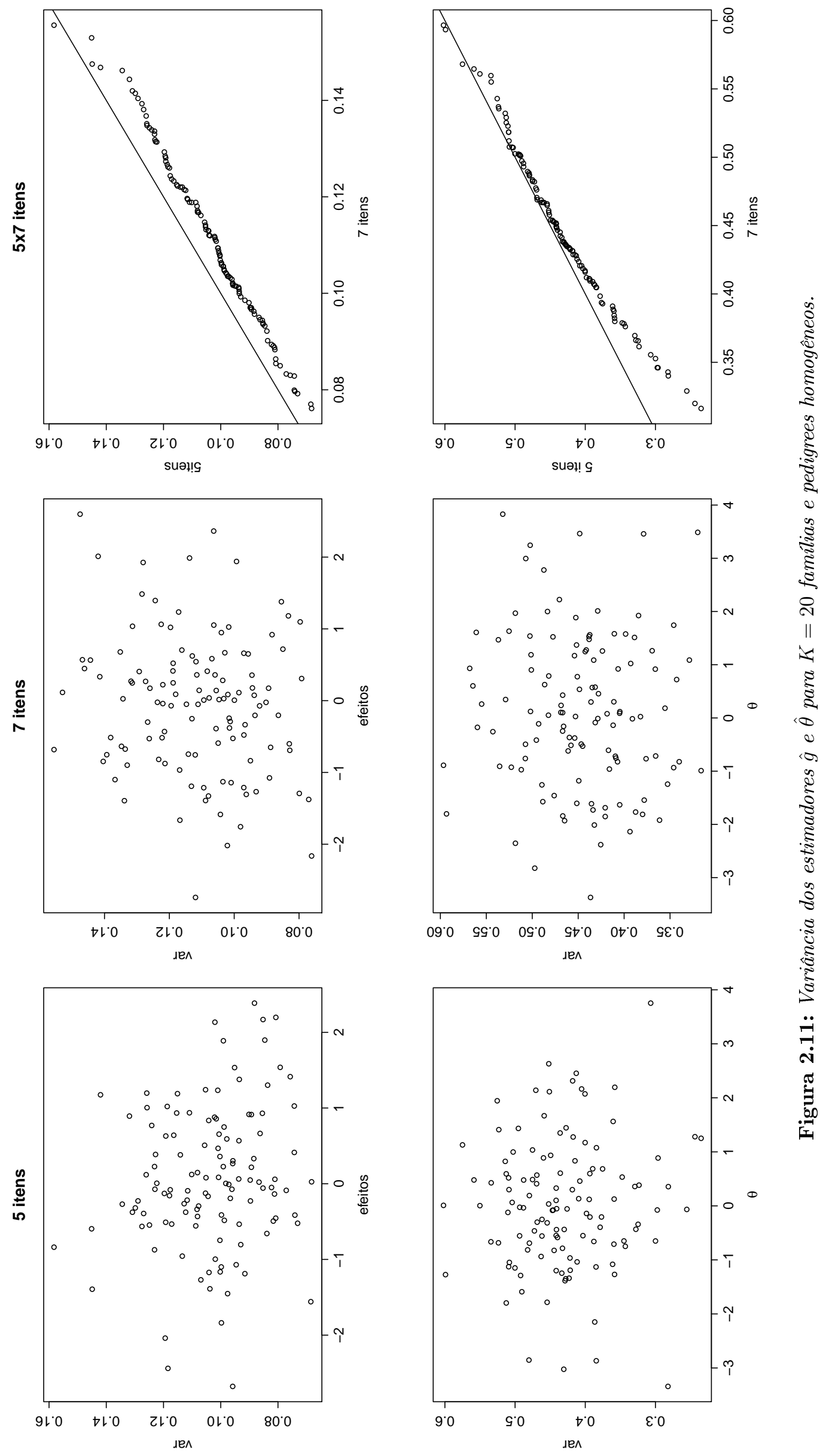

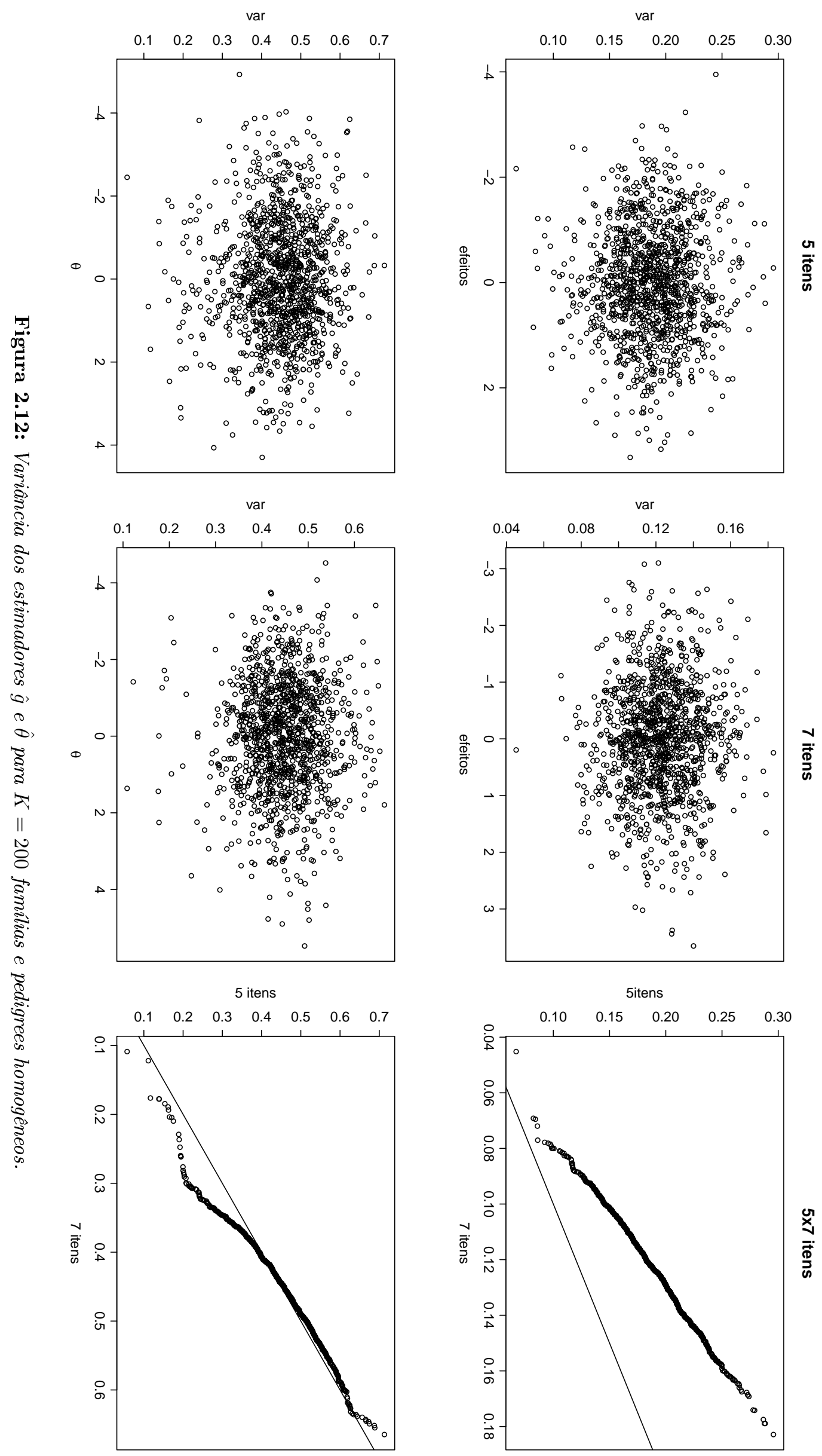

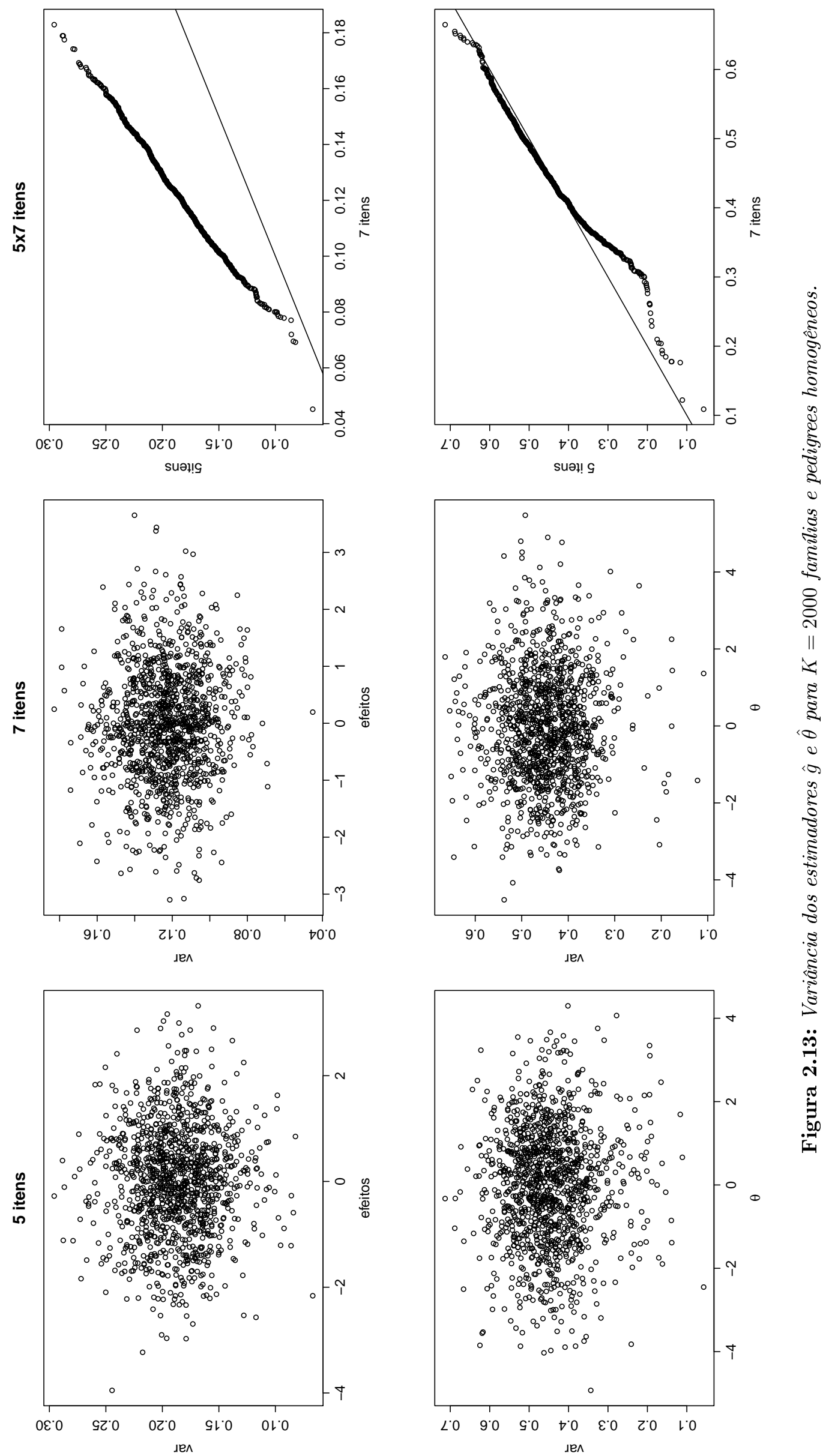

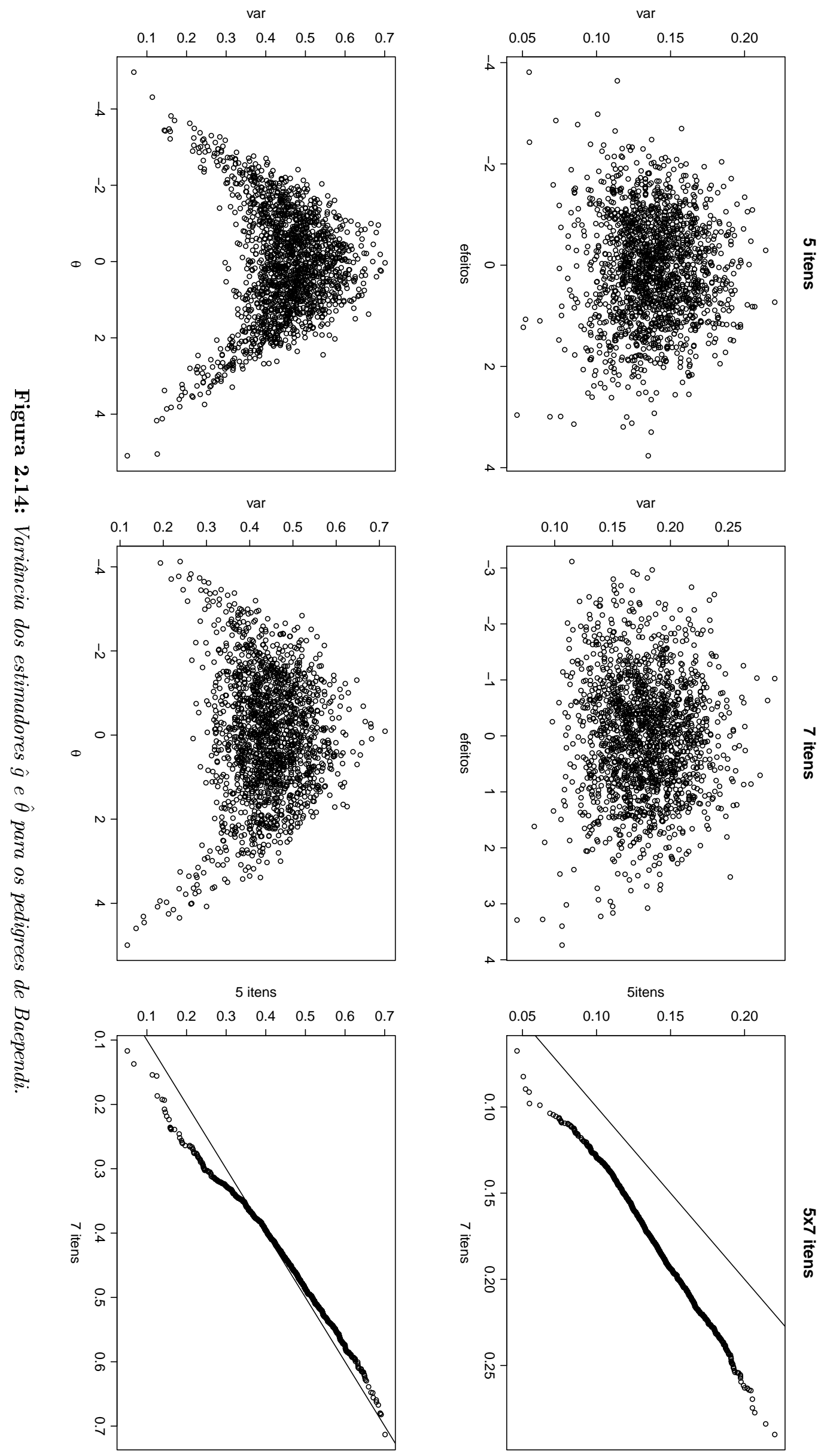

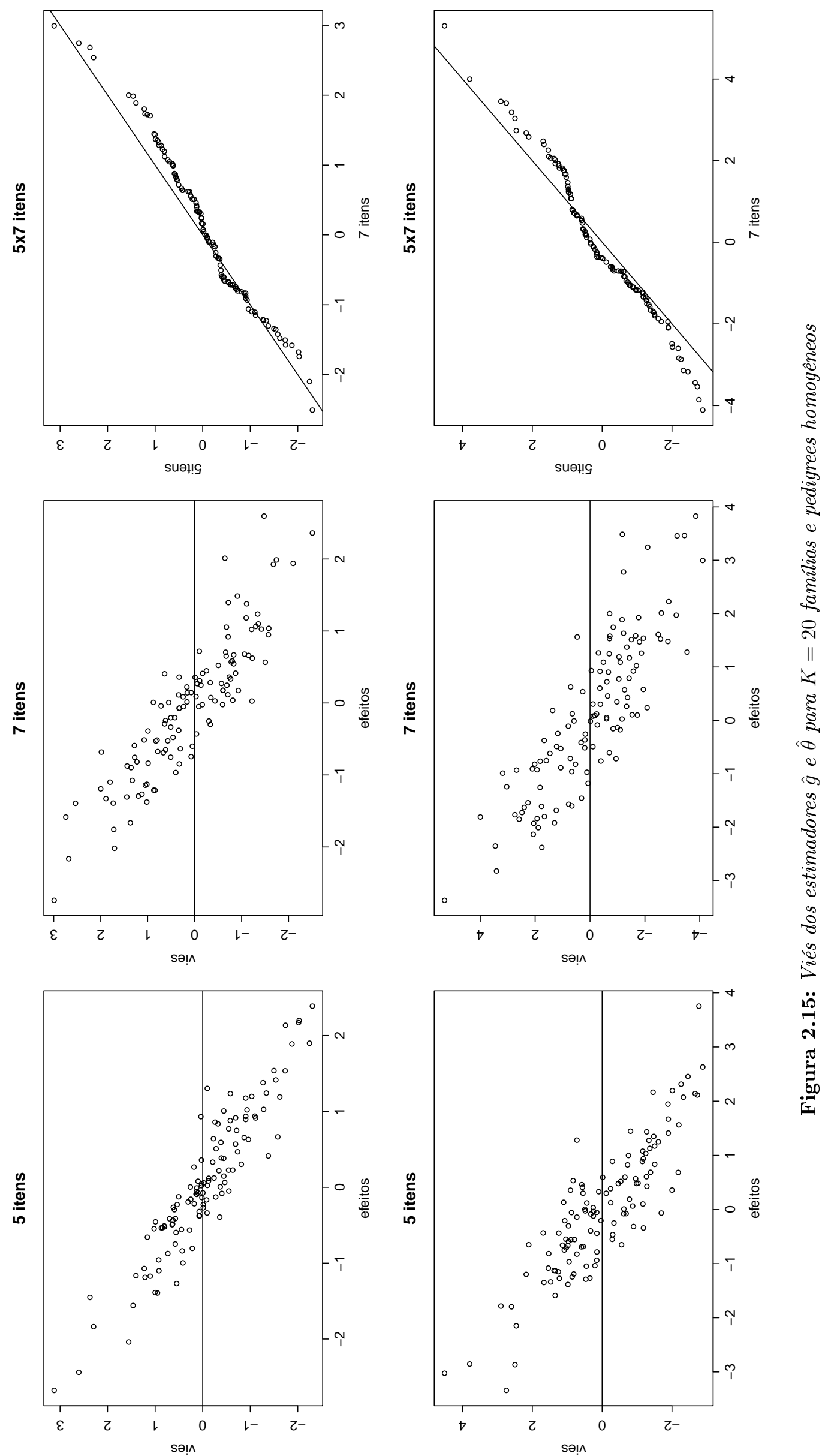

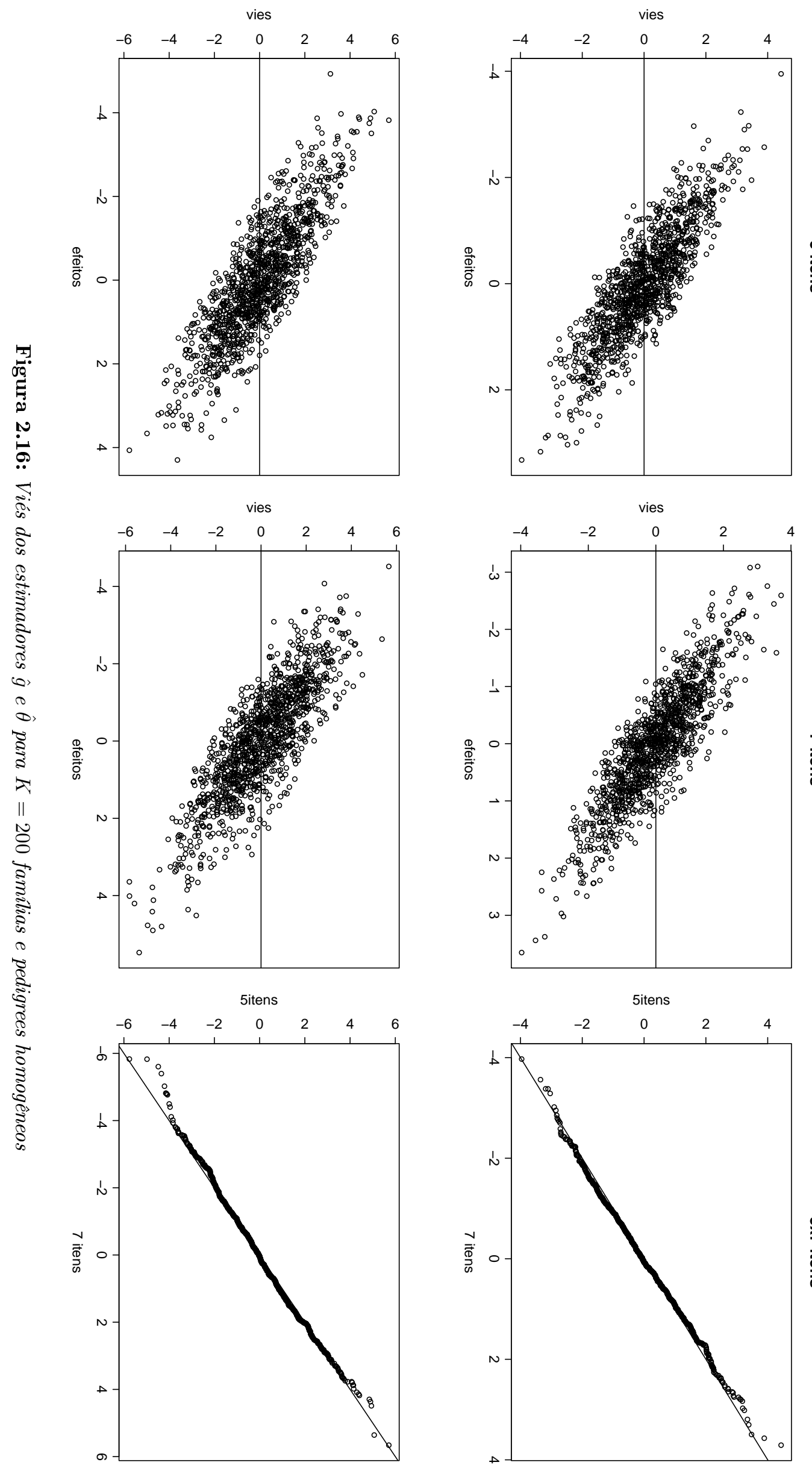

ज
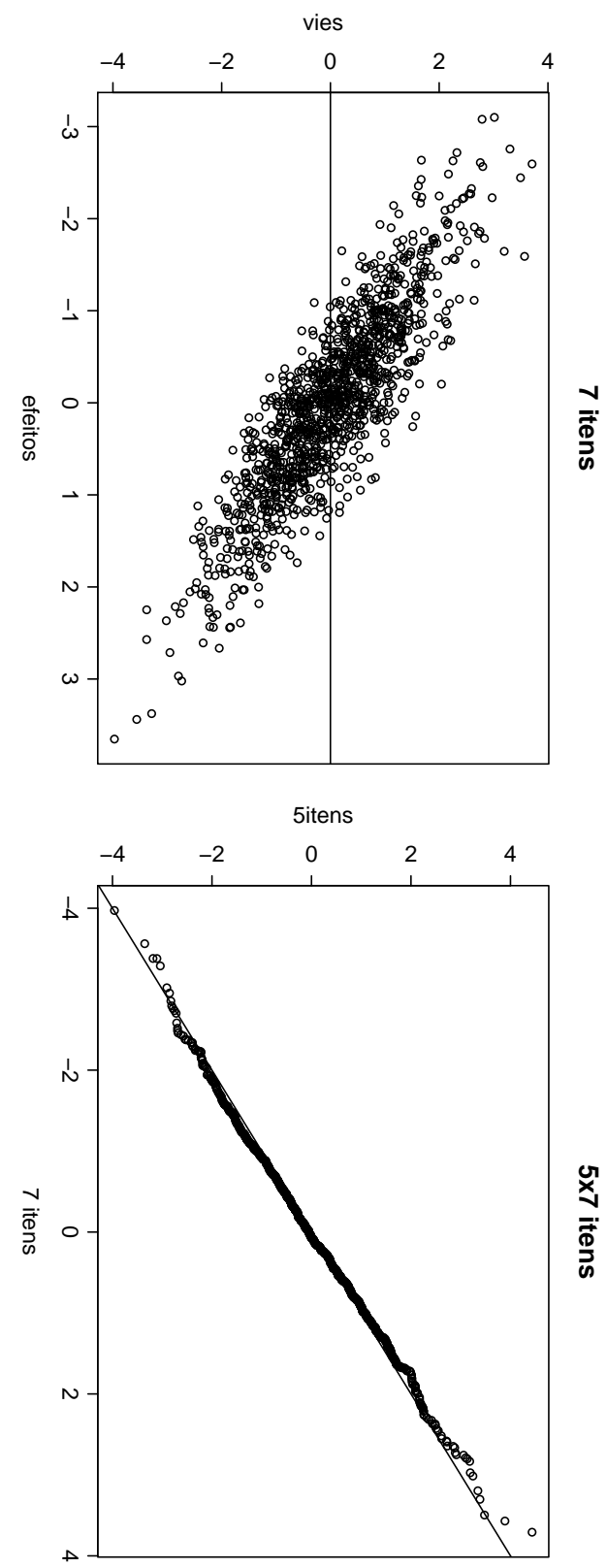

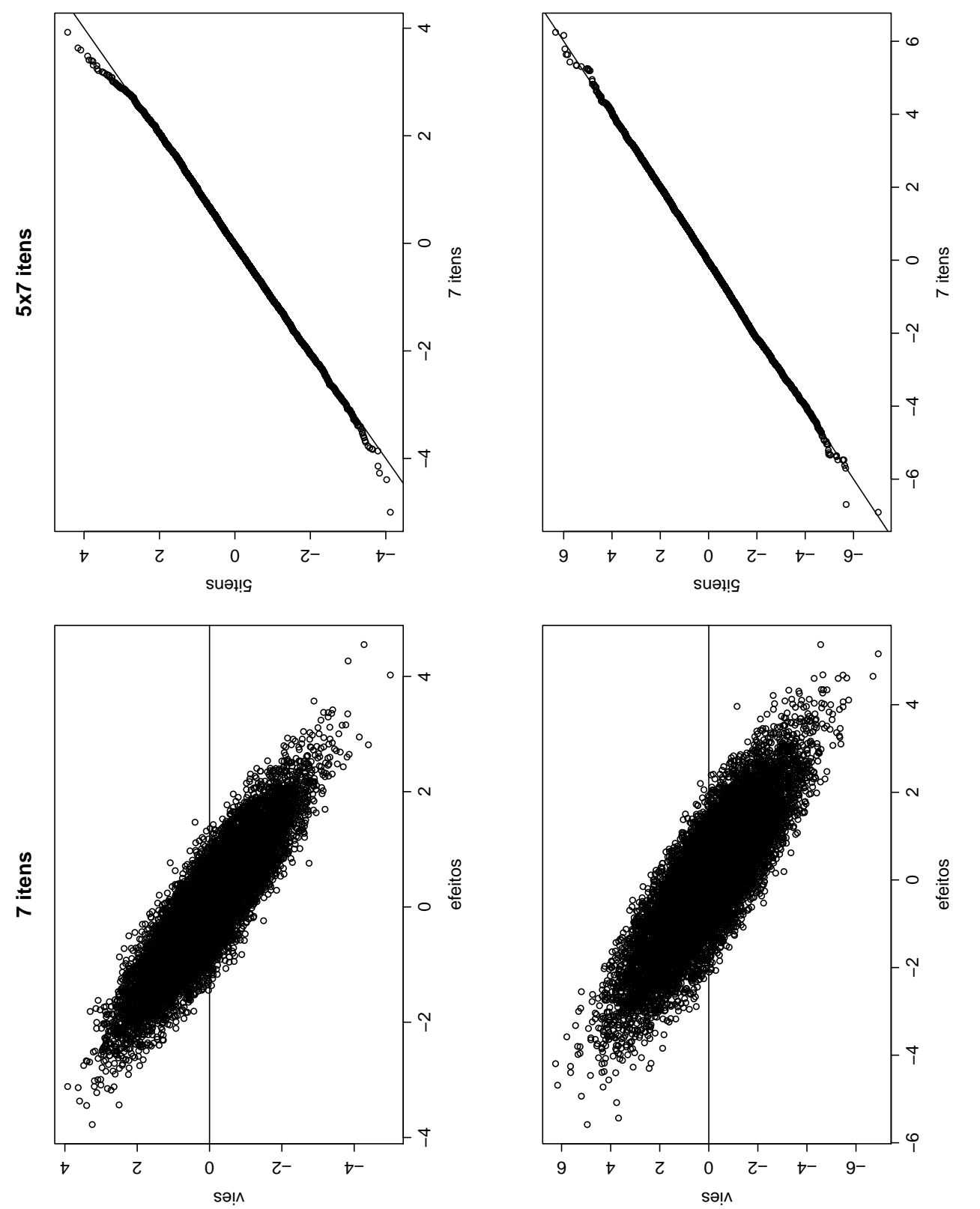

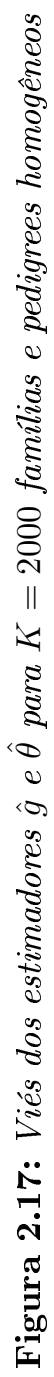
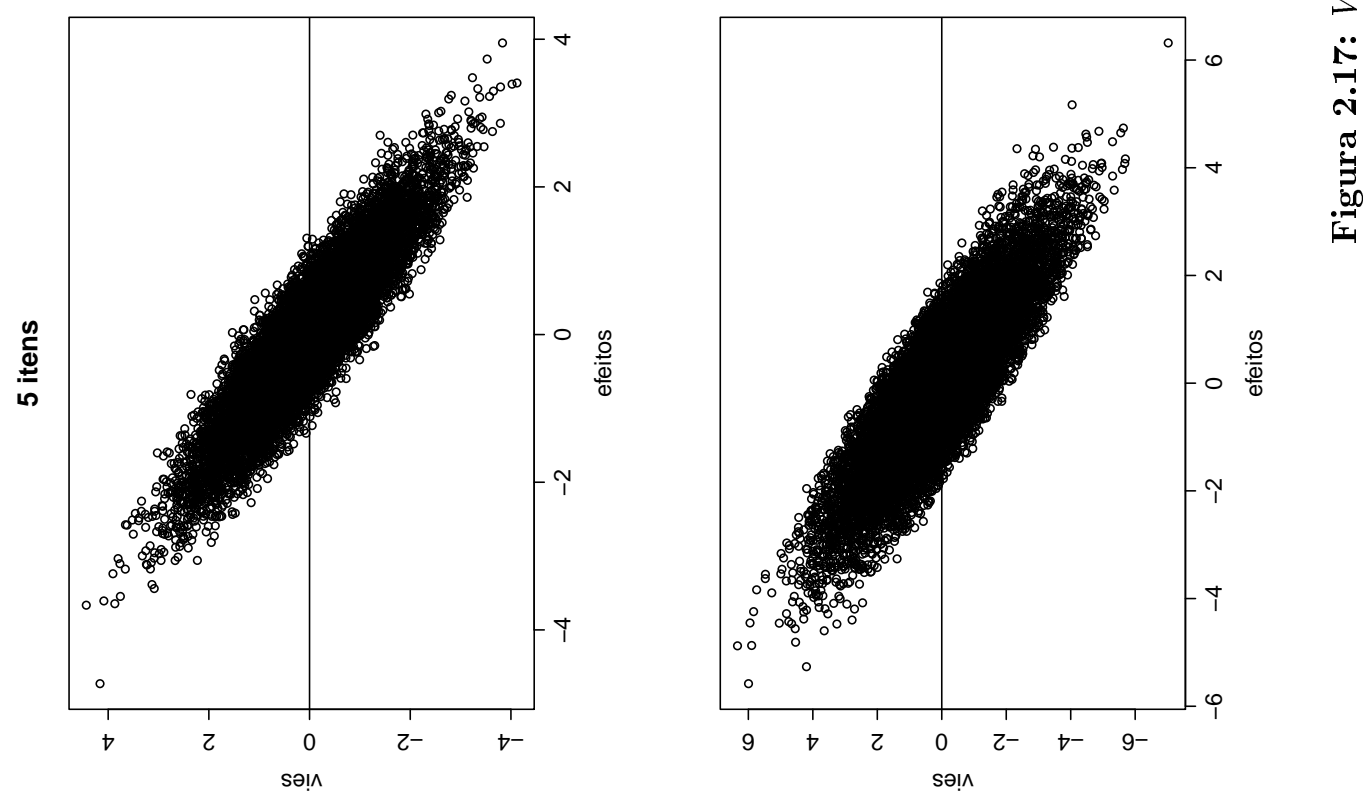


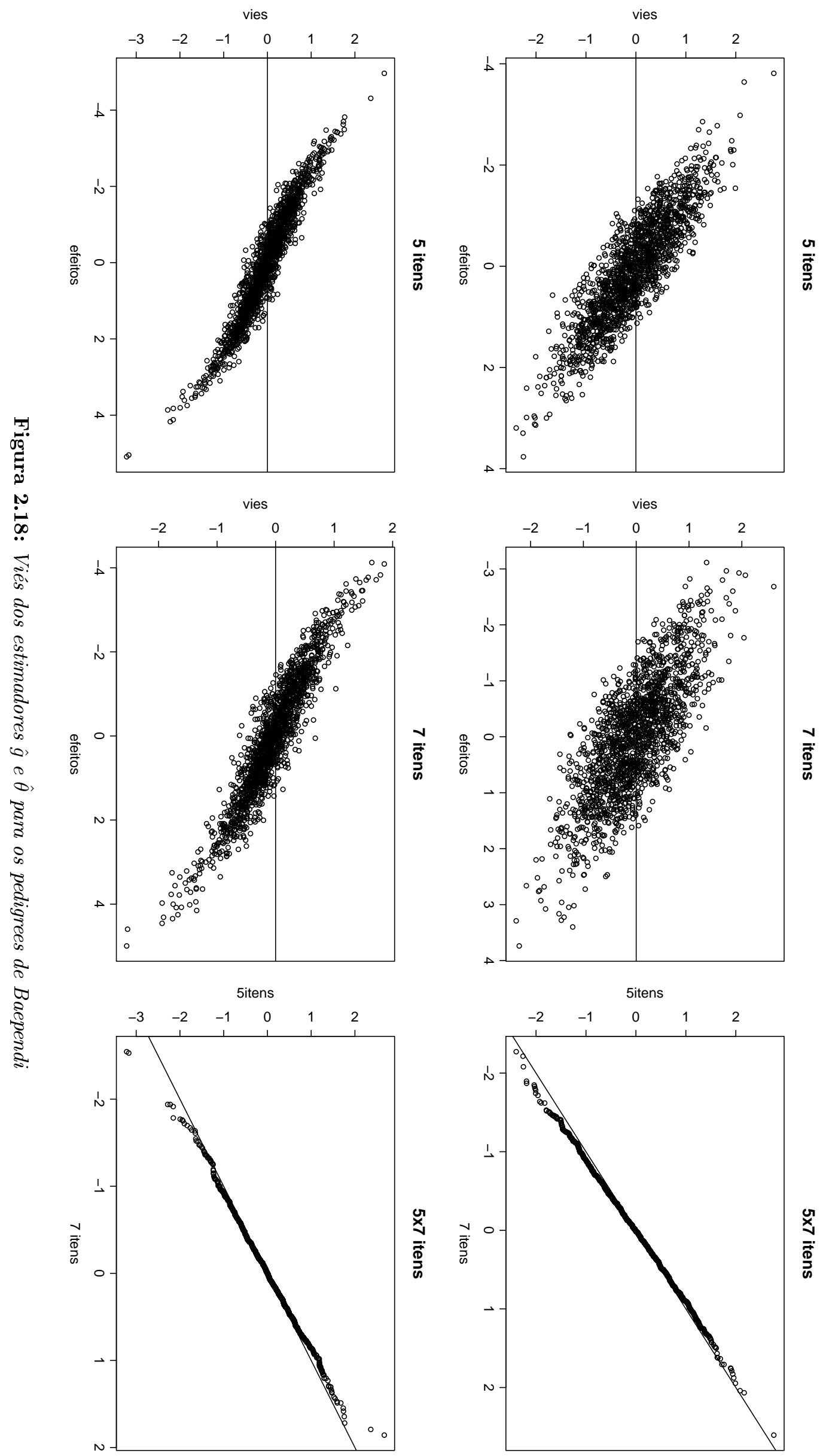


Uma vantagem da TRI é que é possível modelar o construto referente à SM para cada indivíduo em termos do traço latente. Um indivíduo com um fenótipo característico de baixos níveis do traço latente e um fenótipo associado com um nível moderado tende a ter um traço latente maior do que o indivíduo com um fenótipo associado a um baixo nível e um eventual fenótipo de alto risco, sendo mais eficiente que simplesmente contar o número de sintomas.

Utilizando o traço latente, podemos derivar uma herdabilidade estimada de forma conjunta (na modelagem do traço latente), enriquecendo a interpretação de condições multifatoriais como a SM. Podemos também construir uma escala sobre a qual podemos comparar indivíduos e grupos, enriquecer a relação entre a SM e o conjunto de fenótipos através da prevalência esperada de cada fenótipo em cada nível do traço latente e compreender melhor o papel de cada fenótipo no diagnóstico da doença através dos parâmetros dos itens.

Neste trabalho, é utilizado o conjunto de dados obtido do Projeto "Corações de Baependi" estudado em Oliveira et al. (2008), composto da medição de 5 fenótipos em 1.696 indivíduos arranjados em estrutura familiar provenientes da cidade de Baependi,MG.

Os indivíduos foram selecionados aleatoriamente a partir de um esquema amostral em três passos (setor censitário, unidade domiciliar e indivíduo)e, conjuntamente com seus parentes foram submetidos a um instrumento epidemiológico baseado no questionário WHO-MONICA e feitas medidas do peso, altura, circunferência da cintura dentre muitas outras.

Os traços dicotomizados utilizados como a matriz de respostas foram obtidos de acordo com o critério diagnóstico ATP-III definido da seguinte maneira: obesidade truncal é diagnosticada em indivíduos do sexo masculino com circunferência da cintura superior a $102 \mathrm{~cm}$ e do sexo feminino superior a $88 \mathrm{~cm}$, alta glicose em jejum com medições acima de $110 \mathrm{mg} / \mathrm{dL}$ ou uso de medicação para diabetes, baixo colesterol HDL é definido como níveis abaixo de $40 \mathrm{mg} / \mathrm{dL}$ em homens e $50 \mathrm{mg} / \mathrm{dL}$ em mulheres, alta triglicérides por níveis acima de $150 \mathrm{mg} / \mathrm{dL}$. Hipertensão foi definida como pressão média sistólica média superior a $140 \mathrm{mmHg}$ e/ou diastólica superior a $90 \mathrm{mmHg}$ ou uso de medicação para a hipertensão.

O conjunto de dados consiste então de uma matriz com 1.696 indivíduos nas linhas e 5 fenótipos nas colunas e de $K=95$ matrizes de parentesco relativas às famílias do estudo. As matrizes de parentesco esperadas foram calculadas utilizando o pacote kinship2 do R.

Entretanto, uma precaução adicional é necessaria antes da aplicação dos modelos da TRI. Assim como em suas aplicações em Educação e Psicometria, os itens foram formulados de maneira a se correlacionar com o construto sendo modelado, mas não estabelecemos que a amostra sobre a qual o ajuste do modelo está sendo feita é composta de indivíduos diversos o suficiente para validar o instrumento de avaliação. Por exemplo, como citado anteriormente, em Educação a aplicação de um instrumento desenvolvido para alunos com conhecimento do Ensino Médio aplicado em uma amostra do Ensino Fundamental indicaria erroneamente que todos os itens apresentam alta dificuldade. Da mesma maneira, devemos estabelecer que a amostra consiste de elementos com síndrome metabólica e indivíduos saudáveis, de maneira que o centro da escala esteja sobre o indivíduo saudável e valores elevados possam ser associados com a SM.

Para tal, foram calculadas algumas estatísticas descritivas (Tabela 2.4) e foram feitos alguns histogramas (Figura 2.19) com o objetivo de caracterizar os indivíduos da amostra com respeito às características relacionadas com a SM.

A Tabela 2.4 mostra que de fato temos uma amostra bem diversa com respeito aos sintomas da SM. Por exemplo, o triglicérides no qual temos uma boa parcela da amostra apresentando níveis saudáveis (menores que $150 \mathrm{mg} / \mathrm{dL}$ ) com o terceiro quartil sobre a faixa envolvendo algum risco até valores de alto risco (maiores que $500 \mathrm{mg} / \mathrm{dL}$ ). Também podemos observar esse padrão na abundância do colesterol HDL ou 'colesterol bom'. Temos que a amostra está centrada em $56 \mathrm{mg} / \mathrm{dL}$ que é um nível moderado para o HDL e englobando desde deficiências de HDL ( $<40$ para homens, $<50$ para mulheres) até níveis protetores contra doenças cardíacas $(>60)$ (Expert Panel on Detection and Evaluation and and Treatment of High Blood Cholesterol in Adults , 2001). Da mesma forma, a pressão arterial parece estar centrada no par de valores considerados saudáveis, englobando desde indivíduos com hipotensão ( $P A S / P A D<90 / 60 \mathrm{mmHg}$ ) até hiper- 
Tabela 2.4: Estatísticas descritivas para os dados de Baependi e prevalência (Prev) do diagnóstico de alteração segundo o critério ATP-III. Circunf. = Circunferência truncal, Trig = Triglicérides, Glic $=$ Glicose, $H D L=$ baixo colesterol de alta densidade, PAS = pressão arterial sistólica, $P A D=$ pressao arterial diastólica

\begin{tabular}{r|rrrrrrr}
\hline & Média (DP) & Mín. & $1^{\circ}$ Quartil & Mediana & $2^{\circ}$ Quartil & Max. & Prev \\
\hline Circunf. & $87,47(12,45)$ & 54 & 78 & 87 & 95 & 166 & 0,28 \\
Trig. & $134,1(76,52)$ & 34,2 & 84,3 & 114 & 162,2 & 719 & 0,19 \\
Glic. & $93,89(29,66)$ & 44,6 & 76,85 & 89,2 & 103,5 & 392 & 0,28 \\
HDL & $56,01(15,72)$ & 13 & 45,05 & 54,1 & 66 & 128,4 & 0,20 \\
PAS & $126,9(19,4)$ & 79,7 & 112,5 & 124,7 & 137,2 & 216,3 & 0,21 \\
PAD & $78,7(11,39)$ & 50 & 70,7 & 77,7 & 85,7 & 129,7 & 0,15 \\
\hline
\end{tabular}

tensão ( $P A S / P A D>140 / 90 \mathrm{mmHg})$.

Adicionalmente, a Figura 2.19 mostra a forma das distribuições dos sintomas antes da sua dicotomização reforçando a afirmação de que os valores estão bem distribuídos sobre indivíduos saudáveis, indivíduos com SM e com condições deletérios de saúde resultantes da ausência de alguns sintomas da SM (como HDL ou hipotensão). Também é apresentado um histograma da idade, em que observa-se que a amostra consiste de indivíduos distribuídos ao longo de diversas faixas acima de 18 anos, sendo essa a idade mínima de participação no estudo.

Dois modelos multiníveis da TRI foram então ajustados ao conjunto de dados. O primeiro (modelo 1) não assume efeitos fixos, enquanto o segundo (modelo 2) assume como covariáveis a idade e a idade ao quadrado, esse último termo para modelar um efeito não linear da idade. Para manter a identificabilidade, assumimos $\beta_{0}=0$. A escolha dos dois modelos tem como objetivo traçar um paralelo ao trabalho de Oliveira et al. (2008) e verificar que conclusões a modelagem da SM como traço latente tem em comum com a modelagem marginal realizada com cada fenótipo.

Entretanto, ao contrário de Oliveira et al. (2008), não utilizamos o sexo como covariável, pois o mesmo é utilizado nos critérios de dicotomização dos itens relativos à hipertensão e colesterol. Além disso, não utilizamos 7 itens como em Oliveira et al. (2008), pois retiramos dois itens relativos ao colesterol (alto LDL e colesterol total). O instrumento utilizado em Oliveira et al. (2008) utiliza duas componentes do colesterol (LDL e HDL) as quais eram somadas com uma terceira componente para o colesterol total. Dessa maneira, as componentes do colesterol e seu total não são necessariamente independentes condicionadas ao traço latente, violando a premissa de independência local, fundamental nas modelagens em TRI.

Tratando-se da formulação do modelo multníveis, o nível estrutural é bem estabelecido pela equação (2.4), mas diversos modelos da TRI poderiam ser aplicados ao invés do modelo de Rasch. A possibilidade de falsos positivos nos diagnósticos dos fenótipos é rara, o que descarta um parâmetro de acerto casual. Entretanto, a premissa de discriminações iguais entre os itens é mais difícil de estabelecer. Buscamos algum indicativo nas correlações ponto-bisseriais entre item respondido e escore total dada por

$$
\rho_{i E}=\frac{M_{1}-M_{0}}{s_{n}} \sqrt{\frac{n_{1} n_{0}}{n^{2}}},
$$

em que $M_{l}$ é a média dos escores dos $n_{l}$ indivíduos com resposta $l=0,1$ no item $i$ em um total de $n$ respondentes e $s_{n}$ é o desvio padrão do escore ao longo da amostra. É conhecido que sob algumas premissas como a ausência de acerto casual e normalidade do traço latente, o parâmetro de discriminação do item é uma função monotona da correlação item-escore (Lord, 1980), de maneira que valores próximos da correlação implicariam em discriminações próximas indicando a adequação do modelo de Rasch. De fato, as correlações item-escore variam de 0,50 (HDL) a 0,64 (Obesidade truncal) indicando que assumir discriminações iguais não parece inadequado.

Os parâmetros foram então estimados utilizando-se o amostrador de Gibbs descrito anterior- 
mente. A cadeia de Markov foi simulada para 200.000 iterações com um burn-in de 20.000 iterações. A convergência foi observada graficamente através do histórico das cadeias e da função de autocorrelação como ilustrados na Figura 2.20 para o parâmetro $\beta_{1}$ do modelo 2. Os gráficos para os outros parâmetros são similares e serão omitidos.

As estimativas pontuais e intervalares dos parâmetros do modelo 1 podem ser encontradas na Tabela 2.5. Denotamos por $b_{i}, i=1,2, \cdots, 5$ os parâmetros de locação de cada um dos fenótipos. As estimativas pontuais e intervalares foram calculadas utilizando-se o pacote coda do R.

Tabela 2.5: Estimativas pontuais e intervalares para o modelo 1

\begin{tabular}{rrrrr}
\hline Parâmetro & Média $(\mathrm{dp})$ & Quantil $2,5 \%$ & Mediana & Quantil $97,5 \%$ \\
\hline$b_{1}$ & $1,17(0,07)$ & 1,02 & 1,17 & 1,30 \\
$b_{2}$ & $1,74(0,06)$ & 1,61 & 1,75 & 1,88 \\
$b_{3}$ & $1,11(0,06)$ & 0,99 & 1,11 & 1,24 \\
$b_{4}$ & $1,65(0,07)$ & 1,52 & 1,65 & 1,80 \\
$b_{5}$ & $0,66(0,06)$ & 0,53 & 0,66 & 0,78 \\
$\sigma_{g}^{2}$ & $0,25(0,06)$ & 0,13 & 0,24 & 0,39 \\
$\sigma_{e}^{2}$ & $0,89(0,11)$ & 0,68 & 0,89 & 1,11 \\
$h^{2}$ & $0,21(0,05)$ & 0,12 & 0,21 & 0,34 \\
\hline
\end{tabular}

As estimativas pontuais e intervalares para o modelo 2 encontram-se na Tabela 2.6. Além dos parâmetros anteriores, denotamos por $\beta_{1}$ e $\beta_{2}$ os parâmetros relativos aos efeitos fixos da idade e idade ao quadrado, respectivamente.

Tabela 2.6: Estimativas pontuais e intervalares para o modelo 2

\begin{tabular}{rrrrr}
\hline Parâmetro & Média $(\mathrm{dp})$ & Quantil $2,5 \%$ & Mediana & Quantil $97,5 \%$ \\
\hline$b_{1}$ & $1,02(0,07)$ & 0,87 & 1,02 & 1,16 \\
$b_{2}$ & $1,59(0,07)$ & 1,44 & 1,59 & 1,74 \\
$b_{3}$ & $0,94(0,07)$ & 0,80 & 0,94 & 1,09 \\
$b_{4}$ & $1,50(0,07)$ & 1,35 & 1,50 & 1,66 \\
$b_{5}$ & $0,52(0,06)$ & 0,39 & 0,51 & 0,64 \\
$\sigma_{g}^{2}$ & $0,35(0,06)$ & 0,20 & 0,34 & 0,50 \\
$\sigma_{e}^{2}$ & $0,31(0,07)$ & 0,17 & 0,30 & 0,48 \\
$h^{2}$ & $0,53(0,10)$ & 0,32 & 0,53 & 0,71 \\
$\beta_{1}$ & $0,78(0,04)$ & 0,71 & 0,78 & 0,86 \\
$\beta_{2}$ & $-0,18(0,03)$ & $-0,24$ & $-0,18$ & $-0,12$ \\
\hline
\end{tabular}

Oa parâmetros de locação são positivos para todos os fenótipos associados com a SM, indicando que os indivíduos com valores positivos do traço latente terão uma maior probabilidade de diagnóstico de um fenótipo alterado, isto é, uma prevalência maior da SM. Os valores dos parâmetros de locação variam no modelo 1 de 0,66 (hipertensão, denotado por $b_{5}$ ) a 1,74 (alta glicose, denotado $b_{2}$ ), consistentes com a prevalência dos diagnósticos alterados na população. Por exemplo, hipertensão é prevalente em 47,6\% dos indivíduos, enquanto alta glicose foi diagnosticada em 18,8\% da amostra.Deste modo, o modelo de Rasch associa baixas prevalências com altos níveis do traço latente. Tal característica parece ser reminiscente da sua utilização em contextos educacionais, nos quais uma baixa prevalência (respostas corretas) de um item indica um item mais difícil, sendo necessário um alto traço latente para uma resposta correta.

O traço latente pode ser ainda interpretado em termos dos padrôes de resposta dos indivíduos. O menor traço latente estimado na amostra corresponde ao indivíduo 73 da família 53 , com $\theta_{5373}=$ 
$-2,14$. Este indivíduo tem 19 anos e não apresenta nenhum dos sintomas. Por outro lado, o maior traço latente estimado encontra-se na família 4 no indivíduo 9 com $\theta_{49}=1,87,63$ anos e todos os sintomas.

Podemos observar que tivemos estimativas bem próximas dos parâmetros de locação para os dois modelos, resultando em funções de informação (Figura 2.21) bem similares. Ambas estão concentradas em valores elevados do traço latente, indicando que os fenótipos avaliam predominantemente valores positivos na escala dos traços latentes, como é esperado de um traço modelando a SM.

Sobre as componentes da variância, a estimativa para a variância genética $\left(\sigma_{g}^{2}\right)$ é similar em ambos os modelos, mas a variância do erro é menor no modelo com covariáveis $\left(\hat{\sigma}_{e}^{2}=0,31\right)$ comparada ao modelo sem covariáveis $\left(\hat{\sigma}_{e}^{2}=0,89\right)$. Nota-se ainda que não há sobreposição dos seus intervalos de credibilidade, indicando que a variância do erro foi explicada pela inserção das covariáveis. Tal mudança tem um óbvio impacto nas estimativas da herdabilidade, no qual existe um aumento do modelo $1\left(\hat{h}^{2}=0.21\right)$ para o modelo $2\left(\hat{h}^{2}=0.53\right)$, indicando que a correção por efeitos lineares e quadráticos da idade revelam um peso maior da herança genética. Essa mesma tendência é observada na literatura nos estudos que consideram a análise de cada variável separadamente (Giolo et al., 2010; Oliveira et al., 2008; Pilia et al., 2006).

Ainda, os efeitos da idade no modelo 2 podem ser considerados significantes, pois seus intervalos de credibilidade não contêm o valor 0 . O efeito linear da idade $\left(\hat{\beta}_{1}=0,78\right)$ indica que para cada aumento (decréscimo) de uma unidade na idade, observa-se um aumento (decréscimo) esperado de 0,78 no traço latente do indivíduo. Tal achado é condizente com a natureza da SM, cuja prevalência tende a aumentar com a idade (Ford et al., 2002). O efeito quadrático da idade $\left(\hat{\beta}_{2}=-0,18\right)$ também é coerente com o aumento desigual da SM com a idade (Giolo et al., 2010; Pilia et al. , 2006).

Utilizamos a checagem preditiva da posteriori com a frequência dos escores como estatística de teste pelo seu apelo intuitivo e pelo uso do número de sintomas, basicamente o escore, como ferramenta de diagnóstico da SM. De fato, a SM é diagnosticada de acordo com o critério do NCEP (National Cholesterol Education Program (NCEP), 2002) em que observam-se três ou mais fenótipos alterados de acordo com o critério estabelecido anteriormente. A checagem preditiva pode ser vista na Figura 2.22 para o modelo 1. A figura para o modelo 2 é idêntica e sera omitida. Podese observar que todos os valores observados são adequadamente previstos pela CPP, indicando um bom ajuste.

Ajustado o modelo, ainda pode existir a dúvida de como reportar os traços latentes e relacionalos com os sintomas. Em outros modelos da TRI, apesar da dependência contra-intuitiva com o número de itens acertados, (isto é, um indivíduo com $r$ acertos pode ter um traço latente menor que um indivíduo com $r-1$ acertos ), o traço latente é unicamente determinado pelo padrão de resposta do indivíduo mesmo em modelos multiníveis como o modelo de grupos múltiplos como o apresentado em (Azevedo et al., 2012).

No presente caso, apesar de aparentado com o modelo de múltiplos grupos, o modelo incorpora mais informação sobre o indivíduo. Em ambos os modelos, temos informação sobre a heterogenidade dentro de cada grupo por meio da matriz de parentesco esperada e, no caso do modelo 2 temos informação sobre potenciais confundidores. Nesse contexto, não podemos esperar que o padrão de resposta determine univocamente os traços latentes.

Interpretando os vetores dos padrões de resposta dos indivíduos como números inteiros em notação binária, podemos estabelecer uma correspondência direta dos padrões de resposta de maneira a facilitar a exposição de uma maneira mais informativa do que o escore. Por exemplo, um indivíduo que apresente o fenótipo 1 e o fenótipo 5 tem o mesmo escore do indivíduo com os fenótipos 2 e 3 ( 2 no caso), mas correspondem a padrões de resposta denotados por $17=1 \times 2^{0}+0 \times 2^{1}+0 \times 2^{2}+0 \times 2^{3}+1 \times 2^{4}$ e $6=0 \times 2^{0}+1 \times 2^{1}+1 \times 2^{2}+0 \times 2^{3}+0 \times 2^{4}$. Cabe notar que essa notação estabelece uma enumeração e não uma ordem dos padrões de resposta.

Utilizando essa notação, podemos observar na Figura 2.23 boxplots dos estimadores pontuais do traço latente e efeito poligênico para cada classe de padrão de resposta. Podemos observar para o traço latente que, apesar da variabilidade ser relativamente pequena, existe hetereogenidade dentro 
de cada padrão de resposta e entre os mesmos.

A introdução dos efeitos linear e quadrático da idade aumenta a informação sobre o traço latente não advinda dos sintomas e consequentemente aumenta a variabilidade em cada classe. Como podese observar na Figura 2.24 a introdução do efeito da idade aumenta a variabilidade em cada classe do traço latente. Dessa maneira, não parece suficiente apenas reportar o traço latente e utilizá-lo como medida da SM e sim reportá-lo em conjunto com seu efeito poligênico relativo a indivíduos com a mesma idade.

Além dos modelos apresentados acima, concebemos a presença do efeito de ambiente compartilhado ((2.11)), o que induz algumas modificações no amostrador de Gibbs exposto anteriormente. Com o efeito de ambuente compartilhado, a esperança condicional do vetor de traços latentes da amostra $\boldsymbol{\theta}$ e dada por

$$
E(\boldsymbol{\theta} \mid \boldsymbol{g}, \boldsymbol{h}, \boldsymbol{\beta})=\boldsymbol{X} \boldsymbol{\beta}+\boldsymbol{g}+\boldsymbol{H} \boldsymbol{h},
$$

e assumindo prioris $\boldsymbol{h} \sim N\left(0, I_{S}\right)$ e $\sigma_{h}^{2} \sim \operatorname{Gama}(1,1)$ temos o amostrador de Gibbs, para $r=$ $1, \cdots, R$

1. Fixam-se valores iniciais para os parâmetros.

2. Amostra-se $u_{i j k}^{r+1} \mid \cdot$ condicionalmente por

- Se $Y_{i j k}=0$, tome $U_{i j k} \mid \cdot \sim U\left(P_{i j k}, 1\right)$

- Se $Y_{i j k}=1$, tome $U_{i j k} \mid \cdot \sim U\left(0, P_{i j k}\right)$

3. Amostra-se, para $i=1,2, \cdots, I, b_{i}^{r+1} \mid \cdot \sim N(0,1) I\left(b_{i}^{L}<b_{i}<b_{i}^{R}\right)$, onde o indicador denota a função de distribuição truncada entre os dois extremos

4. Para $k=1,2, \cdots, K$ famílias e $j=1,2, \cdots, n_{k}$ indivíduos, amostra-se $\theta_{j k}^{r+1} \mid \cdot \sim N\left(\mu_{j k}, \sigma_{e}^{2}\right) I\left(\theta_{j k}^{L}<\theta_{j k}<\theta_{j k}^{R}\right)$ onde $\mu_{j k}=\boldsymbol{X}_{j k} \beta+g_{j k}+\boldsymbol{h}_{j k} \boldsymbol{h}$, e $\boldsymbol{h}_{j k}$ é a linha da matriz $\boldsymbol{H}$ referente ao indivíduo $j$ da família $k$.

5. Amostre para cada $k, \boldsymbol{g}_{k} \mid \cdot \sim N_{n_{k}}\left(\Sigma_{k}^{-1}\left(\boldsymbol{\theta}_{k}-\boldsymbol{X}_{k} \boldsymbol{\beta}-\boldsymbol{H}_{k} \boldsymbol{h}\right) \Sigma_{k}^{-1}\right)$, para $\Sigma_{k}=\sigma_{e}^{-2} I_{n_{k}}+\sigma_{g}^{-2} \Phi_{k}^{-1}$

6. $\sigma_{g}^{2} \mid \cdot \sim I G\left(\frac{N}{2}+1, \sum_{k=1}^{K} \boldsymbol{g}_{k}^{\prime} \Phi_{k}^{-1} \boldsymbol{g}_{k}\right)$, onde $I G()$ é a distribuição gama inversa e $N=\sum_{k=1}^{K} n_{k}$

7. $\sigma_{e}^{2} \mid \cdot \sim I G\left(\frac{N}{2}+1,(\boldsymbol{\theta}-\boldsymbol{X} \boldsymbol{\beta}+\boldsymbol{g}+\boldsymbol{H} \boldsymbol{h})^{\prime}(\boldsymbol{\theta}-\boldsymbol{X} \boldsymbol{\beta}+\boldsymbol{g}+\boldsymbol{H h})\right)$

8. $\boldsymbol{\beta} \mid \cdot \sim N_{p}\left(\mu_{\beta}, V_{\beta}^{-1}\right), \operatorname{com} V_{\beta}=\left(\frac{1}{c}+\frac{1}{\sigma_{e}^{2}}\right) \sum_{k=1}^{K} \boldsymbol{X}_{k}^{\prime} \boldsymbol{X}_{k}$ e $\mu_{\beta}=V_{\beta}^{-1} \frac{1}{\sigma_{e}^{2}}\left(\sum_{k=1}^{K} \boldsymbol{X}_{k}^{\prime}\left(\boldsymbol{\theta}_{k}-\boldsymbol{g}_{k}\right)-\boldsymbol{H} \boldsymbol{h}\right)$

9. $\sigma_{s}^{2} \mid \cdot \sim I G\left(S+1, \frac{1}{2}\left(h^{\prime} h\right)+1\right)$

10. $\boldsymbol{h} \mid \cdot \sim N\left(V_{h}^{-1} \mu_{h}, V_{h}^{-1}\right), \operatorname{com} V_{h}=\frac{\boldsymbol{H}^{\prime} \boldsymbol{H}}{\sigma_{e}^{2}}+\frac{I_{S}}{\sigma_{h}^{2}}$ e $\mu_{h}=\frac{\boldsymbol{H}^{\prime}(\boldsymbol{\theta}-\boldsymbol{g}-\boldsymbol{X} \boldsymbol{\beta})}{\sigma_{e}^{2}}$

e limites de truncamento idênticos aos anteriores.

As estimativas do modelo com o efeito de ambiente compartilhado são virtualmente idênticas em quase todos os parâmetros, tanto no modelo sem covariáveis quanto no modelo com covariáveis. A única diferença encontra-se na herdabilidade. A inserção de um novo componente na variância do erro insere um termo positivo no denominador, diminuindo a estimativa de $h^{2}$. De fato, enquanto a herdabilidade foi estimada em torno de 0,5 no modelo 2 , o parâmetro foi estimado em 0,37 no modelo com ambiente compartilhado, possivelmente uma consequência da premissa a priori de que $\sigma_{h}^{2}$ é não nulo, como afirmado pelo conjunto suporte da priori Gama.

Para escolher entre os dois modelos (com covariáveis), foram utilizados o DIC e o logaritmo na base 10 do Fator de Bayes. O DIC do modelo com covariáveis sem o efeito de ambiente comum foi estimado em $13.422,4\left(\bar{D}=5.428, p_{D}=7.984\right)$ contra $13.362,0\left(\bar{D}=5.419, p_{D}=7.942\right)$ do modelo sem o efeito. Os dois DICs são extremamente próximos, tendo em vista a magnitude dos índices 
estimados. Para o Fator de Bayes, o $\log _{10}(B F)$ em favor do modelo com ambiente compartilhado foi estimado em 5,12, indicando fortes evidências em favor do efeito. Entretanto, esse resultado não parece ser estável para múltiplas simulações indicando alguma instabilidade numérica.

Em vista dos DICs próximos e do custo computacional envolvido, mantém-se o modelo sem ambiente compartilhado acompanhando as conclusões de Horimoto et al. (2012) e Horimoto et al. (2011). 

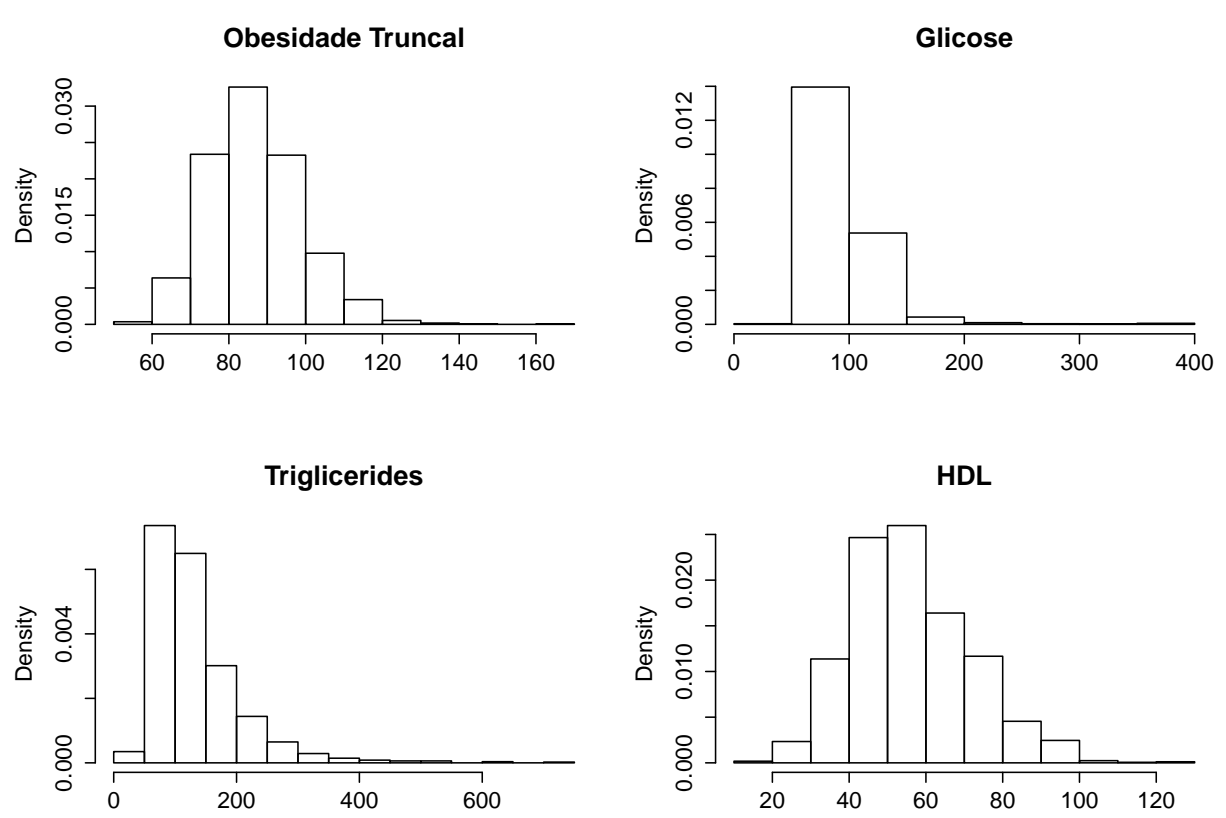

HDL
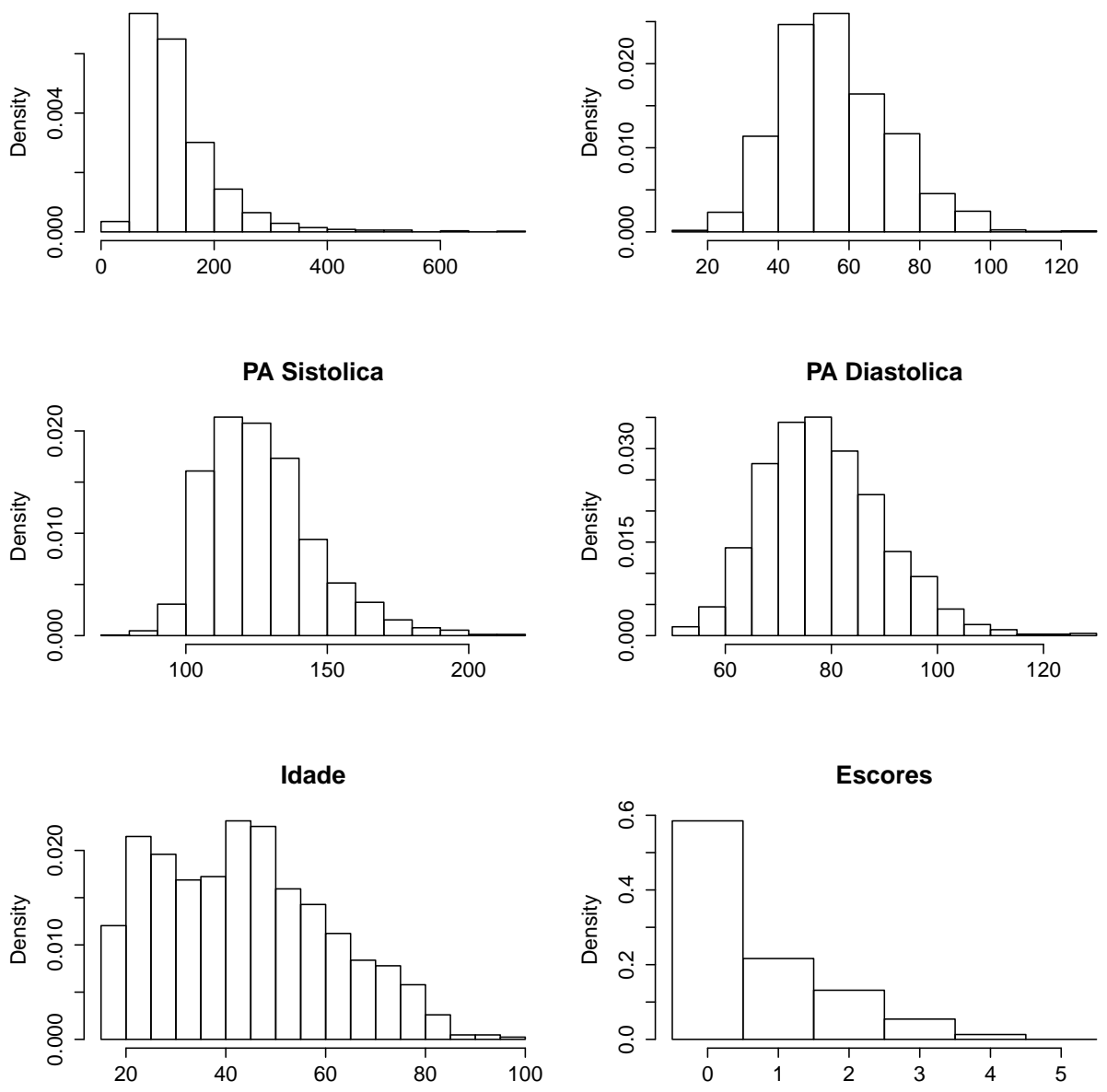

Figura 2.19: Histograma dos sintomas da SM e da idade para a amostra de Baependi. 
Histórico de $\beta_{1}$

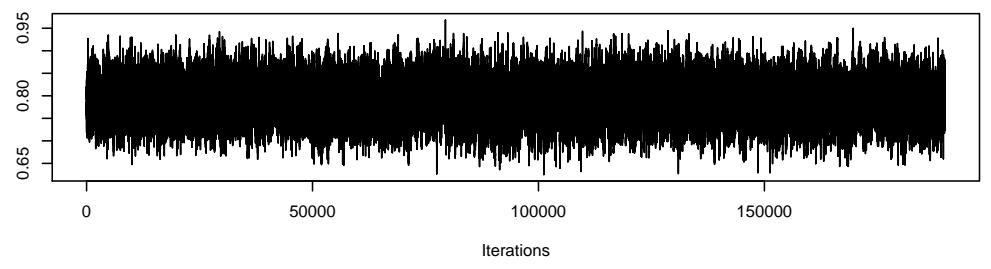

Densidade de $\beta_{1}$

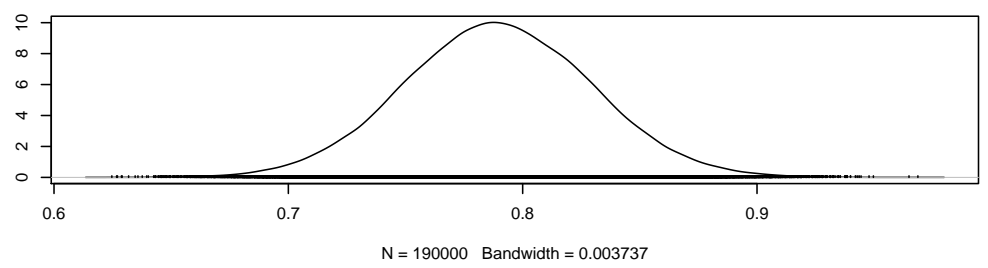

Autocorrelação para a cadeia de $\beta_{1}$

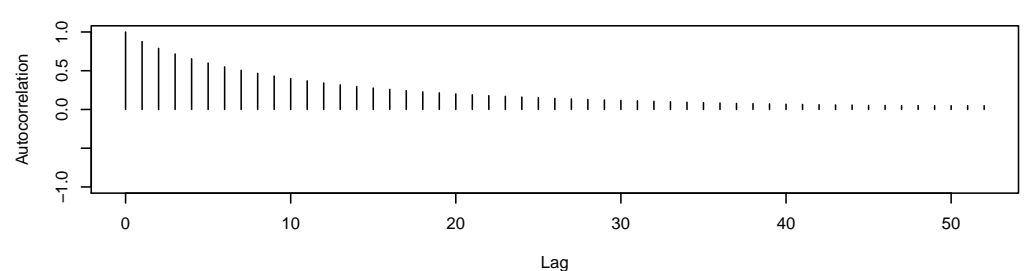

Figura 2.20: Histórico, densidade e função de autocorrelação para o parâmetro $\beta_{1}$. 


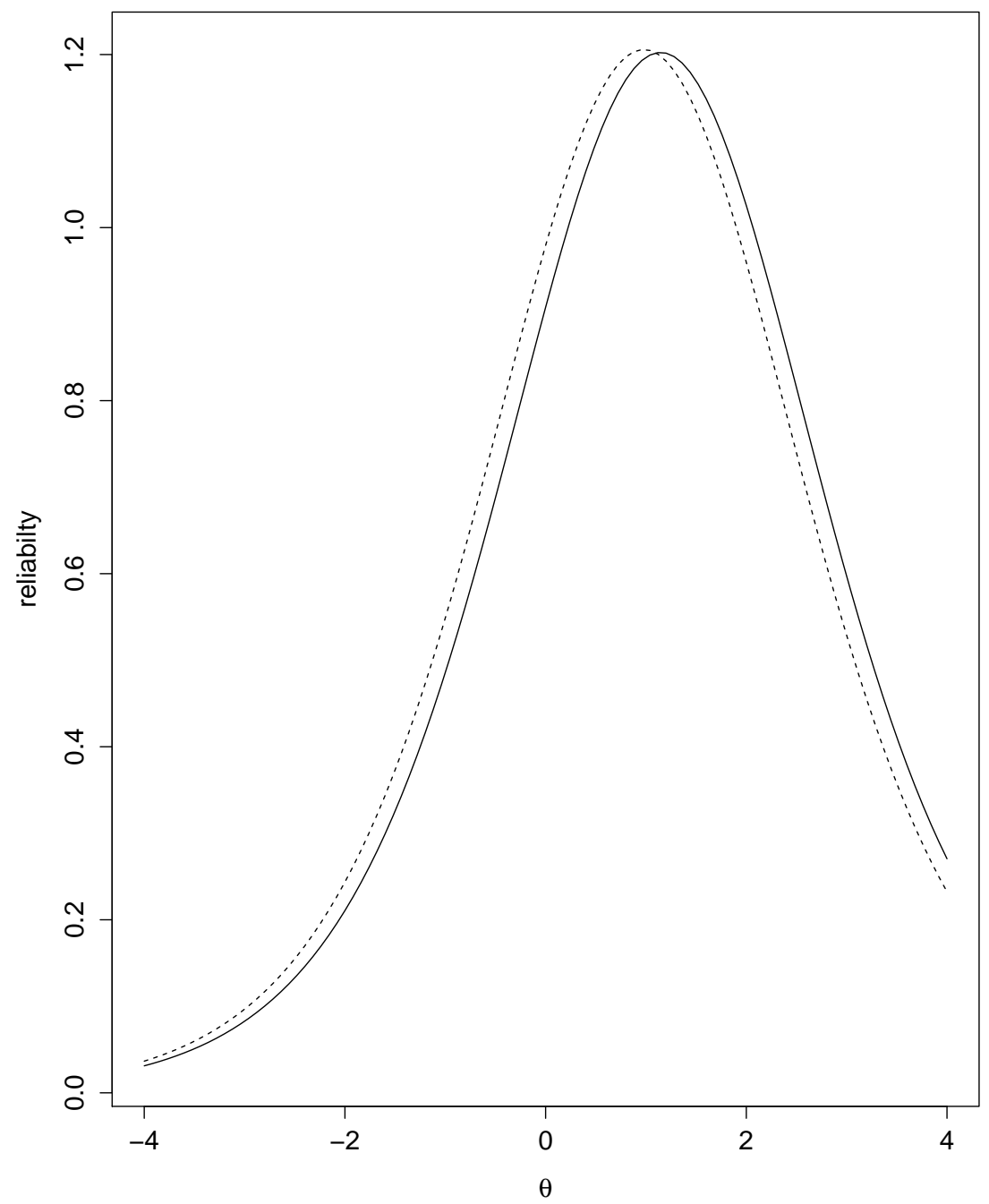

Figura 2.21: Funções de Informação do teste para o modelo 1 (linha sólida) e modelo 2(linha pontilhada) 


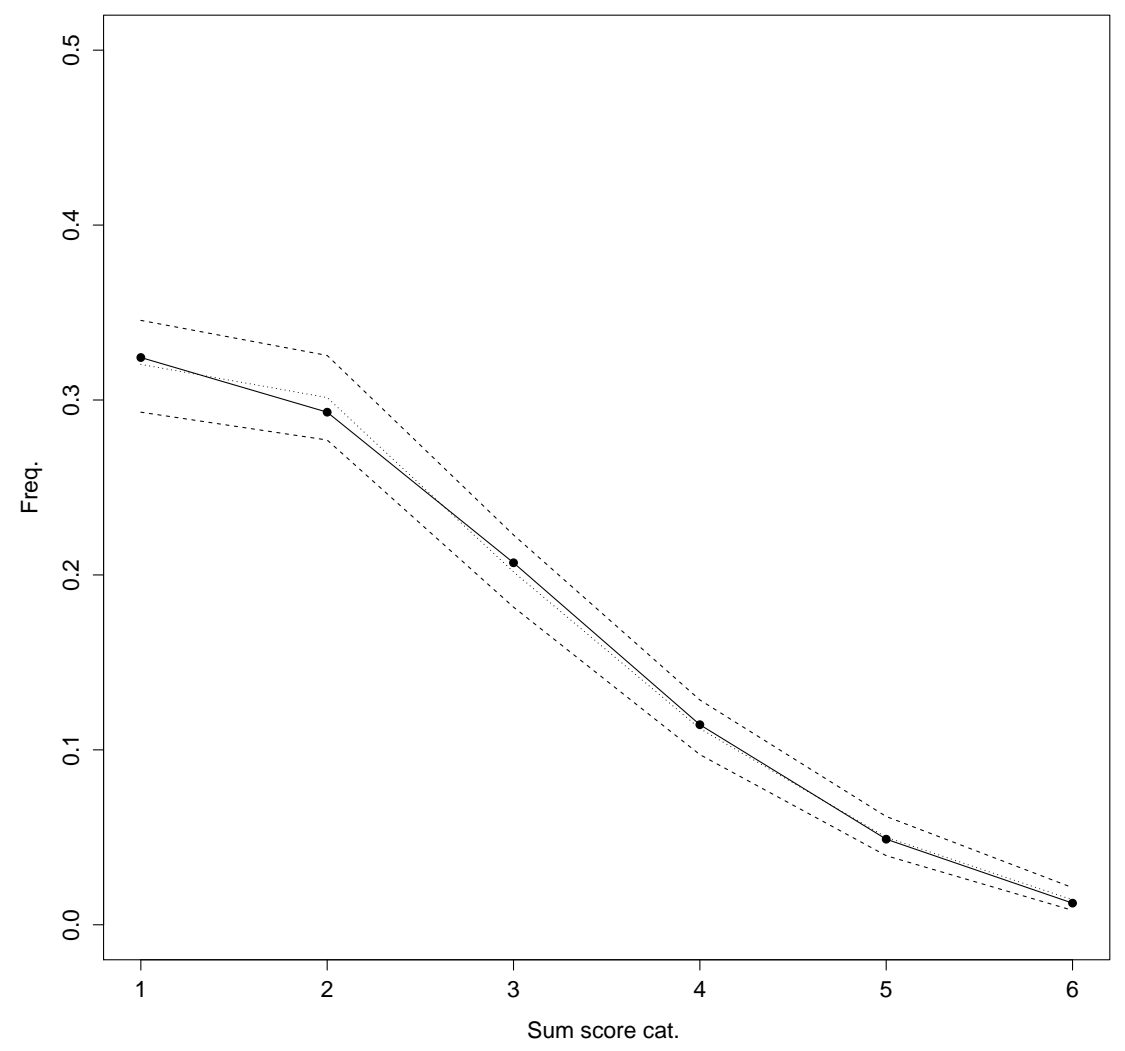

Figura 2.22: CPP utilizando a frequência de escores para o modelo 1
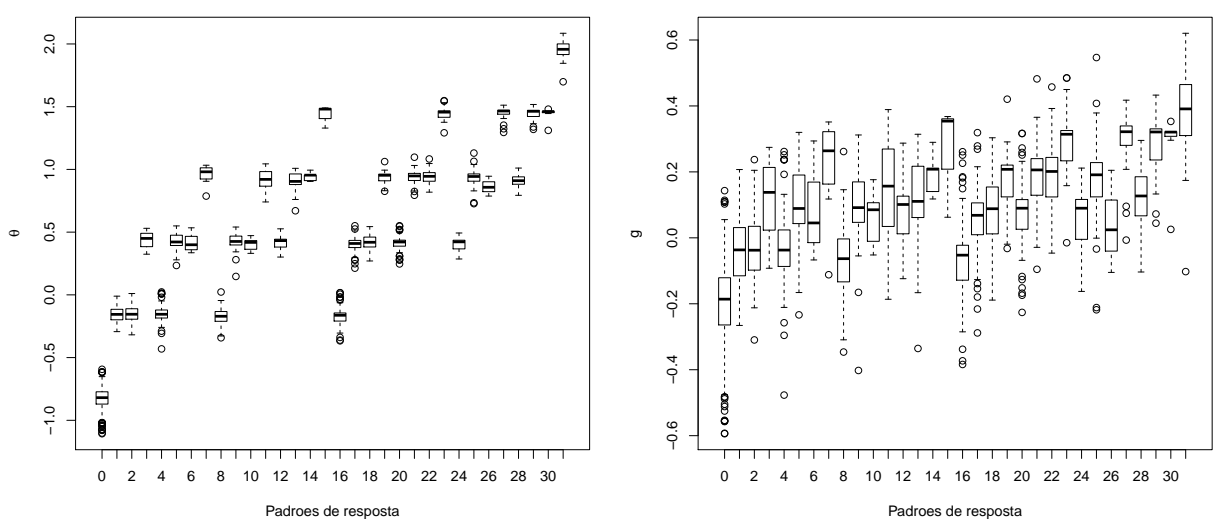

Figura 2.23: Box-plots para o traço latente e efeito poligênico em cada classe de padrão de resposta para o modelo 1. 

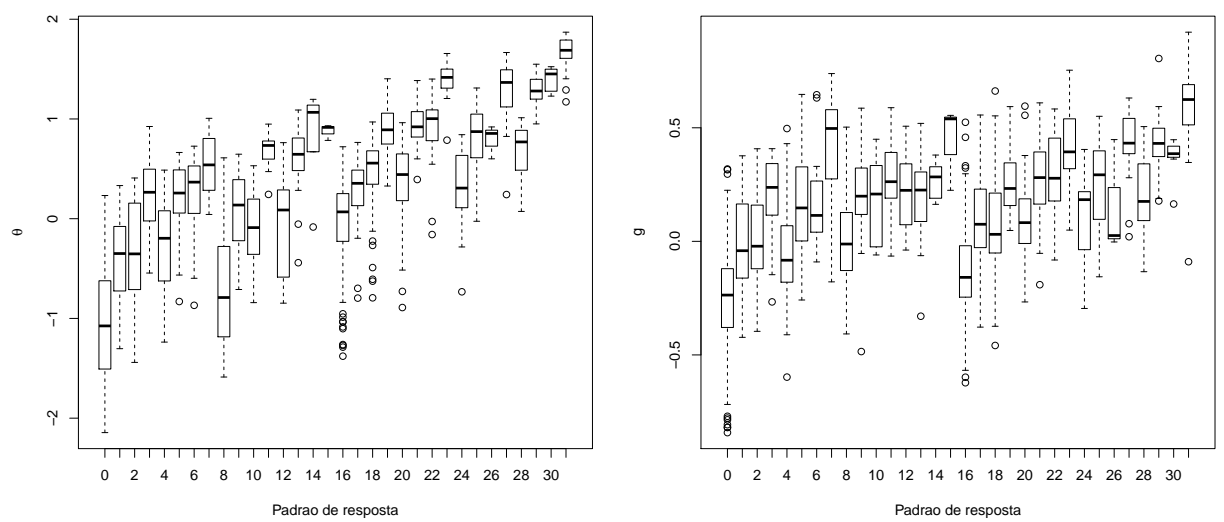

Figura 2.24: Box-plots para o traço latente e efeito poligênico em cada classe de padrão de resposta para o modelo 2. 


\section{Capítulo 3}

\section{Seleção de covariáveis em modelos multiníveis}

Nesse capítulo, duas alternativas para seleção de covariáveis em modelos multiníveis da TRI são apresentadas baseadas em dois métodos estabelecidos para modelos de regressão: LASSO Bayesiano e Busca Estocástica. A extensão é particularmente motivada pelo desejo de integrar o traço latente identificado com a doença e a informação genética do indivíduo sob a dificuldade adicional de filtrar tal informação. Os dois métodos são apresentados, estendendo-se o amostrador de Gibbs do capítulo anterior para um passo adicional de seleção, avaliados em estudo de simulação. O modelo multiníveis com a busca estocástica é então aplicado ao conjunto de dados de Baependi em que, além das variáveis fenotípicas da SM, foram avaliados os genótipos de um número elevado de marcadores moleculares em 1.119 indivíduos.

\subsection{Introdução}

Após reunir múltiplas fontes de informação fenotípica em torno de uma medida como conseguimos utilizando a TRI, queremos incorporar ao modelo a informação genética dos indivíduos obtida por meio de técnicas empregadas em Biologia Molecular. A potencial associação entre o traço latente e elementos indicadores do genótipo podem trazer novas informações sobre a genética de doenças complexas como a Síndrome Metabólica.

Com os avanços tecnológicos, tem sido possível inferir com crescente resolução a composição, função e estrutura do material genético em termos das bases componentes do DNA, dos produtos do processo de transcrição do material genético e da assinatura bioquímica dos processos intracelulares. Tais processos são de interesse central para a Genômica, Proteômica e Metabolômica (chamadas coletivamente de "omics"1) dentro da Biologia Molecular. Um problema comum nesses três campos é a quantidade imensa de dados resultantes dos seus experimentos.

De particular interesse no presente trabalho é o conjunto de marcadores moleculares relativos às bases constituintes do genótipo. O DNA é constituído de quatro tipos de bases nitrogenadas: adenina $(A)$, citosina $(C)$, guanina $(G)$ e timina $(T)$, de maneira que adenina liga-se com timina e citosina liga-se com guanina formando um dos dois pares de bases componentes de uma determinada locação no cromossomo.

Em seres humanos, cada posição do cromossomo corresponde a dois pares de bases e essa posição é a mesma nos dois cromossomos homólogos de cada indivíduo. São chamados homólogos pois cada um deles é herdado por um dos pais. Cada um dos locus dos dois cromossomos homólogos pode ter um de dois pares de bases, um par Adenina-Timina (AT) ou um par Citosina-Guanina (CG).

Variações nessas bases foram recentemente associadas com a presença de doenças e outras características fenotípicas. Quando as diferenças entre indivíduos se restringem a uma única base em uma região e essa variação é relativamente comum na população, a mesma é denominada um

\footnotetext{
${ }^{1}$ do inglês Genomics, Proteomics and Metabolomics
} 
SNP (polimorfismo em um nucleotídeo ${ }^{2}$ ).

A forma mais utilizada de investigar a associação entre SNP e fenótipo é através dos estudos de associação ampla $\left(\mathrm{GWAS}^{3}\right)$. O primeiro passo nesses estudos é uma análise unilocus, na qual cada um dos SNPs é considerado separadamente como variável explanatória em um modelo de regressão sobre algum fenótipo de interesse.

Os resultados desses múltiplos ajustes são então comparados através dos efeitos ou de valores $\mathrm{P}$ sob a hipótese nula da ausência de associação. Tais resultados são comumente apresentados em um gráfico conhecido como Manhattan plot (por exemplo na discussão em Gibson (2010)). Após alguma correção adequada para múltiplos testes, os SNPs considerados significantes são então apontados e então a região do genoma a qual pertencem é alvo de investigações subsequentes.

Acredita-se que a prevalência de doenças complexas seja influenciada por interações de múltiplos polimorfismos (Fridley, 2009). Dessa forma, efeitos pequenos demais podem não ser encontrados em análises unilocus de GWAS, mas aparecerem quando levamos múltiplos loci ou mesmo todos os marcadores genéticos em consideração no modelo (de Maturana et al., 2013), de forma que é desejável estudar todos os marcadores simultaneamente. Nesse caso, temos um problema estatístico de seleção de variáveis preditoras em um modelo de regressão.

O aumento da resolução no equipamento utilizado nos experimentos em Genômica permite que cada vez mais polimorfismos sejam mapeados nas diferentes populações humanas, animais ou vegetais. Atualmente, experimentos resultam em milhares ou milhões de polimorfismos para cada indivíduo na amostra, o que impõe dificuldades e desafios à busca de associação entre os polimorfismos e o fenótipo. Um destes desafios corresponde à análise de dados em espaços de alta dimensão no número de variáveis e de baixa dimensão no número de unidades amostrais, um problema conhecido como " $n<<p$ ".

Uma outra frente é o custo computacional do ajuste dos modelos bem como o tratamento e gerenciamento dos dados. Os bancos de dados são gigantescos, de maneira que o tratamento, mesmo que trivial, dos dados é uma tarefa complexa.

Além disso, é pouco prático utilizar métodos que ajustem todos ou uma parcela considerável dos $2^{p}$ modelos possíveis (cada SNP sendo uma variável preditora em três níveis relativos ao número de polimorfismos, há 2 graus de liberdade para seu efeito ser estudado) ${ }^{4}$ com respeito às covariáveis. Mesmo algoritmos que ajustem modelos arbitrariamente grandes rapidamente se tornam proibitivos em problemas dessa escala. Por exemplo, um estudo no qual 10 genes candidatos são suspeitos de estarem associados com uma doença (Fridley, 2009), considerando a genotipagem de 100 ou 200 SNPs, temos entre $2^{100}$ e $2^{200}$ (aproximadamente $10^{30}$ a $10^{60}$ ) modelos possíveis.

Uma dificuldade específica da modelagem com SNPs consiste na possível correlação existente entre as variáveis. É esperado que SNPs estejam associados entre si em um fenômeno denominado desequilíbrio de ligação $\left(\mathrm{LD}^{5}\right)$ devido a causas relacionadas com o fenótipo de interesse ou outras causas como a miscigenação. O LD resulta em uma associação entre duas localizações do genótipo devido a fatores biológicos diversos. Tal possível correlação deve ser considerada no ajuste de modelos que pretendam selecionar SNPs e envolvam a inclusão de vários deles simultaneamente nos modelos.

Além disso, efeito do SNP também não é necessariamente puramente aditivo, podendo apresentar uma componente de dominância. Neste caso, o efeito principal de cada SNP é decomposto em dois graus de liberdade, o aditivo e o de dominância.

Outras possibilidades a serem contempladas na modelagem de SNPs envolve a existência de interação entre dois SNPs (em um fenômeno denominado epistasia) no qual o genótipo de um certo SNP (digamos, SNP2) em outro local do cromossomo interfere com o efeito do SNP (digamos, SNP1) sobre o fenótipo. No contexto do modelo de regressão utilizado em genética quantitativa, a epistasia é considerada um efeito de interação entre duas variáveis preditoras.

\footnotetext{
${ }^{2}$ do inglês Single Nucleotide Polimorphism

${ }^{3}$ do inglês Genome Wide Association Studies

${ }^{4}$ assumindo apenas os termos relativos aos marcadores sem nenhuma interação

${ }^{5}$ do inglês, linkage disequilibrium
} 
Dessa forma, com o efeito principal de cada SNP decomposto em dois graus de liberdade, temse quatro graus de liberdade para se estudar o efeito de interação entre pares de SNPs. Em uma primeira análise, assume-se a ausência de epistasia e de dominância, assim somente o efeito aditivo de cada SNP é considerado.

Algumas abordagens clássicas para o problema de seleção de covariáveis envolvem regressões penalizadas que "encolhem" as estimativas de parâmetros com pouco ou nenhum efeito sobre a variável resposta para 0, deletando a variável do modelo. Exemplos dessa técnica são o LASSO ${ }^{6}$ (Tibshirani, 1996) e o Elastic Net (Zou e Hastie, 2005). Variáveis nesses casos são selecionadas baseadas nos tamanhos estimados dos seus efeitos.

Diversas abordagens Bayesianas foram propostas para a seleção de variáveis em modelos de regressão, entre elas a média de modelos (Bayesian Model Averaging, BMA, Raftery et al. (1997)), reversible jump MCMC (Green, 1995), LASSO Bayesiano (Park e Casella, 2008) e seleção de variáveis por busca estocástica (Stochastic Search Variable Selection, SSVS, George e McCulloch (1993, 1997)).

No presente trabalho são utilizados o LASSO Bayesiano e a busca estocástica por uma série de motivos. Primeiramente, uma abordagem Bayesiana foi escolhida por se adequar ao restante do paradigma utilizado na inferência do modelo multinível. Além disso, os dois métodos fornecem maneiras de realizar a seleção e estimação conjunta dos efeitos e demais parâmetros do modelo, evitando potencial viés ( $\mathrm{Lu}$ et al., 2005). Finalmente, os dois métodos se comparam favoravelmente a outros métodos utilizados na literatura e fornecem estimativas interpretáveis com respeito à aplicação de interesse.

A BMA é proibitivo pois impõe que se ajuste uma série de modelos aos dados, o que é impossível em qualquer tempo factível para os modelos da TRI mencionados anteriormente tendo em vista a quantidade de iterações do algoritmo MCMC necessárias para obterem-se estimativas razoáveis dos parâmetros. O método também é pouco prático com um número grande de modelos possíveis, devido à quantidade de integrações envolvidas. Na prática, escolhe-se um subconjunto bem menor de covariáveis por algum critério ad hoc e aplica-se a média dos modelos (veja Wu et al. (2010) para uma aplicação em um estudo com 10 genes candidatos).

Reversible Jump MCMC pode ser implementado de maneira a obter velocidade comparável com o SSVS porém com amostras mais correlacionadas (O'Hara e Sillanpaa, 2009). A transição entre modelos se dá em termos de um passo de aceitação-rejeição sobre o número de covariáveis no modelo, uma característica pouco informativa sobre a qual é difícil propor uma distribuição a priori e distribuição de propostas para a mudança entre espaços.

A formulação Bayesiana do LASSO é baseada em uma observação sobre a ligação entre o LASSO (Tibshirani, 1996) e a interpretação dos estimadores obtidos como a moda de uma distribuição a posteriori dos efeitos quando uma distribuição de Laplace é assumida a priori. Como a distribuição de Laplace é representável como a marginal de um modelo hierárquico normal com distribuição exponencial para a precisão, o LASSO Bayesiano é facilmente implementável em algoritmos MCMC mesmo para situações complicadas.

O SSVS tem a possibilidade de ser mais adaptável a espaços de dimensão bem elevada (Baragatti, 2011) e incorporar com mais facilidade relacionamentos biológicos presentes nas covariáveis. Algumas aplicações relevantes em Genética incluem um modelo hierárquico com as covariáveis agrupadas em caminhos metabólicos e genes nos quais os marcadores estão inseridos (Stingo et al., 2011) ou modelando as dependências espaciais das covariáveis (Li e Zhang, 2010).

Não existe um consenso na literatura com respeito ao melhor método para a seleção de variáveis preditoras. No presente trabalho, o LASSO Bayesiano e o SSVS foram implementados para realizar a seleção de variáveis no nível estrutural de um modelo multiníveis da TRI. Como citado anteriormente, ambos os métodos se comparam favoravelmente com respeito a outros descritos na literatura.

\footnotetext{
${ }^{6}$ do inglês Least Absolute Shrinkage and Selection Operator
} 


\subsection{Seleção Bayesiana de variáveis em modelos multiníveis}

No presente trabalho, foram implementados dois passos de seleção de variáveis: o LASSO Bayesiano como proposto em Park e Casella (2008) e a busca estocástica (SSVS ${ }^{7}$, George e McCulloch $(1993,1997))$. Estas duas técnicas são utilizadas amplamente em genética quantitativa na seleção de marcadores genéticos e previsão de traços complexos. A seguir, será feita uma breve revisão de ambas no contexto de modelos de regressão e sua implementação no modelo multiníveis do Capítulo anterior.

O LASSO Bayesiano é derivado do LASSO que propõe um estimador para o vetor de efeitos fixos no modelo de regressão múltipla usual

$$
\boldsymbol{Y}=\boldsymbol{X} \boldsymbol{\beta}+\boldsymbol{e},
$$

$\boldsymbol{Y}$ e $\boldsymbol{e}$ são vetores $1 \times N$ de $N$ variáveis observadas e erros aleatórios respectivamente, $\boldsymbol{X}$ é uma matriz $N \times p$ de covariáveis (matriz de incidência) e $\boldsymbol{\beta}$ é um vetor $1 \times p$ de efeitos fixos. O estimador $\hat{\boldsymbol{\beta}}_{L A S S O}$ é a solução do problema de otimização

$$
\begin{array}{r}
\hat{\boldsymbol{\beta}}_{L A S S O}=\min _{\boldsymbol{\beta}}\left\{(\boldsymbol{Y}-\boldsymbol{X} \boldsymbol{\beta})^{\prime}(\boldsymbol{Y}-\boldsymbol{X} \boldsymbol{\beta})\right\} \\
\text { sujeito a }\|\beta\|_{1} \leq t,
\end{array}
$$

$t$ é uma constante positiva e $\|\boldsymbol{\beta}\|_{1}=\sum_{l=1}^{p}\left|\beta_{l}\right|$. Para um parâmetro de suavização $\lambda(t)$, uma solução por multiplicadores de Lagrange é dada por

$$
\hat{\boldsymbol{\beta}}_{L A S S O}=\min _{\boldsymbol{\beta}}\left\{(\boldsymbol{Y}-\boldsymbol{X} \boldsymbol{\beta})^{\prime}(\boldsymbol{Y}-\boldsymbol{X} \boldsymbol{\beta})+\lambda(t)\|\beta\|_{1}\right\},
$$

que 'encolhe' os coeficientes sem efeito na direção da origem, de fato fixando os valores de alguns coeficientes como zero (Tibshirani, 1996).

O LASSO Bayesiano é derivado da observação de que assumindo-se uma priori Laplace com parâmetros de locação 0 e escala $\lambda$

$$
\pi\left(\beta_{l} \mid \lambda\right)=\frac{\lambda}{2} \exp \left\{-\lambda\left|\beta_{l}\right|\right\} ;-\infty<\beta_{l}<\infty
$$

independentes a priori para cada efeito fixo $l, l=1, \cdots, p$ e uma verossimilhança normal para as observações, são obtidas modas a posteriori iguais a (3.2) . Entretanto, a priori Laplace não conjuga com outras distribuições frequentemente usadas.

Usa-se a identidade (Park e Casella, 2008)

$$
\frac{\lambda}{2} e^{-a|z|}=\int_{0}^{\infty} \frac{1}{\sqrt{2 \pi s}} e^{-\frac{z^{2}}{2 s}} \frac{\lambda^{2}}{2} e^{-\frac{\lambda^{2} s}{2}} d s, a>0 .
$$

Da equação (3.4) segue que a distribuição de Laplace é a distribuição marginal da variável aleatória $Z$ no modelo hierárquico

$$
\begin{array}{r}
Z \mid s \sim N(0, s) \\
s \sim \text { Exponencial }\left(\lambda^{2}\right),
\end{array}
$$

de maneira que a distribuição de Laplace é obtida de uma mistura na escala de uma normal utili-

\footnotetext{
${ }^{7}$ do inglês, Stochastic Search Variable Selection
} 
zando uma exponencial como medida de mistura. Esse tipo de formulação facilita a implementação dos métodos e dá alguma interpretação sobre a natureza das prioris.

Além disso, Park e Casella (2008) propõem uma priori para o hiperparâmetro $\lambda^{2}$

$$
\lambda^{2} \sim \operatorname{Gama}\left(a_{\lambda}, b_{\lambda}\right),
$$

em que os hiperparâmetros $a_{\lambda}$ e $b_{\lambda}$ podem ser fixados. A mesma priori é escolhida no presente trabalho pela facilidade analítica derivada da conjugação.

O LASSO Bayesiano foi aplicado em genética utilizando vários modelos lineares generalizados mistos para selecionar marcadores associados a diversas características como peso do grão de cevada (Yi e Xu, 2008), produção de trigo, peso em ratos (de los Campos et al., 2009b) e risco de câncer de pele em humanos (Vazquez et al., 2012).

Cabe notar, todavia, que não existe nenhuma seleção de fato ocorrendo com o LASSO Bayesiano. Os coeficientes são simplesmente encolhidos para zero, auxiliados pela escolha da distribuição a priori, que é relativamente influente mesmo para amostras grandes na situação $n<<p$ (Gianola, 2013). O que ocorre no caso do LASSO é um ajuste do modelo de regressão com as $p$ covariáveis, as quais são selecionadas com base no tamanho do efeito e na inclusão do zero nos intervalos de credibilidade.

O LASSO Bayesiano se compara favoravelmente com sua contraparte frequentista e extensões como o elastic net (Kyung et al., 2010) e com a abordagem usual com modelos mistos (Wimmer et al. , 2013). A abordagem com o LASSO pode ser estendida para outras penalizações, da norma $l^{1} \mathrm{em}$ (3.2) para a norma euclidiana $\left(l^{2}\right.$, análoga à regressão "ridge"), uma mistura das duas (analogamente ao elastic net (Zou e Hastie, 2005)) entre outras. Uma revisão de possíveis extensões é feita em Kyung et al. (2010).

A busca estocástica realiza uma seleção sobre as covariáveis do modelo, resultando em covariáveis ou conjuntos de covariáveis mais 'promissoras' a posteriori. O SSVS realiza a seleção utilizando o vetor de variáveis latentes $\gamma=\left(\gamma_{1}, \cdots, \gamma_{p}\right)$ tais que, para $l=1, \cdots, p$.

$$
\gamma_{l}=\left\{\begin{array}{l}
1, \text { se a variável } l \text { faz parte do modelo } \\
0, \text { caso contrário }
\end{array}\right.
$$

e a seleção é feita em termos da probabilidade a posteriori $P\left(\gamma_{l}=1 \mid \boldsymbol{Y}\right)$ da inclusão da variável ou de algum subconjunto de covariáveis condicionada aos dados observados. A probabilidade é um índice de seleção de variáveis bem mais interpretável, indicando a probabilidade de que a covariável tenha um efeito funcional sobre a variável dependente (Guan et al., 2011).

George e McCulloch (1993) usam a mistura de normais como priori para cada um dos $p$ efeitos

$$
\pi\left(\beta_{l} \mid \gamma_{l}\right)=\gamma_{l} \phi\left(\frac{\beta_{l}}{\sqrt{c^{2} \sigma_{\beta}^{2}}}\right)+\left(1-\gamma_{l}\right) \phi\left(\frac{\beta_{l}}{\sqrt{\sigma_{\beta}^{2}}}\right) ; l=1, \cdots, p
$$

$\operatorname{com} \phi(\cdot)$ a função densidade de probabilidade da normal padrão, $\sigma_{\beta}^{2}$ é a variância a priori dos efeitos na ausência do efeito $\left(\gamma_{l}=0\right)$ e $c^{2}$ é um fator que aumente a variância na presença do efeito $\left(\gamma_{l}=1\right)$. Sugere-se que $\sigma_{\beta}^{2}$ seja fixado em um valor pequeno de maneira que o coeficiente seja encolhido na direção da origem na ausência do efeito.

Um caso especial da priori é a dita 'spike and slab', que consiste da mistura entre a normal e uma densidade degenerada no zero. Essa é a distribuição usada em Baragatti (2011) e utilizada no presente trabalho.

Denotando por $m=\sum_{l=1}^{p} \gamma_{l}$ o número de covariáveis no modelo, $\boldsymbol{X}_{\gamma}$ a matriz $N \times m$ das covariáveis incluídas no modelo e $\boldsymbol{\beta}_{\gamma}$ o vetor dos coeficientes relativos às variáveis incluidas no modelo, Baragatti (2011) usa a $g$-prior

$$
\boldsymbol{\beta}_{\gamma} \mid \boldsymbol{\gamma} \sim N_{m}\left(0, c\left(\boldsymbol{X}_{\gamma}^{\prime} \boldsymbol{X}_{\gamma}\right)^{-1}\right)
$$


$c$ é um hiperparâmetro escolhido para representar a informação dada pelas covariáveis sobre a estrutura de dependência a priori dos efeitos (Marin e Robert, 2007).

Supõe-se também uma priori Bernoulli para cada um $\operatorname{dos} l=1, \cdots, p$ indicadores

$$
\gamma_{l} \sim \operatorname{Bernoulli}\left(\omega_{l}\right)
$$

$\omega_{l}$ são probabilidades a priori da inclusão de uma variável em particular no modelo.

George e McCulloch $(1993,1997)$ derivam condicionais completas para os efeitos $\boldsymbol{\beta}$ e indicadores $\gamma$ e inserem a seleção de variáveis como mais um passo em um amostrador de Gibbs. Nem sempre a seleção é trivial, mas um passo Metropolis-Hastings pode ser inserido para a seleção em modelos mais complexos (Baragatti, 2011; Stingo et al., 2011). No presente trabalho, todas as covariáveis foram consideradas igualmente importantes a priori, assumindo-se $\omega_{1}=\cdots=\omega_{p}=\omega$.

A SSVS é uma forma interpretável e extremamente flexível de seleção de variáveis, podendo ser estendida para abrigar uma ampla gama de formas e premissas específicas dos modelos.

A estrutura de dependência a priori entre as covariáveis pode ser estendida para formas mais complexas como campos markovianos (Li e Zhang, 2010) e inserção das covariáveis em alguma estrutura hierárquica (como genes ou vias metabólicas, Stingo et al. (2011)). O processo de busca pode ser estendido para selecionar não apenas covariáveis, mas interações entre as mesmas representando o comportamento diferente de certos genes na presença de outros ${ }^{8}$ (Oh et al., 2003) e a estrutura de dependência causada pelo desequilíbrio de ligação entre marcadores (Weinwurm et al., 2013). Além disso, a priori para os efeitos pode ser modificada de maneira a lidar com a singularidade da matriz de delineamento (Baragatti e Pommeret, 2011).

Além da sua flexibilidade, a SSVS se compara favoravelmente a outros métodos de seleção utilizados na literatura. Sua capacidade de lidar com apenas $m<p$ covariáveis em cada passo do algoritmo MCMC diminui o custo computacional frente a alternativas como o LASSO Bayesiano ou o simples ajuste dos efeitos fixos utilizando uma priori $t$ de Student resultando em um método de seleção mais rápido com capacidades preditivas.

Tais capacidades se mostram no mínimo iguais (Verbyla et al., 2010) ou superiores (Verbyla et al. , 2009) à priori $t$, alternativas frequentistas utilizando o melhor preditor linear não viciado ${ }^{9} \mathrm{em}$ modelos mistos com a matriz de parentesco ou matriz de parentesco generalizadas (Calus e Veerkamp, 2011) e o LASSO (Srivastava e Chen, 2010).

Ambos os métodos de seleção foram implementados no pacote computacional $\mathrm{R}$ (Team, 2005) com partes do código compiladas em $\mathrm{C}++$ para melhor desempenho utilizando-se o pacote RcppArmadillo (Eddelbuettel e Sanderson, 2013).

\subsubsection{LASSO Bayesiano para o modelo multiníveis}

Retornando ao modelo multiníveis (2.4), seja

$$
\boldsymbol{\theta}_{(N \times 1)}=\boldsymbol{X}_{(N \times p)} \boldsymbol{\beta}_{(p \times 1)}+\boldsymbol{g}_{(N \times 1)}+\boldsymbol{e}_{(N \times 1)} .
$$

gerando um modelo idêntico a (2.4) sob a premissa

$$
\boldsymbol{g} \sim N\left(0, \sigma_{g}^{2} \boldsymbol{A}\right)
$$

com $\boldsymbol{A}=\operatorname{diag}\left(\Phi_{1}, \cdots, \Phi_{K}\right)$ a matriz bloco diagonal de parentesco das famílias. Da formulação por misturas (3.4) assumem-se as prioris

\footnotetext{
${ }^{8}$ um fenômeno denominado epistasia em genética

${ }^{9}$ Best Unbiased Linear Predictor (BLUP)
} 


$$
\begin{array}{r}
\boldsymbol{\beta} \mid \boldsymbol{\tau} \sim N(0, \operatorname{diag}(\boldsymbol{\tau})) \\
\tau_{l} \mid \lambda^{2} \sim \text { Exponencial }\left(\frac{\lambda^{2}}{2}\right) ; l=1, \cdots, p \\
\lambda^{2} \sim \operatorname{Gama}\left(a_{\lambda}, b_{\lambda}\right)
\end{array}
$$

a dependência a priori entre o efeito fixo e a variância do erro é sugerida por Park e Casella (2008) para evitar eventuais bimodalidades na posteriori conjunta $\pi\left(\boldsymbol{\beta}, \sigma_{e}^{2} \mid \boldsymbol{Y}\right)$ e assim acelerar a convergência do amostrador de Gibbs mas escolheu-se não assumir a mesma dependência no presente trabalho ${ }^{10}$.

A derivação das distribuições condicionais completas para o modelo completo é feita no Capítulo 2, então são denotadas no presente capítulo apenas as modificações devidas à adição da estrutura a priori (3.13).

Para o vetor de efeitos $\boldsymbol{\beta}$, temos, para $D_{\tau}^{-1}=\operatorname{diag}(\boldsymbol{\tau})$

$$
\begin{array}{r}
\pi(\boldsymbol{\beta} \mid \cdot) \propto \exp \left\{-\frac{1}{2 \sigma_{e}^{2}}(\boldsymbol{\theta}-\boldsymbol{X} \boldsymbol{\beta}-\boldsymbol{g})^{\prime}(\boldsymbol{\theta}-\boldsymbol{X} \boldsymbol{\beta}-\boldsymbol{g})-\frac{1}{2 \sigma_{e}^{2}} \boldsymbol{\beta}^{\prime} D_{\tau} \boldsymbol{\beta}\right\} \\
\propto \exp \left\{-\frac{1}{2 \sigma_{e}^{2}}\left(\boldsymbol{\beta}^{\prime}\left(\boldsymbol{X}^{\prime} \boldsymbol{X}+D_{\tau}\right) \boldsymbol{\beta}-(\boldsymbol{\theta}-\boldsymbol{g})^{\prime} \boldsymbol{X} \boldsymbol{\beta}-\boldsymbol{\beta}^{\prime} \boldsymbol{X}^{\prime}(\boldsymbol{\theta}-\boldsymbol{g})\right)\right\} \\
\propto \exp \left\{-\frac{1}{2}\left(\boldsymbol{\beta}-V_{\beta}^{-1} \mu_{\beta}\right)^{\prime} V_{\beta}^{-1}\left(\boldsymbol{\beta}-V_{\beta}^{-1} \mu_{\beta}\right)\right\},
\end{array}
$$

com

$$
\begin{array}{r}
V_{\beta}=\frac{1}{\sigma_{e}^{2}}\left(\boldsymbol{X}^{\prime} \boldsymbol{X}+D_{\tau}\right), \\
\mu_{\beta}=\boldsymbol{X}^{\prime} \frac{(\boldsymbol{\theta}-\boldsymbol{g})}{\sigma_{e}^{2}},
\end{array}
$$

temos o mesmo núcleo da distribuição normal $p$-variada, portanto,

$$
\boldsymbol{\beta} \mid \cdot \sim N\left(V_{\beta}^{-1} \mu_{\beta}, V_{\beta}^{-1}\right) .
$$

Para a variância do erro, note que agora a priori dos efeitos entra no cálculo da condicional completa. Sob a mesma priori $\operatorname{Gama}(1,1)$ do Capítulo 2, temos

$$
\pi\left(\sigma_{e}^{2} \mid \cdot\right) \propto\left(\frac{1}{\sigma_{e}^{2}}\right)^{\frac{N+p+1-1}{2}} \exp \left[-\frac{1}{\sigma_{e}^{2}}\left(\frac{(\boldsymbol{\theta}-\boldsymbol{X} \boldsymbol{\beta}-\boldsymbol{g})^{\prime}(\boldsymbol{\theta}-\boldsymbol{X} \boldsymbol{\beta}-\boldsymbol{g})+\boldsymbol{\beta}^{\prime} D_{\tau} \boldsymbol{\beta}}{2}+1\right)\right],
$$

que é o núcleo de uma distribuição gama-inversa. Segue-se que

$$
\sigma_{e}^{2} \mid \cdot \sim I G\left(\frac{N+p+1}{2}, \frac{(\boldsymbol{\theta}-\boldsymbol{X} \boldsymbol{\beta}-\boldsymbol{g})^{\prime}(\boldsymbol{\theta}-\boldsymbol{X} \boldsymbol{\beta}-\boldsymbol{g})+\boldsymbol{\beta}^{\prime} D_{\tau} \boldsymbol{\beta}}{2}+1\right) .
$$

Para os elementos da medida misturadora $\tau_{l}, l=1,2, \cdots, p$, tem-se que

\footnotetext{
${ }^{10}$ Apesar de contra indicado em Park e Casella (2008), a dependência dos efeitos pode causar instabilidade na cadeia relativa a $\sigma_{e}^{2}$, gerando estimativas degeneradas quando o número de covariáveis é grande, um comportamento análogo ao descrito em Gelman (2006). Dessa forma, é possível usar prioris independentes simplesmente retirando $\sigma_{e}^{2}$ da priori dos efeitos fixos. Nesse caso, a condicional completa para $\sigma_{e}^{2}$ é idêntica à do Capítulo 2.
} 


$$
\begin{aligned}
\pi\left(\tau_{l} \mid \cdot\right) \propto\left(\frac{1}{\tau_{l}}\right)^{\frac{1}{2}} & \exp \left\{-\frac{1}{\tau_{l}}\left(\frac{\beta_{l}^{2}}{2 \sigma_{e}^{2}}\right)\right\} \frac{\lambda^{2}}{2} \exp \left\{-\frac{\lambda^{2} \tau_{l}}{2}\right\} \\
& =\frac{\lambda^{2}}{2} \sqrt{\frac{1}{\tau_{l}}} \exp \left\{-\frac{1}{2}\left(\lambda^{2} \tau_{l}+\frac{\beta_{l}^{2}}{\sigma_{e}^{2} \tau_{l}}\right)\right\},
\end{aligned}
$$

a qual não se assemelha com nenhum núcleo de distribuições usualmente utilizadas.

Entretanto, com $\psi_{l}=g\left(\tau_{l}\right)=\frac{1}{\tau_{l}}$, tem-se

$$
\pi\left(\psi_{l} \mid \cdot\right) \propto \sqrt{\frac{\lambda}{2 \pi \psi_{l}^{3}}} \exp \left\{-\frac{1}{2}\left(\frac{\lambda^{2}}{\psi_{l}}+\frac{\beta_{l}^{2} \psi_{l}}{\sigma_{e}^{2}}\right)\right\},
$$

$\mathrm{e} \operatorname{com} \mu_{\psi_{l}}^{2}=\frac{\lambda^{2} \sigma_{e}^{2}}{\beta_{l}^{2}}$

$$
\pi\left(\psi_{l} \mid \cdot\right) \propto \sqrt{\frac{\lambda}{2 \pi \psi_{l}^{3}}} \exp \left\{-\frac{1}{2}\left(\frac{\lambda^{2}\left(\psi_{l}-\mu_{\psi_{l}}\right)^{2}}{\mu_{\psi_{l}}^{2} \psi_{l}}\right)\right\},
$$

idêntica à densidade de uma normal inversa com parâmetros $\mu_{\psi_{l}}$ e $\lambda^{2}$, então para $l=1, \cdots, p$ tem-se que

$$
\frac{1}{\tau_{l}} \mid \cdot \sim \text { Normal }- \text { Inversa }\left(\mu_{\psi_{l}}, \lambda^{2}\right) .
$$

Para o hiperparâmetro $\lambda^{2}$ da distribuição de Laplace, sob a priori $\operatorname{Gama}\left(a_{\lambda}, b_{\lambda}\right)$ tem-se que

$$
\pi\left(\lambda^{2} \mid \cdot\right) \propto\left(\lambda^{2}\right)^{a_{\lambda}+p-1} \exp \left\{-\lambda^{2}\left(\frac{1}{b_{\lambda}}+\frac{\mathbf{1}^{\prime} \boldsymbol{\tau}}{2}\right)\right\},
$$

que é o núcleo da densidade correspondente à distribuição Gama

$$
\lambda^{2} \mid \cdot \sim \operatorname{Gama}\left(a_{\lambda}+p, \frac{1}{\frac{1}{b_{\lambda}}+\frac{\mathbf{1}^{\prime} \boldsymbol{\tau}}{2}}\right) .
$$

Dessa forma, o ajuste do modelo aos dados e a realização da escolha de covariáveis através do LASSO Bayesiano pode ser feita modificando-se o Amostrador de Gibbs nos sequintes passos

1. Modifique o passo 8 para a equação (3.16)

2. Modifique o passo 7 para a equação (3.18)

3. Para $l=1, \cdots, p$, amostre $\tau_{l}$ da distribuição (3.22) utilizando o método de Michael et al. (1976).

4. Amostre $\lambda^{2}$ utilizando (3.24).

A implementação do LASSO Bayesiano é computacionalmente mais custosa do que os modelos multiníveis do Capítulo 2. Como o modelo completo (com $p$ covariáveis) é ajustado em todo passo, o esforço computacional aumenta consideravelmente com o número de covariáveis.

Além disso, a estrutura de covariância da condicional completa (3.15), é mais complexa do que no caso Normal-Gama por conta da mistura. Com isso, a amostragem requer uma decomposição espectral a cada passo ao invés de apenas uma no caso da $g$-prior. Resumidamente, o processo de estimação para o modelo multiníveis pode ser ilustrado com a Figura 3.1. 


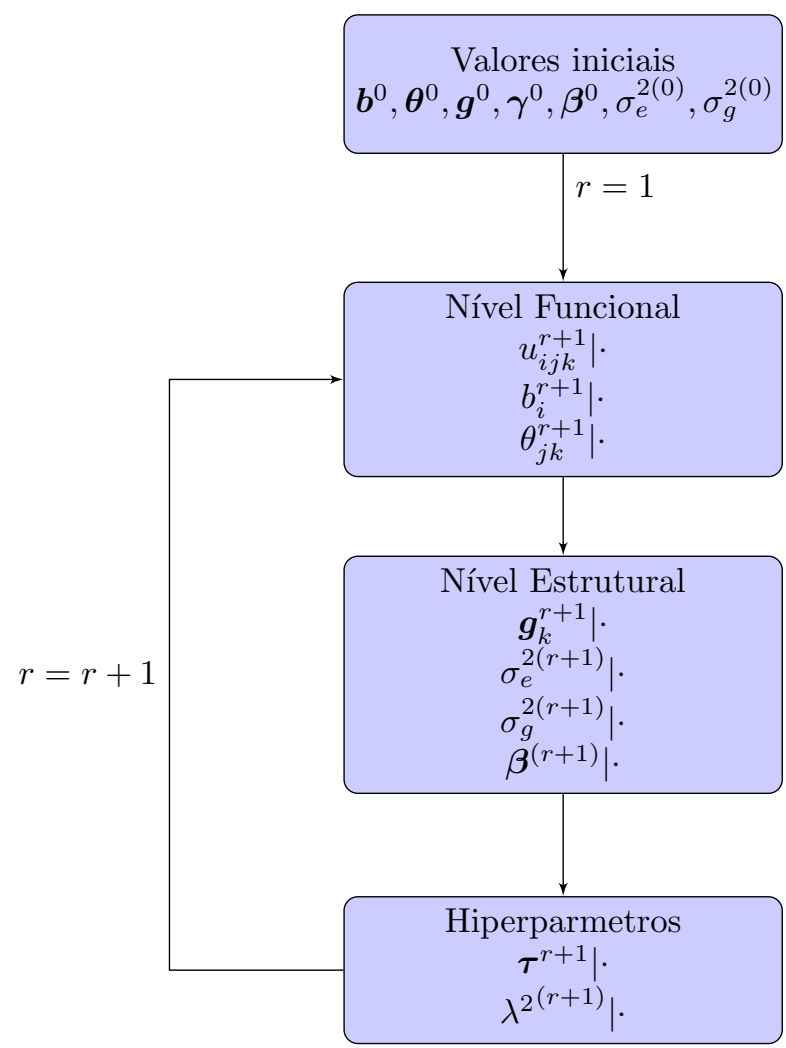

Figura 3.1: Amostrador de Gibbs proposto para os parâmetros do modelo multiníveis e seleção de covariáveis através do LASSO Bayesiano

\subsubsection{SSVS para o modelo multiníveis}

O modelo multiníveis do Capítulo 2 pode ser estendido com as prioris (3.9) e (3.10) obtendo-se o núcleo da posteriori

$$
\begin{aligned}
\pi\left(\boldsymbol{\theta}, \boldsymbol{b}, \boldsymbol{\gamma}, \boldsymbol{\beta}, \boldsymbol{U}, \sigma_{g}^{2}, \sigma_{e}^{2} \mid \boldsymbol{Y}\right) \propto & \prod_{k=1}^{K} \prod_{j=1}^{n_{k}} \prod_{i=1}^{I}\left(I\left(u_{i j k} \leq P_{i j k}\right) I\left(Y_{i j k}=1\right)+\right. \\
& \left.I\left(u_{i j k} \geq P_{i j k}\right) I\left(Y_{i j k}=0\right)\right) \exp \left\{-\frac{b_{i}^{2}}{2}\right\}\left(\frac{1}{\sigma_{e}^{2}}\right)^{-\frac{N}{2}} \\
& \exp \left\{-\frac{1}{2 \sigma_{e}^{2}}\left(\boldsymbol{\theta}-\boldsymbol{X}_{\gamma} \boldsymbol{\beta}_{\gamma}-\boldsymbol{g}\right)^{\prime}\left(\boldsymbol{\theta}-\boldsymbol{X}_{\gamma} \boldsymbol{\beta}_{\gamma}-\boldsymbol{g}\right)\right\} \\
& \left(\frac{1}{\sigma_{g}^{2}}\right)^{-\frac{N}{2}} \exp \left\{-\frac{1}{2 \sigma_{g}^{2}} \boldsymbol{g}^{\prime} \boldsymbol{A}^{-1} \boldsymbol{g}\right\} \exp \left\{-\frac{1}{2 \sigma_{e}^{2}}\right\} \\
& \exp \left\{-\frac{1}{2 \sigma_{g}^{2}}\right\} \exp \left\{-\frac{1}{2 c} \boldsymbol{\beta}_{\gamma}^{\prime}\left(\boldsymbol{X}_{\gamma}^{\prime} \boldsymbol{X}_{\gamma}\right) \boldsymbol{\beta}_{\gamma}\right\} \\
& \prod_{l=1}^{p} \omega^{\gamma_{l}}(1-\omega)^{\left(1-\gamma_{l}\right)} .
\end{aligned}
$$

De maneira análoga ao Capítulo 2 e utilizando a notação (3.11) e definindo

$$
V_{\gamma}=\left(\frac{1}{\sigma_{e}^{2}}+\frac{1}{c}\right) \boldsymbol{X}_{\gamma}^{\prime} \boldsymbol{X}_{\gamma}
$$




$$
\mu_{\gamma}=\frac{1}{\sigma_{e}^{2}} \boldsymbol{X}_{\gamma}^{\prime}(\boldsymbol{\theta}-\boldsymbol{g})
$$

temos a condicional completa

$$
\boldsymbol{\beta}_{\gamma} \mid \boldsymbol{\gamma}, \cdot N\left(V_{\gamma}^{-1} \mu_{\gamma}, V_{\gamma}^{-1}\right) .
$$

O principal problema reside no vetor de indicadores $\gamma$, cuja condicional completa tem o núcleo

$$
\begin{aligned}
\pi\left(\boldsymbol{\gamma} \mid \boldsymbol{\beta}_{\gamma}, \cdot\right) \propto & \exp \left\{\frac{1}{2 \sigma_{e}^{2}}\left(\boldsymbol{\theta}-\boldsymbol{X}_{\gamma} \boldsymbol{\beta}_{\gamma}-\boldsymbol{g}\right)^{\prime}\left(\boldsymbol{\theta}-\boldsymbol{X}_{\gamma} \boldsymbol{\beta}_{\gamma}-\boldsymbol{g}\right)\right\} \\
& \exp \left\{-\frac{1}{2 c} \boldsymbol{\beta}_{\gamma}^{\prime}\left(\boldsymbol{X}_{\gamma}^{\prime} \boldsymbol{X}_{\gamma}\right) \boldsymbol{\beta}_{\gamma}\right\} \\
& \prod_{l=1}^{p} \omega^{\gamma_{l}}(1-\omega)^{\left(1-\gamma_{l}\right)}(2 \pi)^{-\frac{\sum_{l=1}^{p} \gamma_{l}}{2}}\left|c\left(\boldsymbol{X}_{\gamma}^{\prime} \boldsymbol{X}_{\gamma}\right)^{-1}\right|^{-\frac{1}{2}},
\end{aligned}
$$

que não tem forma fechada.

Um passo utilizando-se Metropolis-Hastings (MH) poderia ser empregado, mas para cada proposta $\gamma^{*}$ retirada de uma densidade apropriada $q(\cdot)$, a probabilidade de aceitação $(2.24)$ utilizando a equação anterior é função dos efeitos fixos na iteração $\boldsymbol{\beta}_{\gamma}^{(r)}$ e do vetor de efeitos fixos do modelo proposto $\boldsymbol{\beta}_{\gamma^{*}}$ cujo valor é desconhecido.

No presente trabalho, é aplicada a mesma técnica empregada em Baragatti (2011) para obter uma condicional para o vetor de indicadores. Marginaliza-se a condicional (3.29) com respeito ao vetor $\boldsymbol{\beta}_{\gamma}$, resultando em um amostrador colapsado de Gibbs (Liu, 1994).

A integração resulta na condicional marginal

$$
\begin{array}{r}
\pi(\boldsymbol{\gamma} \mid \cdot) \propto\left(\frac{c+\sigma_{e}^{2}}{\sigma_{e}^{2}}\right)^{-\frac{1}{2} \sum_{l=1}^{p} \gamma_{l}} \exp \left\{-\frac{1}{2}\left[\frac{1}{\sigma_{e}^{2}}(\boldsymbol{\theta}-\boldsymbol{g})^{\prime}(\boldsymbol{\theta}-\boldsymbol{g})\right.\right. \\
\left.\left.-\left(\boldsymbol{X}_{\gamma}^{\prime}(\boldsymbol{\theta}-\boldsymbol{g})\right)^{\prime}\left(\left(\frac{1}{\sigma_{e}^{2}}+\frac{1}{c}\right) \boldsymbol{X}_{\gamma}^{\prime} \boldsymbol{X}_{\gamma}\right)^{-1} \boldsymbol{X}_{\gamma}^{\prime}(\boldsymbol{\theta}-\boldsymbol{g})\right]\right\} \\
\prod_{l=1}^{p} \omega^{\gamma_{l}}(1-\omega)^{1-\gamma_{l}}
\end{array}
$$

Dessa forma, para uma proposta $\gamma^{*}$, calcula-se sua probabilidade de aceitação para o passo MH por

$$
\begin{aligned}
\rho\left(\boldsymbol{\gamma}^{*}, \boldsymbol{\gamma}^{r}\right)= & \min \left\{\operatorname { e x p } \left[\frac { 1 } { 2 } ( \frac { 1 } { \sigma _ { e } ^ { 2 } } + \frac { 1 } { c } ) ^ { - 1 } ( \boldsymbol { \theta } - \boldsymbol { g } ) ^ { \prime } \left(\boldsymbol{X}_{\gamma^{*}}\left(\boldsymbol{X}_{\gamma^{*}}^{\prime} \boldsymbol{X}_{\gamma^{*}}\right) \boldsymbol{X}_{\gamma^{*}}^{\prime}-\right.\right.\right. \\
& \left.\left.\boldsymbol{X}_{\gamma^{r}}\left(\boldsymbol{X}_{\gamma^{r}}^{\prime} \boldsymbol{X}_{\gamma^{r}}\right) \boldsymbol{X}_{\gamma^{r}}^{\prime}\right)(\boldsymbol{\theta}-\boldsymbol{g})\right] \\
& \left.\left(\frac{c+\sigma_{e}^{2}}{\sigma_{e}^{2}}\right)^{\sum_{l=1}^{p}\left(\gamma_{l}^{*}-\gamma_{l}^{r}\right)}\left(\frac{\omega}{1-\omega}\right)^{\sum_{l=1}^{p}\left(\gamma_{l}^{*}-\gamma_{l}^{r}\right)}, 1\right\}
\end{aligned}
$$

e um novo valor para o vetor $\gamma^{(r+1)}$ é escolhido como o último valor aceito após um número especificado de iterações do passo MH dentro do amostrador de Gibbs.

Nem sempre é apropriado impor a mesma escala e estrutura presente nas covariáveis para os efeitos (Guan et al., 2011). Além disso, a matriz $\boldsymbol{X}^{\prime} \boldsymbol{X}$ pode ser singular por conta de eventuais multicolinearidades. Como uma solução, Baragatti e Pommeret (2011) modificam a estrutura de 
covariâncias a priori para

$$
\Sigma(c, \lambda, \gamma)=c \boldsymbol{X}_{\gamma}^{\prime} \boldsymbol{X}_{\gamma}+\lambda I_{m},
$$

$I_{m}$ é a matriz identidade de ordem $m$ e $\lambda$ é um parâmetro a ser fixado arbitrariamente. Note que temos trivialmente a $g$-prior para $\lambda=0$ e a priori independente $\operatorname{com} c=0$, e que $c$ nessa priori é o inverso da constante da $g$-prior usada anteriormente.

Sob essa estrutura, assume-se

$$
\boldsymbol{\beta} \mid \boldsymbol{\gamma}, \Sigma(c, \lambda, \gamma) \sim N_{m}\left(0, \Sigma^{-1}(c, \lambda, \gamma)\right) .
$$

A condicional completa para $\boldsymbol{\beta}_{\gamma}$ (3.28) é a mesma, mas com

$$
\boldsymbol{V}_{\gamma}=\left(\frac{1}{\sigma_{e}^{2}}+c\right) \boldsymbol{X}_{\gamma}^{\prime} \boldsymbol{X}_{\gamma}+\lambda I_{m}
$$

no lugar da matriz de covariâncias (3.26).

Da mesma forma, a marginal para $\gamma$ muda para

$$
\pi(\gamma \mid \cdot) \propto \sqrt{\frac{|\Sigma(c, \lambda, \gamma)|}{\left|V_{\gamma}\right|}} \exp \left\{-\frac{1}{2}\left(\boldsymbol{\mu}_{\gamma}^{\prime} V_{\gamma}^{-1} \boldsymbol{\mu}_{\gamma}\right)\right\} \prod_{l=1}^{p} \omega^{\gamma_{l}}(1-\omega)^{1-\gamma_{l}},
$$

e $\boldsymbol{\mu}_{\gamma}$ é dado por (3.27).

A probabilidade de aceitação do vetor $\gamma^{*}$ é dada por

$$
\begin{array}{r}
\rho\left(\boldsymbol{\gamma}^{*}, \boldsymbol{\gamma}^{(r)}\right)=\min \left\{1, \sqrt{\frac{\left|V_{\gamma^{*}}\right|\left|\Sigma\left(c, \lambda, \gamma^{(r)}\right)\right|}{\left|V_{\gamma^{(r)}}\right|\left|\Sigma\left(c, \lambda, \gamma^{*}\right)\right|}} \exp \left\{\frac { 1 } { 2 \sigma _ { e } ^ { 4 } } \left[( \boldsymbol { \theta } - \boldsymbol { g } ) ^ { \prime } \left(\boldsymbol{X}_{\gamma^{*}}^{\prime} V_{\gamma^{*}}^{-1} \boldsymbol{X}_{\gamma^{*}}-\right.\right.\right.\right. \\
\left.\left.\left.\left.-\boldsymbol{X}_{\gamma^{(r)}}^{\prime} V_{\gamma^{(r)}}^{-1} \boldsymbol{X}_{\gamma^{(r)}}\right)(\boldsymbol{\theta}-\boldsymbol{g})\right]\right\}\left(\frac{\omega}{1-\omega}\right)^{\sum_{l=1}^{p}\left(\gamma_{l}^{*}-\gamma_{l}^{r}\right)}\right\} .
\end{array}
$$

O movimento no espaço dos modelos possíveis utilizando o passo $\mathrm{MH}$ fornece uma alternativa flexível às condicionais completas de George e McCulloch (1993). Com condicionais completas, o número de covariáveis no modelo a cada passo $m$ muda de uma iteração para a outra. Para $p$ elevado, isso pode causar lentidão no processo de estimação quando $d$ se torna muito elevado, demandando cuidado na escolha dos hiperparâmetros de maneira a privilegiar modelos esparsos.

Uma solução exposta em Baragatti (2011) e que é adotada no presente trabalho é manter $d$ constante a cada iteração e gerar propostas $\gamma^{*}$ sorteando-se $s \leq m$ índices para serem excluidos a cada passo e $s$ índices nos $p-m$ índices nulos de $\gamma^{(r)}$ para serem incluídos no próximo passo.

Essa heurística resulta em uma densidade de proposta simétrica que gera um vetor $\gamma^{\prime}$ tendo apenas uma componente alterada $(s=1)$ com probabilidade

$$
q\left(\gamma^{\prime} \mid \gamma^{(r)}\right)=\frac{1}{m(p-m)},
$$

de forma que gera-se o vetor de propostas $\gamma^{*}$ repetindo a proposta (3.36) $s$ vezes em sucessivos vetores $\gamma^{\prime}$ sem reposição. Outras operações podem ser utilizadas para a geração de propostas. Algumas propostas podem ser encontradas em Kwon et al. (2011).

O controle sobre o tamanho do modelo de regressão em cada passo permite maior controle sobre o custo computacional do processo de seleção de variáveis, além disso, o tamanho constante simplifica os dois últimos membros da taxa de aceitação (3.31), efetivamente eliminando a influência do hiperparâmetro $\omega$ sobre as propostas. O número de variáveis trocadas em cada passo foi controlado para obter uma taxa de aceitação ao longo dos passos MH entre 0, 5 e 0, 8. Simulações preliminares indicaram que o valor $s=1$ é capaz de produzir essas taxas para diversos valores de $m$. 
Ainda estamos interessados na inferência sobre o vetor de efeitos fixos, então, após a seleção de um novo vetor de indicadores $\gamma$, amostramos o vetor de efeitos, resultando na condicional conjunta

$$
\pi\left(\beta_{\gamma}, \gamma \mid \cdot\right) \propto \pi(\gamma \mid \cdot) \pi\left(\beta_{\gamma} \mid \gamma, \cdot\right),
$$

resultando no amostrador de Gibbs colapsado parcialmente (van Dyk e Park, 2008). O vetor de indicadores é amostrado antes do vetor $\boldsymbol{\beta}$ para preservar a estrutura de dependência na cadeia.

Com a introdução do passo de escolha de covariáveis no amostrador, temos um processo de estimação de parâmetros em três níveis: o nível funcional das respostas dos indivíduos aos fenótipos, o nível estrutural das famílias e o nível de escolha de covariáveis. Por simplicidade, resume-se o amostrador no fluxograma exposto na Figura 3.2.

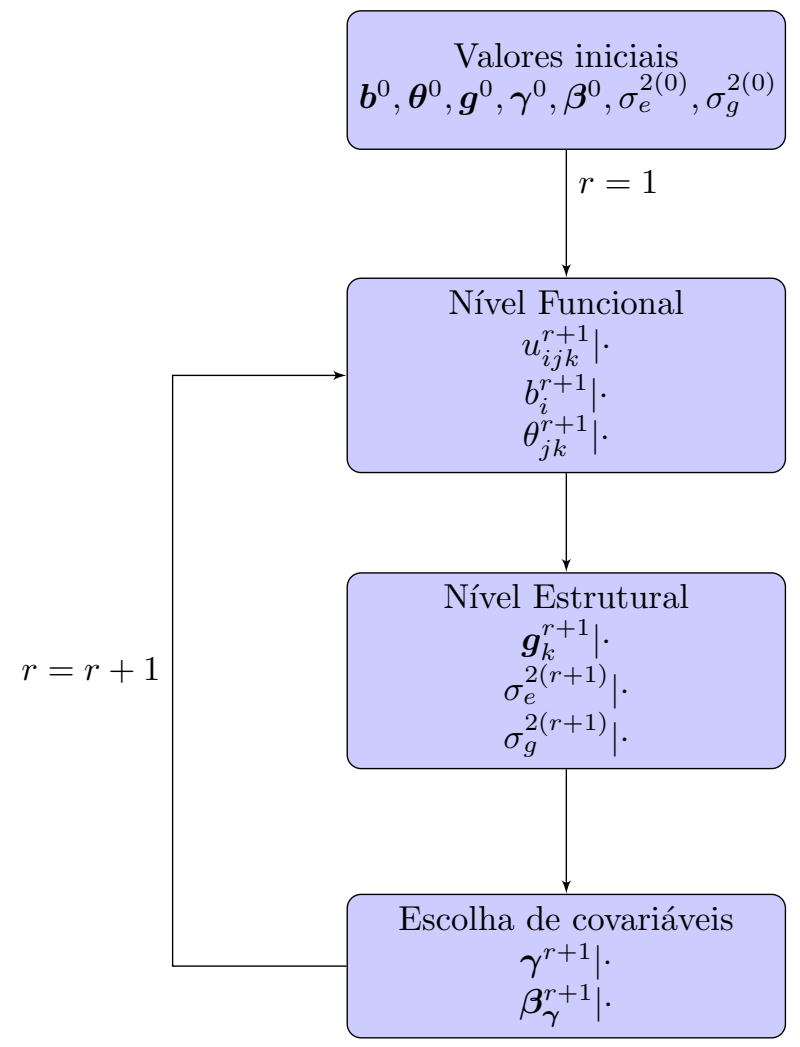

Figura 3.2: Amostrador de Gibbs proposto para os parâmetros do modelo multiniveis e seleção de covariáveis

\subsection{Estudo de simulação}

O método de seleção de variáveis foi avaliado através de uma série de estudos de simulação com o objetivo de avaliar a capacidade dos mesmos de recuperar as covaríáveis simuladas sob o modelo multinível.

Assim como nas simulações do capítulo anterior, utilizou-se a estrutura familiar da amostra do estudo "Corações de Baependi" (Oliveira et al., 2008). Na presente simulação, utilizamos os $K=95$ pedigrees de uma amostra de $N=2.318$ indivíduos contendo os indivíduos medidos ou apenas reportados como parte da família. As famílias apresentam tamanhos de 1 a 203, com uma média de 25 indivíduos por família e mediana de 17 indivíduos por família.

Covariáveis foram simuladas com o objetivo de emular dados de marcadores, estes localizados em diversas posições ${ }^{11}$ de um único cromossomo. Doravante, marcadores são utilizados de forma intercambiável assim como locus e índice da covariável.

\footnotetext{
${ }^{11}$ denominadas locus (plural: loci), do latim para lugar
} 
Tabela 3.1: Efeitos e frequências alélicas para a Simulação 3

\begin{tabular}{rrr}
\hline Marcador & Efeito & Frequência \\
\hline 1 & $-1,25$ & $1 \%$ \\
2 & $-1,00$ & $5 \%$ \\
3 & $-0,75$ & $10 \%$ \\
4 & $-0,50$ & $20 \%$ \\
5 & $-0,25$ & $25 \%$ \\
6 & 0,25 & $1 \%$ \\
7 & 0,50 & $5 \%$ \\
8 & 0,75 & $10 \%$ \\
9 & 1,00 & $20 \%$ \\
10 & 1,25 & $25 \%$
\end{tabular}

Utilizando o programa SimPed (Leal et al., 2005), $p=1.000$ e 10.000 marcadores foram simulados utilizando-se a estrutura familiar resultando em uma matriz $N \times p$ utilizada nas simulações. Algumas simplificações foram feitas nesse passo. Assumimos que cada um dos marcadores é independente dos demais e que não houveram eventos de recombinação ou mutação na transmissão dos marcadores ao longo das famílias. Os marcadores foram então codificados como 0, 1 ou 2 indicando a quantidade do alelo em cada indivíduo. A frequência do alelo foi fixada para os 5 primeiros marcadores em $1 \%, 5 \%, 10 \%, 20 \%$ e $25 \%$ e esse padrão foi repetido $\frac{p}{5}-1$ vezes para simular o resto dos marcadores.

Os efeitos poligênicos (variável $\boldsymbol{g}$ no modelo (3.11)) foram simulados utilizando-se a distribuição normal multivariada centrada na origem e com covariância dada em (2.6) e os efeitos residuais (variável $\boldsymbol{e}$ no modelo (3.11)) foram simulados da normal multivariada (2.5). As componentes da variância foram fixadas em $\sigma_{e}^{2}=1$ e $\sigma_{g}^{2}=1$, resultando em uma herdabilidade de $h^{2}=0,5$.

Com respeito ao vetor de efeitos dos marcadores $\boldsymbol{\beta}$, três cenários foram simulados.

- Simulação 1: investigou-se a presença de falsos positivos tomando-se $\boldsymbol{\beta}=\mathbf{0}$

- Simulação 2: os 5 primeiros marcadores foram assumidos como loci associados sobre o traço latente com efeito $\beta_{l}=1, l=1, \cdots, 5$ representando loci com grandes efeitos e os 5 subsequentes foram assumidos com efeitos menores de $\beta_{l}=0,25, l=6, \cdots, 10$ e efeito nulo nas demais $\left(\beta_{l}=\mathbf{0}\right.$ para $\left.l>10\right)$.

- Simulação 3: os 10 primeiros marcadores foram assumidos como atuantes sobre o traço latente, com vetor de efeitos dado pelos valores indicados na Tabela 3.1, de maneira a alternar o tamanho dos efeitos e as frequências alélicas. Assim como no cenário anterior, o restante das covariáveis não teve efeito sobre o traço latente.

O traço latente para cada indivíduo (variável $\boldsymbol{\theta}$ no modelo (3.11)) foi então simulado somandose o preditor linear $\boldsymbol{X} \boldsymbol{\beta}$ e os efeitos aleatórios. Com os traços latentes, a resposta a cada um dos $I=5$ itens com parâmetros de locação $\boldsymbol{b}=(-2,-1,0,1,2)$ foi simulada utilizando-se uma amostra da distribuição de Bernoulli com probabilidade de sucesso dada pelo modelo de Rasch (2.2). O procedimento encontra-se ilustrado na Figura 3.3.

A seleção de variáveis foi então feita utilizando-se o LASSO Bayesiano e o SSVS para o caso $p=1.000$ e apenas o SSVS para o caso $p=10.000$, pois o LASSO Bayesiano se mostrou lento demais para obtermos um número razoável de passos na cadeia de Markov.

Para o SSVS, seis configurações do método foram aplicadas. Foram assumidas duas distribuições a priori para o vetor de efeitos fixos. Utilizamos a $g$-prior (Zellner, 1986) mencionada anteriormente com $c=N$ e a matriz identidade, representando $\beta_{l} \sim N(0,1)$, de maneira a não impor sobre os efeitos a mesma escala e estrutura de covariâncias dos marcadores (Guan et al., 2011). Além disso, utilizamos $m=5,10$ e 30 como o número de covariáveis em cada passo do amostrador, representado (no caso com 10 efeitos) uma estimativa conservadora, exata e liberal para o número de marcadores 


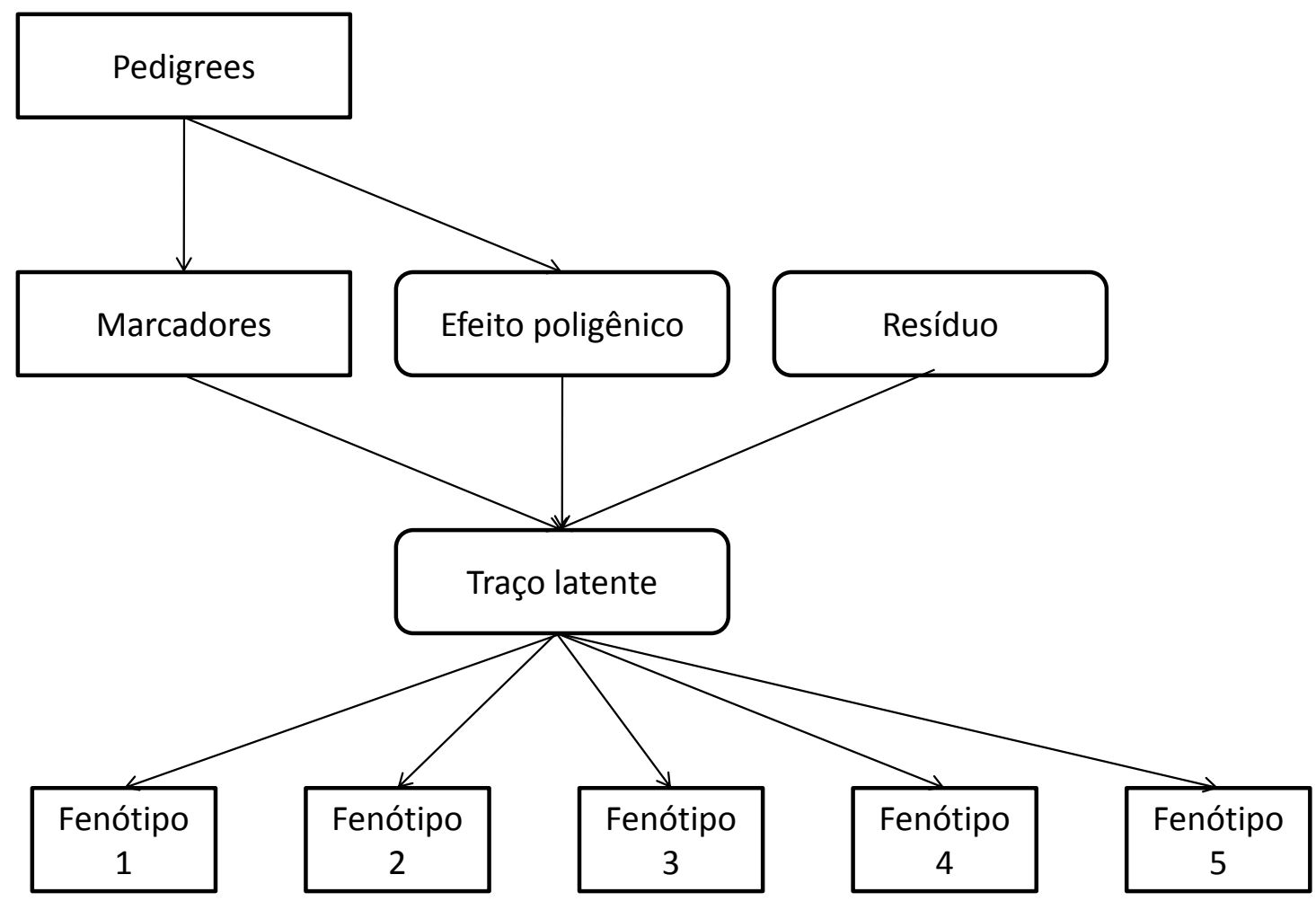

Figura 3.3: Simulação dos dados para a seleção de variáveis. Retângulos representam dados utilizados como entrada no método de estimação, retângulos arredondados indicam variáveis aleatórias simuladas. 
envolvidos. Ainda utilizamos 10 passos para o passo de aceitação, pois simulações preliminares não mostraram diferença em número de iterações maiores. O número de iterações do método MCMC foi de $R=100.000$, e convergência foi observada nos históricos das cadeias dos parâmetros monitorados.

\subsubsection{Simulação 1}

Primeiramente, avaliamos a produção de falsos positivos dos métodos de seleção de variáveis. Na ausência de efeitos fixos $\left(\boldsymbol{\beta}=\mathbf{0}_{p}\right)$, simulações foram realizadas para $p=10^{3}$ e $p=10^{4}$ marcadores utilizando-se o programa SimPed.

Para $p=10^{3}$, utilizando-se o SSVS podemos observar as probabilidades de aceitação para as duas escolhas de priori para os efeitos nas Figuras 3.4 e 3.5. Pode-se observar em ambas a figuras que o modelo apropriadamente não encontra nenhuma variável, com um número diminuto de falsos positivos nos casos com $m=30$, apenas um na simulação com a $g$-prior e dois no caso com os efeitos independentes a priori.

Também aplicou-se o LASSO Bayesiano no mesmo conjunto de dados, e as estimativas dos efeitos (que utilizamos para a seleção de variáveis no LASSO) utilizando-se os dois métodos podem ser observadas nas Figuras 3.6 e 3.7 para as duas configurações de prioris. Pode-se observar estimativas bem pequenas com o eventual efeito diminuto estimado pelo LASSO Bayesiano, que poderia ser confundido com um positivo. Em todas as configurações, contudo, os efeitos são estimados em valores bem próximos de zero.

Para $p=10^{4}$, o LASSO Bayesiano não conseguiu obter um número adequado de amostras em um tempo computacional viável, então apenas o SSVS foi aplicado. Os gráficos com as probabilidades de inclusão podem ser observados nas Figuras 3.8 e 3.9 para as duas escolhas de priori. Observa-se que em ambos os casos, não temos falsos positivos para $m=5,10$, mas para a $g$ - prior, $m=30$ gera três falsos positivos.

Estimativas para os efeitos nessa configuração podem ser vistos nas Figuras 3.10 e 3.11. Os dois gráficos são bem similares e indicam que nenhum efeito foi estimado erroneamente para a priori identidade mas, acompanhando os falsos positivos na $g$ - prior, alguns efeitos foram estimados em valores realmente elevados para $m=10$ e, em particular, para $m=30$.

Conclui-se dessa série de simulações que ambos os métodos de seleção geram poucos falsos positivos tendo em vista o número extremamente elevado de covariáveis, tendo o LASSO Bayesiano um desempenho comparável com o SSVS para os casos $m=10$ ou $m=30$. Com respeito ao SSVS, nota-se que o aumento do número de covariáveis em cada passo MCMC aumenta a ocorrência de falsos positivos, o que não é de todo surpreendente tendo em vista o fato de que $m$ covariáveis são colocadas no modelo em cada iteração, possivelmente superestimando suas probabilidades de inclusão.

Observa-se ainda que a frequência alélica das covariáveis não parece influenciar na produção de falsos positivos, pois não observa-se nenhum padrão aparente nos mesmos. A escolha do tamanho de $m$ e da priori no SSVS parece ter um papel muito mais significativo do que qualquer outra mudança nos dados. Nesse sentido, observamos que a $g$-prior parece gerar menos falsos positivos para menos covariáveis, mas aponta mais falsos positivos que uma priori independente para mais covariáveis, possivelmente por correlações espúrias gerando valores elevados na matriz $\boldsymbol{X} \boldsymbol{X}^{\prime}$.

\subsubsection{Simulação 2}

Para a segunda configuração de simulações, imita-se o esquema aplicado em Yi et al. (2003) com respeito aos efeitos e fixam-se 5 efeitos 'maiores' nos primeiros cinco marcadores, fazendo-se $\beta_{i}=1$ para $i=1, \cdots, 5$ e 5 efeitos 'menores' nos cinco subsequentes $\left(\beta_{i}=0.25, i=1, \cdots, 5\right)$, valor nulo nos restantes e configurações como descritas no início da presente sessão.

Os SNPs foram reparametrizados para $X_{j l}=\{-1,0,1\}$ para os $j=1, \cdots, N$ indivíduos e $l=1, \cdots, p$ marcadores, subtraindo-se 1 do número de cópias usual pois o preditor linear levava o traço latente em valores extremamente elevados comparados com as dificuldades, prejudicando a simulação dos dados e o ajuste. 

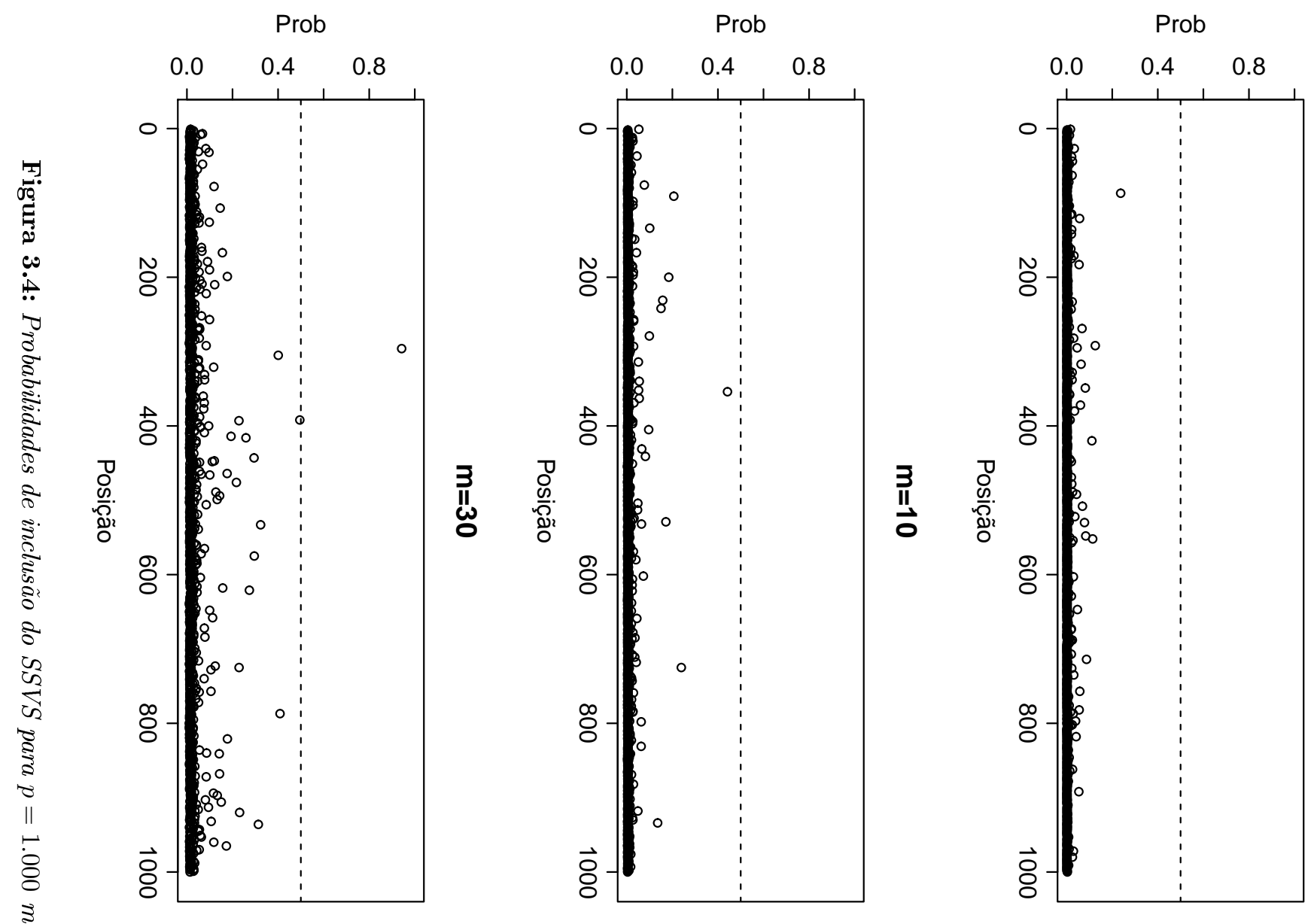

蒠
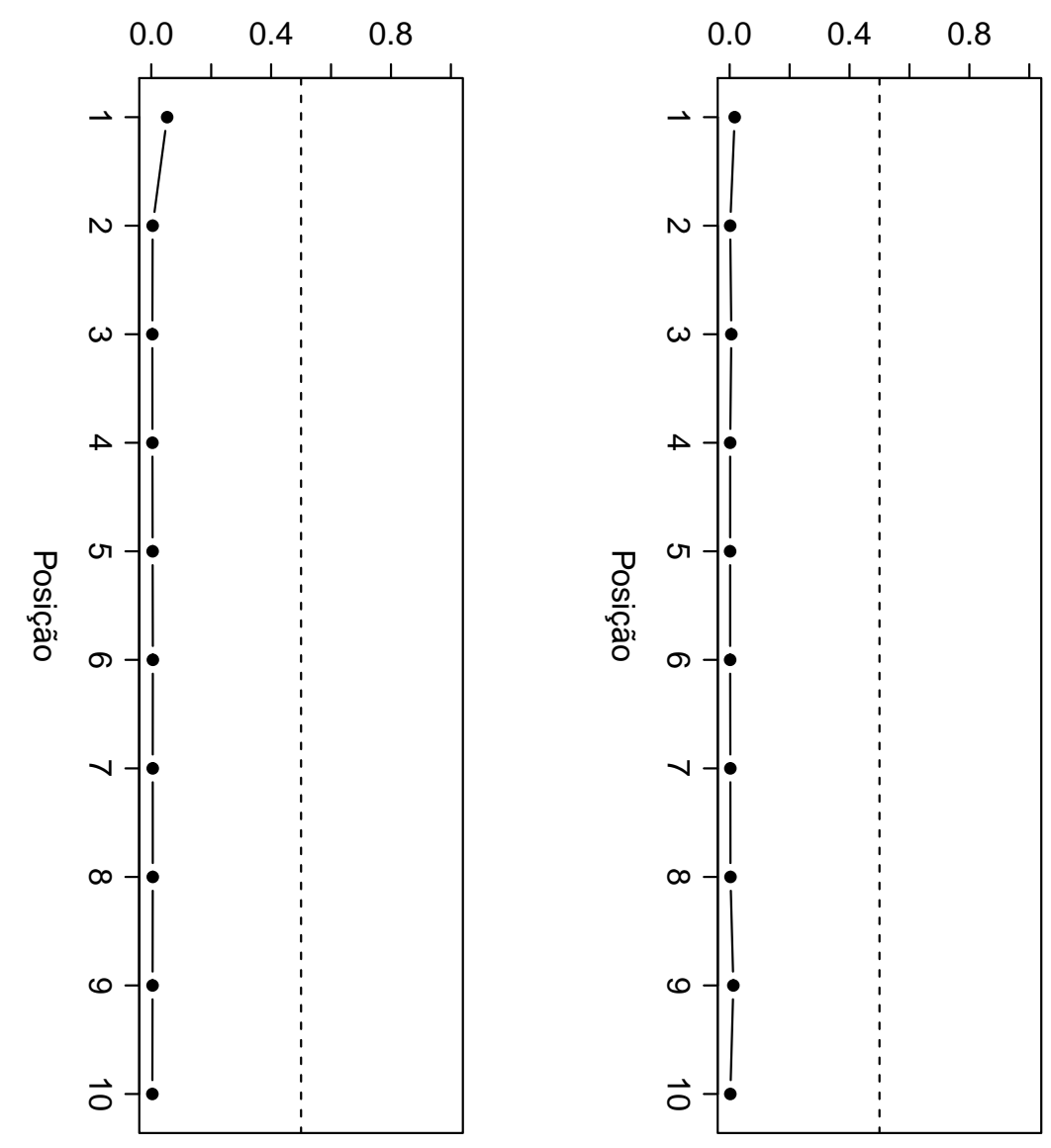

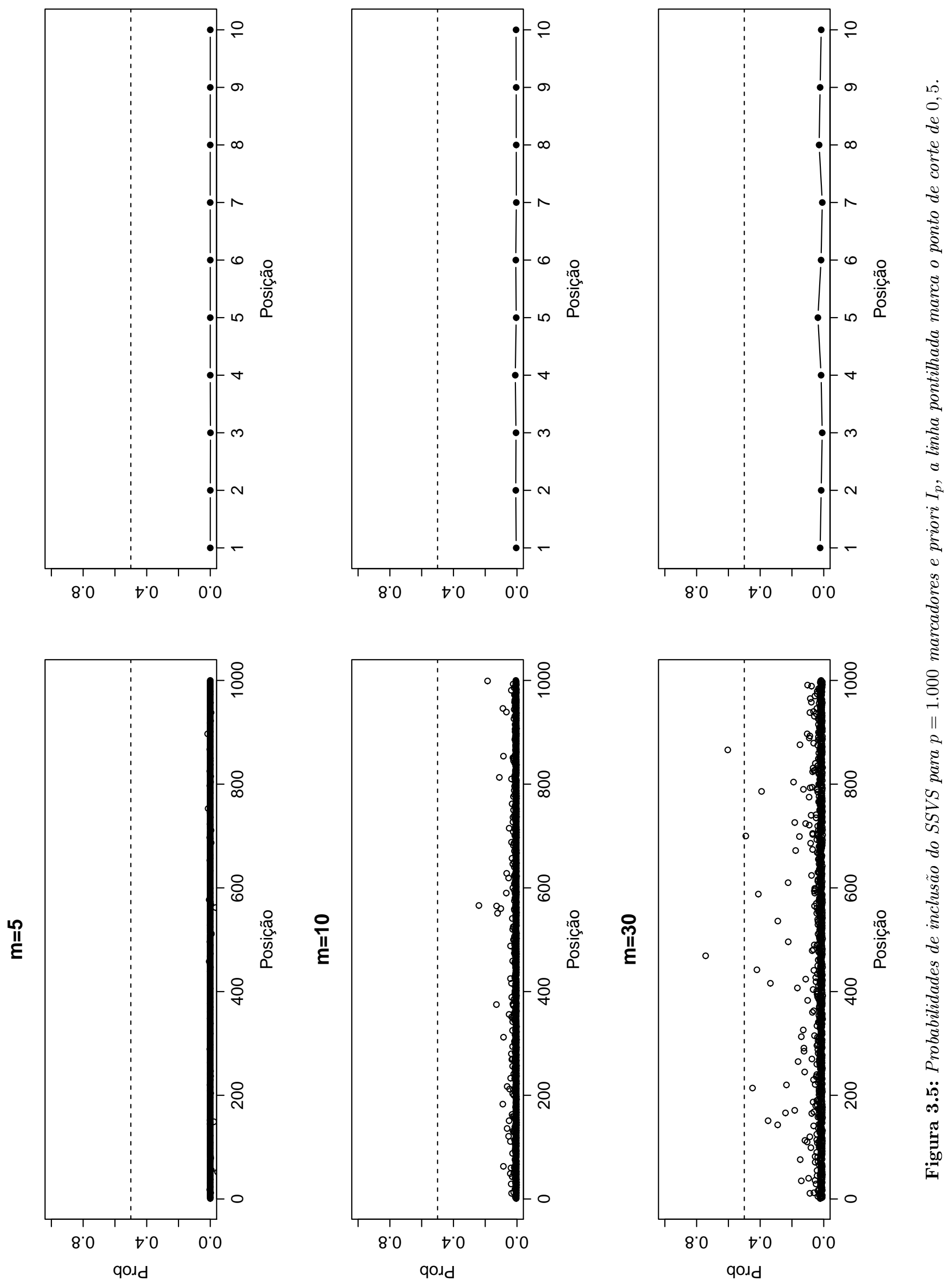

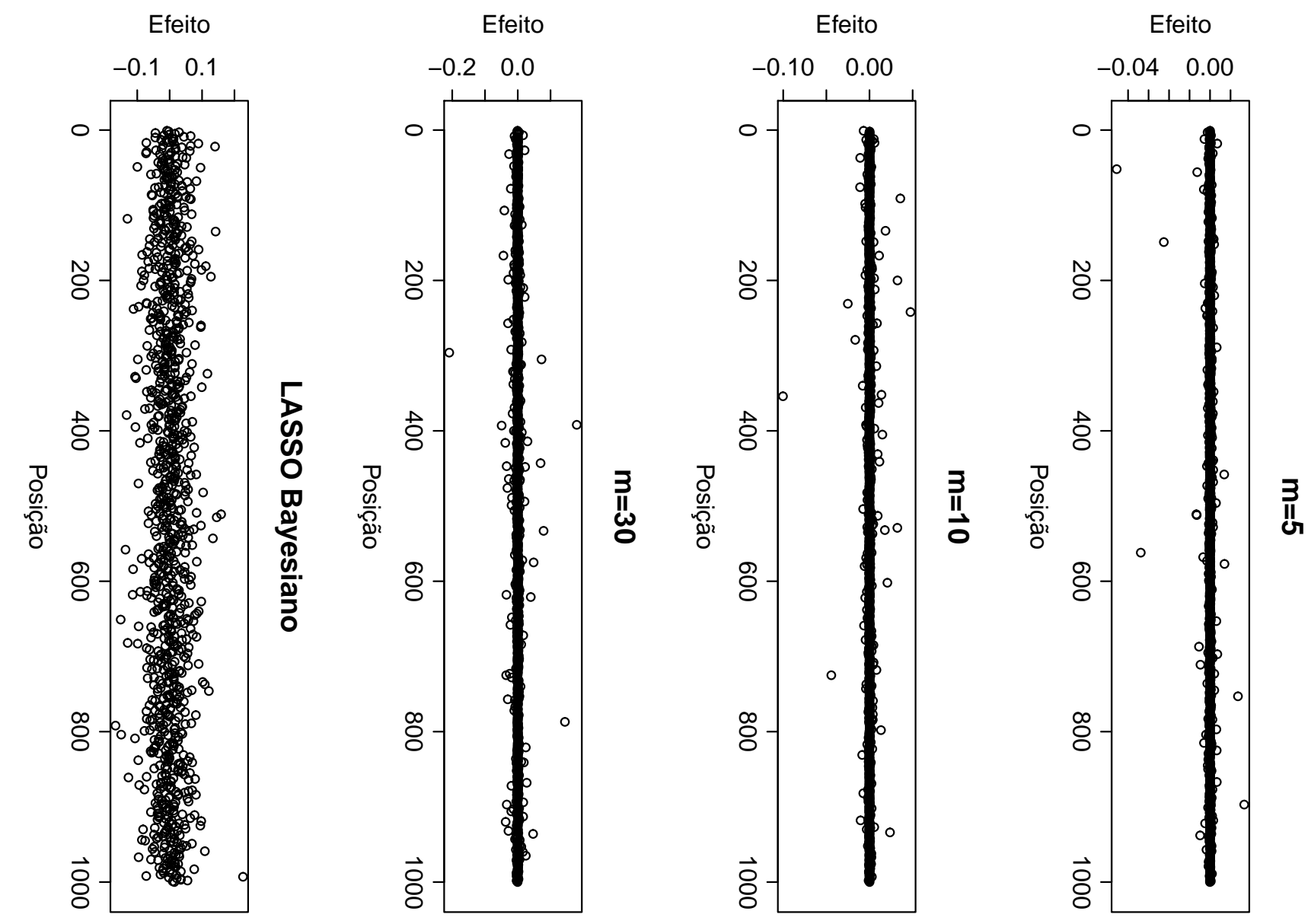

ט
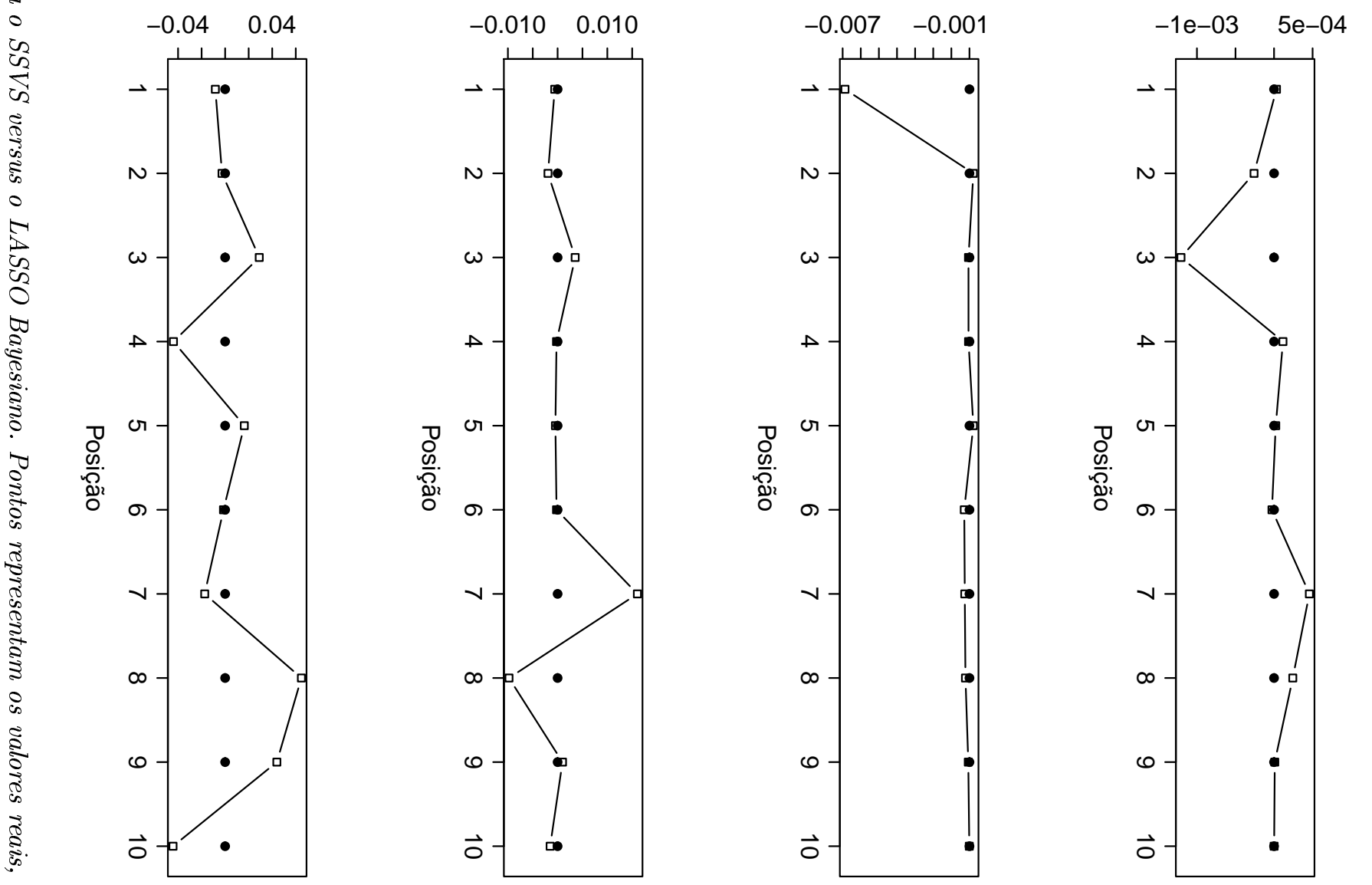

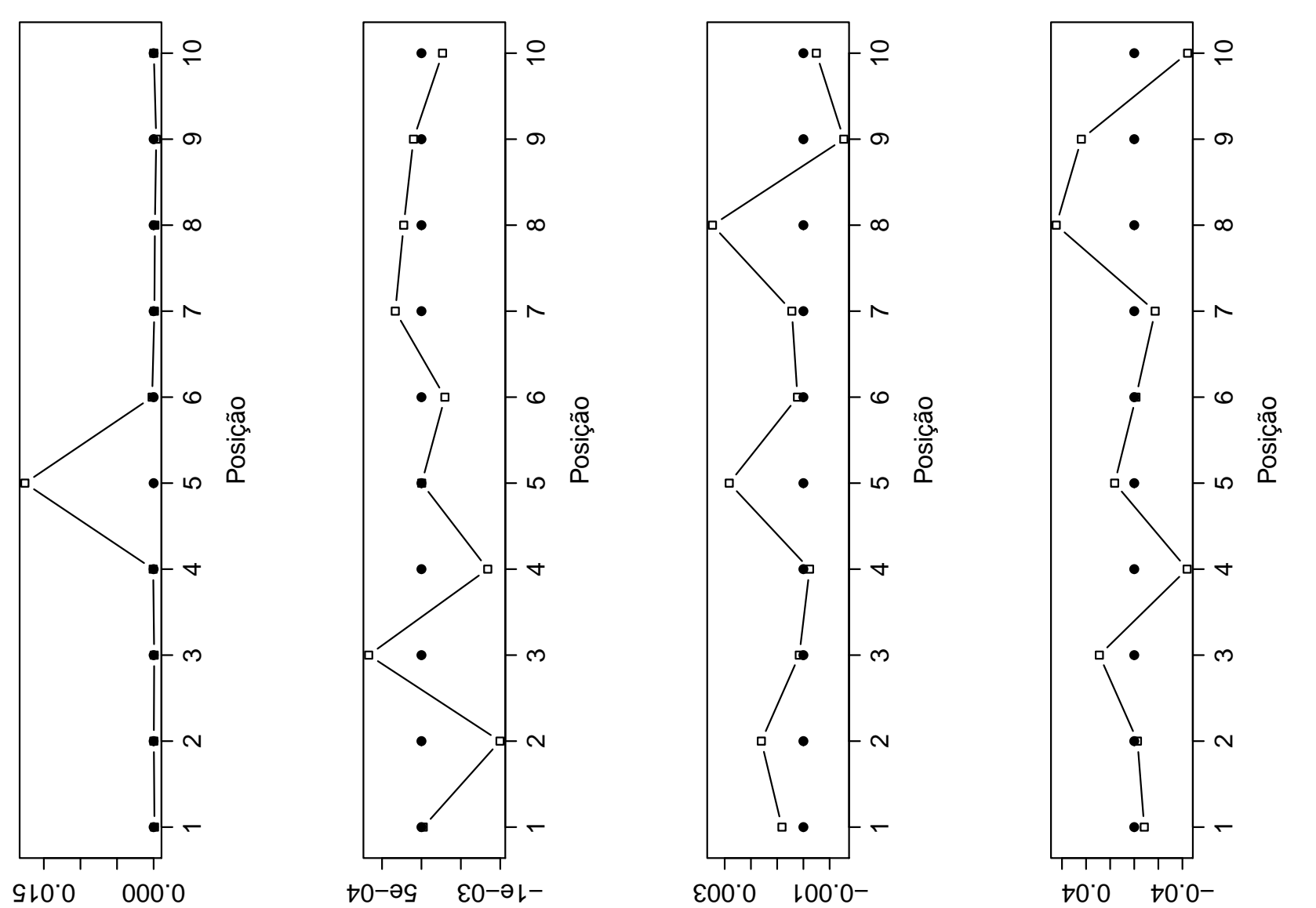

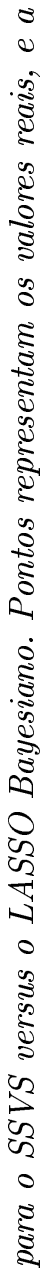
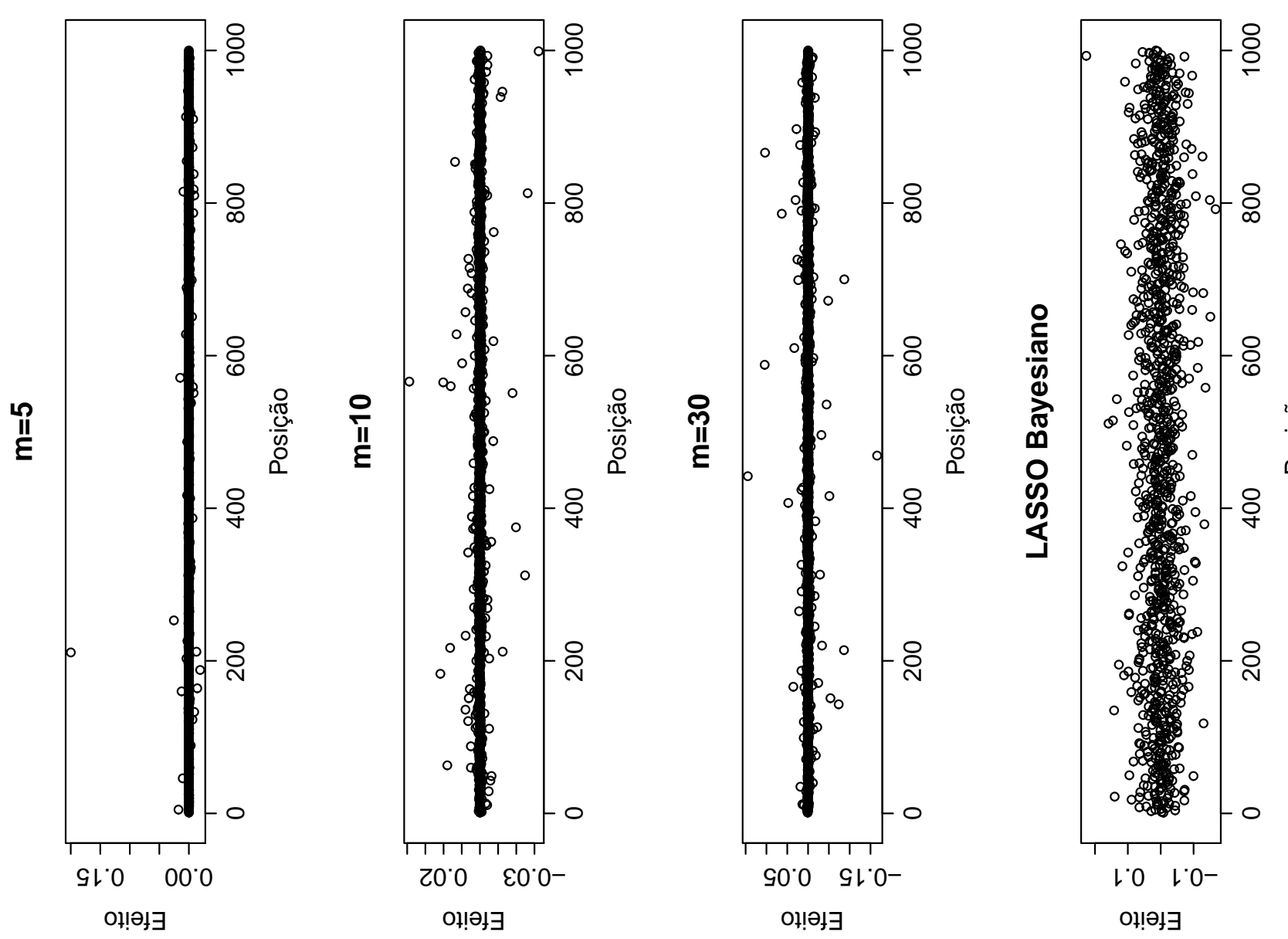

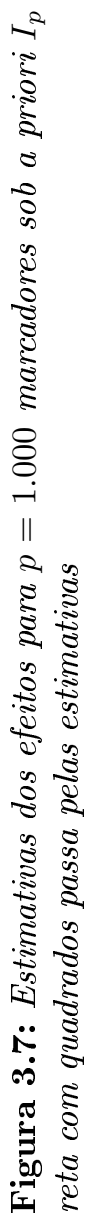



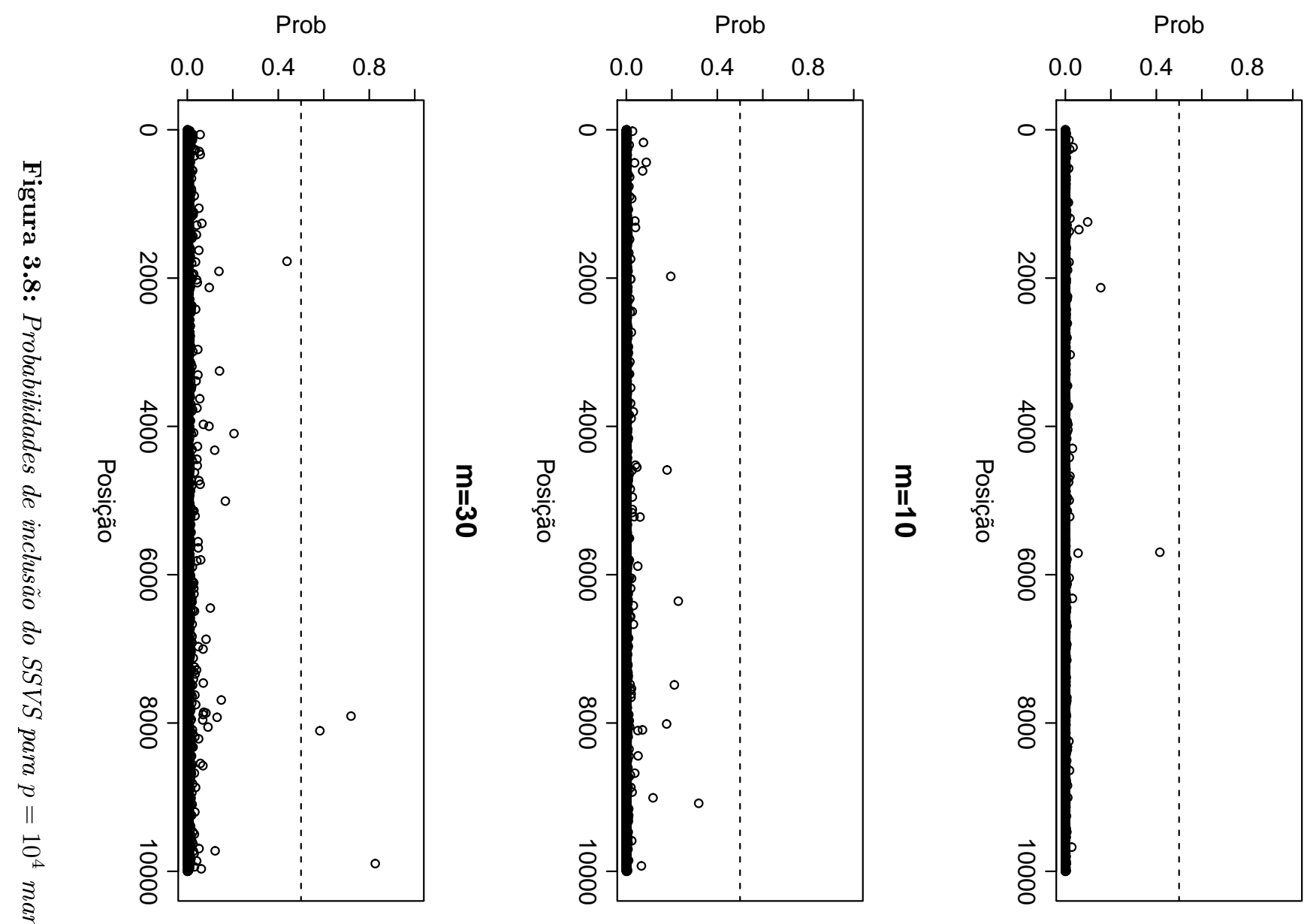

筫
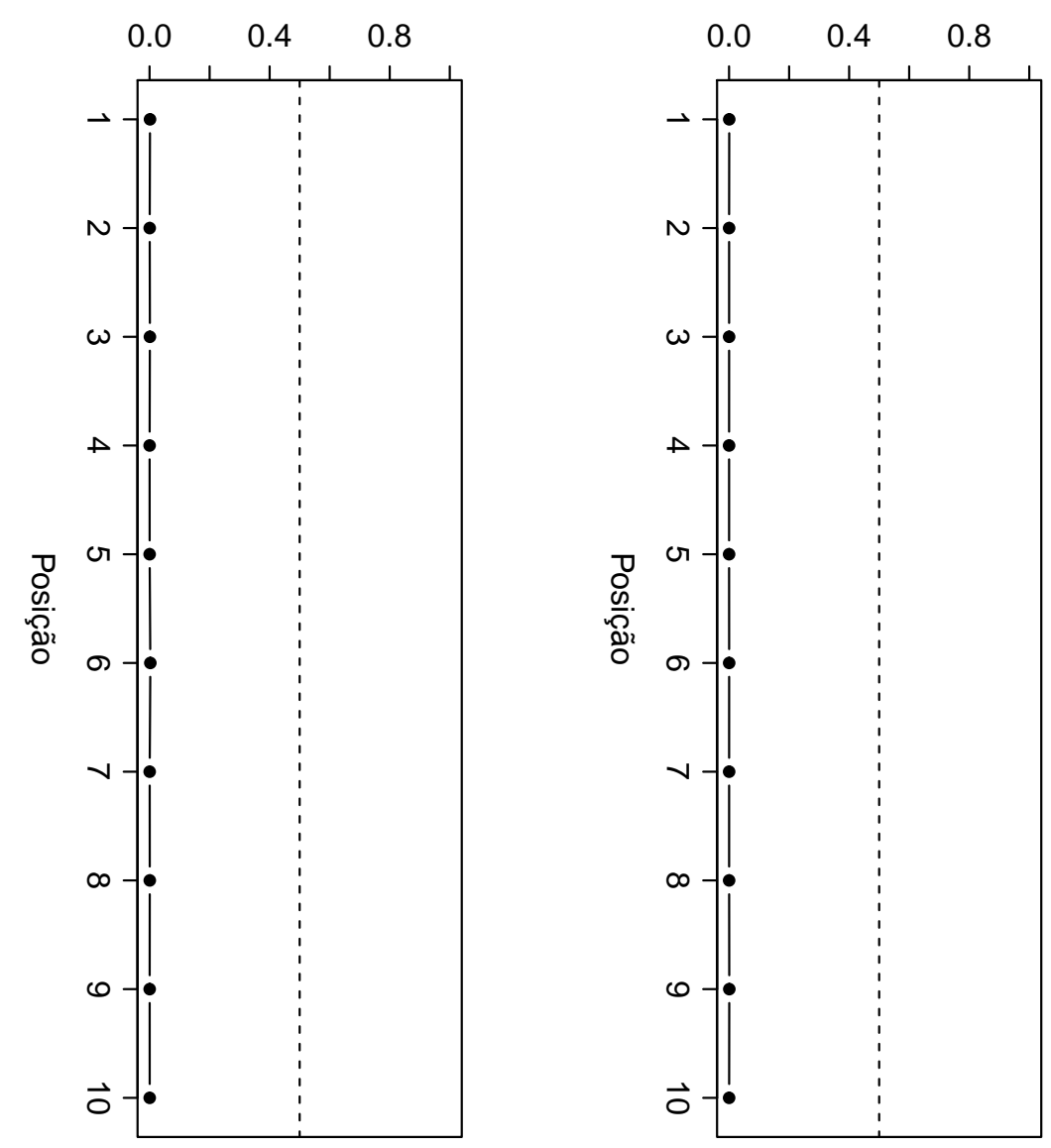

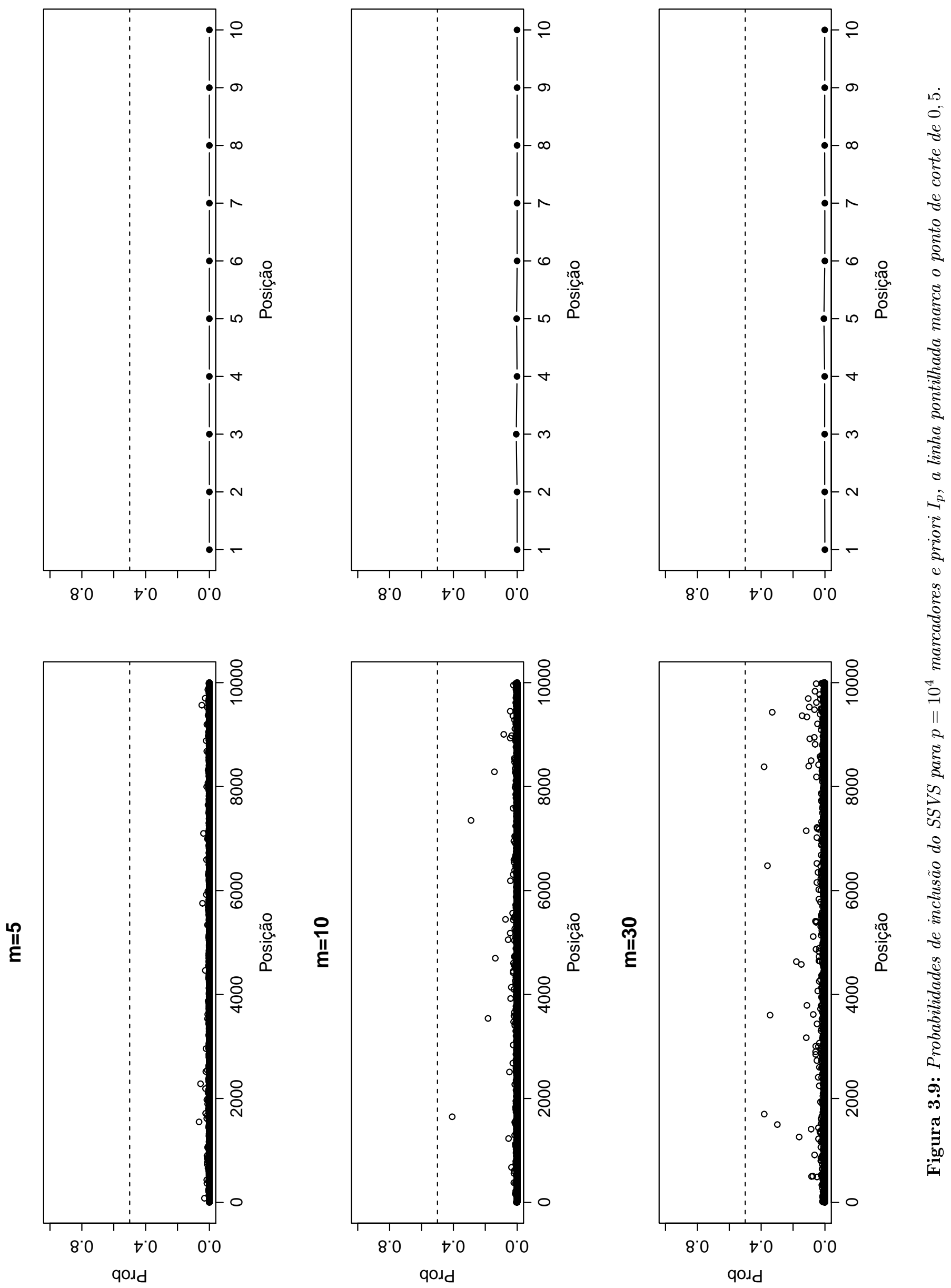

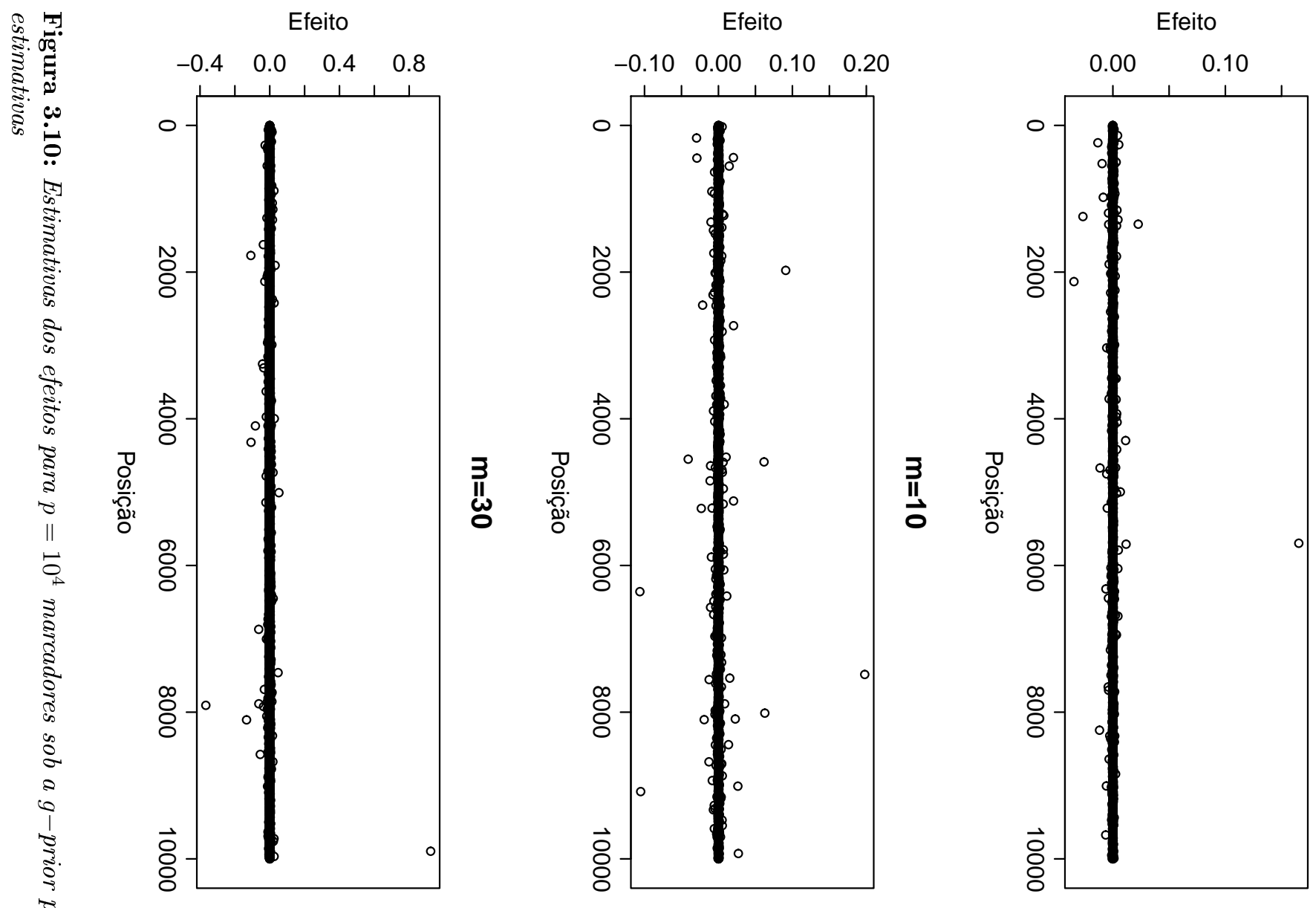

蒠
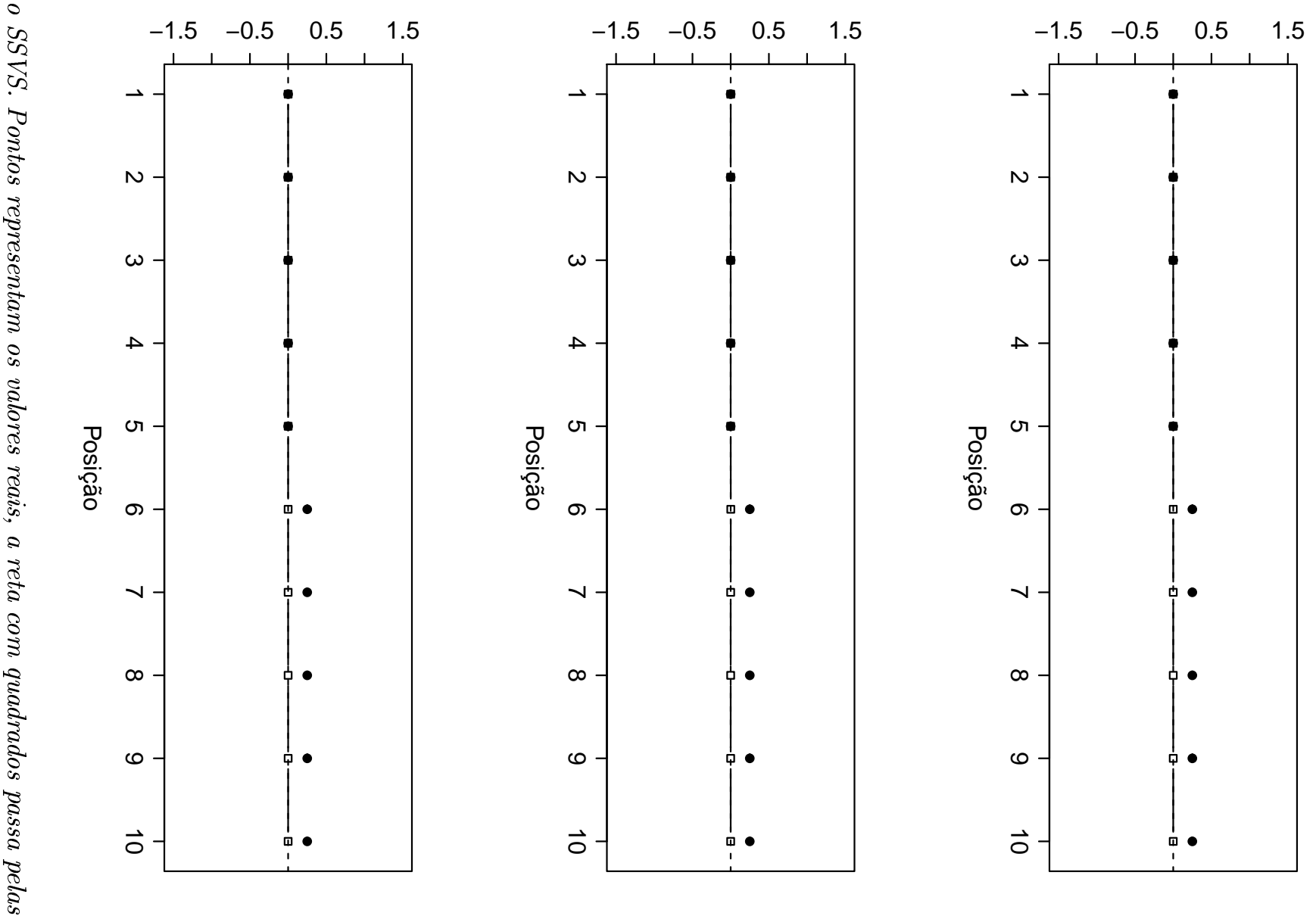

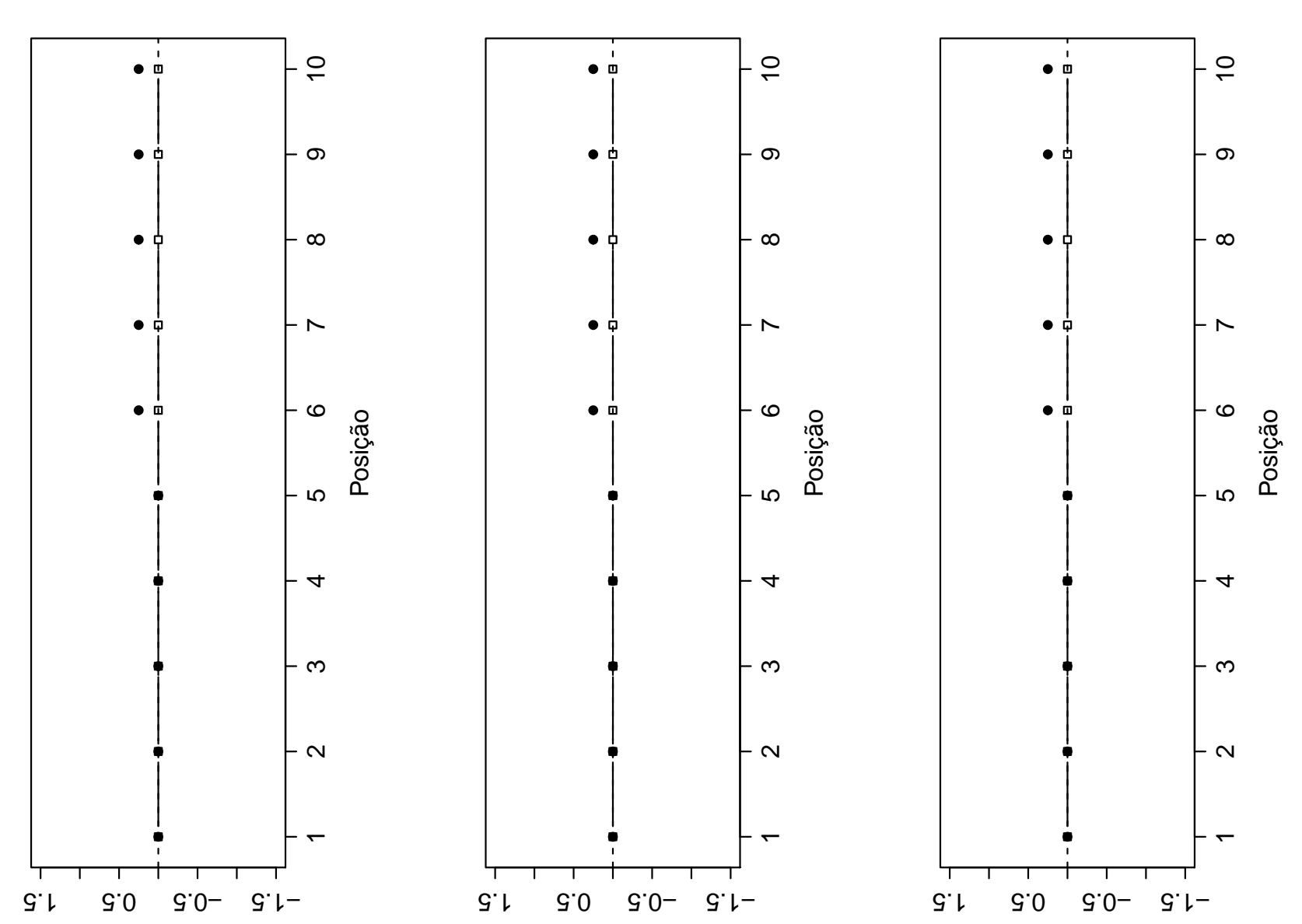

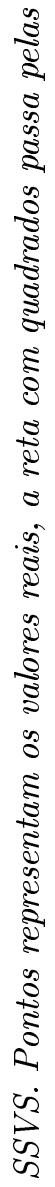
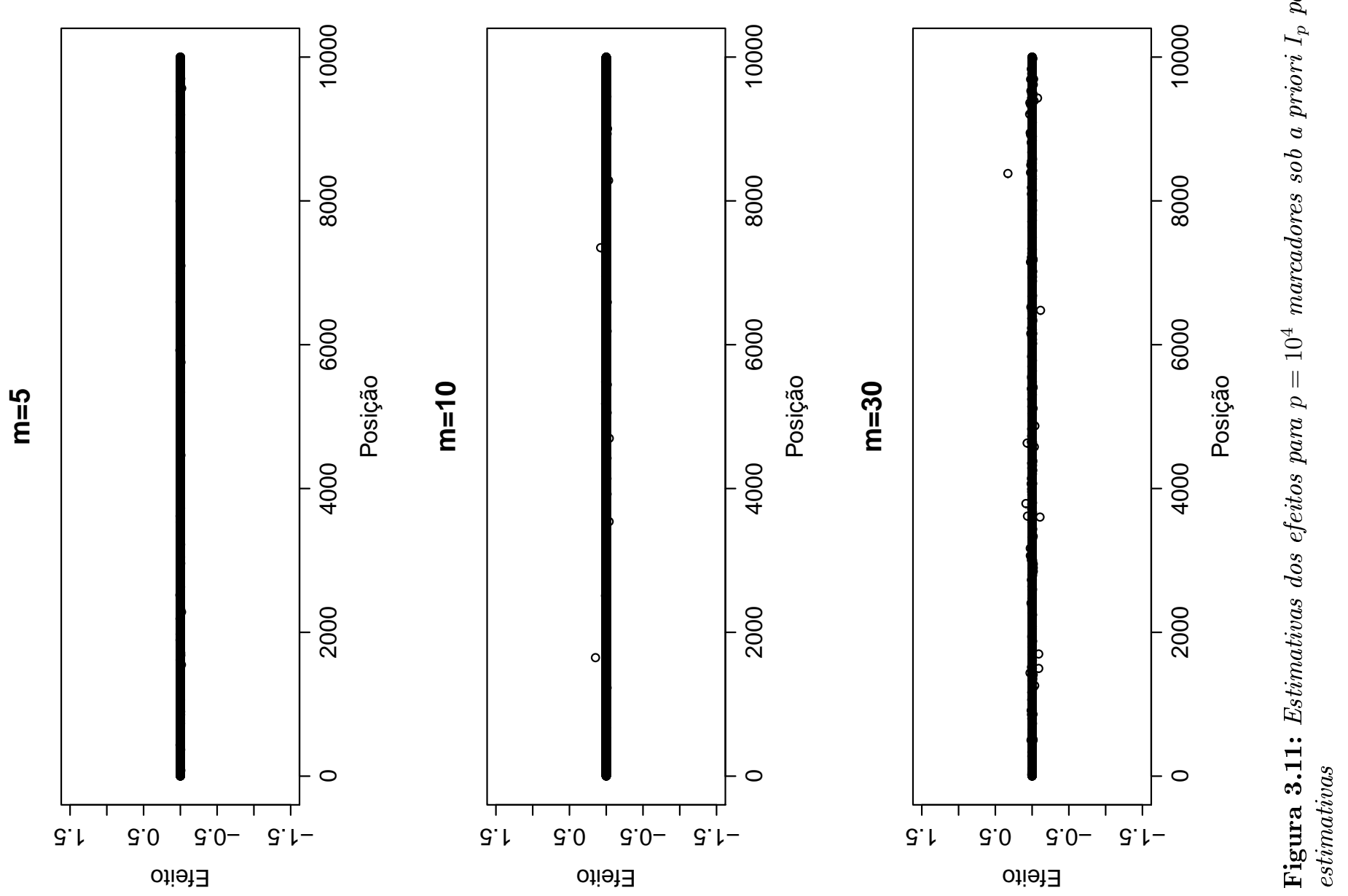
Foram investigados os casos $p=10^{3}, 10^{4}$ utilizando-se o LASSO Bayesiano e o SSVS para o primeiro, e apenas o SSVS para o segundo. O SSVS foi aplicado utilizando $m=5,10,30$ variáveis no modelo em cada passo e duas escolhas de priori para o vetor $\boldsymbol{\beta}$, a $g$-prior e a priori independente. Avaliou-se a capacidade dos métodos em detectar os efeitos e marcadores envolvidos (verdadeiros positivos, falsos negativos) e a existência de evidências espúrias de associação de marcadores sabidamente nulos com o traço latente (falsos positivos).

A aplicação do SSVS resultou nas probabilidades de inclusão vistas nas Figuras 3.12 e 3.13. Podemos observar que os efeitos maiores são encontrados com sucesso em ambas as configurações em oposição aos efeitos menores. Apenas um efeito menor encontrado com $m=10$ e entre um e dois para $m=30$.

Com respeito aos falsos positivos, observamos que a $g$-prior parece identificar menos falsos positivos do que a priori independente, para a qual podemos observar pelo menos 2 pontos acima da linha de $50 \%$ de probabilidade para $m=30$. Selecionando-se variáveis utilizando-se o LASSO, o mesmo estima o efeito de uma variável erroneamente acima de 0,25 e quatro acima de 0,20 .

As estimativas dos efeitos pelo SSVS comparados com o LASSO Bayesiano podem ser vistas nas Figuras 3.14 e 3.15 e mais claramente na Tabela 3.2. Podemos observar que o SSVS estima adequadamente os efeitos maiores para $m=10$ e $m=30$ enquanto o LASSO subestima o efeito 3 , mas estima os outros efeitos menores adequadamente. Com respeito aos efeitos menores, vemos que o SSVS com $m=5$ é incapaz de detectar qualquer um dos efeitos menores, enquanto SSVS e o LASSO detectam entre um e dois dos menores efeitos.

Tabela 3.2: Estimativas dos efeitos para o cenário $p=1.000$ na Simulação 2. $I_{m}$ representa a priori independente, g a g-prior e LASSO o LASSO Bayesiano

\begin{tabular}{rr|rr|rr|rr|r}
\hline & & \multicolumn{2}{|c|}{$m=5$} & \multicolumn{2}{|c|}{$m=10$} & \multicolumn{2}{|c|}{$m=30$} & \\
\hline Efeito & Real & $I_{m}$ & $g$ & $I_{m}$ & $g$ & $I_{m}$ & $g$ & LASSO \\
\hline 1 & 1,00 & 0,91 & 0,96 & 1,09 & 0,99 & 0,87 & 0,95 & 0,91 \\
2 & 1,00 & 1,31 & 1,05 & 0,91 & 0,82 & 0,84 & 1,06 & 1,00 \\
3 & 1,00 & 0,89 & 1,06 & 1,03 & 1,05 & 1,04 & 0,90 & 0,76 \\
4 & 1,00 & 0,93 & 1,01 & 0,98 & 1,19 & 0,97 & 1,08 & 0,96 \\
5 & 1,00 & 0,98 & 1,07 & 0,96 & 1,06 & 1,12 & 0,96 & 1,02 \\
6 & 0,25 & 0,00 & 0,00 & 0,11 & 0,39 & 0,26 & 0,11 & 0,26 \\
7 & 0,25 & 0,00 & 0,00 & 0,00 & 0,00 & 0,01 & 0,00 & $-0,04$ \\
8 & 0,25 & 0,00 & 0,00 & 0,00 & 0,43 & 0,08 & 0,02 & 0,13 \\
9 & 0,25 & 0,00 & 0,00 & 0,00 & 0,00 & 0,23 & 0,37 & 0,08 \\
10 & 0,25 & 0,00 & 0,00 & 0,26 & 0,09 & 0,05 & 0,07 & 0,36 \\
\hline
\end{tabular}

Observa-se outro padrão com $p=10^{4}$. Como visto nas Figuras 3.16 e 3.17, com ambas as prioris, o SSVS tem dificuldades de identificar o efeito 1 (gerado com frequência de $1 \%$ ) nos casos $m=5$ e $m=10$. Com $m=30$, o SSVS encontra os 5 efeitos maiores para a priori identidade, mas não para a $g$ - prior, encontrando apenas 4. Exceto em um único caso, o SSVS não conseguiu encontrar os efeitos menores $\left(m=30, g\right.$ - prior, $\left.P\left(\widehat{\gamma_{9}=1} \mid \boldsymbol{Y}\right)>0,5\right)$.

Com respeito aos falsos positivos, ambas as escolhas de prioris parecem produzir um pequeno número de falsos positivos, tendendo a aumentar com $m$. Temos apenas um em ambos os casos para $m=10$ e $m=30 \mathrm{com}$ a priori independente e dois com a $g$-prior e $m=30$.

As estimativas dos efeitos para $p=10^{4}$ encontram-se nas Figuras 3.18 e 3.19. Como antecipado pelas probabilidades, também observa-se que as estimativas utilizando-se a $g$-prior são piores em todas as configurações do que a priori identidade, com falsos positivos recebendo valores elevados sob a $g$-prior.

Do presente estudo de simulação podemos observar que, assim como Yi et al. (2003), os efeitos pequenos são mais difíceis de identificar, enquanto os efeitos maiores são mais fáceis, especialmente no caso com relativamente menos covariáveis. Podemos observar também que a $g-$ prior parece ser pior no caso com mais covariáveis, sendo incapaz de detectar um dos efeitos maiores, possivelmente 

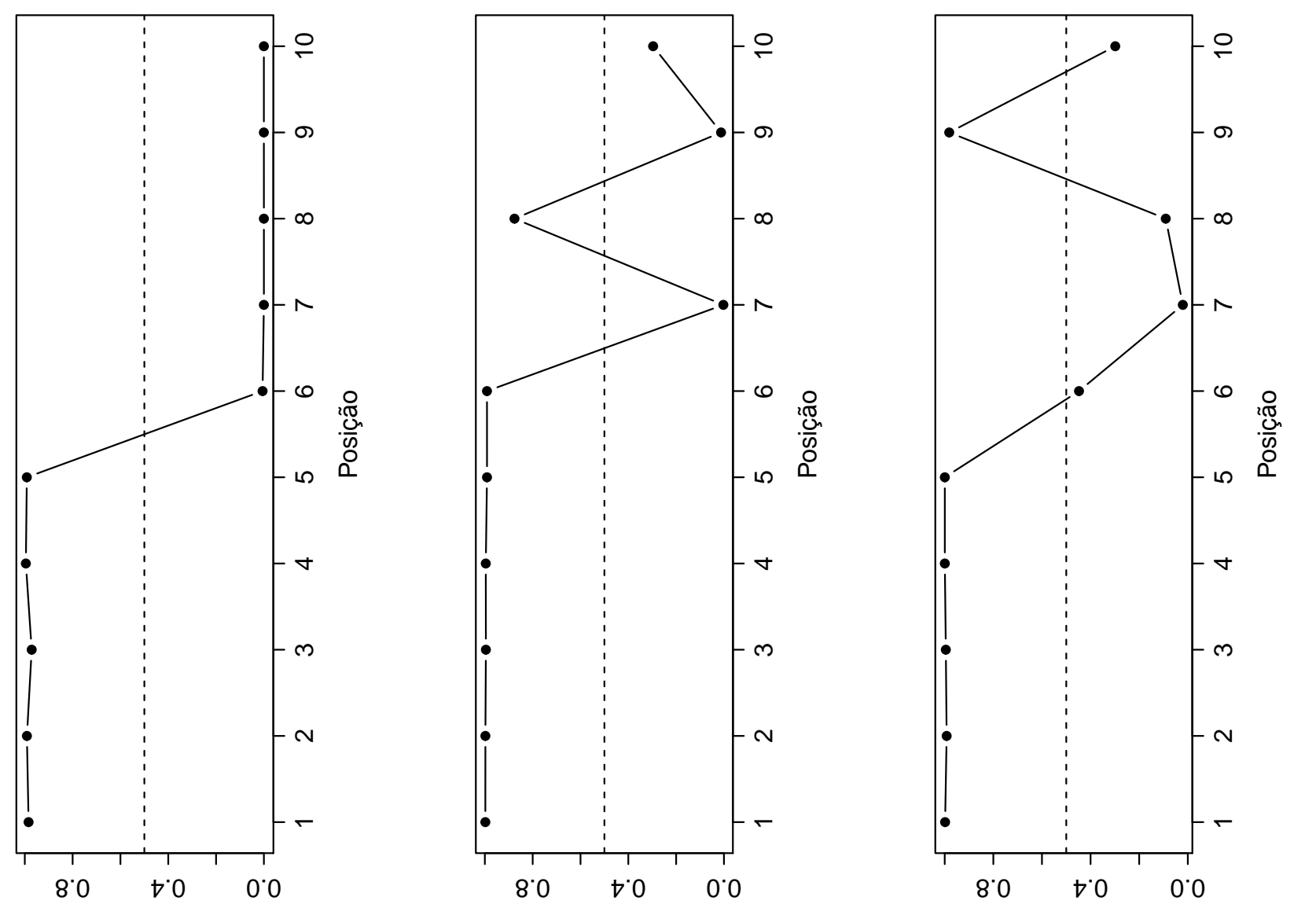

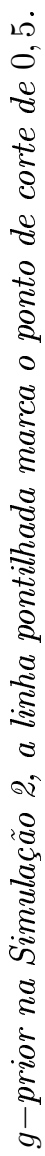
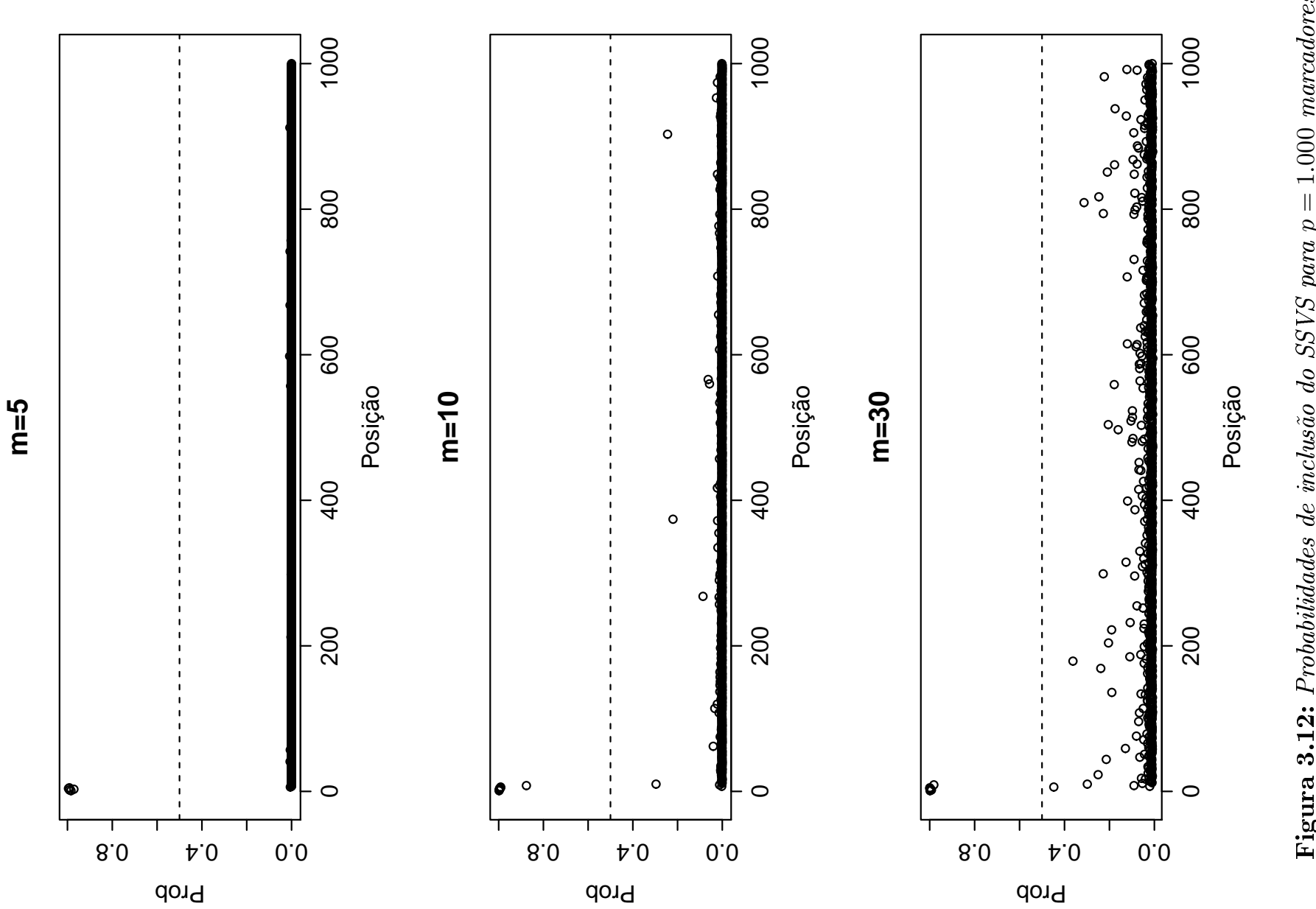


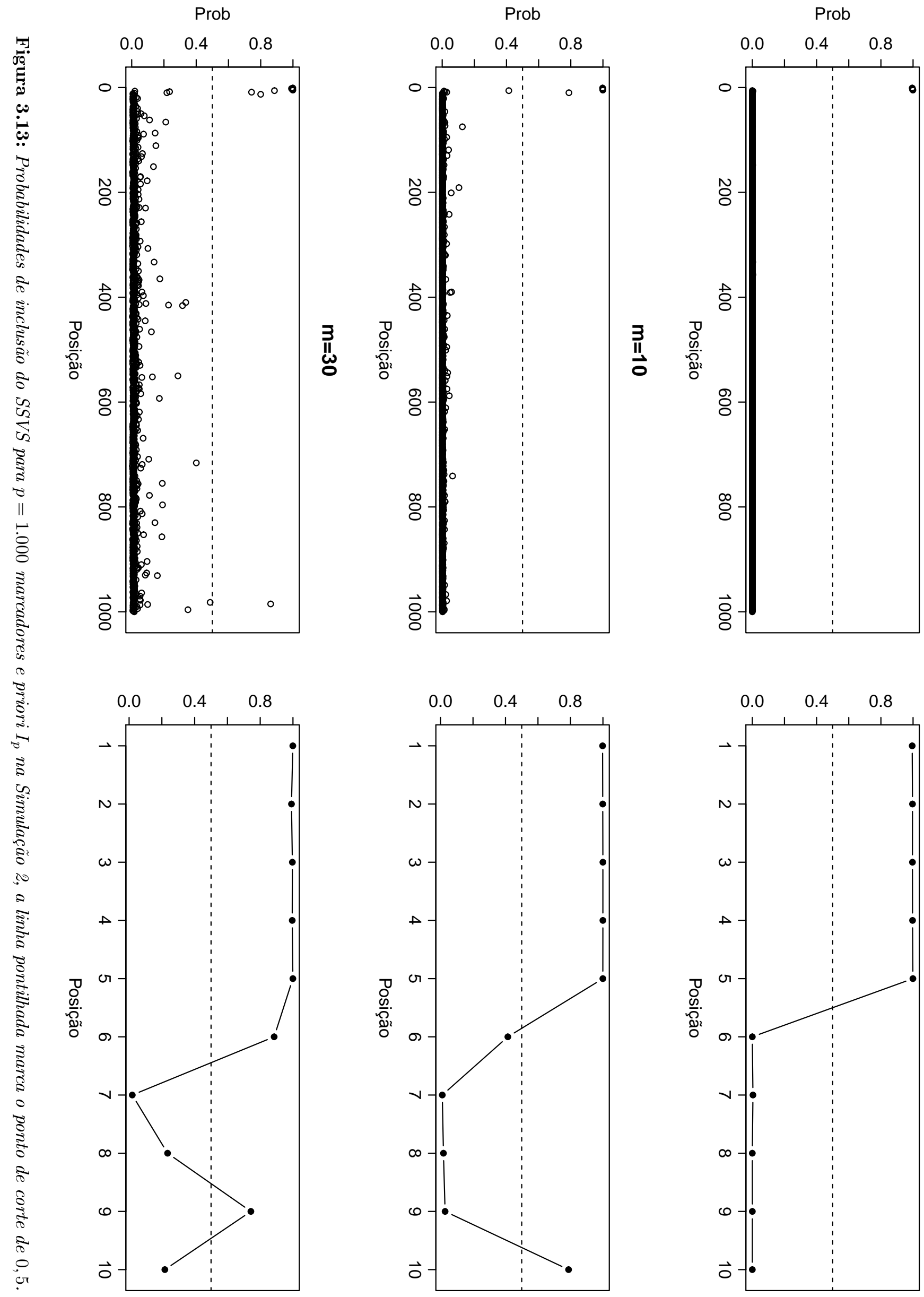



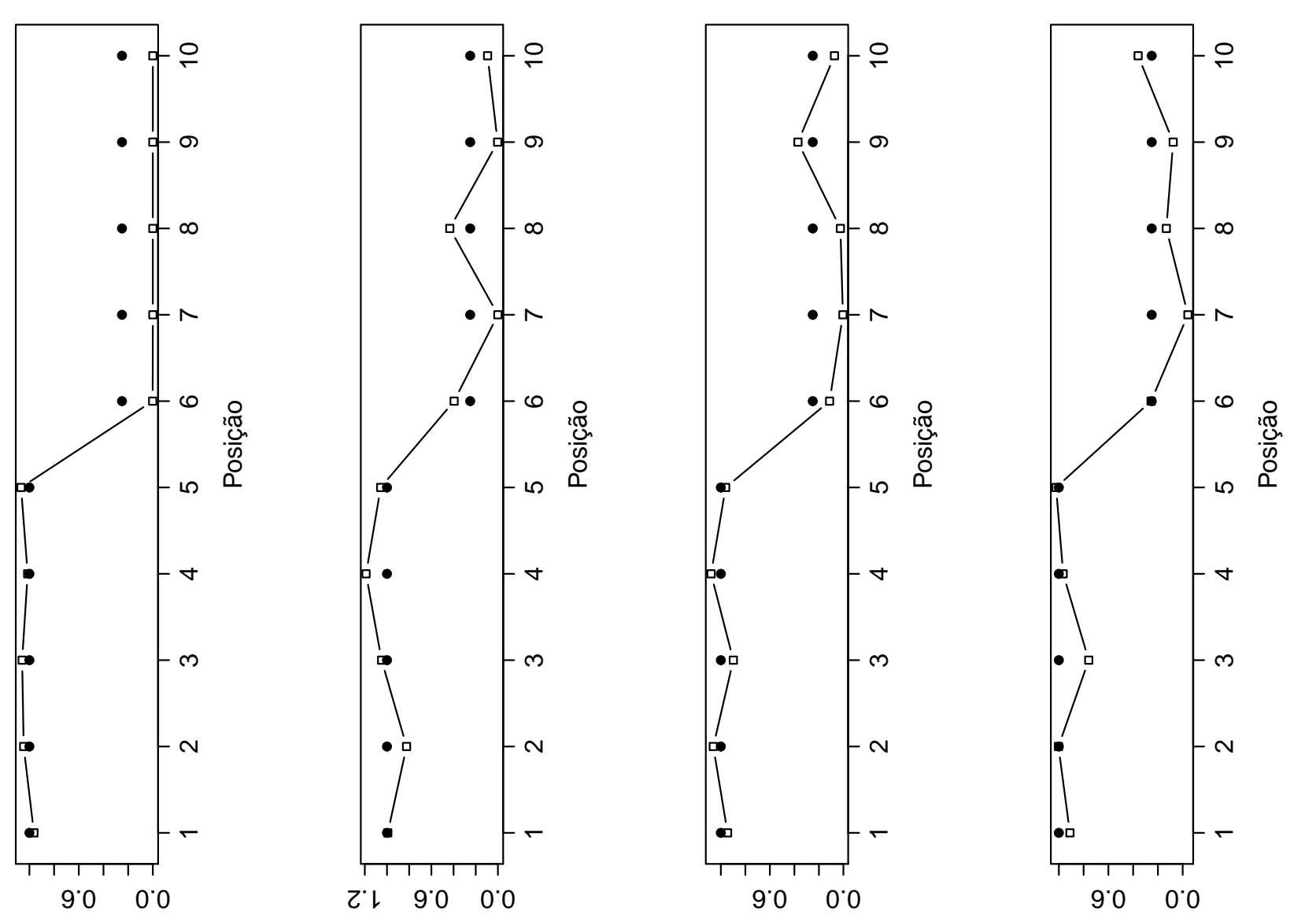

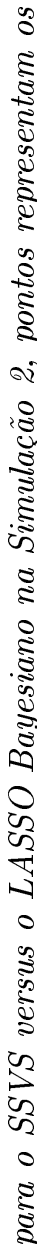
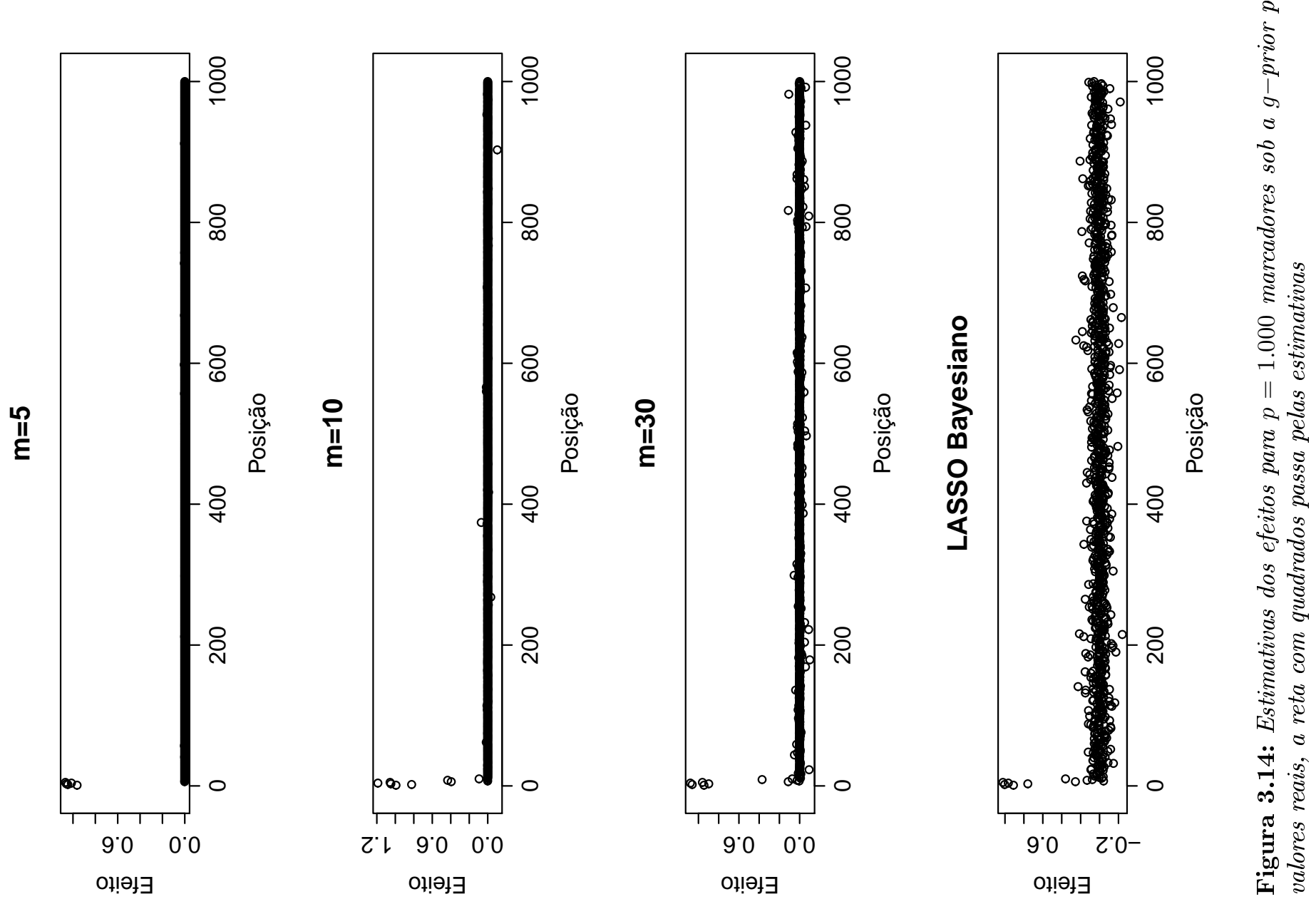

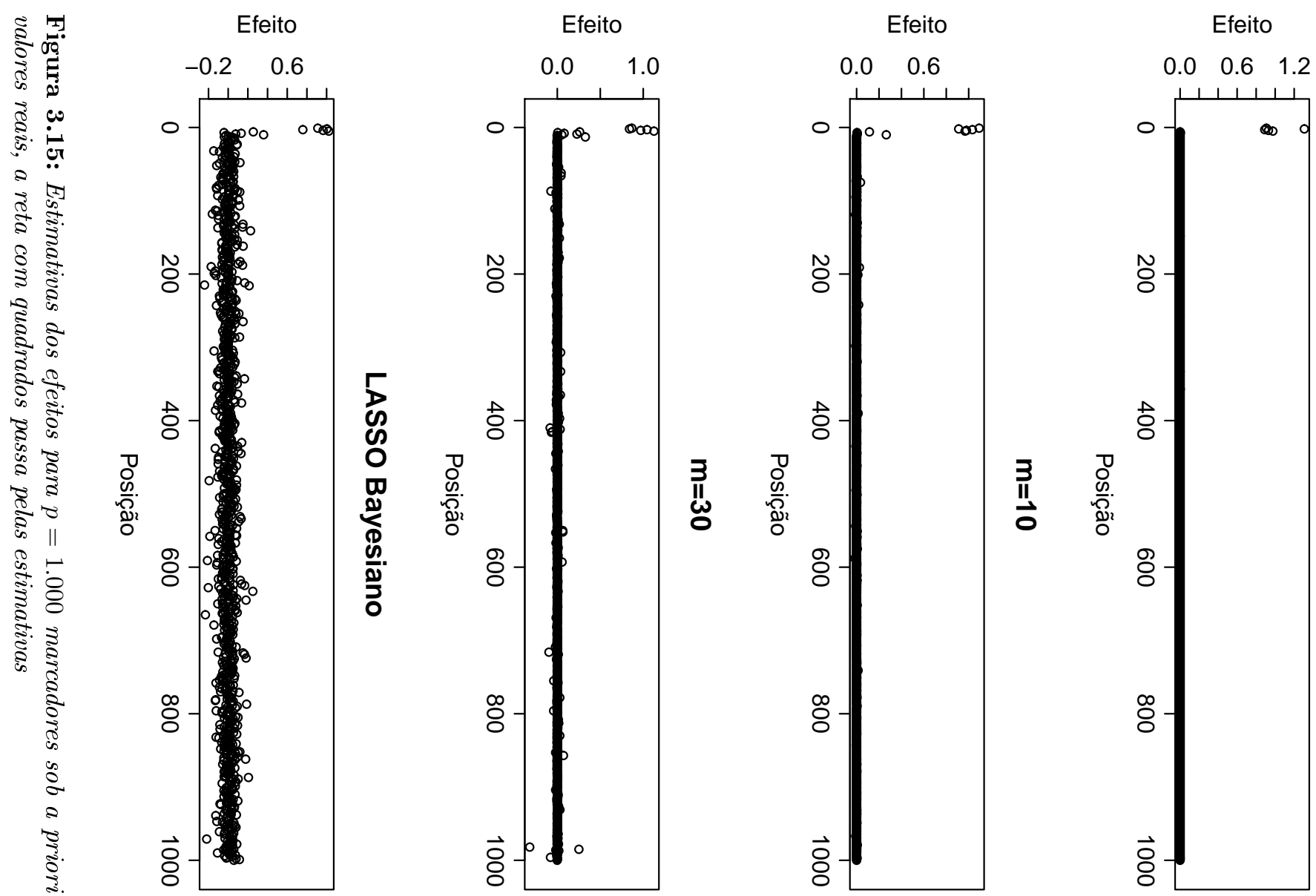

疍

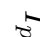

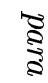

$$
\text { : }
$$

in
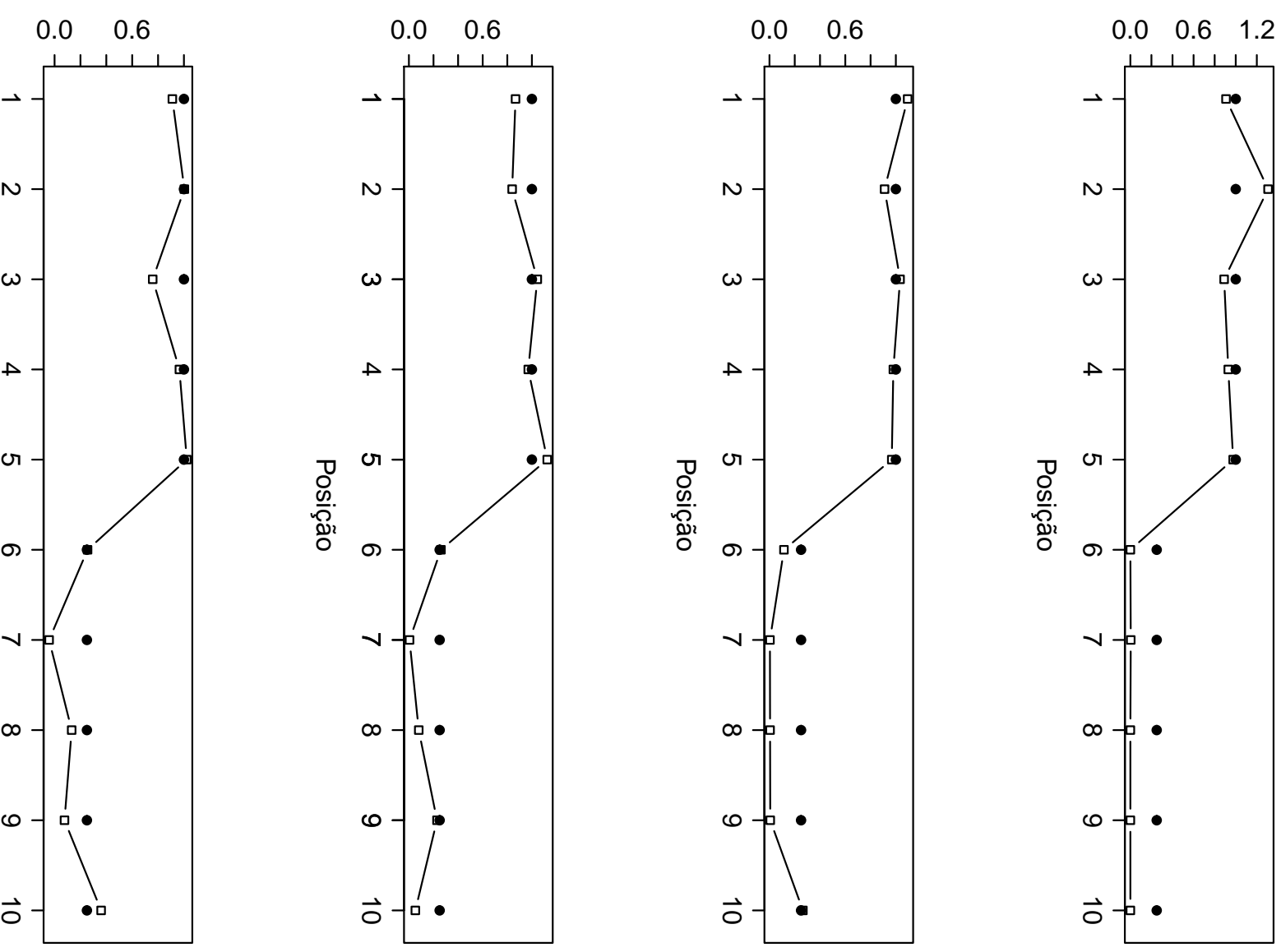

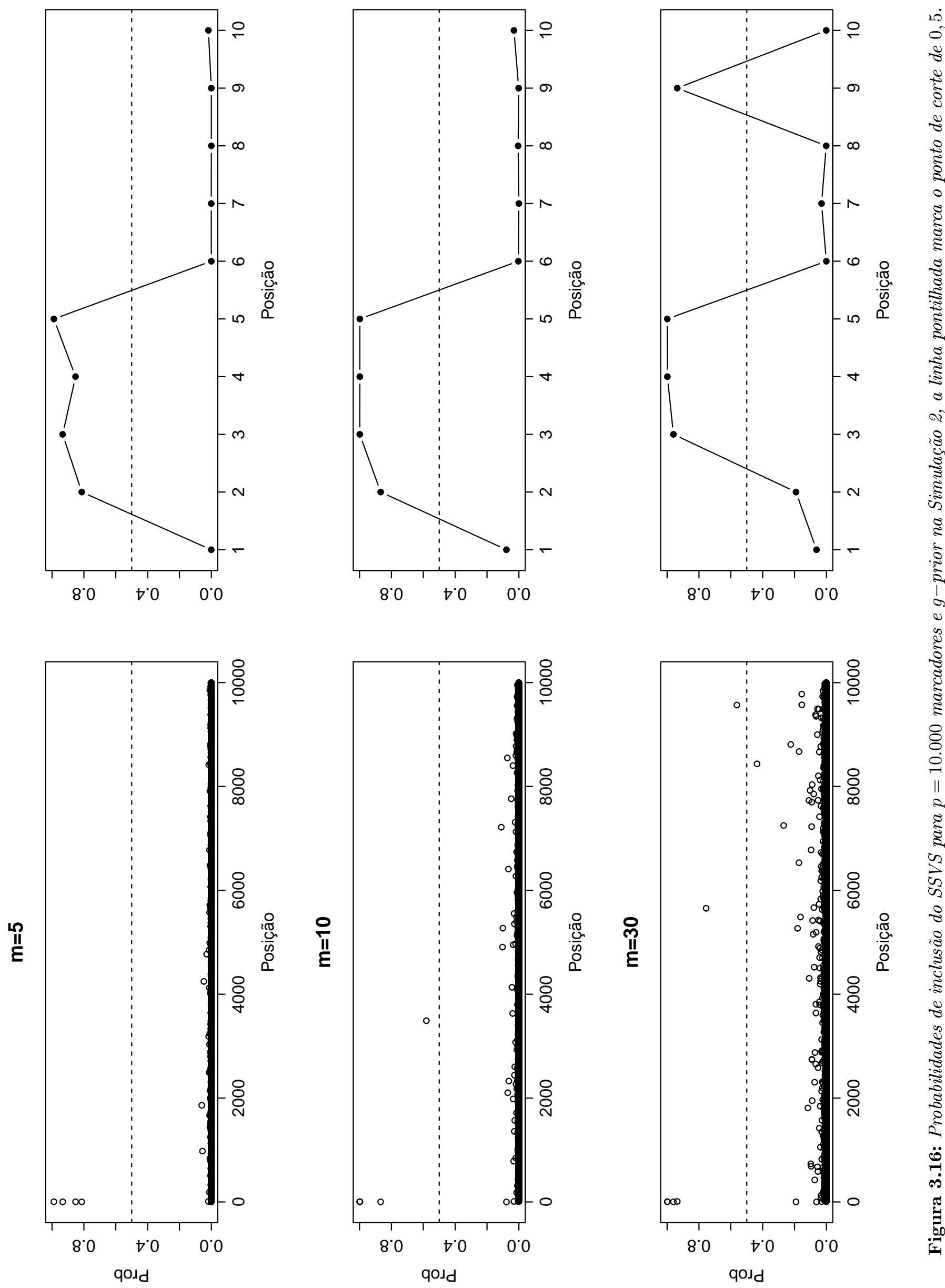

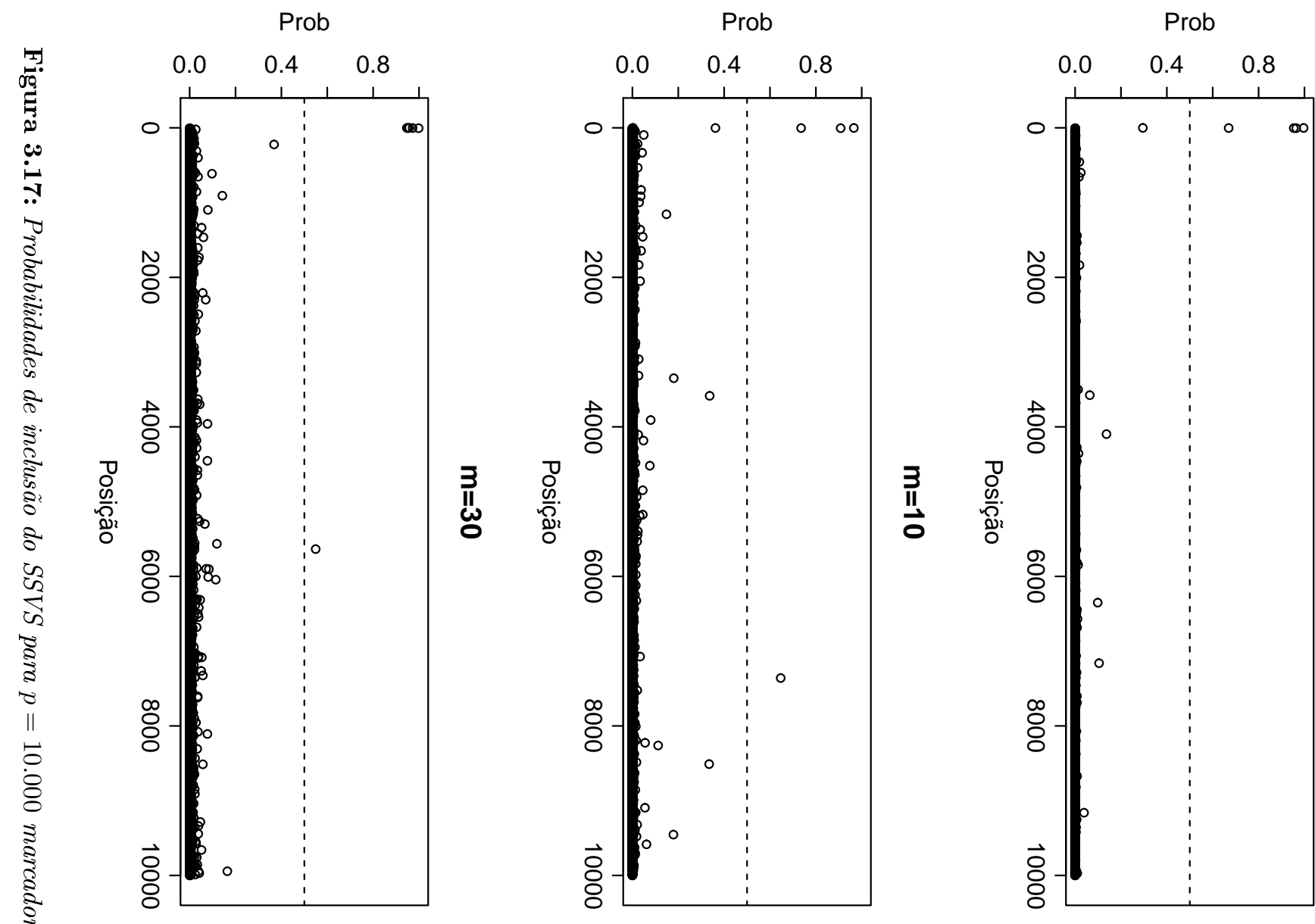

忢

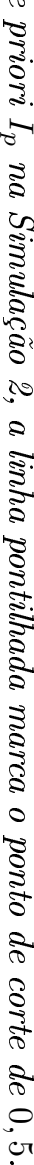
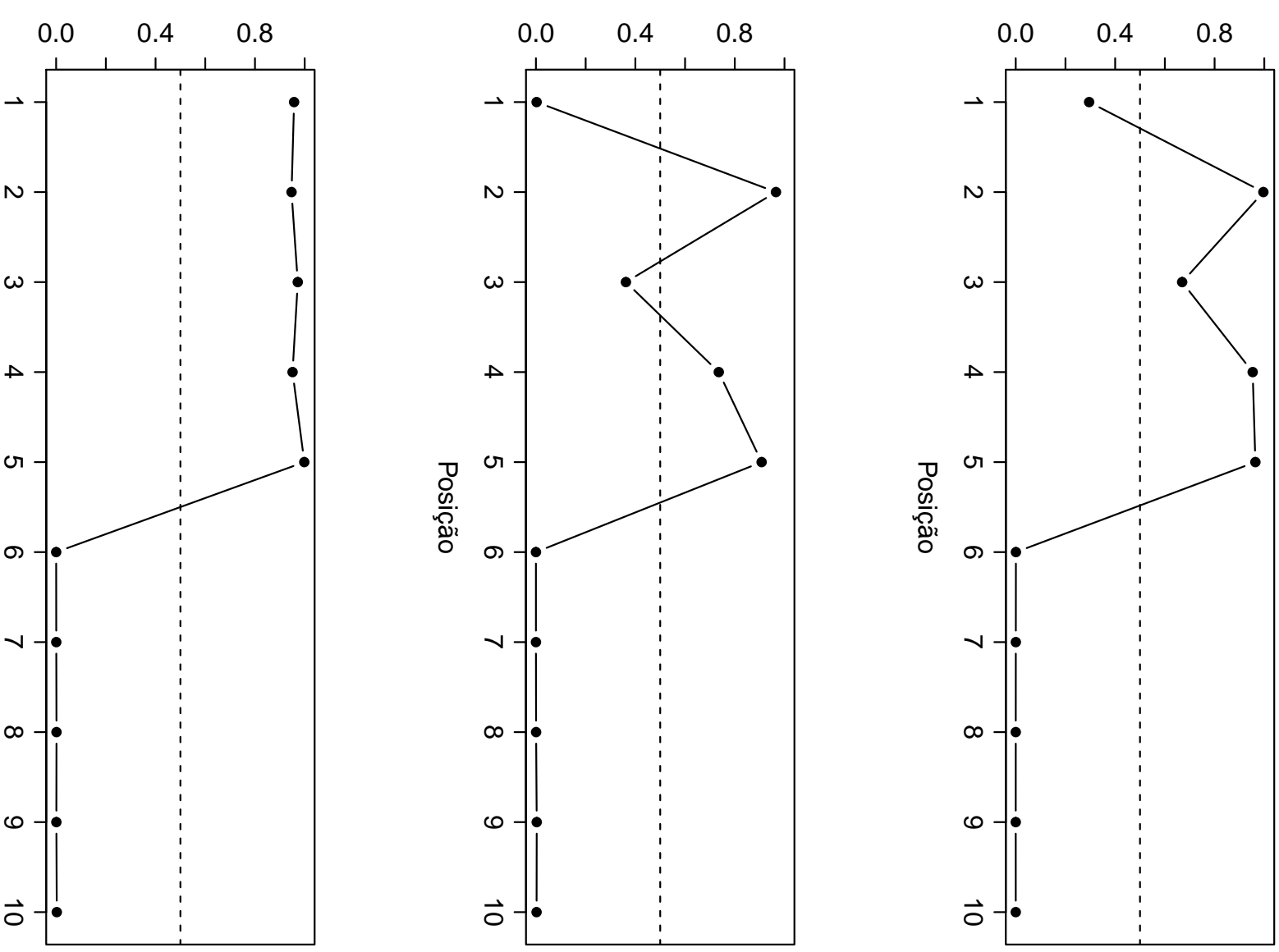

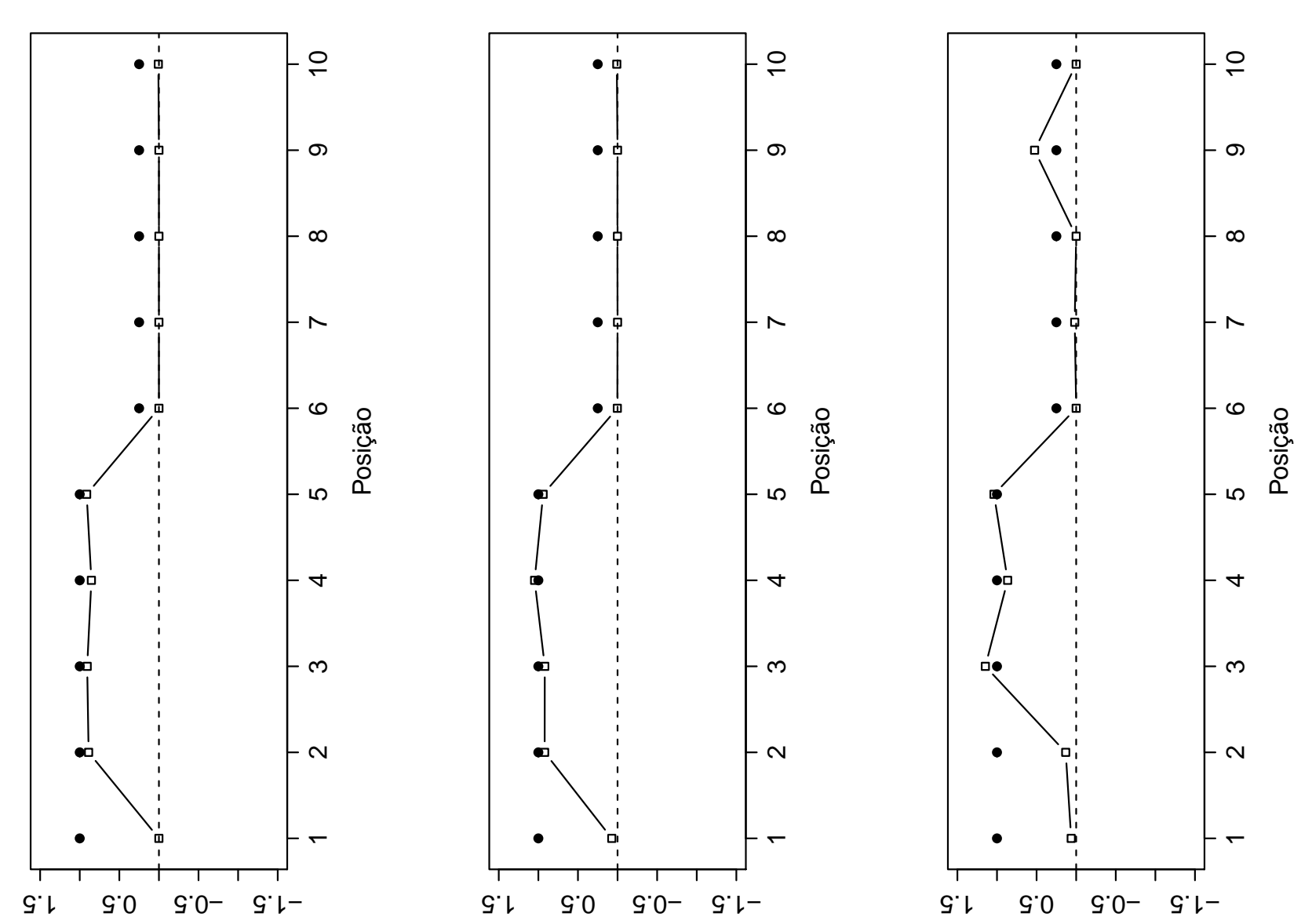

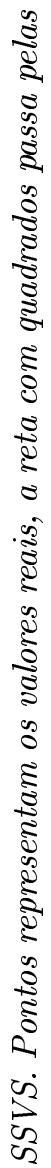
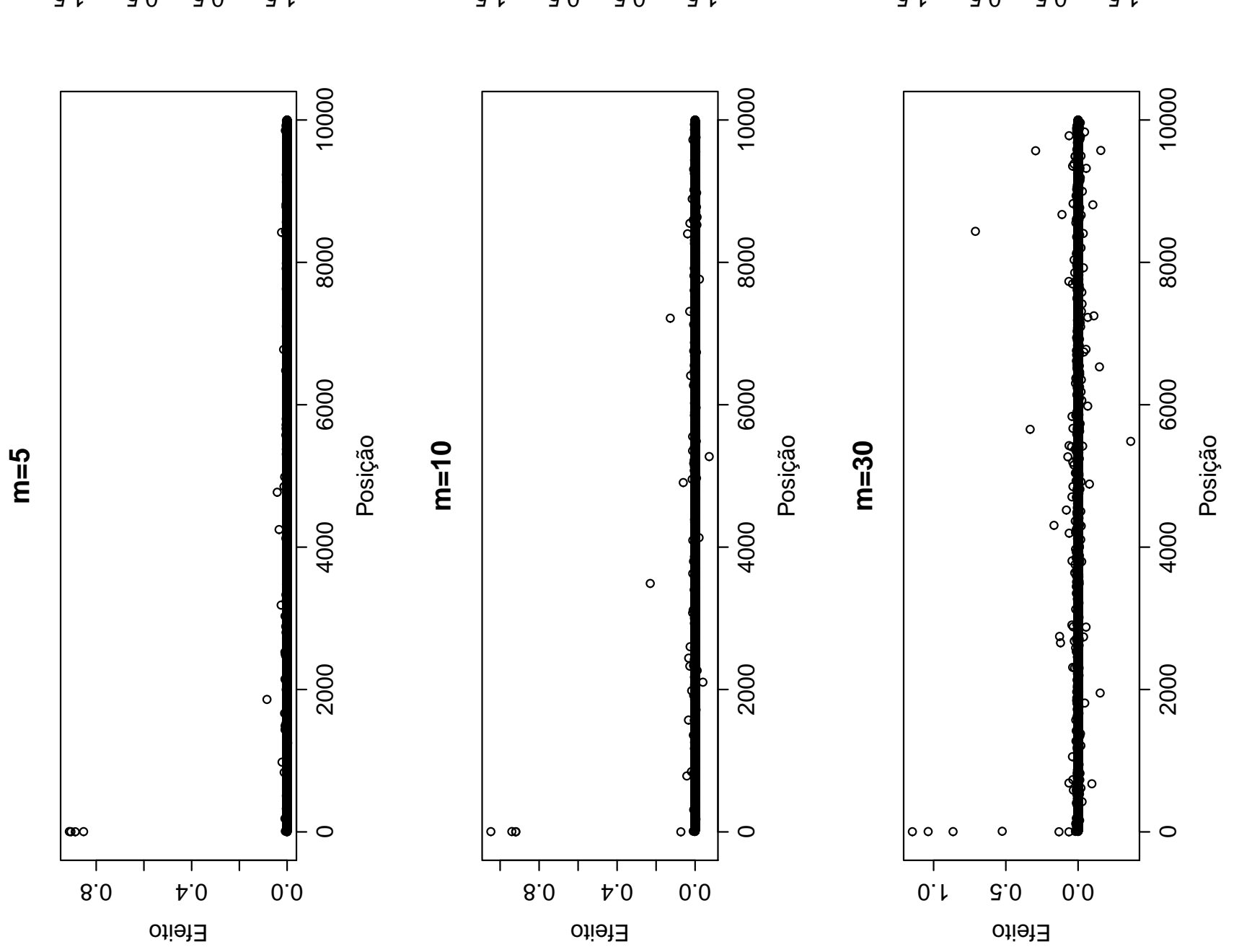

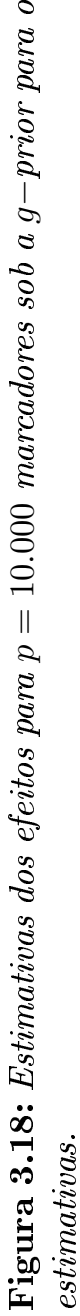



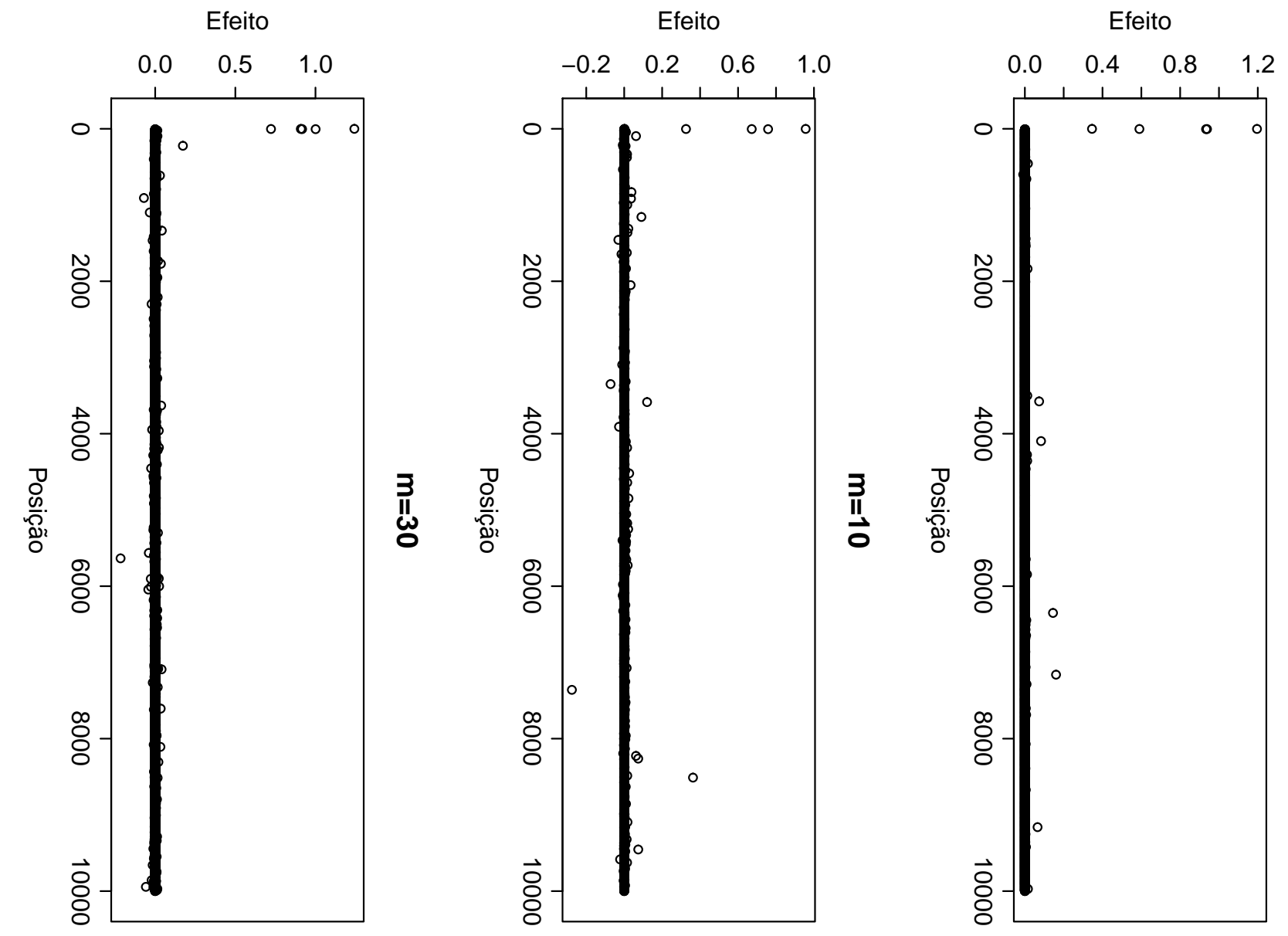

䓌
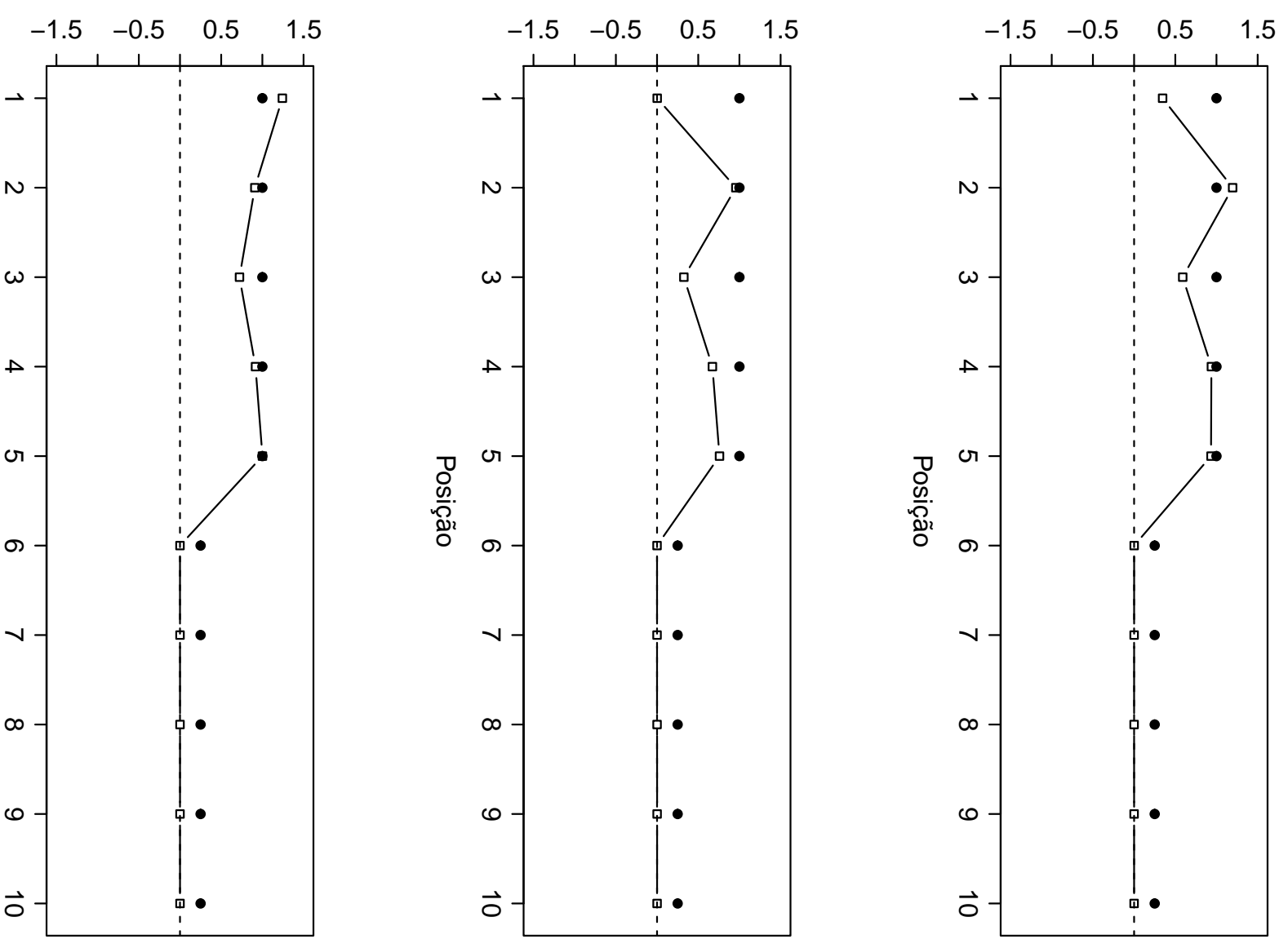
por conta da sua menor frequência alélica, implicando em uma maior variância da condicional (proporcional a $\left.\left(\boldsymbol{X} \boldsymbol{X}^{\prime}\right)^{-1}\right)$.

\subsubsection{Simulação 3}

Na presente simulação, temos uma série de efeitos grandes e pequenos misturados com frequências alélicas baixas e altas como descrito na Tabela 3.1 .

Nas Figuras 3.20 e 3.21 podemos observar as estimativas das probabilidades a posteriori de cada variável $P\left(\gamma_{l}=1 \mid \boldsymbol{Y}\right), l=1, \cdots, p$. Comparando as duas figuras, pode-se observar que um baixo número de variáveis em cada passo do amostrador $(m=5)$ falha em encontrar todos as covariáveis, apesar de sempre encontrar as covariáveis com maior efeito.

Nota-se também que com o aumento de $m$, recuperam-se mais covariáveis para ambas as prioris, assim como o número de falsos positivos, seguindo a tendência das duas últimas simulações. Nesse caso, a $g$ - prior parece produzir mais falsos positivos do que a priori independente. Nas Figuras 3.22 e 3.23, estão as estimativas dos efeitos para as duas configurações do SSVS contra as obtidas pelo LASSO Bayesiano.

O valor das estimativas encontra-se na Tabela 3.3. Para o SSVS, observa-se uma recuperação superior com o aumento de $m$, e superior no caso da priori independente comparada a $g$-prior. Têm-se ainda que o LASSO recupera bem os efeitos, se comparando ao cenário mais favorável do SSVS ( $m=30 \mathrm{com}$ priori independente), encolhendo demais apenas a covariável 7. Além disso, o LASSO não produziu nenhum falso positivo, considerando-se que nenhum efeito inexistente foi estimado com valor absoluto maior que 0,25 .

Entretanto, para efeitos com valores absolutos maiores que 0,20 , o LASSO produz 2 falsos positivos. Com um ponto de corte maior que 0,1, têm-se 67 efeitos inexistentes no modelo, enquanto com o SSVS, as probabilidades de inclusão ponderam essas estimativas espúrias dos efeitos. Em nenhum dos casos observamos tantos falsos positivos com o SSVS. No pior caso $(m=30, g$-prior) observamos apenas 4 estimativas com valores absolutos maiores que 0,1 erroneamente, enquanto no melhor caso ( $m=10$ ou 30, priori independente), observamos apenas um efeito estimado erroneamente acima de 0,1 .

Tabela 3.3: Estimativas dos efeitos para o cenário $p=1$.000. $I_{m}$ representa a priori independente, $g$ a g-prior e LASSO o LASSO Bayesiano.

\begin{tabular}{rr|rr|rr|rr|r}
\hline & & \multicolumn{2}{|c|}{$m=5$} & \multicolumn{2}{|c|}{$m=10$} & \multicolumn{2}{|c}{$m=30$} & \\
\hline Efeito & Real & $I_{m}$ & $g$ & $I_{m}$ & $g$ & $I_{m}$ & $g$ & LASSO \\
\hline 1 & $-1,25$ & $-1,31$ & $-1,28$ & $-1,14$ & $-1,35$ & $-1,27$ & $-1,29$ & $-1,33$ \\
2 & $-1,00$ & $-1,08$ & $-0,90$ & $-0,86$ & $-1,02$ & $-1,21$ & $-1,01$ & $-0,88$ \\
3 & $-0,75$ & 0,00 & 0,00 & $-0,83$ & $-0,75$ & $-0,85$ & $-0,69$ & $-0,60$ \\
4 & $-0,50$ & 0,00 & $-0,50$ & $-0,55$ & $-0,46$ & $-0,49$ & $-0,45$ & $-0,50$ \\
5 & $-0,25$ & $-0,01$ & 0,00 & $-0,15$ & $-0,05$ & $-0,20$ & $-0,08$ & $-0,23$ \\
6 & 0,25 & 0,00 & 0,00 & 0,13 & 0,11 & 0,30 & 0,25 & 0,32 \\
7 & 0,50 & 0,00 & 0,00 & 0,23 & 0,58 & 0,44 & 0,50 & 0,18 \\
8 & 0,75 & 0,58 & 0,00 & 0,68 & 0,61 & 0,78 & 0,82 & 0,66 \\
9 & 1,00 & 0,91 & 1,19 & 1,02 & 1,03 & 0,97 & 1,02 & 0,97 \\
10 & 1,25 & 1,32 & 1,43 & 1,29 & 1,17 & 1,30 & 1,23 & 1,27 \\
\hline
\end{tabular}

Nas Figuras 3.24 e 3.25, encontram-se as probabilidades de inclusão do SSVS. Acompanhando as outras duas simulações, observa-se que o desempenho da escolha de variáveis é consideravelmente pior com o aumento de covariáveis. Observamos que, com ambas as prioris, o SSVS não atribui alta probabilidade às covariáveis associadas com os menores efeitos $\left(\left|\beta_{5}\right|=\left|\beta_{6}\right|=0,25\right)$ a despeito do sinal e das frequências alélicas envolvidas ( $25 \%$ para o marcador $5,1 \%$ para o marcador 6$)$.

O número de falsos positivos também é similar nas duas configurações, com a priori independente produzindo mais falsos positivos que a $g$-prior, um desempenho oposto à priori independente nas outras simulações. Em todo caso, as duas prioris parecem produzir resultados similares. 

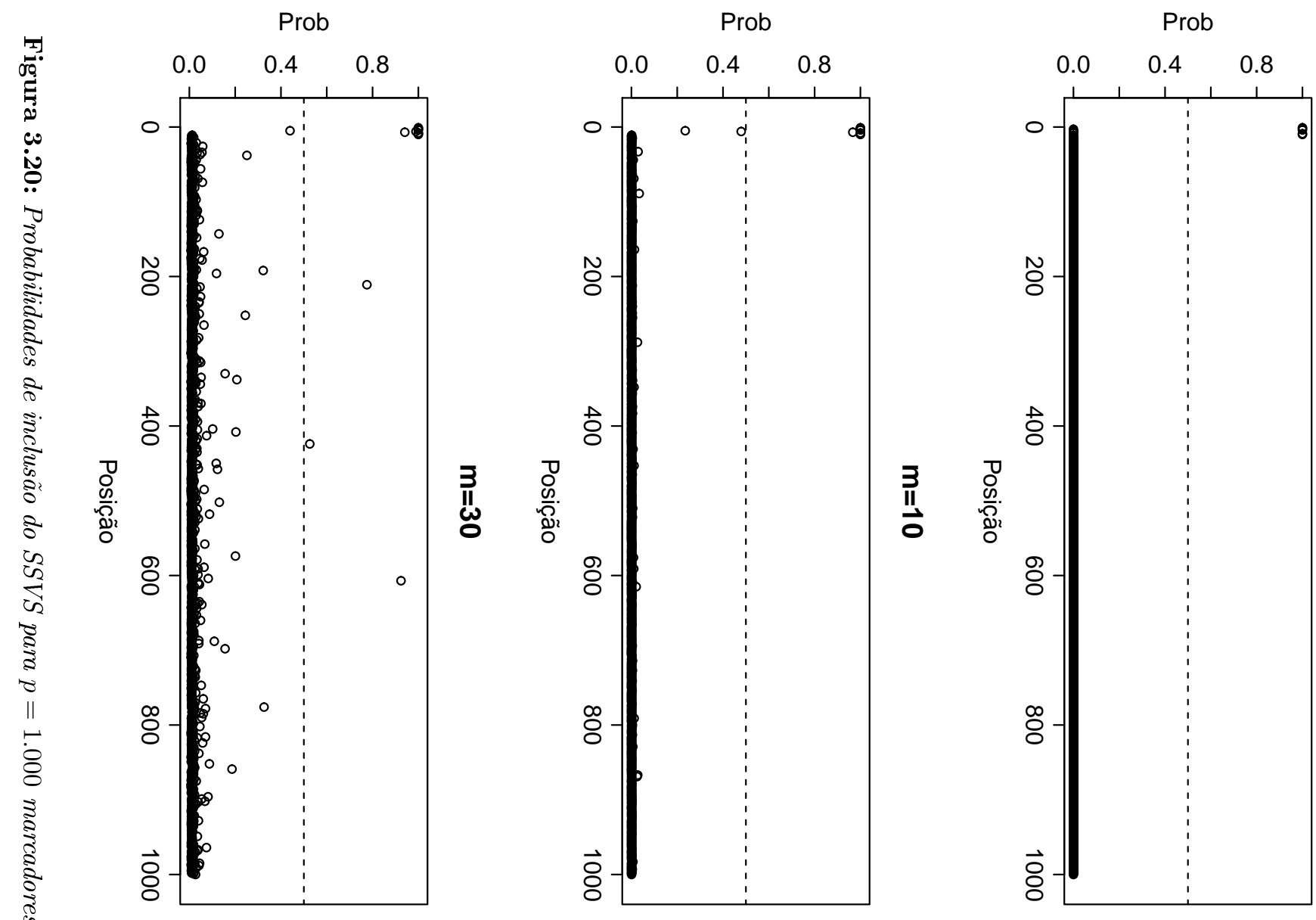

怘

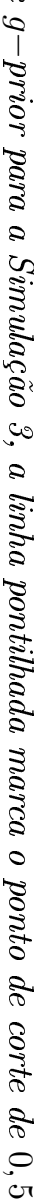
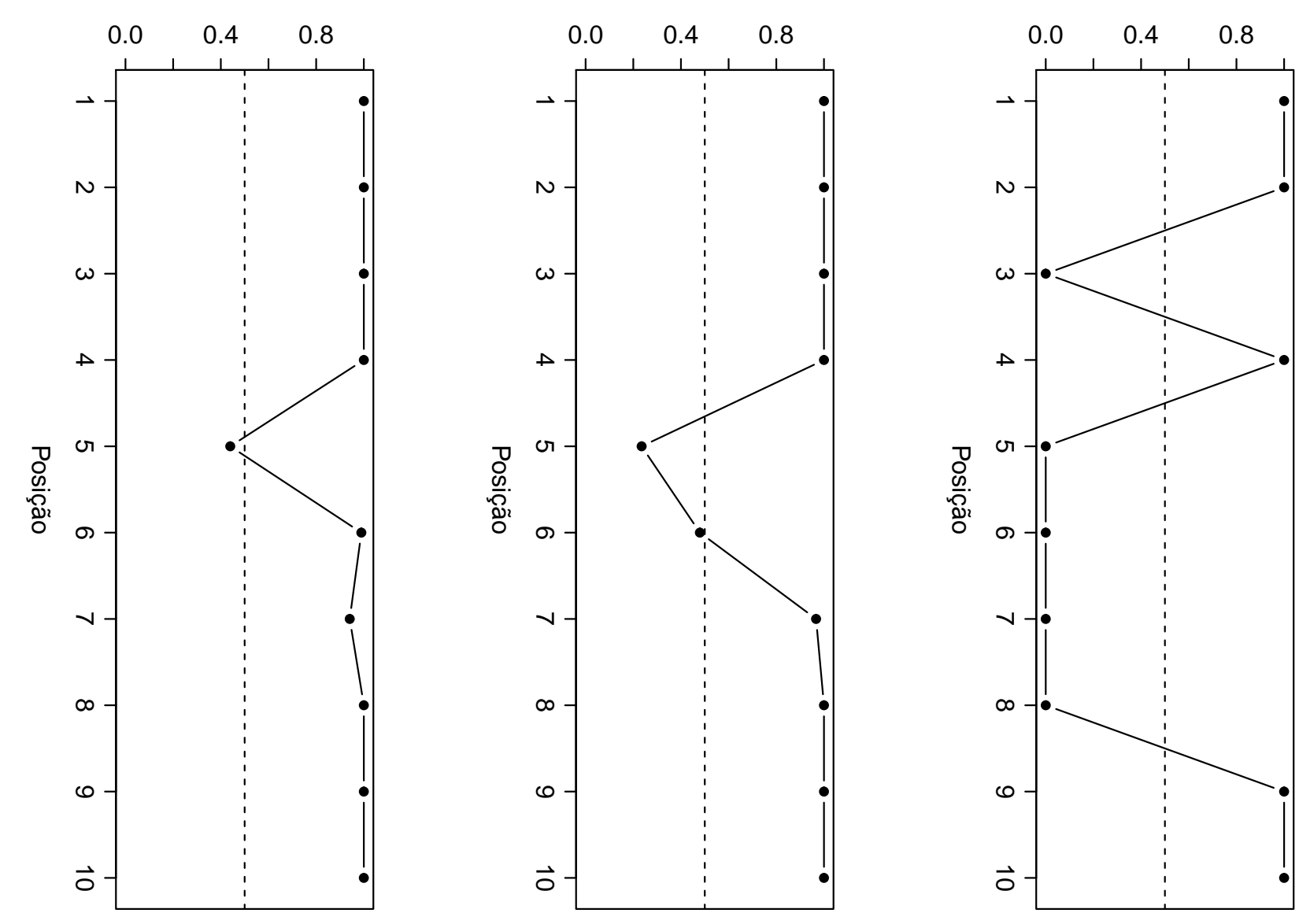

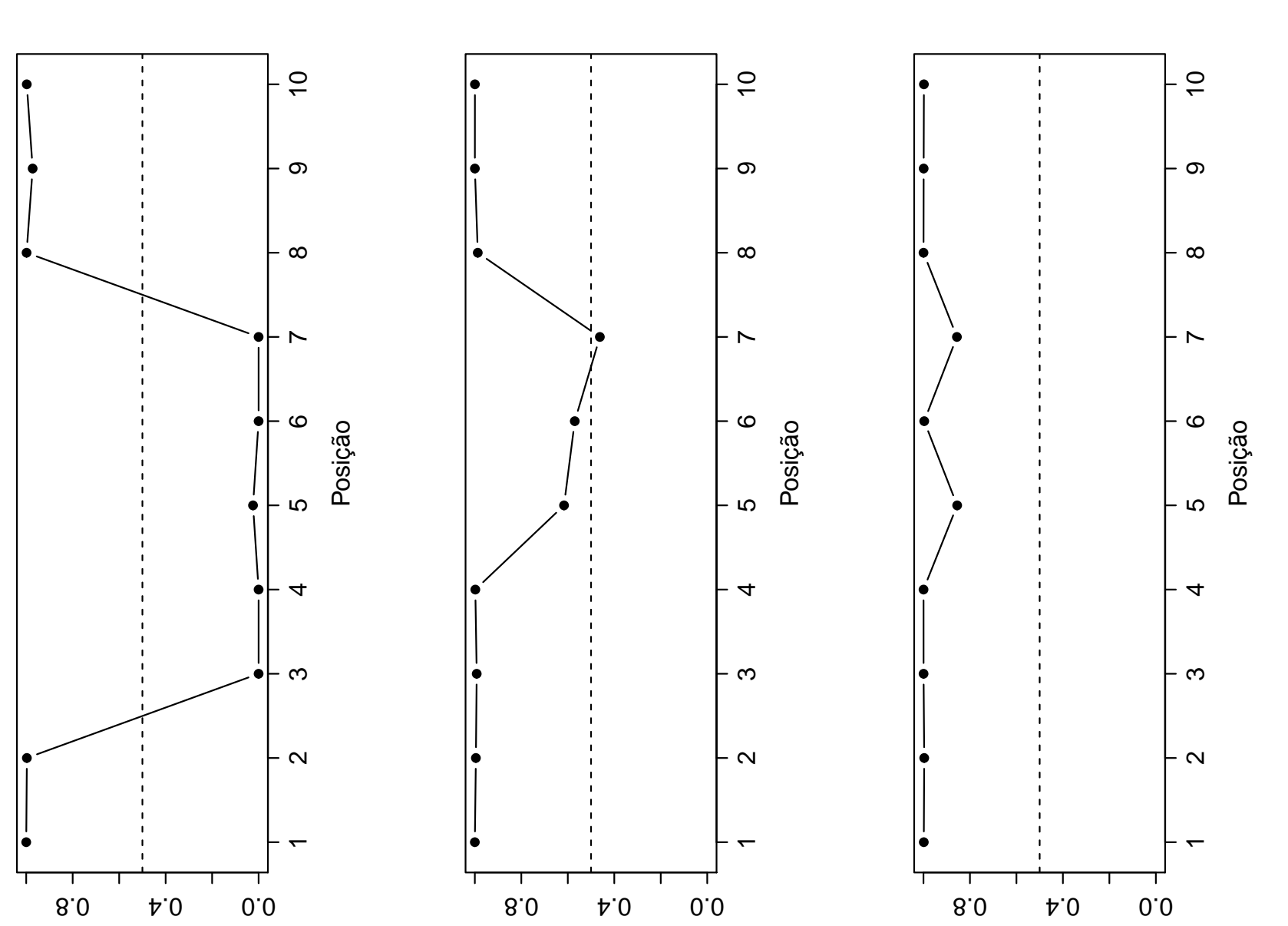

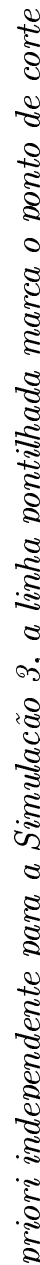
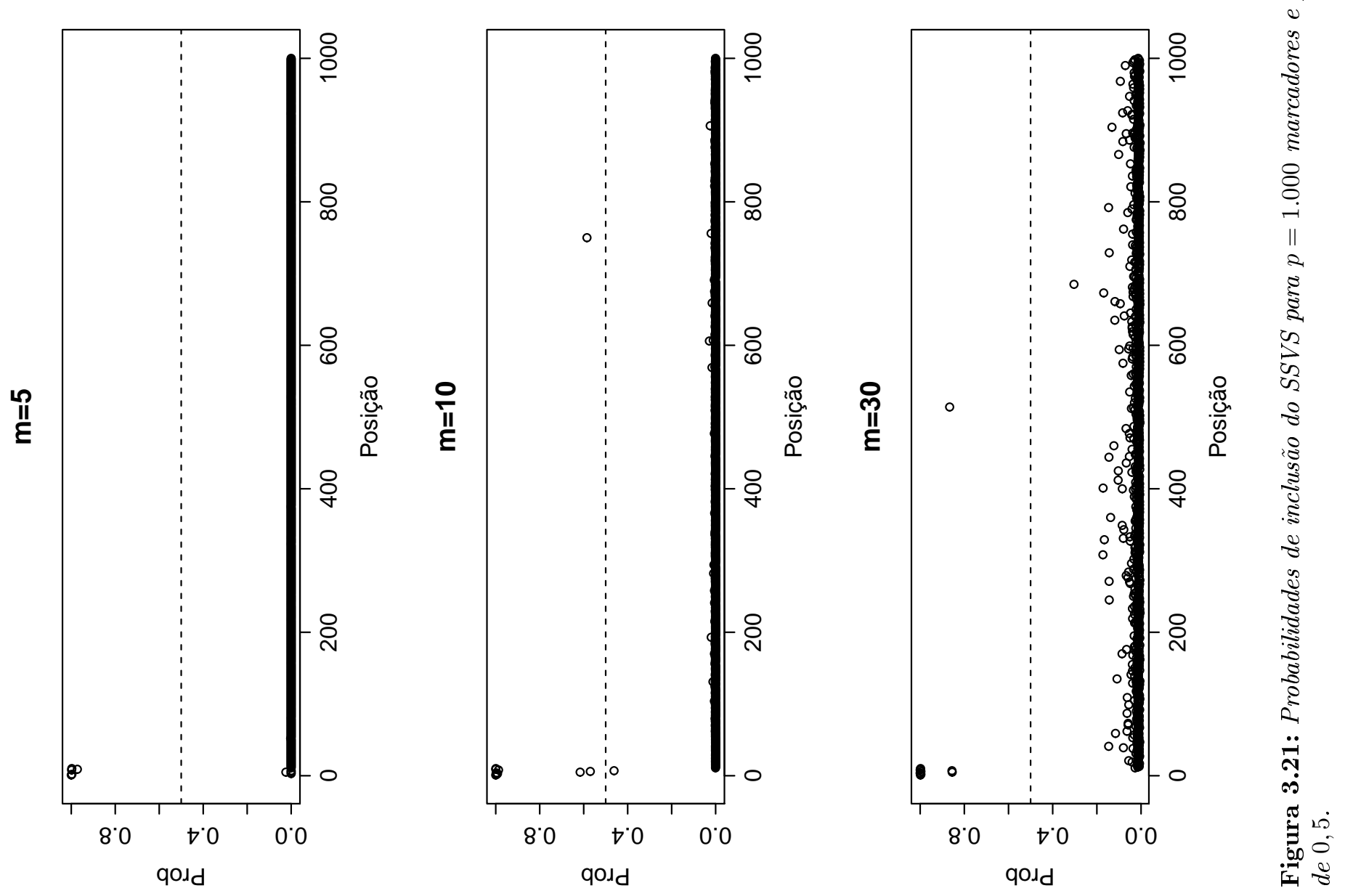

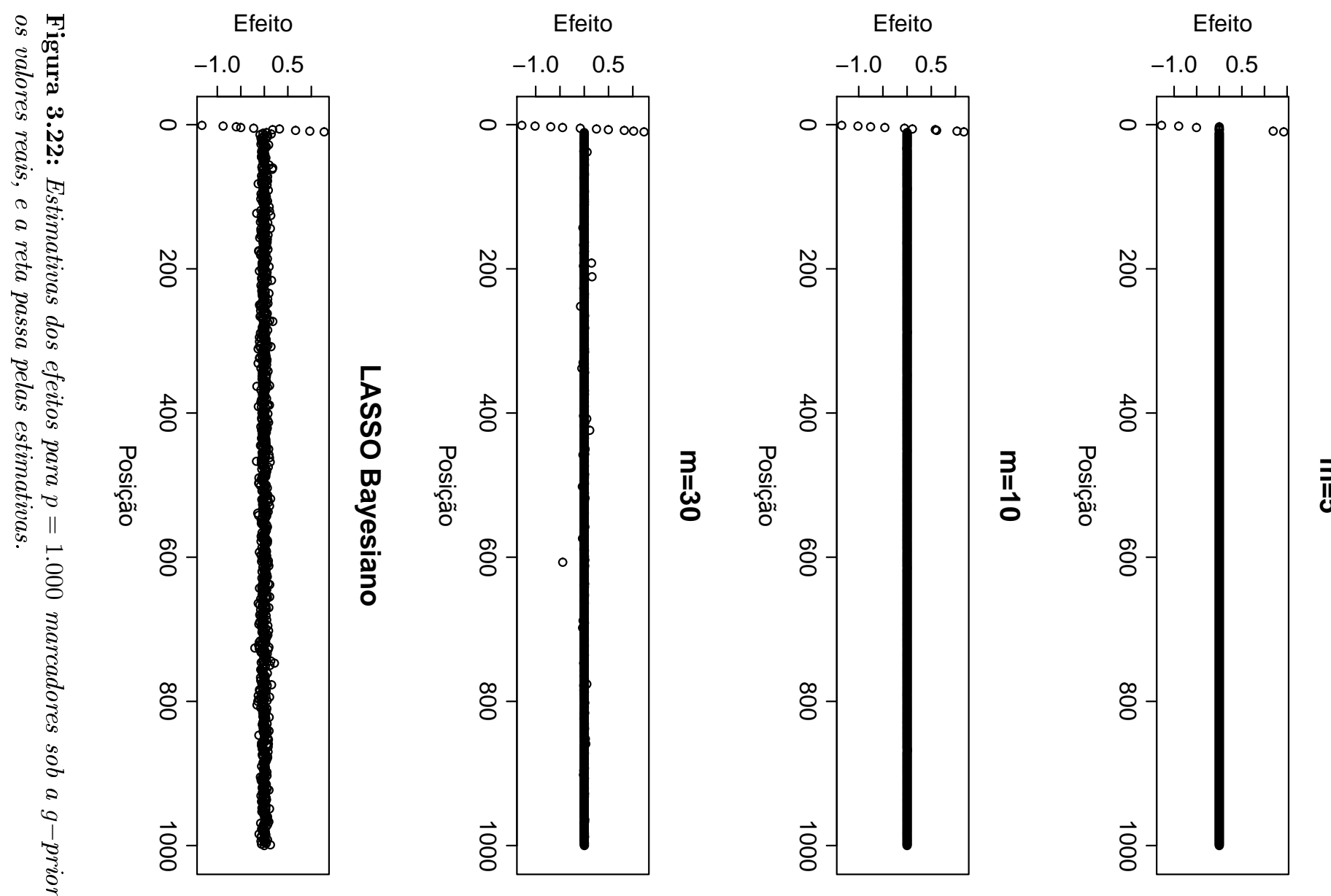

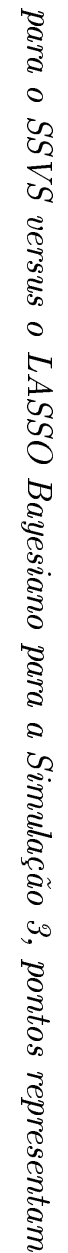
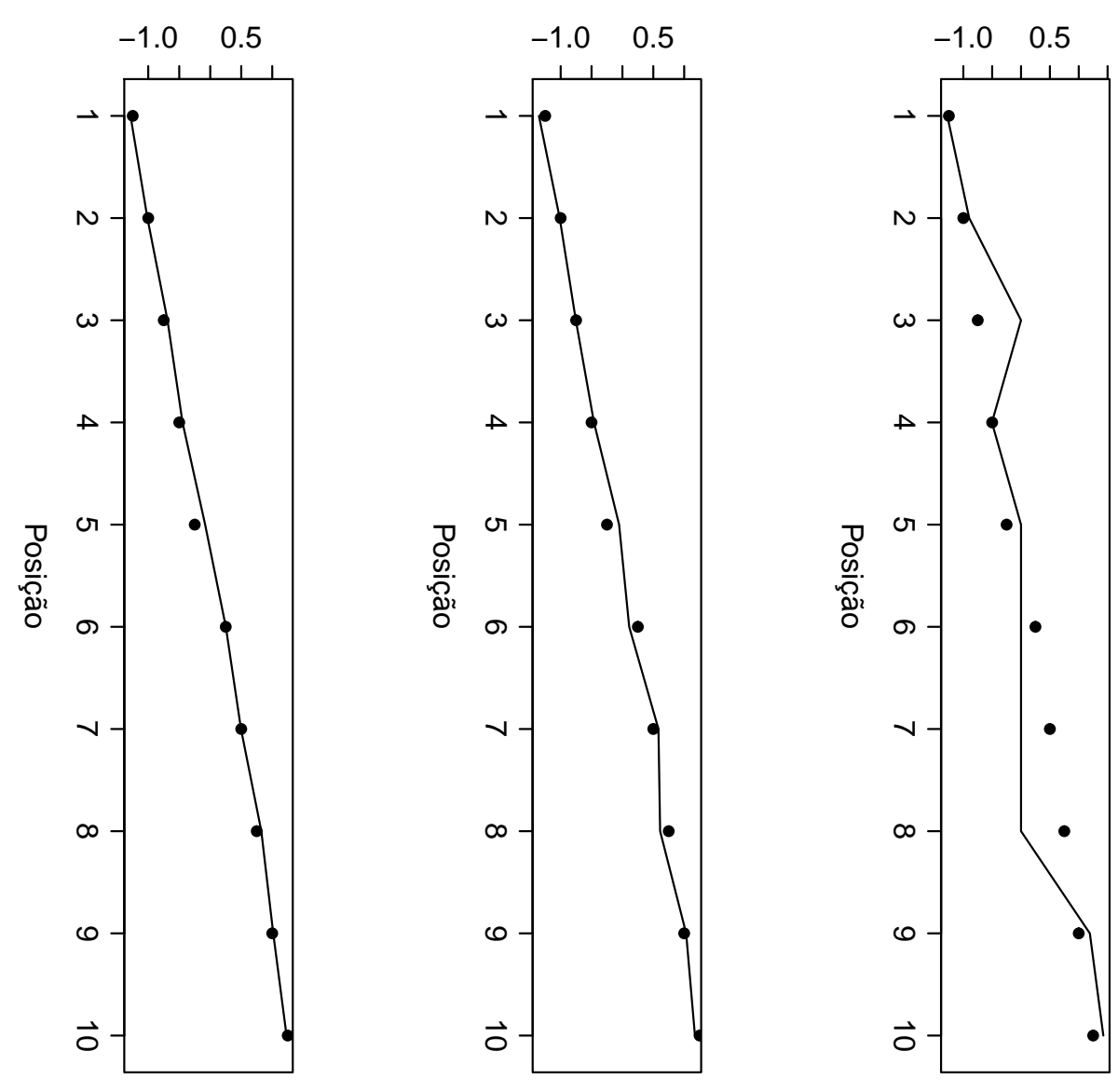

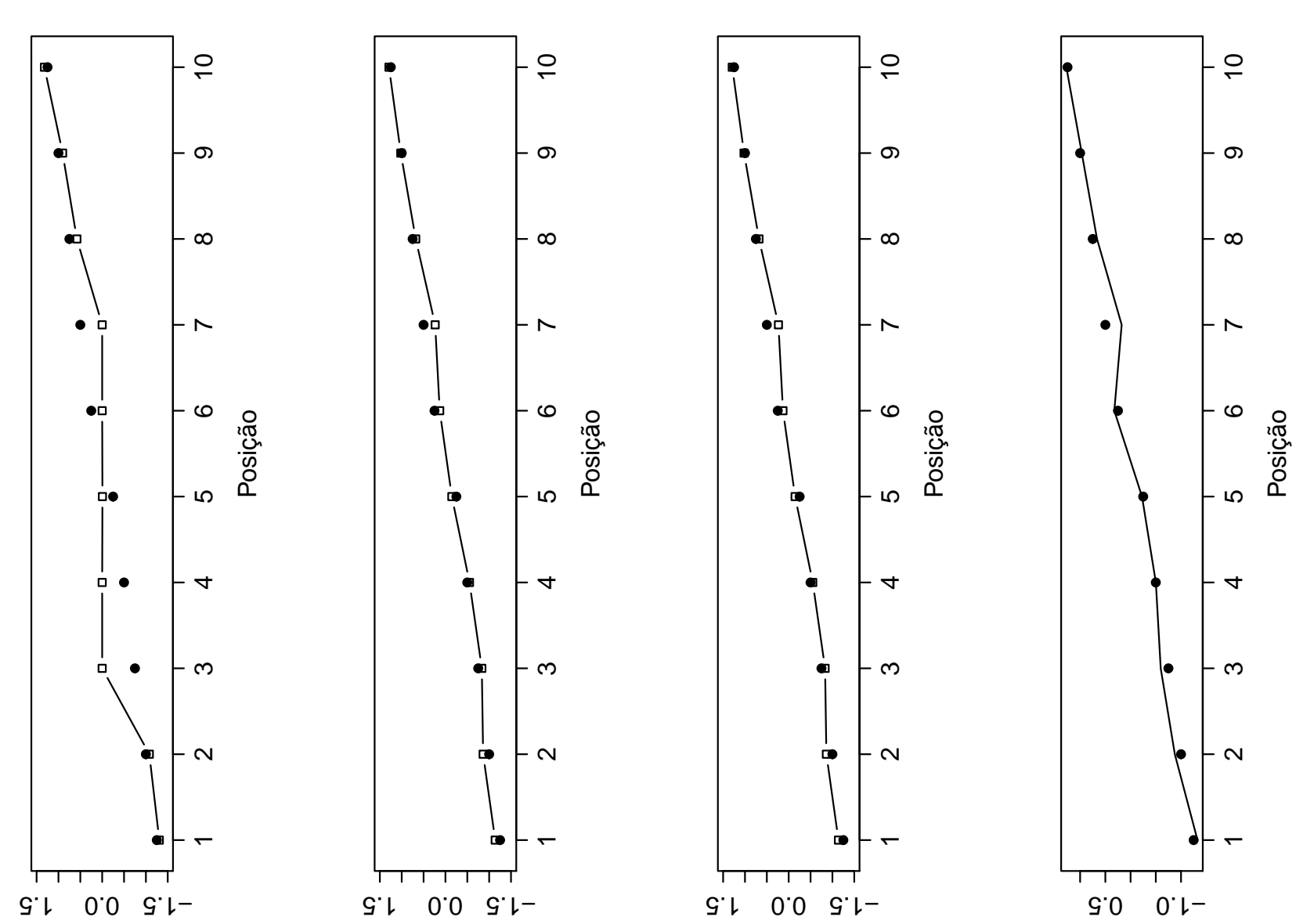

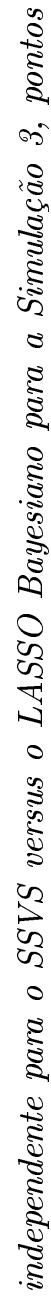
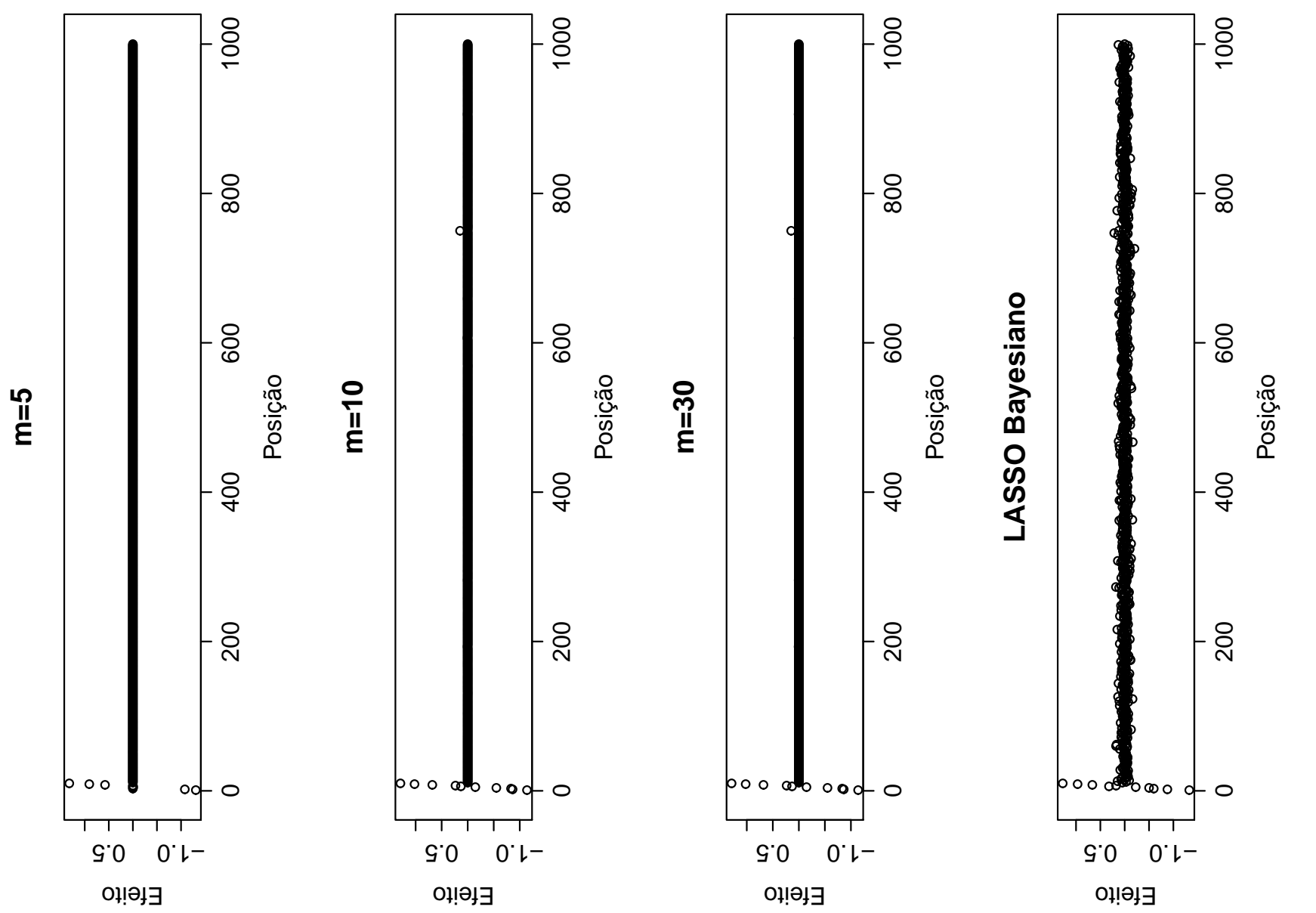

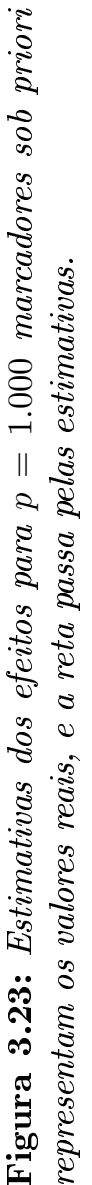



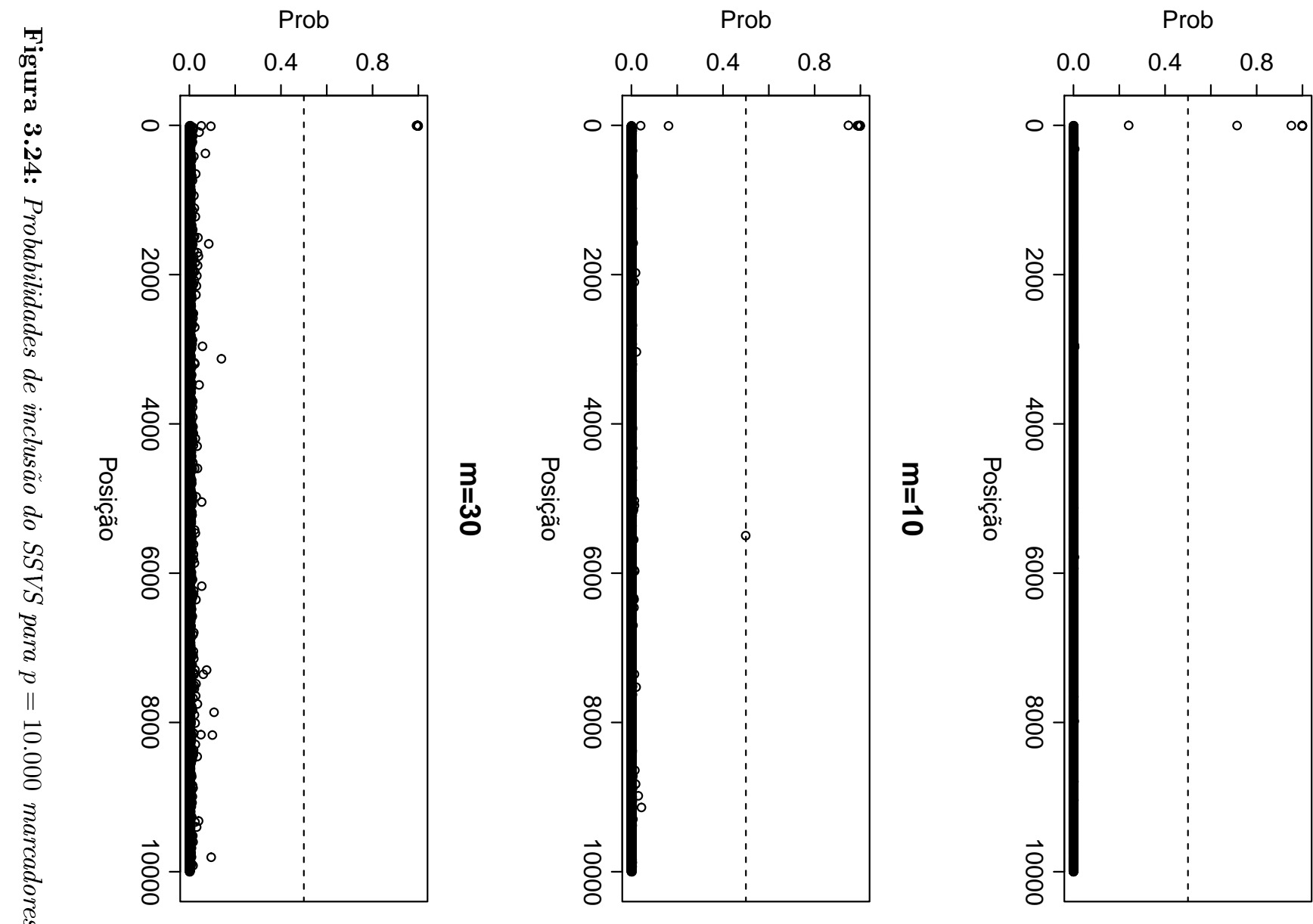

筫
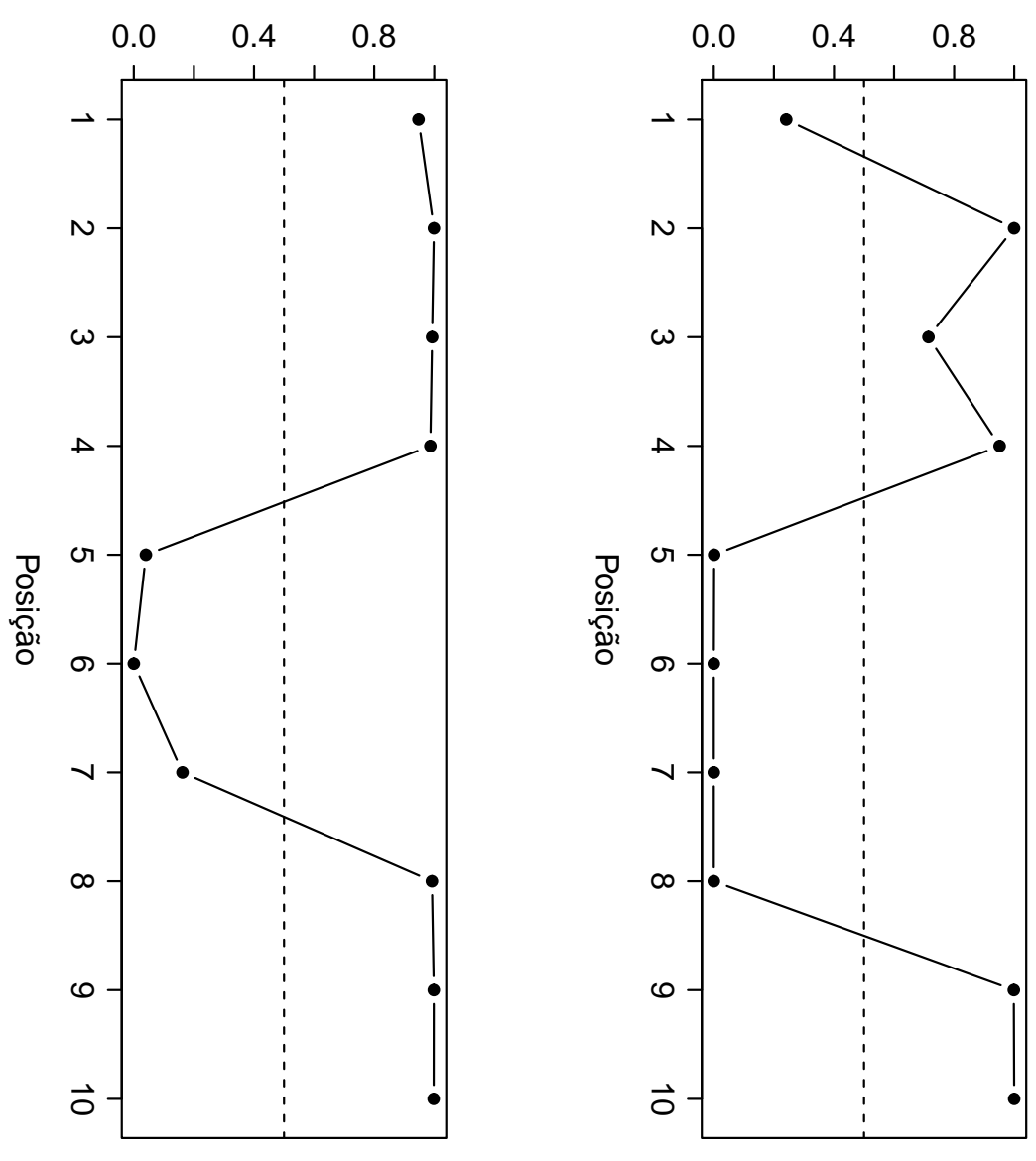

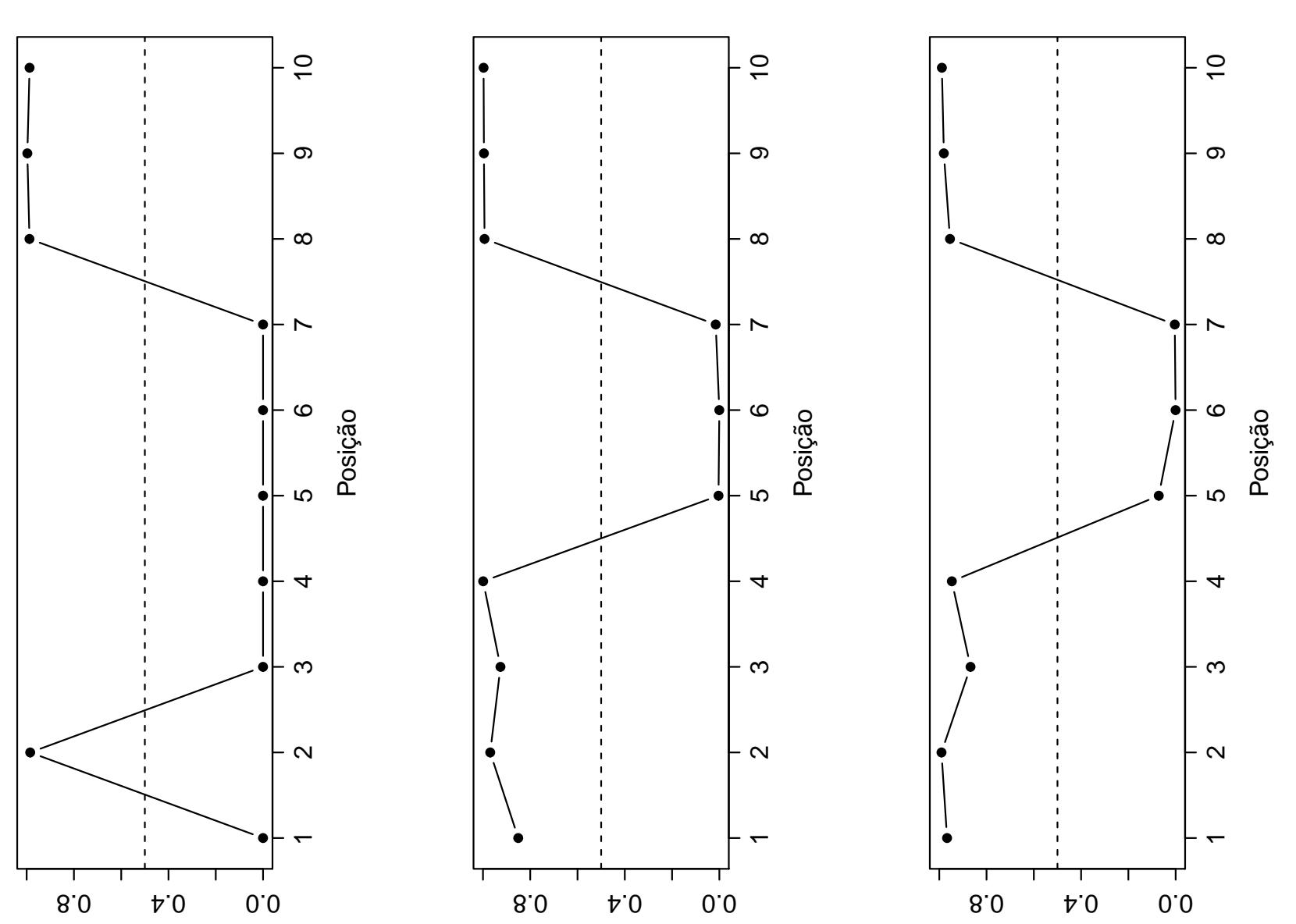

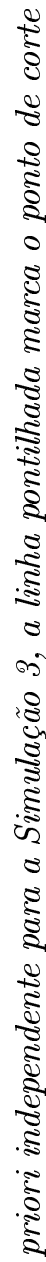
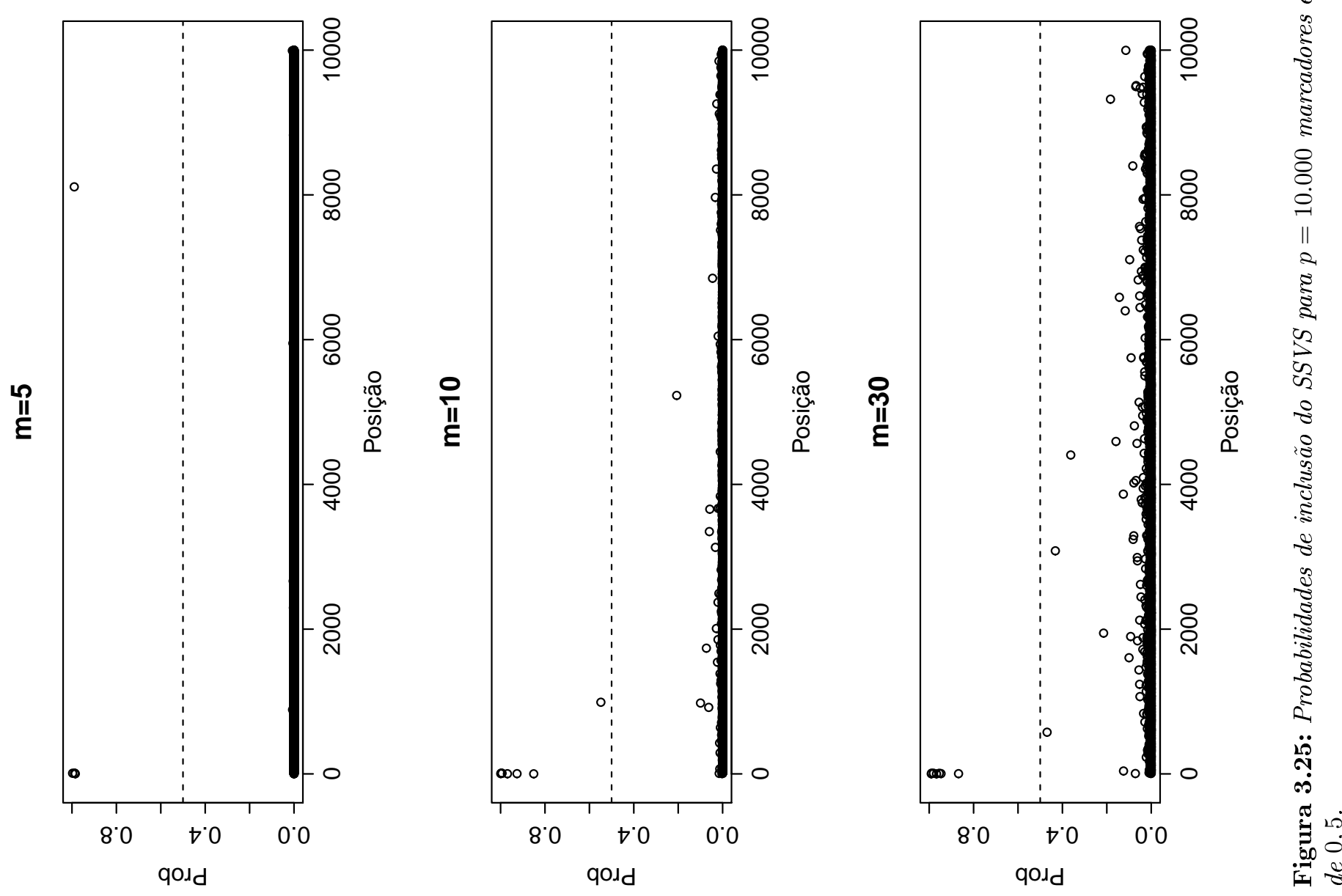
As estimativas dos efeitos dos marcadores encontram-se nas Figuras 3.26 e 3.27. De maneira similar aos cenários anteriores, a recuperação dos efeitos depende da probabilidade de seleção, sendo efetivamente zero se a variável não foi inserida no modelo. Observa-se que, apesar da recuperação pior em termos das probabilidades, a priori independente parece recuperar os efeitos com maior precisão.

Da série de simulações apresentadas podemos concluir que, para cenários mais complicados, nem todos os efeitos são recuperados a despeito de distribuições a priori ou parâmetros do SSVS. A priori identidade tem um desempenho comparável com a $g$-prior, amplamente utilizada na literatura, especialmente com um número elevado de covariáveis. Cabe notar ainda que, mesmo com a observável incapacidade do procedimento de detectar todos os marcadores, uma boa parte é detectada com um número muito pequeno de falsos positivos em todas as configurações, apesar do elevado número de falsos negativos no caso de efeitos pequenos.

Apesar de não termos avaliado esse aspecto nas simulações, sabe-se que a priori identidade ainda tem o benefício adicional de prover alguma robustez com respeito à multicolinearidade, uma possibilidade bem real em conjuntos de dados com SNPs. Além de erros no controle de qualidade dos dados, em situações práticas dois marcadores quaisquer ao longo do genoma podem apresentar alto desequilíbrio de ligação, tornando duas (ou mais) colunas da matriz $\boldsymbol{X}$ praticamente iguais, gerando matrizes de delineamento bem próximas de uma matriz singular.

Cabe citar que o estudo de simulação realizado até agora não é, de maneira alguma, exaustivo. As configurações apresentadas foram propositalmente escolhidas para servir à aplicação de interesse, e mesmo nesse propósito certas simplificações foram feitas. O número de graus de liberdade ao planejar uma simulação de um modelo multiníveis como o presente é extremamente elevado para permitir uma investigação exaustiva.

O número de itens e os valores de seus parâmetros de locação foram fixados de maneira a corresponder aos mesmos utilizados no Capítulo anterior de maneira a utilizar conjuntos de dados similares. A estrutura familiar utilizada também repetiu a estrutura das famílias de Baependi. Ainda na estrutura familiar, a herdabilidade do traço latente foi fixada em apenas um valor $\left(h^{2}=0,5\right)$, fixando-se, arbitrariamente as duas componentes da variância em 1. Outros valores poderiam ser contemplados de maneira a verificar o efeito de mais ruído nos efeitos poligênicos ou residuais na seleção de variáveis.

Utilizamos ainda apenas dois casos de prioris para os efeitos fixos, representando os dois extremos da priori proposta por Baragatti e Pommeret (2011), mas casos intermediários podem ser contemplados. A simulação dos marcadores através do SimPed (Leal et al., 2005) foi feita para $p$ marcadores em equilíbrio de ligação e sem mutações. Outras estruturas de dependência dos marcadores podem ser propostas como em Weinwurm et al. (2013).

Ainda, as métricas escolhidas para avaliar o estudo de simulação também podem ser estendidas. Foram utilizadas as estimativas das probabilidades de inclusão para avaliar a capacidade do SSVS de detectar cada posição em especial e os efeitos para compararmos a seleção via SSVS com o LASSO Bayesiano, mas outras métricas poderiam ser concebidas. Na presença de dependência entre as covariáveis, alguma medida de probabilidade conjunta da região poderia ser utilizada (Guan et al., 2011). Caso os custos computacionais em tempo e processamento se tornem menores, uma série de replicações poderia ser feita e a taxa de falsos positivos e negativos (Swartz et al., 2008), coerência geral do método de seleção (Somol e Novovicova, 2010) ou acurácia prevendo-se o traço latente em um analogo com a predição do efeito poligênico feita em Calus e Veerkamp (2011).

\subsection{Seleção de marcadores no projeto 'Corações de Baependi'}

O modelo multiníveis da TRI com seleção de variáveis através de SSVS foi aplicado em um conjunto de dados obtido do projeto 'Corações de Baependi' composto de medições dos mesmos $I=5$ sintomas do Capítulo anterior em $N=1.119$ indivíduos agrupados em $K=85$ famílias de tamanho médio de 13,16 indivíduos por família e tamanho mediano de 9 indivíduos por família.

O DNA de cada um desses indivíduos foi extraído a partir de amostras de sangue e a genotipagem 

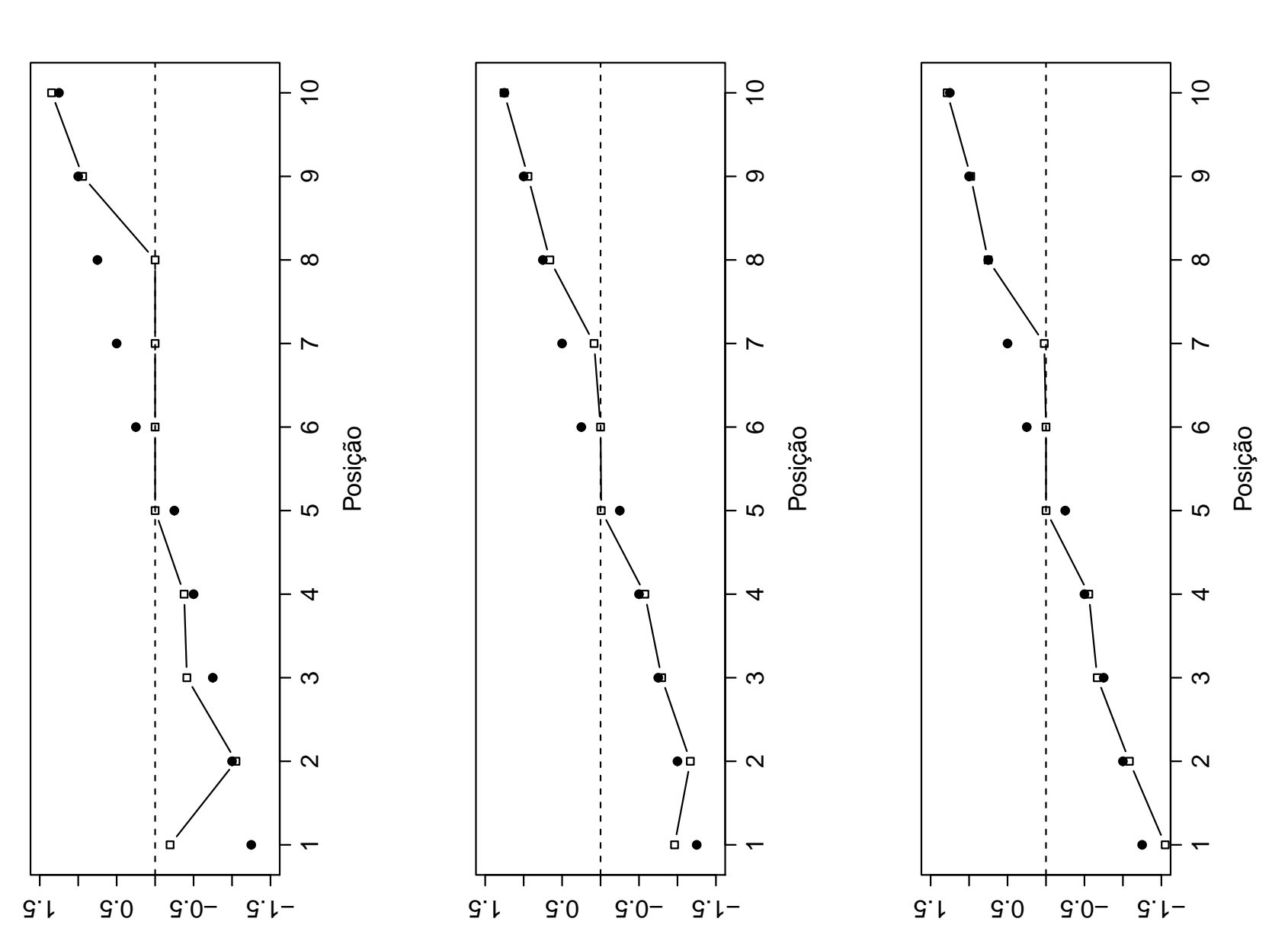

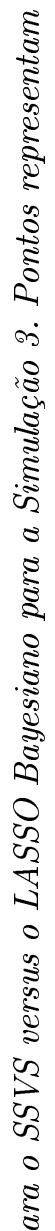
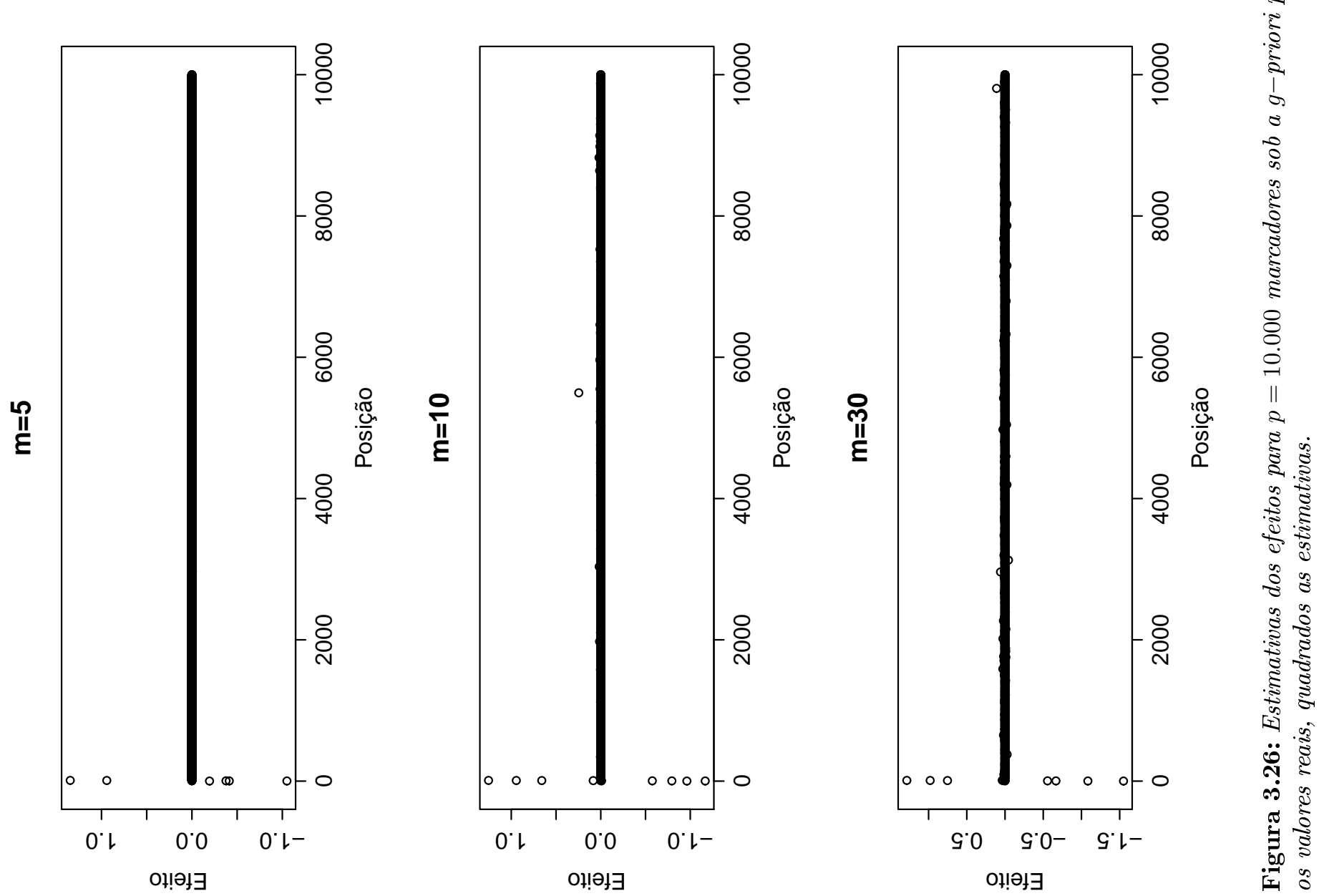

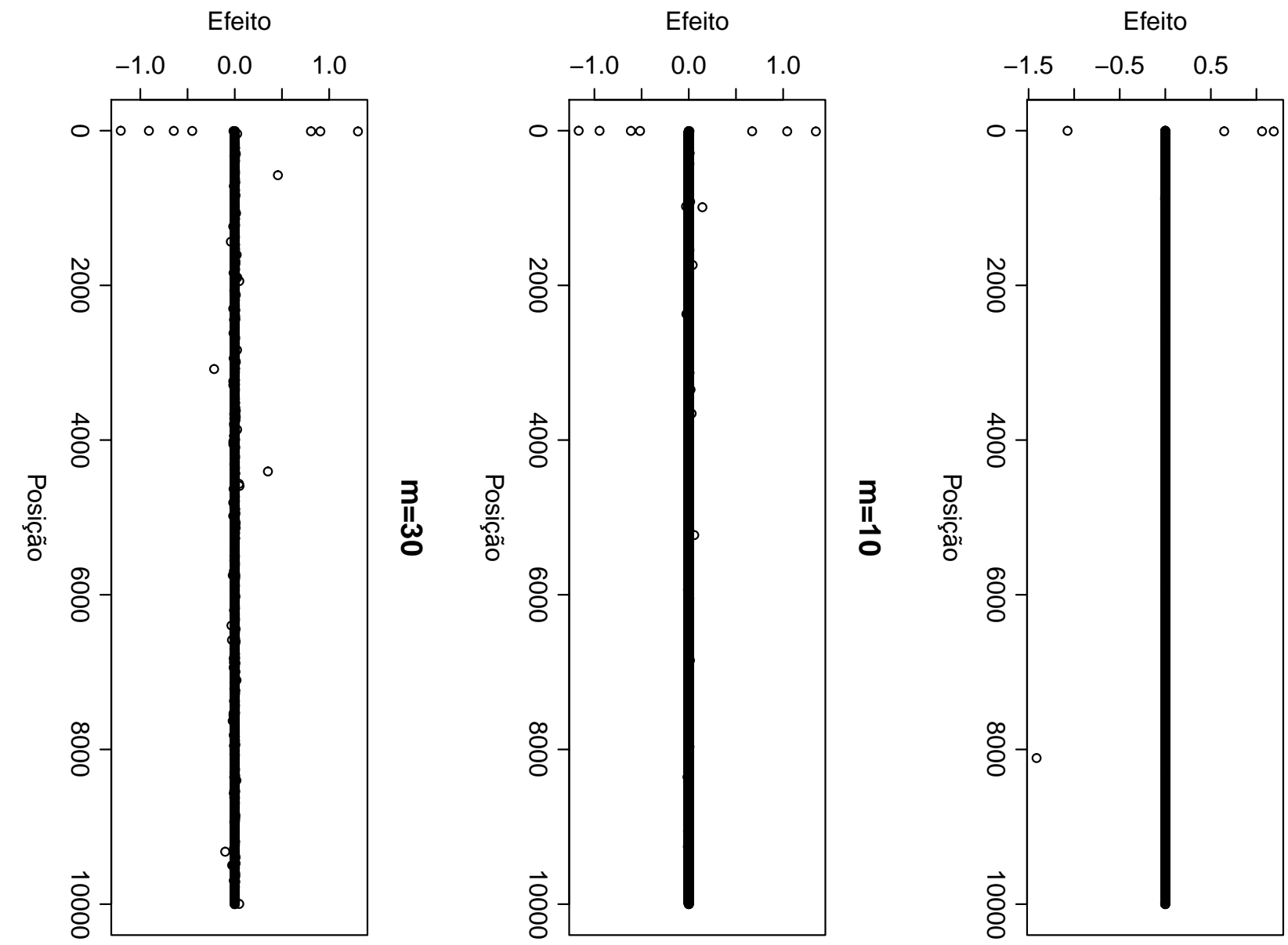

蒠

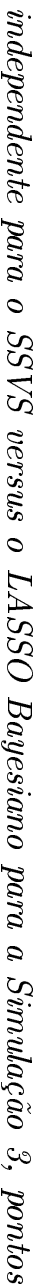
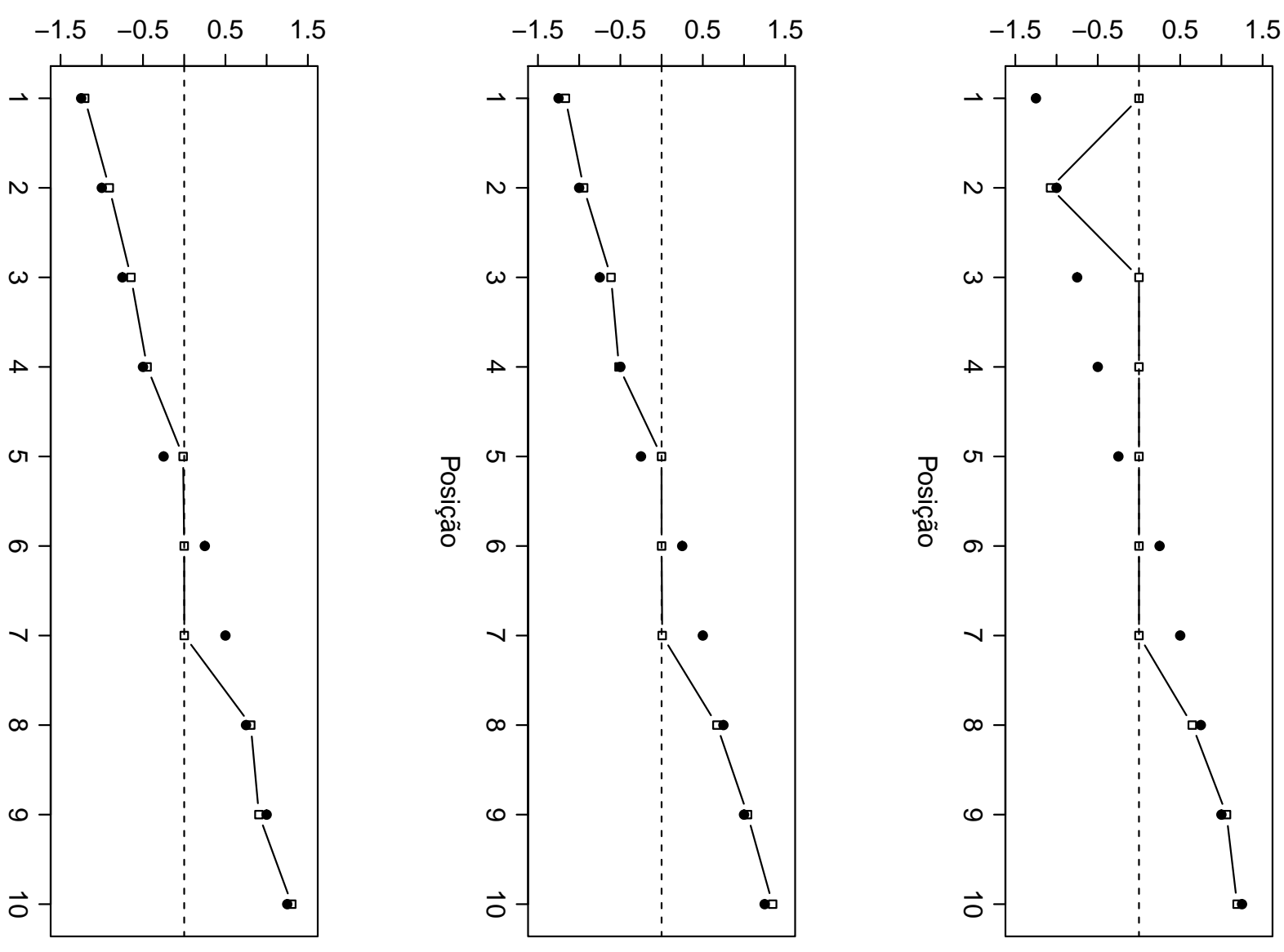
Tabela 3.4: Estimativas dos parâmetros do modelo multiníveis com seleção de variáveis para o conjunto de dados de Baependi

\begin{tabular}{rrrrr}
\hline Parâmetro & Média(DP) & Quantil $2.5 \%$ & Mediana & Quantil $97.5 \%$ \\
\hline$b_{1}$ & $0,47(0.20)$ & 0,07 & 0,49 & 0,82 \\
$b_{2}$ & $1,08(0.19)$ & 0,66 & 1,10 & 1,44 \\
$b_{3}$ & $0,48(0,21)$ & 0,03 & 0,49 & 0,83 \\
$b_{4}$ & $0,62(0,19)$ & 0,15 & 0,63 & 0,97 \\
$b_{5}$ & $0,10(0,20)$ & $-0,33$ & 0,11 & 0,44 \\
$\sigma_{g}^{2}$ & $0,16(0,04)$ & 0,09 & 0,15 & 0,25 \\
$\sigma_{e}^{2}$ & $0,18(0,04)$ & 0,10 & 0,17 & 0,28 \\
$h^{2}$ & $0,46(0,09)$ & 0,29 & 0,46 & 0,65 \\
$\beta_{1}$ & 0,74 & & & \\
$\beta_{2}$ & $-0,13$ & & & \\
$\beta_{410}$ & $-0,62$ & & & \\
\hline \multicolumn{5}{c}{}
\end{tabular}

foi feita usando-se o chip de SNPs da plataforma Affymetrics 6.0, resultando em 843.039 SNPs, que após um controle de qualidade consistindo da exclusão de loci monogênicos, loci posicionados nos cromossomos sexuais, com frequência do alelo menor que 5\%, com mais de $5 \%$ de observações faltantes, em desequilíbrio de Hardy-Weinberg e em desequilíbrio de ligação, produziu um conjunto de dados com $p=8.763$ marcadores aproximadamente independentes. Valores faltantes foram imputados utilizando as frequências alélicas marginais como em Wimmer et al. (2013).

Os fenótipos, genótipos de marcadores e matrizes de parentesco foram então fornecidos como entradas para o amostrador de Gibbs implementado em $\mathrm{R}$ para a seleção de variáveis no modelo multiníveis. O número de marcadores envolvidos na síndrome metabólica não é conhecido a priori então $m=30$ foi utilizado, tendo em vista seu desempenho superior no estudo de simulação. Pela mesma razão, a priori identidade foi assumida para os efeitos fixos. Monitorando a taxa de aceitação nas simulações, decidiu-se por eliminar uma variável por proposta no passo $\mathrm{MH}(s=1)$, resultando em taxas de aceitação próximas de $80 \%$.

Realizaram-se ainda 100 amostras do passo MH para cada uma dos $R=100.000$ realizações do amostrador de Gibbs, ao longo dos quais as cadeias observadas parecem ter atingido convergência. Cada uma das cadeias demorou aproximadamente 195 horas no cluster cedido pelo Laboratório de Genétia e Cardiologia Molecular do Instituto do Coração (LGCM-InCor). Para descartar a influência de valores iniciais pouco representativos da posteriori, os 10.000 primeiros valores da cadeia foram descartados.

As estimativas pontuais para os parâmetros resultantes das amostras da posteriori encontram-se na Tabela 3.4. O custo proibitivo de memória devido ao número elevado de covariáveis inviabilizou a obtenção de uma estimativa adequada para o desvio padrão ${ }^{12}$ e estimativas dos quantis.

As estimativas dos parâmetros dos itens se mostram menores às do Capítulo anterior, mas acompanhando a mesma tendência. Note, contudo, que a ordem dos itens se mantém a mesma. O sintoma com menor parâmetro de locação, e por isso requerendo menor valor do traço latente para uma alta probabilidade ainda é hipertensão $\left(b_{5}\right)$, baixo HDL $\left(b_{3}\right)$ praticamente idêntico à obesidade truncal $\left(b_{1}\right)$, seguido de alto índice de triglicérides $\left(b_{4}\right)$ e glicose em jejum $\left(b_{2}\right)$ como o fenótipo com o maior valor necessário para uma alta probabilidade.

As estimativas dos componentes da variância se mostram menores do que as do modelo com apenas os efeitos da idade, e a herdabilidade estimada é um pouco menor do que a do modelo sem variantes genéticas (0,53 sem marcadores, 0,46 nesse caso).indicando que este único SNP explica

\footnotetext{
${ }^{12}$ a soma das amostras é suficiente para a média amostral, mas a soma dos quadrados estima apenas um dos termos da variância da posteriori, subestimando substancialmente o desvio padrão se a autocorrelação é alta, como é o caso ajustando modelos da TRI (Fox, 2010; Geyer, 2011)
} 
parte da herdabilidade do traço latente. Considerando o problema de herdabilidade perdida ${ }^{13}$ que tem merecido muita atenção da literatura atualmente (Yang et al., 2010), este resultado é bastante importante pois a metodologia proposta neste trabalho foi capaz de identificar um único SNP que explica $7 \%$ da herdabilidade do traço latente da SM.

Apesar do número extremamente elevado de covariáveis, o resultado do processo de seleção de variáveis seleciona um número muito pequeno de marcadores. Apenas três covariáveis tiveram probabilidades maiores do que o ponto de corte de 0,5, como visto na Figura 3.28.

Esse fenômeno não é desconhecido mesmo em seleções de variáveis relacionadas diretamente com o fenótipo. Yi et al. (2003) encontra 5 marcadores em um estudo com cevada com centenas de marcadores. Em humanos, Srivastava e Chen (2010), acham entre 6 e 20 marcadores em 500.000, Baragatti (2011) acha um ou dois marcadores com probabilidade maior que $50 \%$ em 20.000 genes, e Guan et al. (2011) não parecem achar nenhum marcador em especial, recorrendo a métodos alternativos envolvendo a probabilidade conjunta de vizinhos de marcadores e de janelas de marcadores.

Os efeitos lineares e quadráticos da idade foram selecionados (com probabilidades $P\left(\widehat{\gamma_{1}=1} \mid \boldsymbol{Y}\right)=$ 0,99 e $P\left(\widehat{\gamma_{2}=1} \mid \boldsymbol{Y}\right)=0,94$ respectivamente) confirmando o papel dos efeitos da idade no índice de SM. Seus efeitos foram estimados em $\beta_{1}=0,74$ e $\beta_{2}=-0,13$, próximos dos obtidos na modelagem sem efeitos de marcadores.

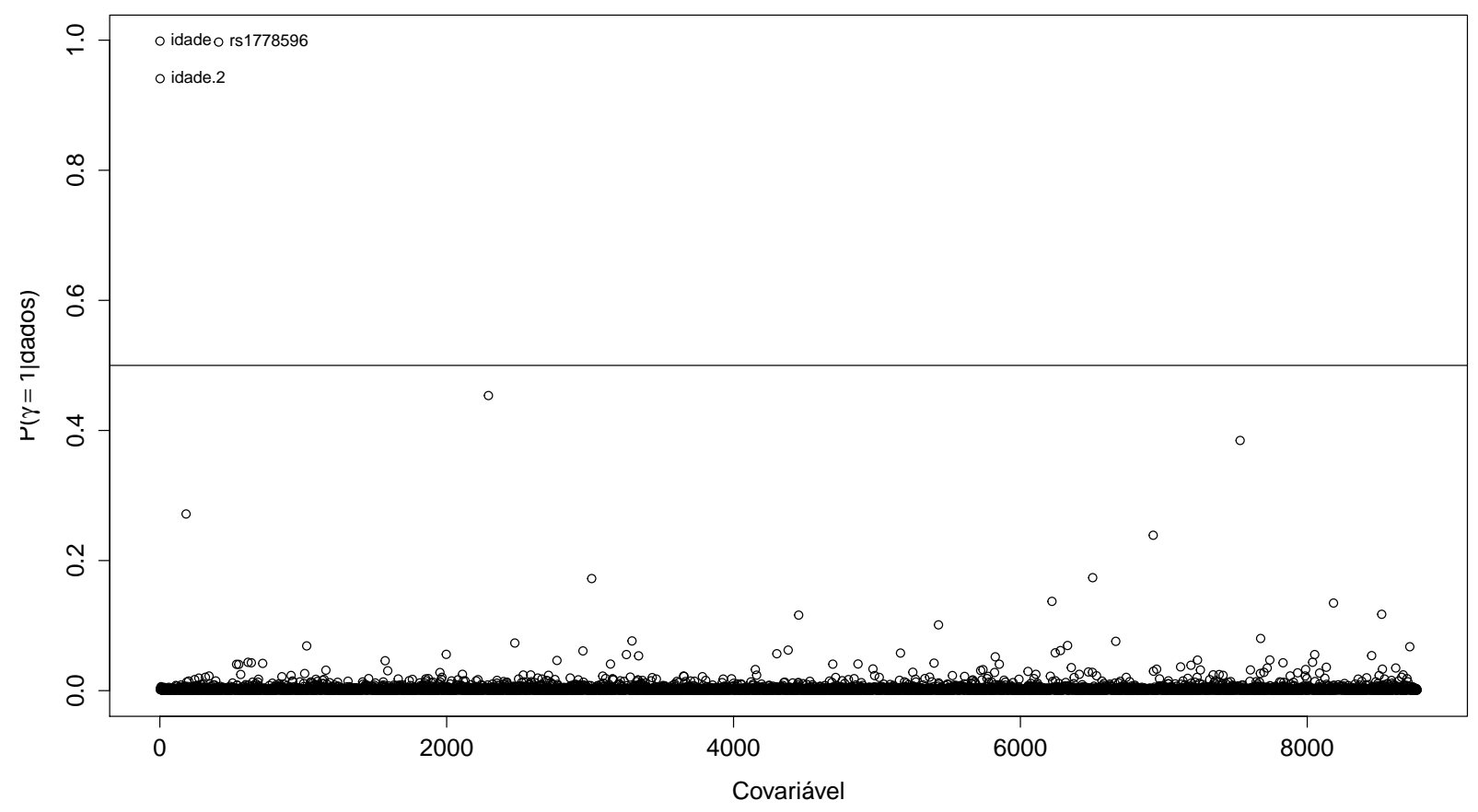

Figura 3.28: Probabilidades de inclusão para as covariáveis no estudo 'Corações de Baependi', a linha horizontal representa o ponto de corte de 0,5 .

O único marcador a ser selecionado no processo de escolha de variáveis foi a covariável de número 410, representando o SNP de código rs1778596, com $P\left(\widehat{\gamma_{410}=1} \mid \boldsymbol{Y}\right)=0,99$ e efeito estimado em $\beta_{410}=-0,62$, indicando que para cada alelo correspondente ao polimorfismo menos prevalente na população (cada par AT ao invés do par CG) o traço latente diminui em média 0,62.

Uma busca do SNP no site do centro nacional norte-americano de informação em biotecnologia $\left(\mathrm{NCBI}^{14}\right)$ não retorna muitas informações sobre esse SNP em particular. O mesmo nunca foi associado a nenhuma doença em estudos de associação ampla e está em uma região não responsável

\footnotetext{
${ }^{13}$ do inglês, missing heritability

${ }^{14}$ do inglês National Center for Biotechnology Information
} 
pela transcrição de proteínas do gene PDE4DIP, localizado no cromossomo 1. O gene PDE4DIP em particular foi associado com fenótipos relacionados a diabetes (Meigs et al., 2007).

A estrutura de dependência do genoma é tal que, apesar desse marcador em particular não parecer associado com alguma doença até o presente momento, o mesmo potencialmente pode marcar alguma região responsável pela suscetibilidade ao risco de doenças próximas ao marcador no genoma.

De fato, estudos indicam que essa região do cromossomo 1 parece estar associada com diversos sintomas da SM e diabetes como visto na Figura 3.29. O marcador está localizado em regiões associadas com obesidade (Chagnon et al., 2001; Diego et al., 2007; Pérusse et al., 2001), níveis de glicose (Ng et al., 2004) e pressão arterial (Ge et al., 2005).

A seleção desse marcador dá uma certa credibilidade para a modelagem da SM utilizando a TRI. A série de fenótipos (obesidade, colesterol, etc) é supostamente regulada em parte por um valor latente representando a SM. Dessa forma, um marcador associado com o traço latente pode ser interpretado como tendo um efeito sobre os fenótipos modulados pelo traço latente. De fato o marcador selecionado como mais associado com o traço latente encontra-se na intersecção de diversas regiões associadas com a série de fenótipos e com diabetes, diretamente influenciada pela SM.

Diabetes, doenças cardiovasculares e a síndrome metabólica são doenças complexas, cuja base genética é orquestrada por múltiplos genes em diversas locações do genoma com efeitos pequenos e interações complexas. Das simulações anteriores, vemos que os métodos de seleção adotados têm alta especificidade, mas são pouco sensíveis a efeitos pequenos, justificando parcialmente o diminuto número de covariáveis selecionadas. 


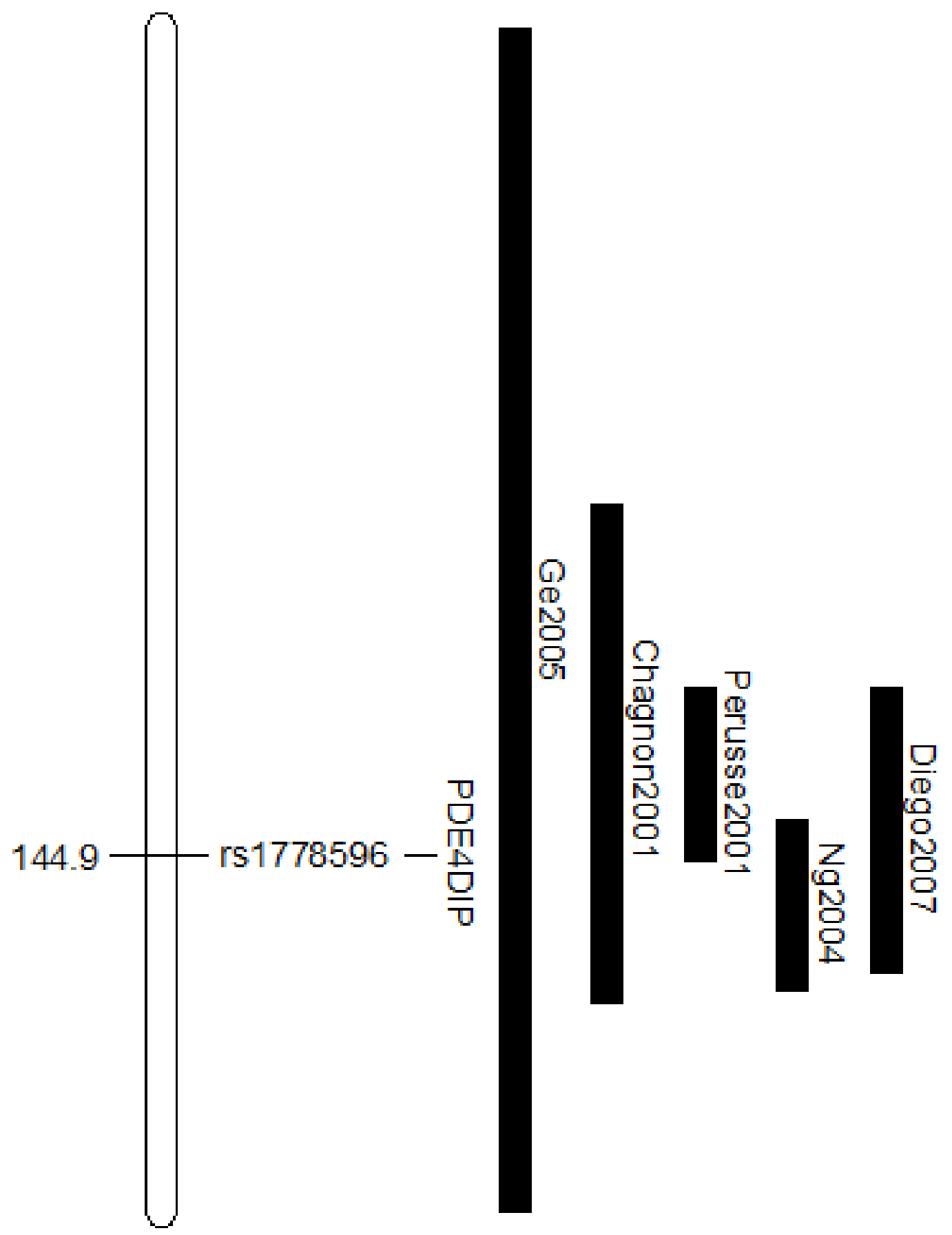

Figura 3.29: Mapa estilizado das regiões do Cromossomo 1 associadas na literatura com sintomas da SM relativas ao marcador encontrado na SSVS. 


\section{Capítulo 4}

\section{Conclusões e Estudos Futuros}

O presente trabalho propõe uma nova maneira de unificar múltiplas fontes de informação dicotômicas, planejamentos experimentais e confundidores através de um modelo multiníveis da TRI. $\mathrm{Na}$ aplicação considerada, o traço latente se mostrou capaz de modelar a síndrome metabólica (SM), recuperando propriedades conhecidas da doença. Tal modelagem pode fornecer a base para uma escala para a SM capaz de resistir a números diferentes de sintomas e diferentes critérios de diagnóstico.

Além do progresso na aplicação, o presente trabalho também fornece a derivação completa de um método de estimação Bayesiano para um modelo multiníveis utilizando a função de ligação logística, estendendo os resultados apresentados em Fu et al. (2009) para um modelo multiníveis com o modelo misto poligênico de genética quantitativa no segundo nível.

Em posse desses resultados, é possível estender o modelo de Rasch para modelos de dois ou três parâmetros, levando-se em conta que a presença de um parâmetro de escala (ou discriminação no contexto educacional) deve ser devidamente controlado para evitar problemas de identificabilidade em modelos multiníveis (Fox, 2010).

Como a dependência do segundo nível do modelo é apenas sobre o traço latente, o modelo pode também ser estendido para respostas em escala tipo Likert (Samejima, 1969) ou modelos no qual haja uma dependência não monotônica entre o traço latente e a probabilidade de resposta como o modelo de ponto ideal usado em Peress e Spirling (2010) e funções de ligação monotônicas assimétricas (Bazan et al., 2006). A própria forma da função de ligação poderia ser inferida utilizando-se as idéias propostas em Rossi et al. (2002), obtendo uma estimativa não paramétrica do traço latente em um modelo semiparamétrico.

O modelo misto também pode ser estendido em diversas direções. Por exemplo, o modelo hierárquico de Fox e Glas (2001) pode ser implementado de maneira análoga ao do presente trabalho provendo maneiras de dissecar cada um dos efeitos fixos em termos de suas próprias associações com covariáveis. A classe de modelos genéticos exposta em Almasy e Blangero (1998) pode ser implementada para modelar outras fontes de informação genética como loci idênticos por descendência (IBD ${ }^{1}$ ). O modelo não paramétrico envolvendo espaços de Hilbert de reprodução proposto em de los Campos et al. (2009a) poderia ser adaptado de maneira a flexibilizar o relacionamento entre o traço latente e a estrutura familiar e os marcadores em uma forma alternativa de modelo semiparamétrico.

Outra direção promissora pouco explorada no presente trabalho é a verificação do ajuste do modelo aos dados. Através de checagens preditivas da posteriori, o modelo foi avaliado com respeito à sua capacidade de prever a distribuição dos escores, um critério popularmente adotado para a síndrome metabólica além de prover um bom índice de ajuste global do modelo da TRI aos dados (Beguin e Glas, 2001).

Entretanto, outras características dos dados podem ser exploradas. Em uma análise preliminar, itens relativos a outros lipídios (como LDL e colesterol total) foram excluídos por serem claramente dependentes, violando a premissa de independência local. Além disso, as correlações ponto-bisserial

\footnotetext{
${ }^{1}$ do inglês Identical by Descent
} 
foram calculadas para cada item e sua similaridade foi utilizada como um argumento em favor do modelo de Rasch. Ambas as premissas podem ser mais profundamente investigadas utilizado-se medidas de divergência adequadas em uma checagem preditiva (Sinharay e Lu, 2008; Sinharay et al., 2006).

A verificação também pode ser feita para o modelo misto no segundo nível do modelo multiníveis. Fox (2010) propõe o uso do DIC, que em conjunto com o Fator de Bayes foi o utilizado no Capítulo 2 para rejeitar a inclusão de um efeito de ambiente compartilhado. Apesar da dificuldade em escolher alguma medida de discrepância no segundo nível (Sinharay e Stern, 2003) representando que qualidade dos dados o segundo nível do modelo deve prever (Gelman, 2007), checagens preditivas podem ser concebidas nesse nível.

De maneira complementar à verificação do ajuste do modelo com as covariáveis selecionadas, o processo de seleção em si poderia ser avaliado de maneira mais profunda do que a análise descritiva (utilizando os efeitos e probabilidades) considerada na simulação do Capítulo 3. Realizar replicações do processo de seleção se mostrou proibitivo devido ao custo computacional, mas em posse de réplicas, uma verificação da consistência do processo de seleção poderia ser avaliada em termos da estatística proposta em Somol e Novovicova (2010). Além disso, com a performance do processo de seleção em classificar cada covariável, pode-se ilustrar a especificiade e sensibilidade do processo de maneira gráfica através de pontos no espaço ROC ${ }^{2}$.

Concluímos no Capítulo 2 que os parâmetros estruturais (no sentido de Neyman e Scott (1948)) são recuperados com grande precisão e pouco viés em todas as configurações, enquanto os parâmetros incidentais são estimados com precisão mas com um enorme viés. O estudo fixou alguns dos muitos graus de liberdade possíveis e uma direção de interesse é o número de itens necessários para uma boa recuperação dos traços latentes. Alguns estudos foram feitos (Borgatto et al., 2013) para modelos da TRI sem níveis adicionais, mas estudos podem ser feitos no contexto do modelo multiníveis.

No Capítulo 3, todos os efeitos fixos, compreendendo os efeitos relativos a idade e os marcadores moleculares foram submetidos ao processo de seleção. Tal medida foi empregada com o objetivo de obter uma validação do traço latente da TRI como uma medida da doença. A presença das covariáveis envolvendo os efeitos da idade no processo de seleção podem potencialmente prejudicar a seleção de alguns marcadores moleculares, estes mais associados com a componente ambiental levando-os a serem ignorados pelo processo por conta dos efeitos maiores associados à idade.

Para tal, pode ser empregada a formulação usada em Vazquez et al. (2012) onde os efeitos fixos são escritos como

$$
\boldsymbol{\beta}_{1} \boldsymbol{X}_{1}+\boldsymbol{\beta}_{2} \boldsymbol{X}_{2}
$$

onde $\boldsymbol{\beta}_{1}$ é um vetor $1 \times p_{1}$ representando os efeitos fixos dos confundidores ( $p_{1}=2$ no caso) com respectivas covariáveis na matrix $N \times p_{1}$ denotada por $\boldsymbol{X}_{1}$ e $\boldsymbol{\beta}_{2}$ é um vetor $1 \times p_{2}$ representando os marcadores na matriz $N \times p_{2}$ denotada por $\boldsymbol{X}_{2}$. O amostrador de Gibbs proposto no Capítulo 3 poderia ser adaptado para um passo que estime o primeiro vetor utilizando o mesmo passo do Capítulo 2 e realize a seleção sobre o segundo, dadas as devidas modificações nas condicionais.

Como mencionado anteriormente, marcadores moleculares apresentam uma complexa estrutura de dependência que pode ser inserida no modelo para inferir relacionamentos biológicos e aumentar o desempenho do processo de seleção. Medidas descritivas do desequilíbrio de ligação podem ser inseridos na distribuição a priori dos efeitos (Swartz et al., 2008), potencialmente melhorando o desempenho dos métodos apresentados.

Os indicadores utilizados no SSVS e sua respectiva distribuição a priori podem ser utilizados para traduzir diversas características biológicas. A dependência espacial dos marcadores com seus vizinhos pode ser modelada através de um campo markoviano, estendendo os resultados de Li e Zhang (2010).

Os marcadores encontram-se apenas em uma das pontas da cadeia entre o genótipo e o fenótipo,

\footnotetext{
${ }^{2}$ do inglês, Receiver Operating Characteristic
} 
fazendo parte da expressão de um gene, este inserido em uma via metabólica. Essas estruturas podem ser inseridas (e selecionadas) no SSVS utilizando a modelagem de Stingo et al. (2011).

Além dessas propriedades mais amplas dos marcadores, interações entre marcadores ${ }^{3}$ podem ser modelados. Sugestões para o modelo de regressão linear múltipla foram dadas em Yi et al. (2003) e Oh et al. (2003) e poderiam ser estendidas para o modelo misto no nível estrutural.

O comportamento do marcador sobre o traço latente também pode ser selecionado. As parametrizações utilizadas implicam em um efeito aditivo do marcador, com cada cópia adicionando (ou subtraindo) em média ao traço latente. Esse modelo dos marcadores ignora potenciais comportamentos de dominância que possam existir nos alelos. Seleções para parametrizações dos marcadores em modelos de regressão foram sugeridas em Wilson et al. (2010).

O presente trabalho também se diferencia das aplicações usuais da TRI pela escolha dos itens utilizados. Frequentemente modelos da TRI são aplicados em dados obtidos de questionários ou inventários especialmente preparados para avaliar um construto de interesse. Apesar do uso da TRI em indicadores presentes nos dados com o objetivo de caracterizar um construto em Ciências Políticas (por exemplo democracia em Treier e Jackman (2008)), a presente aplicação parece ser a primeira utilizando sintomas com o objetivo de descrever uma doença.

Esse uso de indicadores ao invés de itens previamente preparados demanda alguns cuidados com respeito à identificação do traço latente, a presença da independência local e da abrangência dessa premissa nos modelos multinível. São expostos aqui alguns grafos análogos aos utilizados por Pearl (2000), os quais são similares aos diagramas de caminho utilizados nos modelos de equações estruturais. A representação gráfica permite que as premissas de independência local sejam vistas com bem mais clareza.

Variáveis observadas são denotadas por retângulos, enquanto variáveis latentes são denotadas por círculos e ligamos duas variáveis por uma seta se existe uma relação funcional entre as duas. Por exemplo, a Figura 4.1 representa um modelo de regressão linear com erro $e$, covariáveis $X$ e variável resposta $Y$.

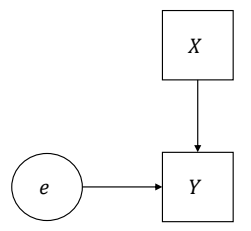

Figura 4.1: Um grafo orientado acíclico para um modelo de regressão linear

Emprestando a notação simbólica de Pearl (2000), na qual cada variável recebendo setas no diagrama pode ser escrita em termos das variáveis produzindo setas, escreve-se a Figura 4.1, na forma

$$
Y=f(X, e),
$$

com eventuais parâmetros adicionais relativos a cada ligação e a cada variável no grafo. No caso, a ligação entre $Y$ e $X$ tem o vetor de efeitos fixos $\beta$ como parâmetro e a variável latente $e$ é somada com peso 1 em $Y$ e assume usualmente uma distribuição $N\left(0, \sigma^{2}\right)$.

\footnotetext{
${ }^{3}$ um fenômeno denominado epistasia em genética
} 
A representação se faz útil em modelos mais complicados como modelos multiníveis no qual os relacionamentos são bem diferentes. De fato, podemos representar a modelagem utilizada no presente trabalho como o grafo da Figura 4.2

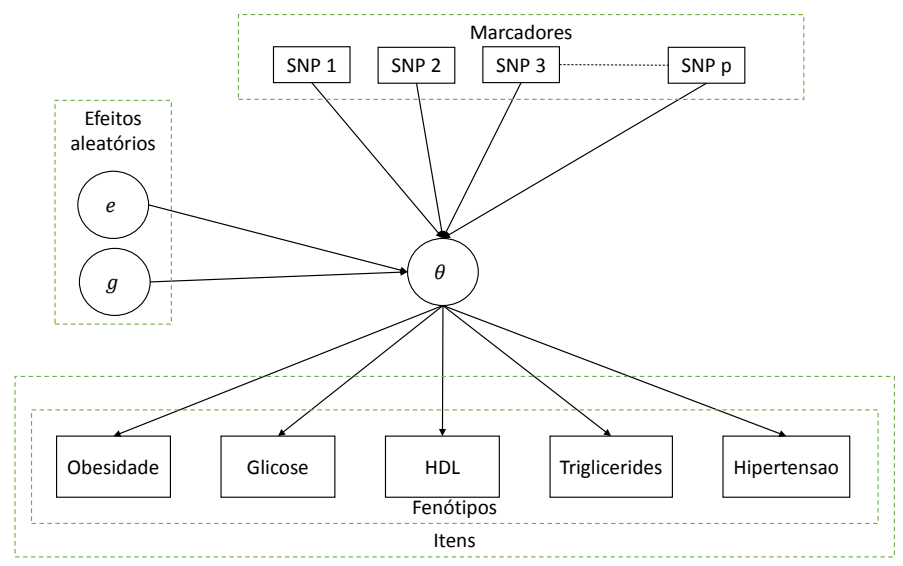

Figura 4.2: Um grafo orientado acíclico para o modelo multiníveis da TRI

no qual a seta ligando os marcadores e efeitos aleatórios ao traço latente $\theta$ representa um relacionamento linear, mas as setas ligando o traço aos fenótipos representam o relacionamento estocástico expresso pelo modelo da TRI.

A representação gráfica representa diretamente a dependência entre os parâmetros. De fato, utilizando critérios para $d$-separação (Pearl, 2000), podemos observar a premissa de independência condicional. Fixando-se um valor de $\theta$, note que não existem caminhos entre quaisquer dois fenótipos na Figura 4.2, implicando que quaisquer dois itens são localmente independentes dado o traço latente como assumido em modelagens com a TRI.

Nota-se ainda que essa formulação também permite observar duas premissas tácitas da modelagem previamente ignoradas.

Primeiramente, o traço latente mostra-se o mediador para toda a ação da genética sobre os fenótipos. Fixando-se um valor para o traço, não só os fenótipos são independentes, como também os marcadores se mostram condicionalmente independentes dos fenótipos, assim como o efeito poligênico se mostra independente dos fenótipos.

Além disso, o traço latente é dito uma colisão para os marcadores e o efeito poligênico. Fixar o valor do traço latente cria dependências entre os efeitos ambientais e poligênicos, e entre os efeitos aleatórios e os marcadores. Tal conclusão parece contra-intuitiva, mas pode ser vista da seguinte maneira. Se observamos um traço latente igual a 0 , os efeitos aleatórios e dos marcadores não podem mais variar livremente. A soma de todos deve ser zero, criando uma dependência ${ }^{4}$.

A primeira premissa se mostra uma afirmação possivelmente restringente na modelagem. De acordo com o modelo, o traço latente é o único mediador entre os marcadores e o fenótipo. Dessa forma, todo marcador associado com o traço latente tem efeito sobre todos os fenótipos em um efeito pleiotrópico ${ }^{5}$.

Diversas regiões do genoma estão associadas com a SM, mas também certas regiões podem estar associadas apenas com o colesterol, ou ainda contribuírem com a SM com um efeito pronunciado em um (ou mais) fenótipos em particular. Uma representação dessa situação pode ser vista na Figura 4.3. O SNP 3 age apenas sobre a triglicérides, não associado com a SM, o SNP $p$ age apenas sobre a hipertensão e o SNP 2 tem um efeito sobre o traço latente, mas tem mais efeito sobre a hipertensão do que sobre os outros fenótipos.

Uma outra possibilidade é a existência de outros traços latentes agindo sobre grupos particulares

\footnotetext{
${ }^{4}$ esse tipo de colisão é denominado 'viés de confirmação' em Pearl (2000)

${ }^{5}$ quando uma região do genoma afeta diversos fenótipos distintos e não necessariamente relacionados
} 


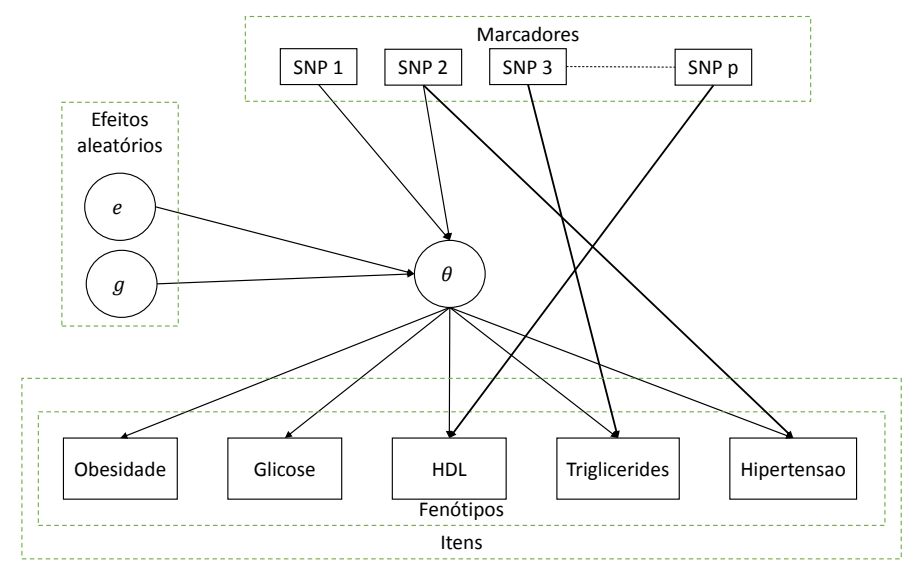

Figura 4.3: Grafo orientado acíclico para SNPs agindo diretamente sobre os itens

de fenótipos, representando denominadores comuns a certos fenótipos não relacionados com a SM em um modelo do tipo bi-fatorial (Gibbons e Hedeker, 1992). Um grafo orientado poder ser visto na Figura 4.4, na qual uma outra variável latente age apenas sobre a Glicose e o Triglicérides, sendo influenciada por um conjunto particular de marcadores genéticos.

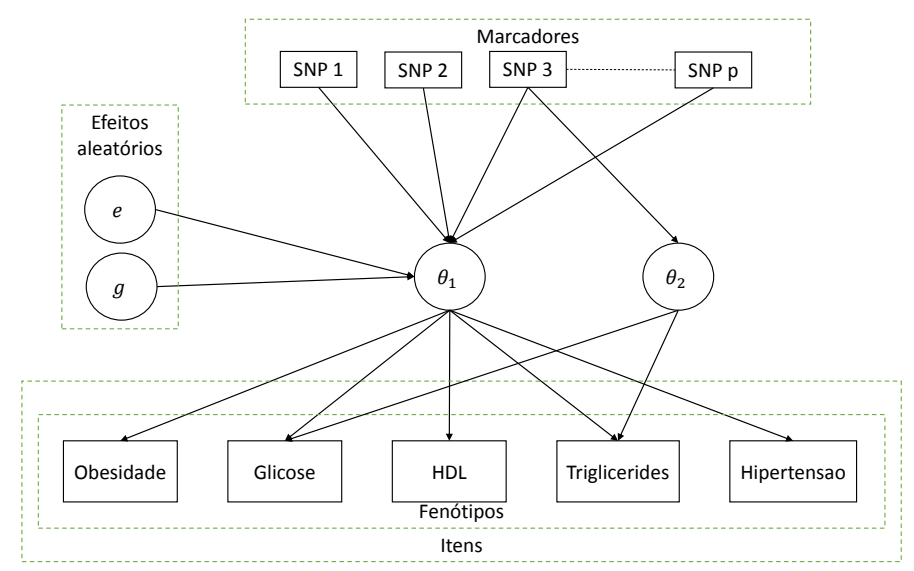

Figura 4.4: Grafo orientado acíclico para um modelo bi-fatorial englobando a SM

Além da independência condicional entre marcadores e fenótipos, a premissa de independência condicional entre fenótipos pode ser questionada. A independência condicional é fundamental para a estimação nos modelos da TRI, e violações óbvias foram retiradas. ${ }^{6}$, mas é concebível que outros relacionamentos existam entre os fenótipos. Por exemplo, níveis elevados de glicose podem ter um efeito sobre o peso do indivíduo, causando obesidade.

Essa situação encontra-se na Figura 4.5, onde podemos ver uma seta indicando a ação da glicose sobre a obesidade em adição a SM.

Para esse caso, a abordagem com a TRI é insuficiente, mas um modelo de Equações Estruturais (MEE) talvez seja capaz de investigar esse comportamento. A ligação entre os modelos da TRI e MEE são um tópico pouco explorado na literatura (Lu et al., 2005), mas oferecem o potencial de modelar esse tipo de interação utilizando modelos não lineares de equações estruturais (Lee et al., 2010).

A direção das setas, indo dos marcadores para o traço latente e para os fenótipos também são

\footnotetext{
${ }^{6}$ Oliveira et al. (2008) usam baixo LDL e coleterol total além dos 5 itens do presente trabalho, ambos com alta correlação com HDL
} 


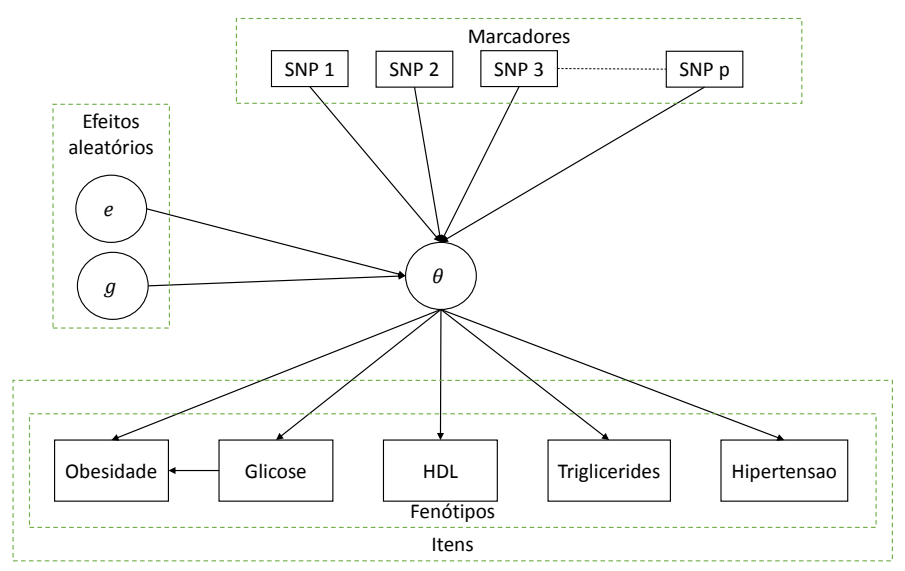

Figura 4.5: Grafo orientado acíclico para o efeito de fenótipos sobre outros fenótipos

uma premissa do modelo. Assume-se os marcadores como variáveis agindo sobre a SM. Por outro lado, poderia ser de interesse utilizar os fenótipos e os marcadores como itens em um modelo da TRI, como representado na Figura 4.6.

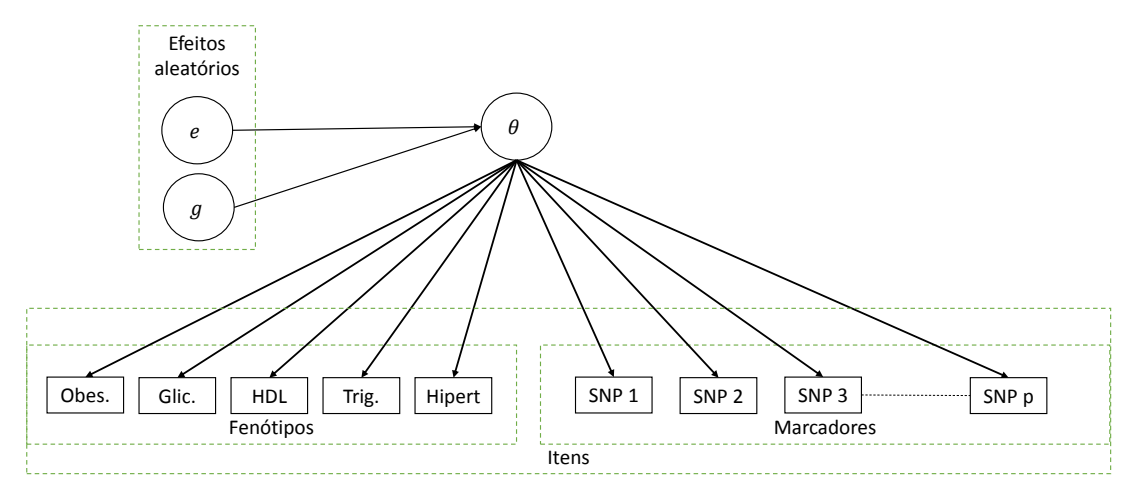

Figura 4.6: Um grafo orientado acíclico para SNPs como itens

O traço latente aqui retém algumas características do traço identificado com a SM do modelo hierárquico do presente trabalho. Esse traço também agrega informações fenotípicas, e dado um conjunto de $p$ SNPs, pode ser interpretado como um índice de SM combinando os sintomas e o genótipo. O efeito poligênico continua relevante, pois da mesma maneira que indivíduos da mesma família podem ter fenótipos próximos, o parentesco obviamente influencia a ocorrência de um genótipo em cada local.

Observa-se ainda que, sob esse modelo, os marcadores e os fenótipos são localmente independentes, o que é plausível dada a definição, em princípio, do traço latente no parágrafo anterior, mas o efeito poligênico e o genótipo também são localmente independentes, o que pode não ser uma premissa adequada. Eventuais efeitos fixos sobre o traço latente são assumidos agindo sobre ambos, fenótipo e genótipo, o que pode ser conflitante na prática.

Por outro lado, com um traço latente bem definido, o mesmo tem indicações de que seria bem estimado. Como visto no Capítulo 2, grande parte do erro na predição do traço latente se deve ao viés possivelmente causado pelo número pequeno de itens por indivíduo, estes incapazes de mitigar o encolhimento para a esperança a priori do traço latente. Nesse caso, o elevado número de marcadores potencialmente empregados podem diminuir esse viés e prover estimativas mais precisas do traço 
latente. 


\section{Apêndice A}

\section{Condicionais completas para o nível funcional}

Nesse apêndice, é feita a derivação das condicionais completas para os parâmetros do nível funcional do modelo multiníveis (dados aumentados, parâmetros de lotação, traços latentes).

Iniciam-se com algumas derivações preliminares na função de verossimilhança e prossegue-se para a derivação das condicionais completas utilizadas no Capítulo 2.

\section{A.1 Preliminares}

Considere a mesma notação do Capítulo 2 para os dados e parâmetros do modelo. Sejam $\boldsymbol{Y}=$ $\left(Y_{111}, \cdots, Y_{i j k}, \cdots, Y_{I n_{K}, K}\right)$ as respostas aos $i=1, \cdots, I, \operatorname{dos} j=1, \cdots, n_{k}$ indivíduos das $k=$ $1, \cdots, K$ famílias. Considere o modelo de Rasch

$$
P_{i j k}=P\left(Y_{i j k}=1 \mid b_{i}, \theta_{j k}\right)=\frac{1}{1+\exp \left(-\left(\theta_{j k}-b_{i}\right)\right)},
$$

com parâmetros de locação $b_{i}$ para dada item e traço latente $\theta_{j k}$ para cada indivíduo $j$ na família $k$.

Recorde que o esquema de dados aumentados de Fu et al. (2009) utiliza as variáveis uniformes $U_{i j k} \sim U(0,1)$ independentes e identicamente distribuídas tais que

$$
Y_{i j k}=I\left(U_{i j k} \leq P_{i j k}\right)
$$

resultando na contribuição à verossimilhança completa do item $i$ respondido pelo indivíduo $j$ da família $k$ denotada por $L_{i j k}$ e dada por

$$
L_{i j k}=I\left(Y_{i j k}=1\right) P_{i j k}+I\left(Y_{i j k}=0\right)\left(1-P_{i j k}\right)
$$

que é igual à esperança da componente da verossimilhança dos dados completos com respeito aos dados aumentados dada por

$$
L_{i j k}^{c}=I\left(Y_{i j k}=1\right) I\left(U_{i j k} \leq P_{i j k}\right)+I\left(Y_{i j k}=0\right) I\left(U_{i j k}>P_{i j k}\right) .
$$

Considere a contribuição do item $i$ a verossimilhança completa, denotada por $L_{i}^{c}$ e dada por

$$
L_{i}^{c}=\prod_{k=1}^{K} \prod_{j=1}^{n_{k}} L_{i j k}^{c} .
$$

Para a obtenção da condicional completa de $b_{i}$, é de interesse escrever $L_{i}^{c}$ como uma função de $b_{i}$. Defina os subconjuntos de índices, dadas realizações das variáveis aumentadas $u_{i j k}$, 


$$
C_{i}=\left\{j, k \mid u_{i j k}>P_{i j k}\right\}
$$

$\mathrm{e}$

$$
D_{i}=\left\{j, k \mid u_{i j k} \leq P_{i j k}\right\} .
$$

Note que, para os indivíduos contidos em $C_{i}$, segue que $b_{i}$ atende

$$
\begin{array}{r}
u_{i j k}>P_{i j k} \\
u_{i j k}>\frac{1}{1+\exp \left\{-\left(\theta_{j k}-b_{i}\right)\right\}} \\
\frac{u_{i j k}}{1-u_{i j k}}>\exp \left\{\theta_{j k}-b_{i}\right\} \\
\log \left(\frac{u_{i j k}}{1-u_{i j k}}\right)>\theta_{j k}-b_{i} \\
b_{i}>\theta_{j k}-\log \left(\frac{u_{i j k}}{1-u_{i j k}}\right)
\end{array}
$$

Note que essas inequações dependem apenas da forma algébrica do modelo de Rasch. De maneira análoga para os indivíduos em $D_{i}$,

$$
b_{i} \leq \theta_{j k}-\log \left(\frac{u_{i j k}}{1-u_{i j k}}\right)
$$

Podemos reescrever (A.5) em função de $b_{i}$ como

$$
L_{i}^{c}=\prod_{(j, k) \in C_{i}} I\left(b_{i}>\theta_{j k}-\log \left(\frac{u_{i j k}}{1-u_{i j k}}\right)\right) \prod_{(j, k) \in D_{i}} I\left(b_{i} \leq \theta_{j k}-\log \left(\frac{u_{i j k}}{1-u_{i j k}}\right)\right) .
$$

Cada uma das duas parcelas do produto anterior pode ser escrita como

$$
\prod_{(j, k) \in C_{i}} I\left(b_{i}>\theta_{j k}-\log \left(\frac{u_{i j k}}{1-u_{i j k}}\right)\right)=I\left(b_{i}>b_{i}^{L}\right),
$$

com

$$
b_{i}^{L}=\max _{j \in C_{i}}\left\{\theta_{j k}-\log \left(\frac{u_{i j k}}{1-u_{i j k}}\right)\right\},
$$

e

$$
\prod_{(j, k) \in D_{i}} I\left(b_{i} \leq \theta_{j k}-\log \left(\frac{u_{i j k}}{1-u_{i j k}}\right)\right)=I\left(b_{i}<b_{i}^{R}\right)
$$

com

$$
b_{i}^{R}=\min _{j \in D_{i}}\left\{\theta_{j k}-\log \left(\frac{u_{i j k}}{1-u_{i j k}}\right)\right\},
$$

resultando em

$$
L_{i}^{c}=I\left(b_{j k}^{L}<b_{j k}<b_{j k}^{R}\right) .
$$

De maneira análoga, podemos definir a contribuição do indivíduo $j$ da família $k$ à função de verossimilhança completa por 


$$
L_{j k}^{c}=\prod_{i=1}^{I} L_{i j k}^{c},
$$

a qual pode ser escrita em função do traço latente $\theta_{j k}$ com o auxílio dos conjuntos definidos por

$$
C_{j k}=\left\{i: u_{i j k}>P_{i j k}\right\}
$$

e

$$
D_{j k}=\left\{i: u_{i j k} \leq P_{i j k}\right\} .
$$

De uma derivação análoga à contribuição do item $i$, têm-se que

$$
L_{j k}^{c}=I\left(\theta_{j k}^{L}<\theta_{j k}<\theta_{j k}^{R}\right),
$$

onde

$$
\theta_{j k}^{L}=\max _{i \in D_{j k}}\left\{b_{i}+\log \left(\frac{u_{i j k}}{1-u_{i j k}}\right)\right\}
$$

$\mathrm{e}$

$$
\theta_{j k}^{R}=\min _{i \in C_{j k}}\left\{b_{i}+\log \left(\frac{u_{i j k}}{1-u_{i j k}}\right)\right\} .
$$

\section{A.2 Condicionais completas}

Com as identidades estabelecidas entre a verossimilhança completa e os indicadores, podemos então derivar as condicionais completas.

Retomando-se do Capítulo 2, dadas as prioris lá estabelecidas, a posteriori completa é proporcional a

$$
\begin{array}{r}
\pi\left(\boldsymbol{\theta}, \boldsymbol{b}, \boldsymbol{\beta}, \sigma_{e}^{2}, \sigma_{g}^{2} \mid \boldsymbol{X}, \boldsymbol{Y}, \boldsymbol{U}\right)=\prod_{i=1}^{I} \prod_{k=1}^{K} \prod_{j=1}^{n_{k}} L_{i j k}^{c} \pi\left(b_{i}\right) \pi\left(\boldsymbol{\theta}_{. k} \mid \boldsymbol{g}_{k}, \boldsymbol{\beta}, \sigma_{e}^{2}\right) \pi\left(\boldsymbol{g}_{k} \mid \sigma_{g}^{2}\right) \\
\pi(\boldsymbol{\beta}) \pi\left(\sigma_{g}^{2}\right) \pi\left(\sigma_{e}^{2}\right),
\end{array}
$$

a qual é avaliada em função dos diferentes parâmetros do modelo para derivar as condicionais completas do amostrador de Gibbs.

Para cara uma das variáveis aumentadas $U_{i j k}$ utiliza-se um esquema de amostragem condicional também utilizado em Albert (1992). Para cada valor da resposta ao item, uma condicional diferente é amostrada.

Note que os dados aumentados figuram na posteriori do modelo apenas através da contribuição da verossimilhança completa (equação (A.4)), na qual os dados aumentados figuram em um indicador.

Separando em dois casos, se $Y_{i j k}=0$, tem-se

$$
\pi\left(U_{i j k} \mid \cdot\right) \propto\left\{\begin{array}{l}
1, \text { se } P_{i j k}<U_{i j k}<1 \\
0, \text { caso contrário }
\end{array},\right.
$$

idêntico ao núcleo de uma distribuição $U\left(P_{i j k}, 1\right)$.

Da mesma forma, se $Y_{i j k}=1$,

$$
\pi\left(U_{i j k} \mid \cdot\right) \propto\left\{\begin{array}{l}
1, \text { se } 0<U_{i j k}<P_{i j k} \\
0, \text { caso contrário }
\end{array},\right.
$$


idêntico ao núcleo de uma distribuição $U\left(0, P_{i j k}\right)$.

Para cada um dos parâmetros de locação $b_{i}, i=1, \cdots, I$, note que os parâmetros de locação figuram em dois lugares na posterori. No indicador (A.19) e na priori $\pi\left(b_{i}\right)$.

Dessa forma, podemos escrever a condicional completa para $b_{i}$ como

$$
\pi\left(b_{i} \mid \cdot\right) \propto \pi\left(b_{i}\right) I\left(b_{i}^{L}<b_{i}<b_{i}^{R}\right),
$$

com os limites de truncamento dados pelas equações (A.16) e (A.18) e idêntica ao núcleo da distribuição a priori $\pi\left(b_{i}\right)$ truncada entre os dois limites $b_{i}^{L}$ e $b_{i}^{R}$. No modelo do capítulo 2, supõe-se uma normal a priori, portanto, obtém-se uma normal truncada.

Para os traços latentes, a derivação é análoga. Note que, dado o efeito aleatório $g_{j k}$ cada traço latente é assumido normal a priori com média $\mu_{j k}=\boldsymbol{X}_{j k} \beta+g_{j k}$ e variância $\sigma_{e}^{2}$. Portanto,

$$
\pi\left(\theta_{j k} \mid \cdot\right) \propto \phi\left(\frac{\theta_{j k}-\mu_{j k}}{\sigma_{e}}\right) I\left(\theta_{j k}^{L}<\theta_{j k}<\theta_{j k}^{R}\right),
$$

$\phi(\cdot)$ representa a função densidade de probabilidade da distribuição normal padrão. A condicional é idêntica ao núcleo de uma distribuição normal centrada em $\mu_{j k}$ com variância $\sigma_{e}^{2}$ e truncada entre os limites definidos pelas equações (A.24) e (A.25). 


\section{Referências Bibliográficas}

Albert (1992) H. J. Albert. Bayesian estimation of normal ogive item response curves using gibbs sampling. Journal of Educational Statistics, 17(3):251-269. Citado na pág. 10, 13, 103

Almasy e Blangero (1998) L. Almasy e J. Blangero. Multipoint quantitative-trait linkage analysis in general pedigrees. Am J Hum. Genet., 62:1198-1211. Citado na pág. 1, 4, 8, 93

Azevedo et al. (2012) C. L. N. Azevedo, D. F. Andrade e J. P. Fox. A bayesian generalized multiple group irt model with model-fit assessment tools. Computational Statistics and Data Analysis, 56(12):4399 - 4412. ISSN 0167-9473. doi: http://dx.doi.org/10.1016/j.csda.2012.03.017. URL http://www.sciencedirect.com/science/article/pii/S0167947312001430. Citado na pág. 7, 38

Baker e Kim (2004) F. B. Baker e S. Kim. Item Response Theory Parameter Estimation Techniques. Marcel Dekker, Inc, New York, 2nd ed. Citado na pág. 3, 7, 8, 9, 10, 21

Baragatti (2011) M. Baragatti. Bayesian variable selection for probit mixed models applied to gene selection. Bayesian Analysis, 6(2):209-230. Citado na pág. 49, 51, 52, 56, 57, 90

Baragatti e Pommeret (2011) M. Baragatti e D. Pommeret. A study of variable selection using g-prior distribution with ridge parameter. Computational Statistics and Data Analysis, 56 : 1920-1934. Citado na pág. 52, 56, 86

Bazan et al. (2006) J. L. Bazan, D. M. Branco e H. Bolfarine. A skew item response model. Bayesian Analysis, 1(4):861-892. Citado na pág. 7, 93

Beguin e Glas (2001) A. A. Beguin e C. A. W. Glas. Mcmc estimation and some model-fit analysis in multidimensional irt models. Psychometrika, 66(4):541-562. Citado na pág. 9, 10, 11, 93

Bock e Aitkin (1981) R. D. Bock e M. Aitkin. Marginal maximum likelihood estimation of item parameters: an application of the em algorithm. Psychometrika, 46:443-459. Citado na pág. 10

Bock et al. (1988) R. D. Bock, R. Gibbons e E.J. Muraki. Full information item factor analysis. Applied Psychological Measurement, 12:261-280. Citado na pág. 10

Borgatto et al. (2013) A. Borgatto, C. L. N. Azevedo, A. Pinheiro e D. F. Andrade. Comparison of ability estimation methods using irt for tests with different degrees of difficulty. Communications in Statistics - Simulation and Computation. Citado na pág. 21, 94

Calus e Veerkamp (2011) M. Calus e R. Veerkamp. Accuracy of multi-trait genomic selection using different methods. Genetics Selection Evolution, 43(1):1-14. Citado na pág. 52, 86

Chagnon et al. (2001) Y. C. Chagnon, T. Rice, L. Pérusse, I. B. Borecki, M. Ho-Kim, M. Lacaille, C. Paré, L. Bouchard, J. Gagnon e A. S. Leon. Genomic scan for genes affecting body composition before and after training in caucasians from heritage. Journal of Applied Physiology, 90(5):17771787. Citado na pág. 91

Chen et al. (2009) C. Chen, K. Mengersen, J. Keith, N. Martin e D Nyholt. Bayesian latent trait modeling of migraine symptom data. Human Genetics, 126:277-288. Citado na pág. 4, 6, 14 
de Ayala (2009) R. J. de Ayala. Theory and practice of item response theory. Guilford Publications. Citado na pág. 21

de los Campos et al. (2009a) G. de los Campos, D. Gianola e G. J. M. Rosa. Reproducing kernel hilbert spaces regression: a general framework for genetic evaluation. Journal of animal science, 87(6):1883-1887. Citado na pág. 93

de los Campos et al. (2009b) G. de los Campos, H. Naya, D. Gianola, J. Crossa, A. Legarra, E. Manfredi, K. Weigel e J. M. Cotes. Predicting quantitative traits with regression models for dense molecular markers and pedigree. Genetics, 182(1):375-385. Citado na pág. 51

de Maturana et al. (2013) E. López de Maturana, Y. Ye, M. Calle, N. Rothman, M. Urrea, V.and Kogevinas, S. Petrus, S. J. Chanock, A. Tardón e M. García-Closas. Application of multisnp approaches bayesian lasso and auc-rf to detect main effects of inflammatory-gene variants associated with bladder cancer risk. PloS one, 8(12):e83745. Citado na pág. 48

DeGroot (2005) M. H DeGroot. Optimal statistical decisions, volume 82. Wiley-Interscience. Citado na pág. 10

Diego et al. (2007) V. P. Diego, D. L Rainwater, X. Wang, S. A Cole, J. E Curran, M. P Johnson, J. Jowett, T. D Dyer, J. T Williams e E. K Moses. Genotype× adiposity interaction linkage analyses reveal a locus on chromosome 1 for lipoprotein-associated phospholipase $\mathrm{a}<\mathrm{sub}>2</$ sub $>$, a marker of inflammation and oxidative stress. The American Journal of Human Genetics, 80 (1):168-177. Citado na pág. 91

Eaves et al. (2004) L. Eaves, J. Silberg, D. Foley, C. Bulik, H. Maes, A. Erkanli, A. Angold, J. Costello e C. Worthman. Genetic and enviromental influences on the timing of pubertal change. Twin Research, 7(5):471-481. Citado na pág. 4, 6

Eaves et al. (2005) L. Eaves, J. Silberg, D. Foley, H. Maes, A. Erkanli e A. Angold. Application of bayesian inference using gibbs sampling to item-response theory modeling of multi-symptom genetic data. Behavior Genetics, 35(6):765-780. Citado na pág. 4, 6

Eddelbuettel e François (2011) D. Eddelbuettel e R. François. Rcpp: Seamless R and C ++ integration. Journal of Statistical Software, 40(8):1-18. URL http://www.jstatsoft.org/v40/i08/. Citado na pág. 14

Eddelbuettel e Sanderson (2013) D. Eddelbuettel e C. Sanderson. Rcpparmadillo: Accelerating $\mathrm{r}$ with high-performance $\mathrm{c}++$ linear algebra. Computational Statistics and Data Analysis, in press. URL http://dx.doi.org/10.1016/j.csda.2013.02.005. Citado na pág. 14, 52

Expert Panel on Detection and Evaluation and and Treatment of High Blood Cholesterol in Adults (2001) Expert Panel on Detection and Evaluation and and Treatment of High Blood Cholesterol in Adults. Executive summary of the third report of the national cholesterol education program (ncep) expert panel on detection, evaluation, and treatment of high blood cholesterol in adults (adult treatment panel iii). JAMA: The Journal of the American Medical Association, 285(19):2486-2497. doi: 10.1001/jama.285.19.2486. URL +http://dx.doi.org/10.1001/jama.285.19.2486. Citado na pág. 21, 35

Ford et al. (2002) E. S. Ford, W. H. Giles e W. H. Dietz. Prevalence of the metabolic syndrome amongs: Findings from the third national health and nutrition examination survey. JAMA: The Journal of the American Medical Association, 287(3):356-359. doi: 10.1001/jama.287.3.356. URL +http://dx.doi.org/10.1001/jama.287.3.356. Citado na pág. 2, 38

Fox (2010) J. P. Fox. Bayesian Item Response Modeling: Theory and Applications. Statistics for Social and Behavioral Sciences. Springer, New York. Citado na pág. 1, 89, 93, 94 
Fox e Glas (2001) J. P. Fox e C. A. W. Glas. Bayesian estimation of a multilevel irt model using gibbs sampling. Psychometrika, 66:271-288. Citado na pág. 3, 5, 93

Fragoso et al. (2014) T. M. Fragoso, S. R Giolo, A. C Pereira, M. de Andrade e J. M. P. Soler. Using item response theory to model multiple phenotypes and their joint heritability in family data. Genetic epidemiology, 38(2):152-161. Citado na pág. 4, 5

Fridley (2009) B. L. Fridley. Bayesian variable and model selection methods for genetic association studies. Genetic Epidemiology, 33:27-37. Citado na pág. 48

Fu et al. (2009) Z. Fu, J. Tao e N. Shi. Bayesian estimation in the multidimensional three-parameter logistic model. Journal of Statistical Computation and Simulation, 79(6):819-835. Citado na pág. 5, $9,10,12,13,93,101$

Ge et al. (2005) D Ge, J Huang, W Yang, J Zhao, Y Shen, B Qiang e D Gu. Linkage analysis of chromosome 1 with essential hypertension and blood pressure quantitative traits in chinese families. Annals of human genetics, 69(1):45-54. Citado na pág. 91

Gelman (2006) A. Gelman. Prior distributions for variance parameters in hierarchical models (comment on article by browne and draper). Bayesian Analysis, 1:515-534. Citado na pág. 13, 53

Gelman (2007) A. Gelman. Comment: Bayesian checking of the second levels of hierarchical models. Statistical Science, 22(3):349-352. doi: 10.1214/07-STS235A. URL http://dx.doi.org/ 10.1214/07-STS235A. Citado na pág. 94

Gelman et al. (2004) A. Gelman, J. B. Carlin e D. B. Rubin. Bayesian Data Analysis (2nd ed.). Chapman and Hall/CRC, Boca Raton - Florida. Citado na pág. 9, 11

Geman e Geman (1984) S. Geman e D. Geman. Stochastic relaxation, gibbs distributions, and the bayesian restoration of images. Pattern Analysis and Machine Intelligence, IEEE Transactions on Volume PAMI-6, 6:721-741. Citado na pág. 12

George e McCulloch (1993) E. I. George e R. E. McCulloch. Variable selection via gibbs sampling. Journal of the American Statistical Association, 88(423):881-889. Citado na pág. 4, 49, $50,51,52,57$

George e McCulloch (1997) E. I. George e R. E. McCulloch. Approaches for bayesian variable selection. Statistica Sinica, 7:339-373. Citado na pág. 4, 49, 50, 52

Geyer (2011) C. Geyer. Introduction to markov chain monte carlo. Em Steve Brooks, Andrew Gelman, Galin Jones e Xiao-Li Meng, editors, Handbook of Markov Chain Monte Carlo. Taylor \& Francis US. Citado na pág. 12, 89

Gianola (2013) D. Gianola. Priors in whole-genome regression: the bayesian alphabet returns. Genetics, 194(3):573-596. Citado na pág. 51

Gianola e Sorensen (2002) D. Gianola e D. Sorensen. Likelihood, Bayesian, and MCMC methods in quantitative genetics: Statistics for Biology and Health. Springer New York. Citado na pág. 12

Gibbons e Hedeker (1992) R. D. Gibbons e D. R. Hedeker. Full-information item bi-factor analysis. Psychometrika, 57(3):423-436. Citado na pág. 97

Gibson (2010) G. Gibson. Hints of hidden heritability in gwas. Nat Genet, 42(7):558-560. Citado na pág. 48

Giolo et al. (2010) S.R. Giolo, M. Pereira, A.C.and de Andrade e J.M.P. Krieger, J.E.and Soler. Evaluating gene by sex and age interactions on cardiovascular risk factors in brazilian families. BMC Medical Genetics, 11(132). Citado na pág. 8, 38 
Green (1995) P. J. Green. Reversible jump markov chain monte carlo computation and bayesian model determination. Biometrika, 82(4):711-732. Citado na pág. 4, 49

Grundy et al. (2005) S. M. Grundy, J. I Cleeman, S. R. Daniels, K. A. Donato, R. H. Eckel, B. A. Franklin, D. J. Gordon, R. M. Krauss, P. J. Savage, S. C. Smith et al. Diagnosis and management of the metabolic syndrome an american heart association/national heart, lung, and blood institute scientific statement. Circulation, 112(17):2735-2752. Citado na pág. 2

Guan et al. (2011) Yongtao Guan, Matthew Stephens et al. Bayesian variable selection regression for genome-wide association studies and other large-scale problems. The Annals of Applied Statistics, 5(3):1780-1815. Citado na pág. 51, 56, 59, 86, 90

Hayes et al. (2001) BJ Hayes, ME Goddard et al. Prediction of total genetic value using genomewide dense marker maps. Genetics, 157(4):1819-1829. Citado na pág. 4

Horimoto et al. (2011) A. R. V. R. Horimoto, C. Oliveira, R. Alvim, S. R. Giolo, J. M. P. Soler, M. de Andrade, J. E. Krieger e A.C. Pereira. Heritability of physical activity traits in brazilian families: the baependi heart study. BMC Medical Genetics, 12(155). Citado na pág. 8, 40

Horimoto et al. (2012) A. R. V. R. Horimoto, C. Oliveira, S. R. Giolo, J. M. P. Soler, M. de Andrade, J. E. Krieger e A.C. Pereira. Genetic analyses of smoking initiation, persistence, quantity and age-at-onset of regular cigarette use in brazilan families: the baependi heart study. $B M C$ Medical Genetics, 13(9). Citado na pág. 8, 40

Hulin e Drasgow (1982) C. L. Hulin e F. Drasgow. Recovery of two- and three-parameter logistic item characteristic curves: A monte carlo study. Applied Psychological Measurement, 6 (3):249-260. Citado na pág. 21

Kass e Raftery (1995) R. E. Kass e A. E. Raftery. Bayes factors. Journal of the american statistical association, 90(430):773-795. Citado na pág. 11

Kusnierczyk (2012) W. Kusnierczyk. rbenchmark: Benchmarking routine for $R, 2012$. URL http://CRAN.R-project.org/package=rbenchmark. R package version 1.0.0. Citado na pág. 15

Kwon et al. (2011) D. Kwon, M. T. Landi, M. Vannucci, H. J. Issaq, D. Prieto e R. M. Pfeiffer. An efficient stochastic search for bayesian variable selection with high-dimensional correlated predictors. Computational statistics $\mathcal{G}$ data analysis, 55(10):2807-2818. Citado na pág. 57

Kyung et al. (2010) M. Kyung, J. Gill, M. Ghosh, G. Casella et al. Penalized regression, standard errors, and bayesian lassos. Bayesian Analysis, 5(2):369-411. Citado na pág. 51

Leal et al. (2005) S. M Leal, K. Yan e B. Müller-Myhsok. Simped: a simulation program to generate haplotype and genotype data for pedigree structures. Human heredity, 60(2):119-122. Citado na pág. 59, 86

Lee et al. (2010) S. Lee, X. Song e J. Cai. A bayesian approach for nonlinear structural equation models with dichotomous variables using logit and probit links. Structural Equation Modeling, 17(2):280-302. Citado na pág. 97

Li e Zhang (2010) F. Li e N. R. Zhang. Bayesian variable selection in structured-high dimensional covariate spaces with applications in genomics. Journal of the American Statistical Association, 105(491):1202-1214. Citado na pág. 49, 52, 94

Liu (1994) J. Liu. The collapsed gibbs sampler in bayesian computations with application to a gene-regulation problem. Journal of the American Statistical Association, 89(427):958-966. Citado na pág. 56 
Lord (1980) F. M. Lord. Applications of Item Response Theory to practical testing problems. Erlbaum, Hillsdale,NJ. Citado na pág. 7, 36

Lord (1952) F.M. Lord. A theory of text scores (no 7). Psychometric Monograph, 1952. Citado na pág. 3

Lu et al. (2005) I. R. R. Lu, D. Roland Thomas e B. D. Zumbo. Embedding irt in structural equation models: A comparison with regression based on irt scores. Structural Equation Modeling, 12(2):263-277. Citado na pág. 4, 49, 97

Marin e Robert (2007) J. M. Marin e C. P. Robert. Bayesian core: a practical approach to computational Bayesian statistics. Springer. Citado na pág. 9, 12, 13, 52

Marin e Robert (2009) J.M. Marin e C. P. Robert. Importance sampling methods for bayesian discrimination between embedded models. arXiv preprint arXiv:0910.2325. Citado na pág. 12

Meigs et al. (2007) J. B. Meigs, A. K. Manning, C. S. Fox, J. C. Florez, C. Liu, L. A. Cupples e J. Dupuis. Genome-wide association with diabetes-related traits in the framingham heart study. BMC medical genetics, 8(Suppl 1):S16. Citado na pág. 91

Michael et al. (1976) J. R Michael, W. R Schucany e R. W Haas. Generating random variates using transformations with multiple roots. The American Statistician, 30(2):88-90. Citado na pág. 54

National Cholesterol Education Program (NCEP) (2002) National Cholesterol Education Program (NCEP). Detection, evaluation, and treatment of high blood cholesterol in adults (adult treatment panel iii). NIH publication, 02-5215. Citado na pág. 38

Neyman e Scott (1948) J. Neyman e E. L. Scott. Consistent estimates based on partially consistent observations. Econometrica, 16(1):1-32. Citado na pág. 10, 94

Ng et al. (2004) M. C. Y. Ng, W. Y. So, N. J. Cox, V. K. L. Lam, C. S. Cockram, J. Critchley, G. Bell e J. C. N. Chan. Genome-wide scan for type 2 diabetes loci in hong kong chinese and confirmation of a susceptibility locus on chromosome 1q21-q25. Diabetes, 53(6):1609-1613. Citado na pág. 91

Oh et al. (2003) C. Oh, Q. Kenny, Q. He e N. Mendell. Locating disease genes using bayesian variable selection with the haseman-elston method. BMC genetics, 4(Suppl 1):S69. Citado na pág. 52,95

O'Hara e Sillanpaa (2009) R. B. O'Hara e M. J. Sillanpaa. A review of bayesian variable selection methods: What, how and which. Bayesian Analysis, 4(1):85-118. Citado na pág. 49

Oliveira et al. (2008) C. Oliveira, A. C. Pereira, M. Andrade, J. M. Soler e J. E. Krieger. Heritability of cardiovascular risk factors in a brazilian population: Baependi heart study. $B M C$ Medical Genetics, 9(32). Citado na pág. 2, 5, 8, 15, 21, 35, 36, 38, 58, 97

Ott e Rabinowitz (1999) J. Ott e D. Rabinowitz. A principal-components approach based on heritability for combining phenotype information. Hum Hered, 49:106-111. Citado na pág. 21

Oualkacha et al. (2012) K. Oualkacha, A. Labbe, A. Ciampi e M. Roy, M-A. Maziade. Principal components of heritability for high dimension quantitative traits and general pedigrees. Statistical Applications in Genetics and Molecular Biology, 11(2). doi: 10.2202/1544-6115.1711. Citado na pág. 21

Park e Casella (2008) T. Park e G. Casella. The bayesian lasso. Journal of the American Statistical Association, 103(482):681-686. Citado na pág. 4, 49, 50, 51, 53 
Patz e Junker (1999) R. J. Patz e B. W. Junker. A straightforward approach to markov chain monte carlo methods for item response theory models. Journal of Educational and Behavioral Statistics, 24:146-178. Citado na pág. 10

Pearl (2000) J. Pearl. Causality: models, reasoning and inference, volume 29. Cambridge Univ Press. Citado na pág. 4, 95, 96

Peress e Spirling (2010) M. Peress e A. Spirling. Scaling the critics: Uncovering the latent dimensions of movie criticism with an item response approach. Journal of the American Statistical Association, 105(489). Citado na pág. 93

Pérusse et al. (2001) L. Pérusse, T. Rice, Y. C Chagnon, J.P. Després, S. Lemieux, S. Roy, M. Lacaille, M. A. Ho-Kim, M. Chagnon, M. A. Province et al. A genome-wide scan for abdominal fat assessed by computed tomography in the quebec family study. Diabetes, 50(3):614-621. Citado na pág. 91

Pilia et al. (2006) G. Pilia, W.M. Chen, i A. Scuter, M. Orru, G. Albai, M. Dei, S. Lai, G. Usala, M. Lai e P. Loi. Heritability of cardiovascular and personality traits in 6148 sardinians. PLos Genet, 2:1207-1223. Citado na pág. 38

Pollex e Hegele (2006) R. L. Pollex e R. A. Hegele. Genetic determinants of the metabolic syndrome. Nat Clin Pract Cardiovasc Med., 3(9):482-489. Citado na pág. 2

Raftery et al. (1997) A. E. Raftery, D. Madigan e J. A. Hoeting. Bayesian model averaging for linear regresion models. Journal of the American Statistical Association, 92(437):179-191. Citado na pág. 49

Rasch (1960) G. Rasch. Probabilistic Models for Some Intelligence and Attainment Tests. Danish Institute for Educational Research, Copenhagen. Citado na pág. 3, 6

Reckase (1985) M. D. Reckase. The difficulty of items that measure more than one ability. Applied Psychological Measurement, 9:401-412. Citado na pág. 3

Rizopoulos (2006) D. Rizopoulos. ltm: An r package for latent variable modelling and item response theory analyses. Journal of Statistical Software, 17(5). Citado na pág. 14

Robert e Casella (1999) C. P. Robert e G. Casella. Monte Carlo Statistical Methods. SpringerVerlag, New York. Citado na pág. 11, 12

Rossi et al. (2002) N. Rossi, X. Wang e J. O. Ramsay. Nonparametric item response function estimates with the em algorithm. Journal of Educational and Behavioral Statistics, 27(3):291-317. Citado na pág. 3, 93

Sahu (2002) S. K. Sahu. Bayesian estimation and model choice in item response models. Journal of Statistical Computation and Simulation, 72(3):217-232. Citado na pág. 10, 13

Samejima (1969) F. Samejima. Estimation of latent ability using a response pattern of graded scores. Psychometrika Monograph Supplement, 34(17):1-100. Citado na pág. 93

Shmueli (2010) G. Shmueli. To explain or to predict? Statistical Science, 25(3):289-310. Citado na pág. 1

Sinharay e Lu (2008) S. Sinharay e Y. Lu. A further look at the correlation between item parameters and item fit statistics. Journal of Educational Measurement, 45(1):1-15. Citado na pág. 94

Sinharay e Stern (2003) S. Sinharay e H. S. Stern. Posterior predictive model checking in hierarchical models. Journal of Statistical Planning and Inference, 111(1):209-221. Citado na pág. 94 
Sinharay et al. (2006) S. Sinharay, H. S. Stern e M. S. Johnson. Posterior predictive assessment in item response theory. Applied Psychological Measurement, 30(4):298-321. Citado na pág. 10, 94

Skrondal e Rabe-Hesketh (2004) A. Skrondal e S. Rabe-Hesketh. Generalized latent variable modeling: Multilevel, longitudinal, and structural equation models. CRC Press. Citado na pág. 1

Somol e Novovicova (2010) P. Somol e J. Novovicova. Evaluating stability and comparing output of feature selectors that optimize feature subset cardinality. Pattern Analysis and Machine Intelligence, IEEE Transactions on, 32(11):1921-1939. Citado na pág. 86, 94

Srivastava e Chen (2010) S. Srivastava e L. Chen. Model selection methods for genome wide association studies. Comunications in Information and Systems, 10(1):39-52. Citado na pág. 52, 90

Stingo et al. (2011) F. C. Stingo, Y. A. Chen, M. G. Tadesse e M. Vannucci. Incorporating biological information into linear models: A bayesian approach to the selection of pathways and genes. The Annals of Applied Statistics, 5(3):1978-2002. Citado na pág. 49, 52, 95

Swartz et al. (2008) M. D Swartz, R. K Yu e S. Shete. Finding factors influencing risk: comparing bayesian stochastic search and standard variable selection methods applied to logistic regression models of cases and controls. Statistics in medicine, 27(29):6158-6174. Citado na pág. 86, 94

Tanner e Wong (1987) M. A. Tanner e H. W. Wong. The calculation of posterior distributions by data augmentation. Journal of the American Statistical Association, 82(398):528-540. Citado na pág. 12

Team (2005) R Development Core Team. R: A language and environment for statistical computing. R Foundation for Statistical Computing, Vienna, Austria, 2005. Citado na pág. 14, 52

Thomas et al. (2006) A. Thomas, B. O'Hara, U. Ligges e S. Sturtz. Making bugs open. R News, 6:12-17. Citado na pág. 14

Tibshirani (1996) R. Tibshirani. Regression shrinkage and selection via the lasso. Journal of the Royal Statistical Society, 1996(58):267-288. Citado na pág. 4, 49, 50

Treier e Jackman (2008) S. Treier e S. Jackman. Democracy as a latent variable. American Journal of Political Science, 52(1):201-217. Citado na pág. 95

van der Berg et al. (2007) S. van der Berg, C. A. Glas e D. Boomsma. Variance decomposition using an irt measurement model. Behavior Genetics, 34:604-616. Citado na pág. 4, 6, 14

van Dyk e Park (2008) D. van Dyk e T. Park. Partially collapsed gibbs samplers: Theory and methods. Journal of the American Statistical Association, 103(482):790-796. Citado na pág. 58

Vazquez et al. (2012) A. I. Vazquez, G. de los Campos, Y. C. Klimentidis, G. J. M. Rosa, D. Gianola, N. Yi e D. B. Allison. A comprehensive genetic approach for improving prediction of skin cancer risk in humans. Genetics, 192:1493-1502. Citado na pág. 1, 51, 94

Verbyla et al. (2009) K. L Verbyla, B. J. Hayes, P. J. Bowman e M. E. Goddard. Accuracy of genomic selection using stochastic search variable selection in australian holstein friesian dairy cattle. Genetics research, 91(05):307-311. Citado na pág. 52

Verbyla et al. (2010) K. L Verbyla, P. J Bowman, B. J Hayes e M. E Goddard. Sensitivity of genomic selection to using different prior distributions. 4(Suppl 1):S5. Citado na pág. 52

Wang et al. (1994) C.S. Wang, J. J. Rutledge e D. Gianola. Bayesian analysis of mixed linear models via gibbs sampling with an application to litter size in iberian pigs. Genet Sel Evol, 26: 91-115. Citado na pág. 13 
Weinwurm et al. (2013) S. Weinwurm, J. Sölkner e P. Waldmann. The effect of linkage disequilibrium on bayesian genome-wide association methods. J Biomet Biostat, 4(180):2. Citado na pág. 52,86

Wilson et al. (2010) M. A. Wilson, E. S. Iversen, M. A. Clyde, S. C. Schmidler e J. M. Schildkraut. Bayesian model search and multilevel inference for snp association studies. The annals of applied statistics, 4(3):1342. Citado na pág. 95

Wimmer et al. (2013) V. Wimmer, C. Lehermeier, T. Albrecht, H. Auinger, Y. Wang e C. C. Schön. Genome-wide prediction of traits with different genetic architecture through efficient variable selection. Genetics, 195(2):573-587. Citado na pág. 51, 89

Wu et al. (2010) X Wu, D. Gianola, G. J. M. Rosa e K. A. Weigel. Bayesian model averaging for evaluation of candidate gene effects. Genetica, 138:395-407. Citado na pág. 49

Yang et al. (2010) J. Yang, B. Benyamin, B. P. McEvoy, S. Gordon, A. Henders, D. Nyholt, P. A. Madden, A. C. Heath, N. G. Martin, G.W. Montgomery, M. E. Goddard e P. M. Visscher. Common snps explain a large proportion of the heritability for human height. Nat Genet, 42(7): 565-569. doi: http://dx.doi.org/10.1038/ng.608. Citado na pág. 90

Yang et al. (2011) J. Yang, S. H. Lee, M. E. Goddard e P. M. Visscher. Gcta: a tool for genomewide complex trait analysis. The American Journal of Human Genetics, 88(1):76-82. Citado na pág. 7

Yi e Xu (2008) N. Yi e S. Xu. Bayesian lasso for quantitative trait loci mapping. Genetics, 179 (2):1045-1055. Citado na pág. 51

Yi et al. (2003) N. Yi, V. George e D. B. Allison. Stochastic search variable selection for identifying multiple quantitative trait loci. Genetics, 164(3):1129-1138. Citado na pág. 61, 70, 90, 95

Zellner (1986) A. Zellner. On assessing prior distributions and bayesian regression analysis with g-prior distributions. Em A. Zellner, editor, Bayesian Inference and Decision Techniques: Essays in Honor of Bruno de Finetti. North-Holland, Amsterdam. Citado na pág. 13, 59

Zou e Hastie (2005) H. Zou e T. Hastie. Regularization and variable selection via the elastic net. Journal of the Royal Statistical Society: Series B (Statistical Methodology), 67(2):301-320. ISSN 1467-9868. doi: 10.1111/j.1467-9868.2005.00503.x. URL http://dx.doi.org/10.1111/j.1467-9868. 2005.00503.x. Citado na pág. 49, 51 